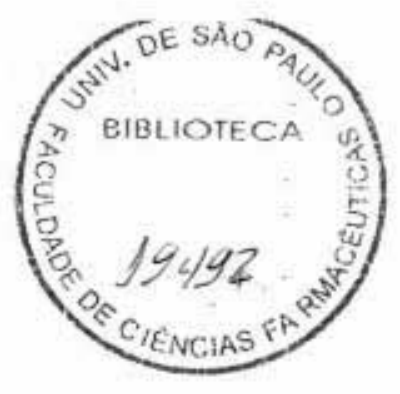

UNIVERSIDADE DE SÃO PAULO

FCF/FEA/FSP

Programa de Pós-Graduação Interunidades

em Nutrição Humana Aplicada - PRONUT

\title{
MEL E ESPECIARIAS COMO PROTETORES DA OXIDAÇÃO LIPÍDICA EM CARNE DE FRANGO
}

\section{GENI RODRIGUES SAMPAIO}

Tese para obtenção do grau de Doutor

Orientador:

Profa. Assoc. Elizabeth A. Ferraz da Silva Torres

São Paulo

2009 
Geni Rodrigues Sampaio

MEL E ESPECIARIAS COMO PROTETORES DA OXIDAÇÃO LIPIDICA EM CARNE DE FRANGO

\author{
Comissão Julgadora \\ Tese para obtenção do grau de Doutor
}

Profa. Assoc. Elizabeth Aparecida Ferraz da Silva Torres Orientador / Presidente

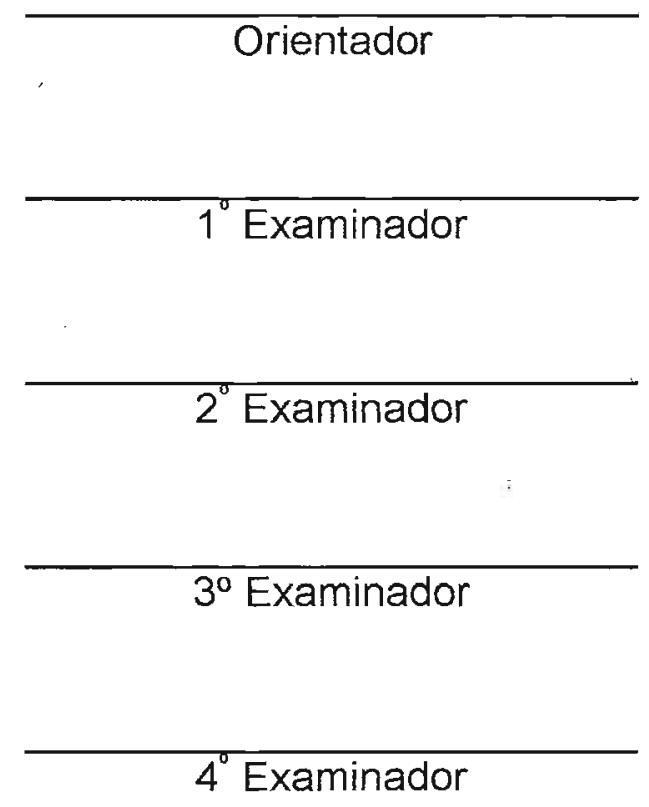

São Paulo, de 2009 
Se nós soubéssemos

o que amanfã traria, não precisaríamos

de nossos sonfios, esperanças e planos. Mas o amanfĩá uma pergunta sem resposta, um novo desafio para enfrentar, uma nova aventura para ousar.

T. Kantountakis 
À minha família pelo apoio: em especial aos meus pais e aos meus sogros por

estarem presentes em todos os momentos.

Especialmente, ao meu esposo Marcus

Vinicius Ferraz e ao meu filho Henrique

Sampaio Ferraz, que com amor, companheirismo e compreensão, apoiaramme em todos os momentos. 


\section{AGRADECIMENTOS}

À Deus, por todas as oportunidades que sempre coloca em minha vida.

À Profa Elizabeth Torres, não só pela orientação, mas pela amizade, confiança, i

encorajamento sem os quais esta etapa seria impossível, e pelos quais não seria possível retribuir apenas com esta dedicatória.

À Coordenação de Aperfeiçoamento de Pessoal de Nível Superior - CAPES pela concessão da bolsa de estudo e à Fundação de Amparo à Pesquisa do Estado de São Paulo - FAPESP pelo auxílio financeiro.

À Comissão de Pós-Graduação do Programa de Pós-Graduação Interunidades em Nutrição Humana Aplicada - PRONUT.

Ao Professor Rubison Olivo por suas críticas e sugestões apresentadas no exame de qualificação.

À Profa Deborah H. Markowicz Bastos por sua amizade, seu apoio e sugestões que permitiram o aperfeiçoamento deste trabalho.

À Tatiana Saldanha, pela amizade e criteriosa correção deste trabalho.

Aos amigos que fiz na vida acadêmica e que se transformaram em amigos que fiz para a vida toda: Rosana, Vanessa, Liania, Yara, Emília, Silvio, Simone, Marcela, Marina, Ana Paula e Érica.

A "turma do frango" pela amizade, companheirismo e troca de experiências: Lilian, Carolina, Caroline, Fernanda e Roberto.

Ao pessoal do Departamento de Nutrição da FSP.

Aos funcionários da CPG da FCF/USP Jorge, Elaine e Monica.

À Empresa Global Food Sistemas Ingredientes e Tecnologia para Alimentos Ltda, que cedeu suas instalações para processamento da carne de frangos. 
À Empresa Fuchs do Brasil por doar as especiarias.

Aos Professores José Alfredo Gomes Arêas e Maria Elisabeth Machado Pinto e Silva por disponibilizarem a estrutura dos Laboratórios de Bioquímica e Propriedades Funcionais de Alimentos e de Técnica Dietética.

A todos que colaboraram na análise sensorial, pela disponibilidade e paciência.

A todas as pessoas que de alguma forma colaboraram para a realização deste estudo. 


\section{ÍNDICE}

ÍNDICE DE TABELAS

ÍNDICE DE QUADROS

iv

ÍNDICE DE FIGURAS

V

LISTA DE ABREVIATURAS

vi

RESUMO

ABSTRACT

viii

ANEXOS

5

CONCLUSÃO FINAL

1. INTRODUÇÃO

\section{CAPÍtulo I}

1.1. Importância da carne de frango

1.2. Cor

1.3. Oxidação lipídica 12

1.4. Antioxidantes $\quad 17$

1.5. Especiarias $\quad$. 19

1.6. $\mathrm{Mel} \cdot 20$

2. OBJETIVO GERAL : $\quad \cdot 22$

2.1. Objetivos específicos . . . 22

3. EXPERIMENTOS

4. REFERÊNCIAS BIBLIOGRÁFICAS 23

1. INTRODUÇÃO

2. OBJETIVO

3. MATERIAIS E MÉTODOS - 32

3.1. Materias $\quad 32$

3.1.1. Solventes e reagentes $\quad 32$

3.1.2. Amostras 33

3.1.3. Preparo das extratos $\quad \cdot 33$

3.2. Métodos $\quad 35$

3.2.1. Determinação do teor de sólidos totais dos extratos •

3.2.2. Quantificação de fenólicos totais . 35

3.2.3. Sistema $\beta$-caroteno/ácido linoléico $\quad 35$

3.2.4. Ensaio em meio lipídico $\left(\right.$ Rancimat $^{\circledR}$ ) $\quad 36$

$\begin{array}{ll}\text { 3.2.5. Atividade antioxidante por ORAC } & 37\end{array}$

3.2.6. Análise Estatística $\quad 38$

4. RESULTADOS e DISCUSSÃO 38

4.1. Teor de fenólicos totais $\quad 38$

4.2. Sistema $\beta$-caroteno/ácido linoléico ‘ ' 40

4.3. Avaliação da capacidade protetra da oxidação lipídica utilizando o aparelho 41 Rancimat ${ }^{\circledR}$.

5. CONCLUSÃO

6. REFERÊNCIAS BIBLIOGRÁFICAS $\quad 46$ 


\section{ÍNDICE}

\section{CAPÍTULO III}

1. INTRODUÇÃO . ' , . 50

2. OBJETIVO

3. MATERIAIS E MÉTODOS

$\begin{array}{ll}\text { 3.1. Materias } & 52\end{array}$

3.1.1. Solventes e reagentes $\quad$

3.1.2. Amostras $\quad 53$

3.1.3. Extratos $\quad 53$

3.2. Métodos 53

3.2.1. Determinação do teor de sólidos totais dos extratos 53

3.2.2. Quantificação de fenólicos totais 53

3.2.3. Sistema $\beta$-caroteno/ácido linoléico $\quad 53$

3.2.4. Ensaio em meio lipídico (Rancimat $^{\left({ }^{*}\right)} \quad 54$

$\begin{array}{ll}\text { 3.2.5. Atividade antioxidante por ORAC } & 54\end{array}$

3.2.6. Obtenção do Substrato Microssomal $\quad 55$

3.2.7. Quantificação de proteínas totais 55

3.2.8. Indução da oxidação lipídica no substrato microssomal 55

3.2.9. Análise Estatística $\quad 56$

4. RESULTADOS e DISCUSSÃO

5. CONCLUSÃO

6. REFERÊNCIAS BIBLIOGRÁFICAS 62

1. INTRODUÇÃO 66

2. OBJETIVO 167

3. MATERIAIS E MÉTODOS $\quad 68$

3.1. Amostras 68

$\begin{array}{ll}\text { 3.2. Preparo do homogenato } & 68\end{array}$

$\begin{array}{ll}\text { 3.3. Análises } & 69\end{array}$

3.3.1. $\mathrm{pH} \quad 69$

3.3.2. Atividade de água $\quad, \quad 69$

3.3.3. Umidade 69

3.3.4. TBARS (Teste das substâncias reativas ao ácido tiobarbitúrico). . $\quad 70$

$\begin{array}{ll}\text { 3.3.5. Derivados de mioglobina } & 71\end{array}$

3.4. Análise estatística $\quad 71$

4. RESULTADOS e DISCUSSÃO 72

$\begin{array}{ll}\text { 4.1. Atividade de água . } & 72 \\ 4.2 . \text { pH }\end{array}$

4.2. $\mathrm{pH}, \quad 74$

4.3. Umidade $\quad 75$

4.4. Derivados de mioglobina $\quad 77$

4.5. TBARS $\quad 81$

5. CONCLUSÃO 1,86

6. REFERÊNCIAS BIBLIOGRÁFICAS 86 


\section{ÍNDICE}

\section{CAPÍtuLO V}

1. INTRODUÇÃO

2. OBJETIVO $\quad 92$

3. MATERIAIS E MÉTODOS 92

3.1. Amostras $\quad 92$

3.2. Preparo das amostras $\quad 92$

3.3. Processo de tambleamento $\quad$ : 93

3.4. Processamento térmico 94

3.5. Planejamento experimental 94

3.6. Métodos $\quad 95$

3.6.1. Potencial Hidrogeniônico $(\mathrm{pH}) \quad$ · 95

3.6.2 Atividade de Água (Aa)

3.6.3 Composição $\quad$. . . 95

3.6.4 Ácidos Graxos $\quad 97$

3.6.5 Colesterol e óxidos de colesterol 99

3.6.5.1. Validação do método de quantificação de colesterol e óxidos de 100 colesterol

$\begin{array}{ll}\text { 3.6.6. Hexanal } & 102\end{array}$

3.6.6.1. Validação do método de quantificação de hexanal 103

$\begin{array}{ll}\text { 3.6.7. Dienos Conjugados } & 105\end{array}$

3.6.8. Avaliação da Oxidação Lipídica pelo teste do ácido 2-Tiobarbitúrico 105 (TBARS)

3.6.9. Análises Microbiológicas 、 106

3.6.10 Análise Sensorial 106

3.7. Análise Estatística $\quad, \quad 109$

4. RESULTADOS E DISCUSSÃO 110

4.1. Umidade e lipídios $\quad 110$

4.2. Atividade de água e $\mathrm{pH} \quad 113$

4.3. TBARS 116

4.4. Dienos conjugados e hexanal $\quad 120$

4.5. Correlações lineares entre as variáveis 123

$\begin{array}{ll}\text { 4.6. Colesterol e óxidos de colesterol } & 126\end{array}$

$\begin{array}{ll}\text { 4.7. Ácidos graxos } & 130\end{array}$

4.8. Análise Microbiológica 137

$\begin{array}{ll}\text { 5. CONCLUSÃO } & 143\end{array}$

6. REFERÊNCIAS BIBLIOGRÁFICAS 


\section{LISTA DE TABELAS}

\section{CAPÍTULO II}

Tabela 1 - Teores médios e desvio padrão (dp) de sólidos totais e de compostos 38 fenólicos totais do orégano, sálvia e mel nos tempos 0,6 e 12 meses.

Tabela 2 - Valores médios e desvio padrão $(\mathrm{dp})$ do método ORAC no orégano, 43 sálvia e mel nos tempos 0,6 e 12 meses.

\section{CAPÍtulo III}

Tabela 1 - Quantidade dos ingredientes adicionados ao substrato microssomal do 54 peito e da sobrecoxa.

Tabela 2 - Valores médios e desvio padrão (dp) de compostos fenólicos totais, \% 57 IOL, IAA e ORAC do orégano e sálvia $(\mathrm{n}=3)$.

Tabela 3 - Valores médios de malonaldeído formado pela reação de oxidação 58 lipídica no sistema microssomal em todos os tratamentos.

\section{CAPÍTULO IV}

Tabela 1 - Quantidade dos ingredientes (Tratamentos) adicionados no experimento.

Tabelas 2 a e $2 b$ - Valores médios e desvio padrão de atividade de água dos homogenatos de peito cru e cozido.

Tabelas $3 a$ e $3 b$ - Valores médios e desvio padrão de atividade de água dos homogenatos de sobrecoxa crua e cozida.

Tabelas 4a e 4b - Valores médios e desvio padrão de $\mathrm{pH}$ do homogenato de peito cru e 74 cozido.

Tabelas $5 \mathrm{a}$ e $5 \mathrm{~b}$ - Valores médios e desvio padrão de $\mathrm{pH}$ do homogenato de sobrecoxa 74 crua e cozida.

Tabelas $6 \mathrm{a}$ e $6 \mathrm{~b}$ - Valores médios e desvio padrão de umidade $(\mathrm{g} / 100 \mathrm{~g})$ do homogenato 76 de peito cru e cozido.

Tabelas $7 \mathrm{a}$ e $7 \mathrm{~b}$ - Valores médios e desvio padrão de umidade $(\mathrm{g} / 100 \mathrm{~g})$ do homogenato 76 de sobrecoxa crua e cozida.

Tabelas 8a e 8 b - Valores médios e desvio padrão de porcentual de metamioglobina 78 $(\mathrm{MMb})$, mioglobina $(\mathrm{Mb})$ e oximioglobina $\left(\mathrm{O}_{2} \mathrm{Mb}\right)$ do homogenato de peito.

Tabelas 9a e 9 b - Valores médios e desvio padrão de porcentual de metamioglobina 79 $(\mathrm{MMb})$, mioglobina $(\mathrm{Mb})$ e oximioglobina $\left(\mathrm{O}_{2} \mathrm{Mb}\right)$ do homogenato de sobrecoxa.

Tabelas 10a e 10b - Valores médios e desvio padrão de TBARS (mg MDA / Kg) dos homogenatos de peito cru e cozido.

Tabelas 11 a e 11 b - Valores médios e desvio padrão de TBARS (mg MDA / Kg) dos homogenatos de sobrecoxa crua e cozida. 


\section{LISTA DE TABELAS}

\section{CAPÍTULO V}

Tabela 1 - Concentração dos ingredientes adicionados às amostras de peito e sobrecoxa 94 de frango (Tratamentos).

Tabela 2: Distribuição das porções, segundo tratamento e tipo de carne.

Tabela 3 - Valores médios e desvio padrão de umidade ( $\mathrm{g} / 100 \mathrm{~g}$ ) e lipídios ( $\mathrm{g} / 100 \mathrm{~g}$ base 110 seca) em peito assado, segundo tratamento e tempo.

Tabela 4 - Valores médios e desvio padrão de umidade (g/100 g) e lipídios (g/ $100 \mathrm{~g}$ base seca) em sobrecoxa assada, segundo tratamento e tempo.

Tabela 5 - Valores médios e desvio padrão de atividade de água e $\mathrm{pH}$ em peito assado, 113 segundo tratamento e tempo.

Tabela 6 - Valores médios e desvio padrão de atividade de água e $\mathrm{pH}$ em sobrecoxa 114 assada, segundo tratamento e tempo.

Tabela 7 - Valores médios (base seca) e desvio padrão de TBARS nos cortes de frango 116 (peito e sobrecoxa) assados, segundo tratamento e tempo.

Tabela 8 - Valores médios (base seca) e desvio padrão de dienos conjugados e hexanal 121 em peito e sobrecoxa assados, segundo tratamento e tempo.

Tabela 9 - Óxidos de colesterol $(\mu \mathrm{g} / \mathrm{g}$ - base seca) $(25-\mathrm{OH}, 7-$ Ceto, $7 \alpha-\mathrm{OH}$ e $7 \beta-\mathrm{OH})$ do 128 peito assado, segundo tratamento e tempo.

Tabela 10 - Óxidos de colesterol $(\mu \mathrm{g} / \mathrm{g}-$ base seca) $(25-\mathrm{OH}, 7-\mathrm{Ceto}, 7 \alpha-\mathrm{OH}$ e $7 \beta-\mathrm{OH})$ de 128 sobrecoxa assada, segundo tratamento e tempo.

Tabela 11 - Composição média de ácidos graxos (\%) do peito de frango assado 131 submetido aos cinco tratamentos, no tempos 0,48 e 96 horas de refrigeração.

Tabela 12 - Composição média de ácidos graxos (\%) do peito de frango assado, segundo 132 tratamento e tempo.

Tabela 13 - Composição média de ácidos graxos (\%) da sobrecoxa de frango assada 134 submetido aos cinco tratamentos, no tempos 0,48 e 96 horas de refrigeração.

Tabela 14 - Composição média de ácidos graxos (\%) da sobrecoxa de frango assada, 135 segundo tratamento e tempo.

Tabela 15 - Média da quantidade de microorganismos encontrados nas amostras de peito 137 de frango assado.

Tabela 16 - Média da quantidade de microorganismos encontrados naș amostras de sobrecoxa assada de frango.

\section{LISTA DE QUADROS}

\section{CApítílo $v$}

Quadro 1 - Correlação linear e recuperação do colesterol e dos óxidos de colesterol $\quad 100$

$\begin{array}{ll}\text { Quadro } 2 \text { - Correlação linear e recuperação do hexanal } & 103\end{array}$

Quadro 3 - Correlações lineares entre as variáveis estudadas : 123 


\section{LISTA DE FIGURAS}

\section{CÁṕ́TULO I}

- Figura 1 - Esquema geral da oxidação lipídica (Silva et al., 1999)

\section{CAPÍTULO II}

Figura 1 - Esquema da extração dos compostos das especiarias orégano e $\quad 34$ sálvia, adaptado de Nuutila et al., (2003).

Figura 2 - Curva cinética da inibição da oxidação lipídica pelo sistema $\beta$ - $\quad 40$ caroteno/ácido linoléico do extrato de orégano e sálvia.

Figura 3 - Porcentagem da inibição da oxidação lipídica (\% IOL), pélo 40 sistema $\beta$-caroteno/ácido linoléico do orégano e sálvia.

Figura 4 - Índice de atividade antioxidante (IAA), utilizando o aparelho

Rancimat, do extrato etanólico do orégano, sálvia e mel.

Figura 5 - Curvas de declínio da fluoresceína no método de ORAC na

presença de extratos de orégano, sálvia, mel e padrão trolox $(20 \mu \mathrm{M})$.

\section{CAPÍTULO III}

Figura 1 - Porcentagem da inibição lipídica no sistema microssomal nos

dois tipos de carne de frango em relação ao controle.

\section{CAPÍTULO IV}

Figura 1 - Porcentagem de inibição da oxidação lipídica em relação ao controle 84 nos homogenatos de peito cozido.

Figura 2 - Porcentagem de inibição da oxidação lipídica em relação ao controle no 85 homogenato de sobrecoxa cozida. 


\section{LISTA DE FIGURAS}

\section{CAPÍtulo V}

Figura 1 - Cromatograma dos 37 padrões de ácidos graxos

Figura 2 - Cromatograma dos padrões de colesterol e óxidos de colesterol. As 101 numerações dos picos correspondem a: (1) Colesterol, (2) 25-OH, (3) 7-Ceto, (4) $7 \alpha-\mathrm{OH}$ e (5) $7 \beta-\mathrm{OH}$.

Figura 3a - Cromatograma do padrão de hexanal.

Figura 3b - Espectro em modo de varreadura de 40 a $150 \mathrm{~m} / \mathrm{z}$ do tempo de 103 retenção do padrão

Figura 4 - Fluxograma do processo de análise sensorial

Figura 5 - Modelo de ficha empregado na análise sensorial de peito e sobrecoxa 107 de frango assado.

Figura 6 - Porcentagem de inibição da oxidação lipídica em relação ao controle 119 nos tratamentos de peito assado.

Figura 7 - Porcentagem de inibição da oxidação lipídica em relação ao controle 120 nos tratamentos de sobrecoxa assada.

Figura 8 - Gráfico de dispersão das variáveis hexanal e TBARS na carne de peito assada

Figura 9 - Gráfico de dispersão das variáveis hexanal e TBARS na carne de 125 sobrecoxa assada

Figura 10 - Concentração do colesterol $(\mathrm{mg} / 100 \mathrm{~g})$ do peito assado, segundo 126 tratamento e tempo.

Figura 11 - Concentração do colesterol (mg/ $100 \mathrm{~g})$ da sobrecoxa assada, 126 segundo tratamento e tempo.

Figura 12 - Gráfico da distribuição percentual dos valores hedônicos atribuídos à 139 aceitabilidade geral de peito de frango submetido a três tratamentos distintos.

Figura 13 - Gráfico da distribuição percentual dos valores hedônicos atribuídos à 140 aceitabilidade geral da sobrecoxa de frango submetido a três tratamentos distintos. 


\section{LISTA DE ABREVIATURAS}

25-OH $=25$-hidroxicolesterol

$7 \beta-\mathrm{OH}=7 \beta$-hidroxicolesterol

$7 \alpha-\mathrm{OH}=7 \alpha$-hidroxicolesterol

7-Ceto $=7$-cetocolesterol

$\mathrm{Aa}=$ Atividade de água

ANOVA = Análise de variância

$\mathrm{BHA}=$ butil hidroxianisol

BHT $=$ butil hidroxitolueno

$\mathrm{CV} .=$ Coeficiente de variação

$\mathrm{COMb}=$ carboximioglobina

$\mathrm{DP}=$ Desvio padrão

$\mathrm{FL}=$ fluoresceína

HPLC = Cromatografia líquida de alta efíciência

IAA = Índice de Atividade Antioxidante

IOL = Inibição da oxidação lipídica

LD $=$ Limite de deteç̧ão

$\mathrm{LQ}=$ Limite de quantificação

$\mathrm{Mb}^{+}=$deoximioglobina

$\mathrm{MMb}=$ metamioglobina

$\mathrm{NOMb}=$ nitrosomioglobina

$\mathrm{O}_{2} \mathrm{Mb}=$ oximioglobina

$\mathrm{OH}^{-}=$radical hidroxila

$\mathrm{PG}=$ propil galato

$\mathrm{pH}=$ Potencial hidrogeniônico

$\mathrm{PTFE}=$ polytetraflouroethylene

ROS = espécies reduzidas de oxigênio

TBARS $=$ Teste das substâncias reativas ao ácido tiobarbitúrico

$\mathrm{TBHQ}=$ terc-butil hidroquinona

$\mathrm{TEP}=1,1,3,3$ tetraetoxipropano

$\mathrm{TI}=$ tempo de indução

$\mathrm{UV}=$ Ultravioleta

WOF $=$ "Warmed-Over-Flavor" 


\section{MEL E ESPECIARIAS COMO PROTETORES DA OXIDAÇÃO LIPÍDICA EM CARNE DE FRANGO}

\section{Resumo}

Este estudo foi estruturado em cinco capitulos. No capítulo I temos um breve referencial teórico sobre a importância da carne de frango, os mecanismos da oxidação lipídica e a utilização de antioxidantes naturais.

O capítulo II traz os ensaios da avaliação da atividade antioxidante in vitro do mel e das especiarias orégano (Origanum vulgare L.) e sálvia (Salvia officinalis L.) durante a vida de prateleira. Os resultados de fenólicos totais do orégano indicaram um aumento de 1154,09 a $1611,28 \mathrm{mgEAG} / 100 \mathrm{~g}$ (0 a 12 meses), na sálvia os valores variaram entre 1309,8 a 2032,4 mgEAG/100g no decorrer do tempo (0 a 12 meses) e no mel os valores medidos foram 1007,$1 ; 1830,4$ e $2129,9 \mathrm{mg} / 100 \mathrm{~g} / \mathrm{EAG}$ para tempos 0,6 e 12 meses, respectivamente. Os resultados da porcentagem da inibição da oxidação lipídica (\% IOL), pelo sistema $\beta$-caroteno/ácido linoléico mostrou que a sálvia inibiu a oxidação em $74,6,81,3$ e $81,3 \%$, nos tempos ( 0,6 e 12 meses) e o orégano apresentou valores de inibição de $(43,2,63,3$ e 50,7\%). Quando se avaliou o índice de atividade antioxidante (IAA) utilizando o aparelho Rancimat, a sálvia apresentou um índice de atividade antioxidante $(3,35)$ superior aos demais, que apresentaram 1,69, 1,25 e 1,08 para o BHT, orégano e mel, respectivamente. Os resultados do ensaio da capacidade de absorbância do radical oxigênio (ORAC) revelou que o orégano apresentou valores de $544,6,430,7$ e $1019,6 \mathrm{ET} \mu \mathrm{mol} / \mathrm{g}$, nos tempos 0,6 e 12 meses, respectivamente. A sálvia apresentou valores de ORAC de: 610,45 (0 mês), 467,44 (6 meses) e 822,21 (12 meses) e no mel foram de: 47,$3 ; 22,4$ e $26,1 \mathrm{ET} \mu \mathrm{mol} / \mathrm{g}$, nos tempos 0,6 e 12 meses. Comparando estes resultados com os descritos na literatura podemos concluir que as especiarias e o mel possuem alto potencial antioxidante.

No capítulo III mostramos a influência dos compostos bioativos da sálvia e de orégano na proteção da oxidação lipídica em substrato microssomal de carne de frango. As concentrações médias de TBARS ( $\mu \mathrm{Mol}$ de MDA/mg de proteína) observadas nas amostras de peito foram: controle $(7,45)$; $\mathrm{BHT}(1,91)$ e orégano+sálvia $(3,45)$ e na carne de sobrecoxa, observou-se os seguintes resultados: controle $(9,83)$; BHT $(4,27)$; orégano+sálvia $(3,15)$. Os tratamentos (BHT e orégano+sálvia) atingiram o ápice de inibição no tempo de 3 horas $(82,42 \%$ e $82,25 \%)$, respectivamente. Porém quando analisamos a inibição da oxidação lipídica na fração microssomal da carne de 
sobrecoxa, o tratamento BHT apresentou o seu ápice de inibição $(66,50$ \%) no tempo de 1 hora de indução e o tratamento orégano+sálvia alcançou a maior porcentagem de inibição no tempo de 3 horas $(82,25 \%)$. Os resultados da inibição da oxidação lipídica durante o período de indução mostram que em relação ao controle, os tratamentos realizados apresentaram influência positiva na proteção da oxidação lipídica em substrato microssomal de carne de peito de frango.

No capítulo IV avaliamos o efeito de especiarias e mel na proteção da oxidação liṕídica em sistema modelo homogenato de carne de frango refrigerada. Os resultados de atividade de água nos homogenatos de peito e sobrecoxa (crus ou cozidos) o tratamento (orégano+sálvia $+10 \% \mathrm{Mel}$ ) reduziu a quantidade de água livre durante o tempo de refrigeração. Em relação aos valores de $\mathrm{pH}$ nos homogenatos de peito notouse uma elevação nos valores de $\mathrm{pH}$ durante o período de refrigeração, em todos os tratamentos avaliados. Na carne de sobrecoxa os valores de $\mathrm{pH}$ foram maiores aos observados na carne de peito. Nos homogenatos de peito cru observou-se uma perda acentuada de umidade em todos os tratamentos, e particularmente em todos os tempos de refrigeração. Nas amostras de peito cozido não foram observadas diferenças significativas na umidade entre os tratamentos controle e orégano+sálvia $+5 \% \mathrm{Mel}$. Nos homogenatos de sobrecoxa crua os valores de umidade variaram entre 60,82 e 66,96 $\mathrm{g} / 100 \mathrm{~g}$. Os teores de mioglobina nos homogenatos de peito cru variaram entre $1,95 \%$ a $2,01 \%$ no tempo 0 . Ao final de 96 horas de refrigeração, a porcentagem de $\mathrm{Mb}$ variou entre 1,85 e 1,96, com redução das concentrações nas amostras tratados com especiarias e mel. Comportamento diferente foi apresentado nos homogenatos de peito cozido, onde após 96 horas de refrigeração observou-se aumento das concentrações de mioglobina em todos os tratamentos avaliados, com exceção do homogenato contendo orégano+sálvia $+10 \%$ de mel. Em relação aos valores de metamioglobina (\% $\mathrm{MMb}$ ) para os homogenatos de peito crus e cozidos observou-se pequenas variações ao longo do tempo de refrigeração. Nas amostras de peito cru, as concentrações de oximioglobina $\left(\% \mathrm{O}_{2} \mathrm{Mb}\right)$ apresentaram-se similares após 96 horas de refrigeração nos tratamentos controle, BHT e orégano+sálvia. Já nas amostras cozidas, os resultados foram similares entre as amostras controle e BHT. Nas amostras de sobrecoxa cruas, após 96 horas de refrigeração, observou-se redução das concentrações de metamioglobina (\% MMb) e elevação dos teores de mioglobina (\% Mb) para todos os tratamentos avaliados. Nas amostras submetidas ao preparo térmico, ao contrário dos homogenatos crus, os teores 
de metamioglobina (\% MMb) elevaram-se após 96 horas de refrigeração nos tratamentos BHT e orégano+sálvia, permanecendo estáveis nos demais. Nos resultados da inibição da oxidação lipídica da carne de peito cozida durante o tempo de refrigeração, observamos que em relação ao controle, os tratamentos realizados apresentaram influência positiva. $\mathrm{O}$ tratamento com BHT inibiu a oxidação em $51,4 \%$ no tempo 0 e após 48 horas 74,3 \%. Atingiu o ápice de inibição no tempo de 96 horas com $77,7 \%$. Dentre os tratamentos avaliados, o contendo orégano+sálvia $+10 \% \mathrm{Mel}$ foi o mais efetivo contra a oxidação em relação aos demais. Nas amostras de sobrecoxa cozida, o tratamento BHT, não inibiu a oxidação em relação ao controle no tempo 0 . Entretando, nos outros tempos ocorreu um efeito protetor de 78,1 após 48 horas e 76,3 \% após 96 horas de rẹfigeração. Nos tratamentos com especiarias, novamente o tratamento com orégano+sálvia $+10 \% \mathrm{Mel}$ foi o mais eficaz, com efeito protetor de $98 \%$.

No capítulo $\mathrm{V}$ avaliou-se o efeito da combinação de especiarias e mel na estabilidade oxidativa em carne de frango assada e refrigerada. Ao final das 96 horas, as amostras com adição de especiarias e mel apresentaram valores de TBARS mais baixos em relação ao controle e ao BHT, sugerindo que a sálvia, o orégano e o mel tenham exercido efeito antioxidante durante o experimento. Quando avaliamos os resultados da análise de dienos conjugados e hexanal, todas as amostras analisadas apresentaram um acréscimo nos valores dos dienos e de hexanal para todos os tempos de refrigeração. $O$ tratamento que apresentou os menores valores de hexanal após 96 horas de refrigeração foi o (orégano+sálvia $+5 \%$ de mel), seguido de (orégano+sálvia $+10 \%$ de mel). Durante o processamento e ao longo do tempo de estocagem foram encontrados apenas traços dos óxidos (25-OH, 7-Ceto, 7 $\alpha-\mathrm{OH}$ e $7 \beta-\mathrm{OH})$, com exceção apenas para o tratamento BHT no tempo de 48 horas (sobrecoxa assada) onde foi quantificada a presença de $7 \alpha-$ $\mathrm{OH}$. Quando avaliamos os resultados dos ácidos graxos polinsaturados da carne de peito, observamos alterações significativas nos tratamentos BHT, orégano+sálvia e orégano+sálvia $+10 \% \mathrm{mel}$, provavelmente ocasionadas pela refrigeração. Nas amostras de sobrecoxa, foram observados efeitos de interação entre tratamentos e tempos de refrigeração para todas as classes de ácidos graxos (saturados, insaturados, monoinsaturados e polinsaturados). As amostras oferecidas na análise sensorial receberam notas acima da nota de corte, no entanto, a maior parcela dos provadores atribuiu notas altas às amostras submetidas aos tratamentos com especiarias e mel. 
Os resultados óbtidos neste estudo reafirmam a hipótese de que os compostos bioativos da sálvia, orégano e do mel foram capazes de inibir a oxidação lipídica, em todas as amostras.

Palavras-Chave: Oxidação lipídica, frangos, antioxidantes, especiarias, sistema microssomal e homogenato 


\section{HONEY AND SPICES AS PROTECTORS AGAINST LIPID OXIDATION IN CHICKEN MEAT}

\section{Abstract}

This study has been structured into five chapters. Chapter I provides a brief historical theoretical reference point regarding the importance of chicken meat, the mechanisms of lipid oxidation and the use of natural antioxidants.

Chapter II presents trials evaluating the in vitro antioxidant activity of honey and the spices oregano (Origanum vulgare L.) and sage (Salvia officinalis L.) over their shelf life. The results for oregano indicated an increase in total phenols from 1154.09 to $1611.28 \mathrm{mg}$ of gallic acid equivalent (GAE)/100 $\mathrm{g}$ ( 0 to 12 months). For sage, the values changed from 1309.8 to $2032.4 \mathrm{mg} \mathrm{GAE} / 100 \mathrm{~g}$ over the period ( 0 to 12 months) and for honey, the values measured were $1007.1,1830.4$ and $2129.9 \mathrm{mg} \mathrm{GAE} / 100 \mathrm{~g}$ at the times of 0,6 and 12 months, respectively. The results relating to the percentage inhibition of lipid oxidation ( $\% \Pi \mathrm{IL}$ ) by the $\beta$-carotene/linoleic acid system showed that sage inhibited oxidation by $74.6,81.3$ and $81.3 \%$ at the times of 0,6 and 12 months, while oregano presented inhibition values of $43.2,63.3$ and $50.7 \%$. Evaluation of the antioxidant activity index (AAI) using the Rancimat apparatus showed that the AAI for sage (3.35) was greater than the indices for the other agents, which were 1.69, 1.25 and 1.08 for $\mathrm{BHT}$, oregano and honey, respectively. The results from testing the oxygen radical absorbance capacity (ORAC) showed that oregano presented values of 544.6, 430.7 and $1019.6 \mathrm{TE} \mu \mathrm{mol} / \mathrm{g}$ at the times of 0,6 and 12 months, respectively. Sage presented ORAC values of $610.45,467.44$ and 822.21 at the times of 0,6 and 12 months and honey presented 47.3,22.4 and 26.1 ET $\mu \mathrm{mol} / \mathrm{g}$, at the times of 0,6 and 12 months. Comparing these results with those described in the literature, it can be concluded that these herbs and honey have high potential as antioxidants.

Chapter III shows the influence of the bioactive compounds in sage and oregano for protection against lipid oxidation, in a microsomal substrate of chicken meat. The mean concentrations of TBARS ( $\mu \mathrm{mol}$ of $\mathrm{MDA} / \mathrm{mg}$ of protein) observed in the breast meat samples were, for the control, 7.45; for BHT, 1.91; and for oregano + sage, 3.45. In the thigh meat samples, the following results were observed: control (9.83); BHT (4.27); oregano + sage (3.15). The treatments (BHT and oregano + sage) reached their peak inhibition after three hours (82.42\% and $82.25 \%$, respectively). However, analysis of the inhibition of lipid oxidation in the microsomal fraction of the thigh meat 
showed that the BHT treatment reached its peak inhibition (66.50\%) after one hour of induction and the oregano+sage treatment reached its peak inhibition after three hours $(82.25 \%)$. The results relating to inhibition of lipid oxidation during the induction period showed that, in relation to the control, the treatments implemented had a positive influence regarding protection against lipid oxidation in a microsomal substrate of chicken breast meat.

Chapter IV evaluates the effect of spices and honey with regard to protecting against lipid oxidation in a system consisting of a homogenate model of chilled chicken meat. The results from water action on the breast and thigh meat homogenates (either raw or cooked) showed that the treatment (oregano + sage $+10 \%$ honey) reduced the quantity of free water over the period of refrigeration. With regard to the $\mathrm{pH}$ values in the breast meat homogenates, it was seen that they rose over the period of refrigeration, in all the treatments evaluated. In the thigh meat, the $\mathrm{pH}$ values were higher than those observed in the breast meat. In the homogenates of raw breast meat, a marked loss of moisture was observed in all of the treatments and, particularly, at all durations of refrigeration. In the samples of cooked breast meat, no significant differences in moisture were seen between the control and the treatment with oregano + sage $+5 \%$ honey. In the homogenates of raw thigh meat, the moisture values ranged from 60.82 to $66.96 \mathrm{~g} / 100 \mathrm{~g}$. The myoglobin content in the homogenates of raw breast meat ranged from $1.95 \%$ to $2.01 \%$ at time zero. After 96 hours of refrigeration, the percentage myoglobin ranged from 1.85 to 1.96 , with lower concentrations in the samples treated with spices and honey. A different pattern of behavior was presented by the homogenates of cooked breast meat, in which after 96 hours of refrigeration, higher concentrations of myoglobin were observed in all the treatments evaluated, with the exception of the homogenate containing oregano+sage $+10 \%$ honey. With regard to the metmyoglobin values (\% MMb) for the homogenates of raw and cooked breast meat, small variations were observed over the refrigeration period. In the samples of raw breast meat, the oxymyoglobin concentrations $\left(\% \mathrm{O}_{2} \mathrm{Mb}\right)$ were similar after 96 hours of refrigeration in the control and BHT and oregano+sage treatments. On the other hand, in the cooked samples, the results were similar between the control and BHT samples. In the raw thigh meat samples after 96 hours of refrigeration, it was observed that the metmyoglobin concentration (\% MMb) was lower and the myoglobin content $(\% \mathrm{Mb})$ was higher, for all the treatments evaluated. In the samples that were subjected to 
cooking, contrasting with the raw homogenates, the metmyoglobin content (\% $\mathrm{MMb})$ was higher after 96 hours in the BHT and oregano+sage treatments, while it remained stable in the other samples. The results relating to inhibition of lipid oxidation in the cooked breast meat over the refrigeration period showed that, in relation to the control, the treatments had a positive influence. The treatment with BHT inhibited oxidation by $51.4 \%$ at time zero and by $74.3 \%$ after 48 hours. The peak inhibition was reached after 96 hours, with $77.7 \%$. Among the treatments evaluated, the one containing oregano + sage $+10 \%$ honey was the most effective treatment against oxidation, in relation to the others. Among the samples of cooked thigh meat, the BHT treatment did not inhibit oxidation in relation to the control at time zero. However, at the other times, there was a protective effect of $78.1 \%$ after 48 hours and $76.3 \%$ after 96 hours of refrigeration. Among the treatments with spices, the one with oregano + sage $+10 \%$ honey was again the most effective treatment, with a protective effect of $98 \%$.

Chapter $\mathrm{V}$ evaluates the effect of combinations of spices and honey on the oxidative stability of roasted and chilled chicken meat. After 96 hours, the samples with added herbs and honey presented TBARS values that were lower than in the control and BHT samples, thus suggesting that sage, oregano and honey had an antioxidant effect during the experiment. Evaluation of the results from analyzing the conjugated dienes and hexanal concentrations showed that all of the samples analyzed presented increased diene and hexanal levels at all durations of refrigeration. The treatment that presented the lowest hexanal values after 96 hours of refrigeration was oregano + sage $+5 \%$ honey, followed by oregano+sage $+10 \%$ honey. During the processing and over the course of storage, only traces of oxides were found $(25-\mathrm{OH}, 7-\mathrm{keto}, 7 \alpha-\mathrm{OH}$ and $7 \dot{\beta}-\mathrm{OH})$, with the sole exception of the BHT treatment on roast thigh meat after 48 hours, in which the presence of $7 \alpha-\mathrm{OH}$ was quantified. Evaluation of the results relating to polyunsaturated fatty acids in the breast meat showed significant changes in the BHT, oregano+sage and oregano + sage $+10 \%$ honey treatments, probably caused by the refrigeration. In the samples of thigh meat, interaction effects between the treatments and duration of refrigeration were observed for all classes of fatty acids (saturated, unsaturated, monounsaturated and polyunsaturated). The samples offered in the sensory analysis received scores that were above the cutoff score, but most of the testers attributed high scores to the treatments with herbs and honey. 
The results obtained from this study reaffirm the hypothesis that the bioactive compounds in sage, oregano and honey were capable of inhibiting lipid oxidation in all the samples.

Key words: lipid oxidation, chicken, antioxidants, spices, microsomal system, homogenate 


\section{Capítulo I - Introdução geral}

\section{Introdução}

\subsection{Importância da carne de frango}

A avicultura nacional tem alcançado, no decorrer dos anos, índices altamente produtivos devido à modernização e desenvolvimento da sua cadeią produtiva, desde a criação dos animais até a aquisição pelo consumidor.

A produção mundial de carne de frango, segundo o FAO, registrou em 2007 um aumento, passando de 64 milhões de toneladas para 75 milhões de toneladas. A produção do Brasil em 2007 foi de 10,2 milhões de toneladas, resultado que manteve o país no terceiro lugar entre os maiores produtores mundiais, atrás somente de Estados Unidos e China, que apresentaram produção de 16,2 e 10,5 milhões de toneladas respectivamente $(\mathrm{ABEF}, 2008)$.

No mercado mundial o volume de exportação da carne de frango foi de 7,2 milhões de toneladas, sendo que as exportações mundiais registraram aumento de $11,4 \%$ em 2007. O Brasil teve participação de $45 \%$ nessas vendas no mercado internacional, mantendo sua posição de maior exportador mundial de carne de frango (ABEF, 2008).

Estes números mostram a importância da avicultura para a economia brasileira. Algumas das razões para este desempenho são os modelos de produção/criação adotados e padrões de qualidade, ambos obtidos a custo relativamente baixo. Estes fatores contribuem de forma relevante para a atual posição do Brasil no mercado mundial (APINCO, 2003).

A carne de frango é a segunda mais consumida no mundo e a que mais cresce em produção e consumo. Nos últimos vinte e sete anos, seu crescimento foi superior a $220 \%$ e o consumo interno nacional chegou a 38 quilos per capita (Olivo, 2008).

Levy-Costa et al,, (2005) realizaram um estudo sobre a disponibilidade domiciliar de alimentos no Brasil referente ao período de 1974 a 2003 . Os autores utilizaram o banco de dados da Pesquisa de Orçamento Familiar (POF) e estimaram que a dieta do brasileiro em $1700 \mathrm{Kcal}$ (meio urbano) e $2400 \mathrm{Kcal}$ (meio rural). Os autores destacaram que os alimentos básicos de origem vegetal (cereais, leguminosas e raízes e tubérculos) correspondem a cerca de 50\% das calorias totais, vindo, a seguir, com cerca de $28 \%$, os alimentos essencialmente calóricos (óleos e gorduras vegetais, gordura animal, açúcar e refrigerantes e bebidas alcoólicas) e, com cerca de $18 \%$, os produtos de 
origem animal (carnes, leite e derivados e ovos). Frutas, verduras e legumes correspondem a apenas $2,3 \%$ das calorias totais.

Neste mesmo. estudo de os autores destacaram variações importantes em indicadores da disponibilidade domiciliar de alimentos foram observadas nas áreas metropolitanas do País no período 1974-2003, seja com relação à participação relativa de alimentos e grupos de alimentos, ou aos macronutrientes na dieta. A participação na dieta aumentou para carnes em geral (aumento de quase $50 \%)$, carne bovina $(+22 \%)$, carne de frango $(+100 \%)$, embutidos $(+300 \%)$, leite e derivados $(+36 \%)$, óleos e gorduras vegetais $(+16 \%)$, biscoitos $(+400 \%)$ e refeições prontas $(+80 \%)$ (Levy-Costa et al., 2005).

O expressivo consumo de carne de aves está ligado ao preço mais baixo comparado às outras carnes, à inexistência de restrição religiosa e cultural, à possibilidade de diversidade de produtos e às características nutricionais (APINCQ, 2003). Estas características fazem com que a carne das aves apresentem maior diversificação de produtos industrializados, em detrimento da venda de carcaças e cortes. Esta tendência é notável nos Estados Unidos da América, onde se observou a formação de três segmentos claros (carcaça, cortes e processados), durante o período de 1960 a 2000 (Sams, 2001 e Barbut, 2002).

Até o início da última década, a indústria avícola preocupava-se somente com a qualidade estética das carcaças e cortes. No entanto, nos últimos anos, as necessidades tecnológicas mudaram esta situação. Tơrnou-se necessária a preocupação, além de uma maior dedicação à qualidade funcional das matérias-primas como forma de evitar perdas econômicas e garantir a qualidade final desejada, e por fim, a satisfâãão dos consumidores (Olivo e Olivo, 2006).

O crescimento na produção de carne de aves é acompanhado por maior diversificação de produtos, com maior elaboração de itens de conveniência, praticidade e valor agregado, em detrimento da comercialização de carcaças inteiras e/ou cortes. Esta tendência ocorre em razão da mudança de hábitos da população, já que a praticidade, conveniência, qualidade nutritiva e segurança alimentar, com preços acessíveis, são condições básicas para os negócios na área de alimentação (Olivo, 2004; Arnaud et al., 2004). 


\subsection{Cor}

A coloração da carne, resultante da presença de vários pigmentos, pode ser influenciada por fatores biológicos, como $\mathrm{pH}$ do músculo, temperatura muscular, umidade relativa, condições visuais como iluminação e raios ultravioletas, além de contaminação bacteriana (Cichoski et al., 1996).

A química da cor da carne envolve os pigmentos heme, especificamente o pigmento mioglobina, que é similar em estrutura à hemoglobina, porém de maior peso molecular, formada por uma proteína globular e uma porção não protéica, denominada grupo heme (Olivo, 2006).

A porção heme do pigmento é de interesse tecnológico, porque a cor da carne é fortemente dependente do estado de oxidação do ferro presente neste grupo, que associado a uma molécula de oxigênio, fará a carne apresentar uma coloração vermelho brilhante e o pigmento formado é a oximioglobina. Quando associada a uma molécula de água, a cor será vermelha púrpura, por causa da mioglobina reduzida. Se a associação ocorrer com uma molécula de dióxido de carbono, ou mesmo, quando houver oxidação do ferro, a cor da carne será marrom, devido à formação da metamioglobina. A conversão da forma ferrosa na forma férrica resulta em oxidação (Morey et al., 1973; Cross et al., 1986; Torres et al., 1988; Asghar et al., 1990; Kanner, 1994).

A cor da carne fresca esta associada à proporção e distribuição relativa de três formas químicas da mioglobina: mioglobina reduzida ou deoximioglobina $\left(\mathrm{Mb}^{+}\right)$, de coloração vermelho-púrpura; oximioglobina $\left(\mathrm{O}_{2} \mathrm{Mb}\right)$, de coloração vermelho-brilhante; e a metamioglobina ( $\mathrm{MMb}$ ), de coloração marrom. Além destes pigmentos, outros derivados químicos são importantes na coloração de carnes e derivados cárneos, dentre eles a nitrosomioglobina (NOMb), de coloração vermelho rósea; e a carboximioglobina (COMb), de coloração vermelho-brilhante (Livingston e Brown, 1981; Baron e Andersen, 2002; Ramos e Gomide, 2007).

No caso de carnes de aves e peixes, a ênfase dada à cor é diferente da observada em animais de carne vermelha. A falta de pigmentação nos músculos do peito de perus e galinhas, por exemplo, é desejada pelo consumidor. Embora para os músculos de algumas espécies de peixes, a falta de pigmentação também seja desejada, a coloração escura ou avermelhada é necessária em outras espécies de peixes, a exemplo do salmão, 
entretanto, esta coloração está relacionado aos carotenóides presentes nos músculos (Ramos e Gomide, 2007).

\subsection{Oxidação lipídica}

A oxidação lipídica é uma reação em cadeia iniciada freqüentemente pelo radical hidroxila $\left(\mathrm{OH}^{-}\right)$, representada pelas etapas de iniciação, propagação e terminação. Estas etapas estão apresentadas nas reações seguintes, onde L representa o lipídio (Nawar, 1996; Ferreira e Matsubara, 1997):

(1) Iniciação: $\quad \mathrm{LH}+\mathrm{OH}^{*}$ (ou $\left.\mathrm{LO}^{\circ}\right) \rightarrow \mathrm{L}^{*}+\mathrm{H}_{2} \mathrm{O}$ (ou $\left.\mathrm{LOH}\right)$

(2) Propagação: $\quad \mathrm{L}^{*}+\mathrm{O}_{2} \rightarrow \mathrm{LOO}^{*}$

$$
\mathrm{LH}+\mathrm{LOO}^{\circ} \rightarrow \mathrm{L}^{*}+\mathrm{LOOH}
$$

(3) Terminação: $\mathrm{LOO}^{\circ}+\mathrm{L}^{*} \rightarrow \mathrm{LOOL}$

$$
\mathrm{LOO}^{*}+\mathrm{LOO}^{*} \rightarrow \mathrm{LOOL}+\mathrm{O}_{2}
$$

(1) Os ácidos graxos insaturados (LH) são convertidos, via abstração de hidrogênio (H) da membrana celular, em radicais livres lipídicos $\left(\mathrm{L}^{*}\right)$. Tal seqüestro pode ser realizado pelo $\mathrm{OH}^{\circ}$ (radical hidroxila) ou pelo $\mathrm{LO}^{\circ}$ (radical alcoxila).

(2) Os radicais livres gerados são oxidados pelo oxigênio molecular $\left(\mathrm{O}_{2}\right)$, originando radicais peroxila $\left(\mathrm{LOO}^{\circ}\right)$, que por sua vez seqüestra novo hidrogênio do ácido graxo insaturado, formando novamente o $\mathrm{L}^{*}$ (radical livre lipídico) na segunda equação da propagação.

(3) A fase de terminação tem como característica a formação de produtos finais estáveis ou não reativos (Ferreira e Matsubara, 1997). 
Durante a iniciação, ocorre a abstração de um átomo de hidrogênio da molécula de ácido graxo insaturado, o que normalmente é caudado por um agente iniciador como a presença de luz, calor, metais, radiações ionizantes, compostos radicais ou fitoquímicos em estado de excitação (Kirk, 1984; Donnelly e Robinson, 1995; Nawar, 1996; Ferreira e Matsubara, 1997.

Em condições anaeróbicas, o radical alila formado se combina com o oxigênio molecular rapidamente, produzindo o radical peroxila. A reatividade deste radical peroxila é muito elevada e suficiente para abstrair outro átomo de hidrogênio de outro ácido graxo insaturado, propagando assim a reação em cadeia característica da oxidação dos lipidios (Donnelly e Robinson, 1995).

$\mathrm{Na}$ propagação os radicais livres que são prontamente susceptiveis ao ataque do oxigênio atmosférico, são convertidos em outros radicais, aparecendo os produtos primários de oxidação (peróxidos e hidroperóxidos), cuja estrutura depende da natureza dos ácidos graxos presentes. Os radicais livres formados atuam como propagadores da reação, resultando em um processo autocatalítico.

Já no término, dois radicais combinam-se com a formação de produtos estáveis (produtos secundários de oxidação) obtidos por cisão e rearranjo dos peróxidos, tais como álcoois, aldeídos, cetonas, ésteres e hidrocarbonetos (Nawar, 1996; Ferreira e Matsubara, 1997)

O malonaldeído é o maior produto secundário da oxidação lipídica, apresentando efeito citotóxico, carcinogênico e mutagênico (St. Angelo, 1996).

A oxidação lipídica é uma das principais reações deteriorativas e ocorre principalmente durante o processamento, distribuição, armazenamento e preparo final dos alimentos, sendo uma das responsáveis pelo desenvolvimento de sabores e odores desagradáveis nos mesmos. Além disso, a oxidação leva ao desenvolvimento de outras alterações que irão afetar a qualidade nutricional, a integridade e a segurança, através da formação de compostos potencialmente tóxicos (Nawar, 1985; Kubow, 1993).

$\mathrm{Na}$ carne, existem três fases de oxidação lipídica, ditas fenômenos da oxidação lipídica. A primeira fase é a oxidação que ocorre in vivo. $\mathrm{O}$ início se dá nos fosfolipídios das membranas celulares, ricas em ácidos graxos polinsaturados. Mesmo em condições normais, as células estão continuamente mudando por ação de agentes estressores, oriundos de fontes internas e externas. Os agentes mais importantes são derivados do 
oxigênio reduzido, as chamadas espécies reduzidas de oxigênio (ROS), livres (Chizzolini et al., 1998).

A formação dos ROS pode ocorrer acidentalmente, na cadeia respiratória, ou intencionalmente, nos fagócitos. Estes ROS causam o chamado estresse oxidativo, oxidando lipídios, proteínas, DNA e outras macromoléculas, levando à morte celular e injúria dos tecidos (Aruoma, et al., 1994). As reações de autoxidação dos lipídios, conhecida como lipoperoxidação, ocorrem principalmente ao nível dos ácidos graxos que compõem os fosfolipídeos presentes nas membranas e nas estruturas subcelulares, provocando alterações estruturais destas membranas (Mello-Filho et al., 1983), levando ao seu rompimento e causando a subseqüente disfunção e morte celular (Hershko, 1989).

Muitos agentes presentes em sistemas biológicos podem atuar como aceleradores das reações de peroxidação, como os íons de metais de transição, componentes heme e radiações, formando radicais livres. Estes catalisam reações que podem afetar todos os aspectos das funções das membranas e o metabolismo celular e levar a significativa perda da qualidade dos alimentos. A perda da integridade das membranas celulares pode afetar, desta maneira, a habilidade das biomembranas de atuarem como semipermeáveis, podendo contribuir para exsudação da carne. Isto poderá provocar a perda de nutrientes e o comprometimento da qualidade funcional da carne (Machlin e Bendich, 1987).

A segunda fase do processo é a oxidação durante a conversão do músculo em carne, que ocorre entre o pré abate e a instalação do rigor mörtis (Morrissey et al., 1998). As mudanças bioquímicas que acompanham a conversão do músculo em carne geram condições favoráveis à oxidação lipídica e da mioglobina. Logo após a morte do animal, devido à redução da concentração do oxigênio celular e à conseqüente falha no aporte do sistema antioxidante natural, inicia-se o processo de peroxidação autocatalítica. $\mathrm{O}$ grau e a extensão desse processo são influenciados pelos eventos pré abate, tais como a alimentação e estresse, bem como por eventos pós abate, como a redução do pH post-mortem. Promovem a desnaturação de proteínas, comprometendo a estrutura das fibras, liberação de umidade, palidez da carne e maior suscetibilidade à rancificação (Kanner, 1994).

A terceira e mais significativa fase da oxidação lipídica ocorre durante o processamento, o armazenamento e a exposição (Decker e Crum, 1993). O rompimento da integridade das membranas musculares pela desossa mecânica, moagem, 
reestruturação ou cozimento, alteram os compartimentos celulares, com liberação do ferro cataliticamente ativo da mioglobina e outras proteínas. A interação deste e de outros agentes peroxidantes com os ácidos graxos polinsaturados resulta na geração de radicais livres e na propagação das reaçốes oxidativas. A exposição das matérias primas ou produtos a temperaturas sem controle, presença de oxigênio e a incidência demasiada de luz colaboram substancialmente para estas reações. Assim os produtos reestruturados e cozidos apresentam grande possibilidade oxidativa (Morrissey, et al., 1998).

Silva et al., (1999) relataram que o desenvolvimento do ranço oxidativo com produção de compostos responsáveis por sabor e aroma indesejáveis, além da reversão e da ocorrência de um elevado número de reações de polimerização e de cisão são produtos de oxidação lipídica. Essas reações não só reḑuzem a vida de prateleira e o valor nutritivo dos produtos alimentares, como podem gerar compostos tóxicos: Os fenômenos de oxidação dos lipídios dependem de mecanismos reacionais diversos e extremamente complexos, os quais estão relacionados com o tipo de estrutura lipídica e o meio onde se encontram. O número e a natureza das insaturações presentes, o tipo de interface entre os lipídios e o oxigênio (fase lipídica contínua, dispersa ou em emulsão), a exposição à luz e ao calor, a presença de pró-oxidantes (como os íons metálicos de transição) ou de antioxidantes, são fatores determinantes para a estabilidade oxidativa dos lipídios (Figura 1).

As diversas conseqüências nutricionais da oxidação lipídica são muito importantes. Em vista disso, sabe-se que ocorre: 1 - degradação parcial dos ácidos graxos insaturados essenciais linoléico e linolênico; 2 - degradação parcial de outros lipídios insaturados, vitamina $\mathrm{A}$, carotenóides e tocoferóis; 3 - degradação parcial da vitamina $\mathrm{C}$ (co-oxidação); 4 - formação de produtos secundários da oxidação lipídica (malonaldeído) além de compostos da reação de Maillard, capazes de reagir com biomoléculas (especialmente proteínas), diminuindo a absorção destas; 5 - irritação da mucosa intestinal por peróxidos, que provoca diarréia e reduz a capacidade de absorção e 6 - formação de lipídios oxidados, que são antagonistas de diversos nutrientes, como a tiamina, o pantotenato de cálcio, a riboflavina, o ácido ascórbico, a vitamina $B_{12}$, os tocoferóis, a vitamina A, lisina e os aminoácidos sulfurados (Kirk, 1984; Ladikos e Lougovois, 1990; Kanner, 1994). 


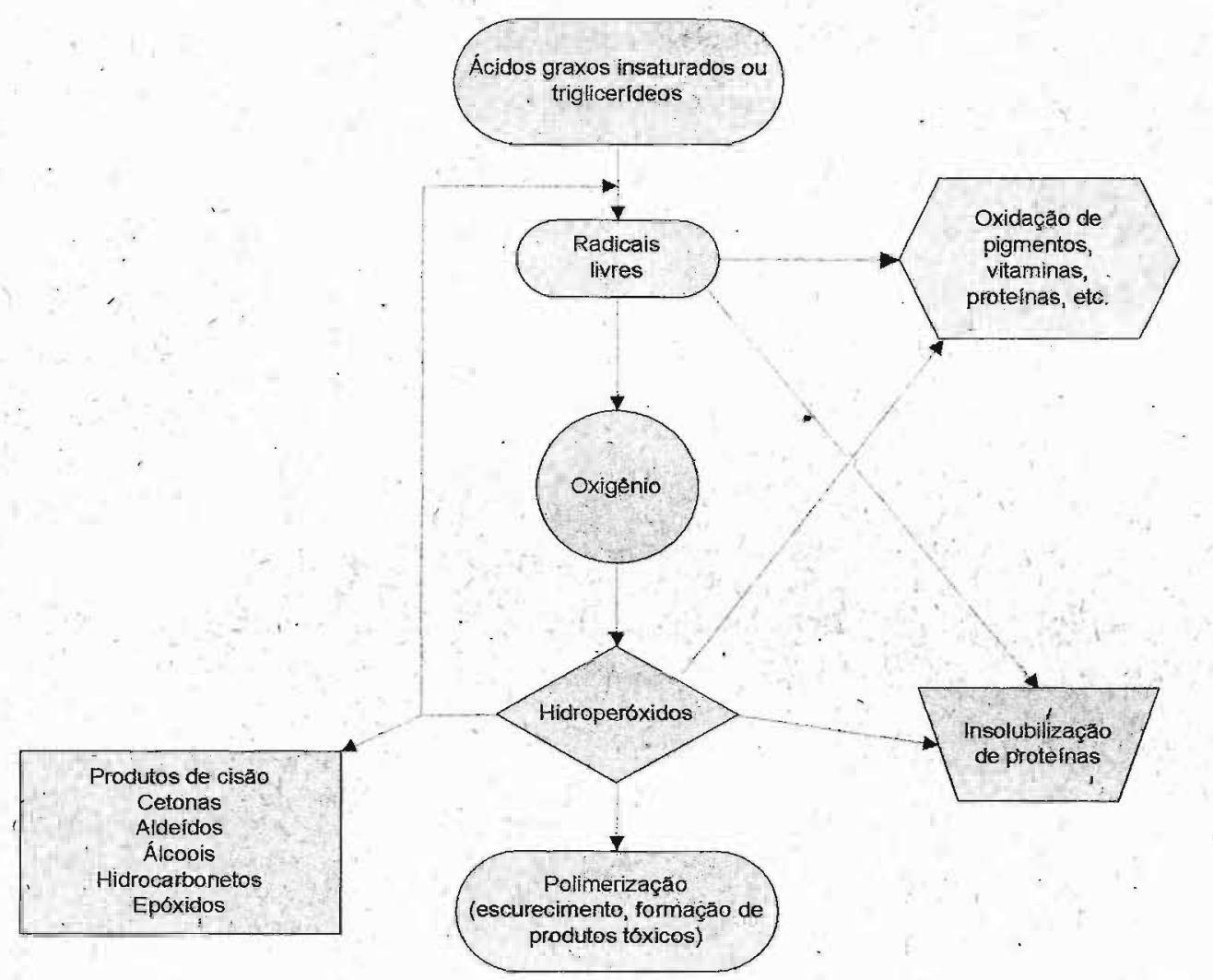

Figura 1 - Esquema geral da oxidação lipídica (Silva et al., 1999)

\subsection{Antioxidantes}

Uma substância antioxidante pode ser definida como: 1) composto ou substância química que inibe a oxidação ou, 2) qualquer substância que quando presente em baixa concentração comparada à do substrato oxidável, reduz ou inibe significativamente a oxidação daquele substrato. Do ponto de vista biológico, podemos definir antioxidantes como compostos que protegem sistemas biológicos contra os efeitos potencialmente danosos de processos ou reações que promovam a oxidação de mac̀romoléculas ou estruturas celulares (Abdalla, 1993).

Labuza et al., (1971) apresentaram a seguinte classificação para os antioxidantes: 
Tipo I - Substâncias capazes de interromper a cadeia de radicais livres, cedendo um átomo de hidrogênio a um radical lipídico livre.

$$
\begin{array}{ll}
\mathrm{AH}+\mathrm{ROO}^{*} & \mathrm{ROOH}+\mathrm{A}^{\bullet} \\
\mathrm{AH}+\mathrm{R}^{\bullet} & \mathrm{RH}+\mathrm{A}^{\bullet} \\
\mathrm{AH}+\mathrm{RO}^{*} & \mathrm{ROH}+\mathrm{A}^{\bullet}
\end{array}
$$

Onde:

AH - antioxidante

$\mathrm{ROO}^{\bullet}, \mathrm{R}^{\bullet}, \mathrm{RO}^{\bullet}$ - radicais livres

$A^{\bullet}$ - radical estável

Os radicais $\mathrm{A}^{\bullet}$ formados são mais estáveis e não reagem com moléculas lipídicas.

Tipo II - Agentes complexantes de metais como o ácido ascórbico, o ácido cítrico e outras substâncias, agem impedindo ou diminuindo a ação dos metais sobre as estruturas lipídicas.

Tipo III - Pertencem a este grupo, fatores ambientais como concentraçãode oxigênio, temperatura e umidade que, quando controlados conferem proteção contra oxidação.

Os antioxidantes podem ser divididos em duas classes: com atividade enzimática e sem atividade enzimática. Na primeira, estão os compostos capazes de bloquear a iniciação da oxidação, ou seja, as enzimas que removem as espécies reativas de oxigênio. Na segunda classe, estão moléculas que interagem com as espécies radicalares, sendo consumidas durante a reação. Neste grupo, incluem-se os antioxidantes naturais e sintéticos, como os compostos fenólicos (Moreira e ManciniFilho, 2004).

Os compostos fenólicos, naturalmente presentes nos condimentos em geral, sendo o principal mecanismo de ação a inativação de radicais livres de lipídios, diminuindo a produção de espécies reativas e conseqüentemente, interrompendo a fase de propagação da autoxidação lipídica (Gordon, 2004).

A atividade antioxidante depende de vários fatores, tais como: 1 - tipo de antioxidante (estrutura química, potencial redox, polaridade, a solubilidade, 
concentração; 2 - tipo de alimento (distribuição em fase aquosa ou lipídica, presença de pro-oxidantes, presença de outros antioxidantes e presença de substâncias sinergistas); 3 - condições de armazenamento e processamento (tempo e temperatura de armazenamento, tempo e temperatura de aquecimento e acesso ao oxigênio) (Pokorný, 2007).

Os antioxidantes sintéticos mais utilizados na indústria de alimentos são BHA (butil hidroxianisol), BHT (butil hidroxitolueno), PG (propil galato) e TBHQ (terc-butil hidroquinona) (Pinho, 2000). A estrutura fenólica destes compostos permite a doação de um próton a um radical livre, regenerando, assim, a molécula do acilglicerol e interrompendo o mecanismo de oxidação iniciado por radicais livres. Assim, estes radicais podem se estabilizar sem promover ou propagar reações de oxidação.

Entre os antioxidantes naturais mais utilizados podem ser citados tocoferóis, ácidos fenólicos e extratos de plantas como alecrim, sálvia, coentro e orégano. Segundo Madsen e Bertelsen (1995), as propriedades antioxidantes das especiarias e de outros vegetais, devem-se principalmente a seus compostos fenólicos. O reino vegetal é rico em compostos fenólicos, os quais são encontrados tanto nas especiarias como nas partes de plantas tais como sementes, frutas, folhas e raízes (Economou, et al., 1991).

Os compostos fenólicos são uma classe extensa de antioxidantes, sendo quimicamente caracterizados pela presença de pelo menos um anel aromático e de grupos substituintes (como hidroxilas e carboxilas) presos a estrutura do anel (Sroka e Cisowki, 2003). Agem como seqüestradores de radicais livres bloqueando as reações em cadeia. Estão largamente distribuídos na natureza e são derivados de ácido benzóico e cinâmico, bem como de flavonóides (Shahidi et al., 1992). Os antioxidantes naturais possuem substratos específicos, e sua atividade antioxidante depende de muitos agentes presentes, tanto na preparação, como o tipo de alimento que está sendo estabilizado (Evans, 1997).

Um antioxidante pode ser ativo sob condições particulares e menos sob diferentes condições. Assim, não é possível afirmar quais tipos de antioxidantes são mais ativos. Geralmente, os antioxidantes naturais são essencialmente menos ativos, mas é aconselhável determinar a real atividade antioxidante, em condições idênticas ou muito prỏximas aos antioxidantes sintéticos (Pokorný, 2007). 


\subsection{Especiarias}

Segundo, a ANVISA (Brasil, 2005) o orégano (Origanum vulgare L.) e a sálvia (Salvia officinalis L.) são considerados especiarias. São produtos constituídos de partes (raizes, rizomas, bulbos, cascas, folhas, flores, frutos, sementes e talos) de uma ou mais espécies vegetais, tradicionalmente utilizadas para agregar sabor ou aroma aos alimentos e bebidas.

A capacidade antioxidante das especiarias está relacionada aos seus compostos fenólicos sendo, sua ação semelhante a dos compostos sintéticos, interrompendo a cadeia de radicais livres na etapa de iniciação do processo oxidativo (Lai et al., 1991).

$\mathrm{O}$ efeito antioxidante das especiarias e ervas foi inicialmente evidenciado, em 32 especiarias, das quais o alecrim e a sálvia foram consideradas as mais eficazes. Posteriormente, esta ação foi evidenciada no orégano, tomilho, pimenta, mostarda, canela, coentro, dentre outras (Chipault et al., 1952; Kikuzaki, et al., 1993; Vekiari et al., 1993; Madsen e Bertelsen, 1995; Mancini-Filho et al., 1998; Lu e Foo, 2000; Matsingou, et al., 2003, Durling, et al., 2007).

As propriedades antioxidantes dos membros da família Labiatae que compreendem espécies de (alecrim, sálvia, orégano, tomilho, manjericão, manjerona, tomilho, entre outras) são atribuídas principalmente aos compostos fenólicos (Evans, 1997; Shan et al., 2005) e, além disso, possuem propriedades antimicrobianas.

Especialmente, o orégano e seus diferentes extratos têm demonstrado propriedades antioxidantes em diferentes modelos in vitro (Vekiari et al., 1983; Nakatani e Kikuzaki, 1987; Cuvelier et al., 1994; Pizzale et al., 2002; Shan et al., 2005). Esta propriedade é atribuída às diferentes variedades de compostos fenólicos, que são encontrados nesta especiaria. Vários estudos demonstraram que a presença do ácido rosmarínico, ácido caféico, carnosol, rosmanol, ácido carnósico, ácido 12 metilcarnósico, metilcarnosol, metilcarnosato, epirosmanol, rosmadial, catequina (Cuvelier et al., 1994; Pizzale et al., 2002; Shan et al., 2005).

Outros compostos, presentes no orégano como o ácido protocatecuico, apigenina, 4-(3,4-dihidroxibenzoiloximetil) fenil- $\beta$-D-glucopiranosideo, fenil glicosídio, ácido 2-cafeiloxi-3-[2-(4-hidroxilbenzil)-4-5-dihidroxifenil] propiônico, diosmetina, eriodictiol, dihidrocampferol, dihidroquercetina, timoquinona, benzilálcool, eugenol, 2fenil-etanol, 3-hexen-1-ol, 4'-O- $\beta$-D-glucopiranosil-3', 4'-dihidroxibenzil protocatecuato foram relatados nos estudos de (Nakatani e Kikuzaki, 1987; Vekiari et al., 1993; Milos et al., 2000; Shan et al., 2005; Suhaj, 2006). 
A sálvia também possui grande quantidade de compostos fenólicos ( $\mathrm{Lu}$ e Foo, 2000) com atividade antioxidante como os ácidos carnósico, caféico, rosmarínico, além de carnosol foram identificados na sálvia (Chang, et al., 1977; Cuvelier, et al., 1994; Areias et al., 2000; Matsingou, et al., 2003, Durling, et al., 2007).

Os extratos de sálvia também possuem flavonóides, luteolina, apigenina, hispidulina e cirsimaritina que contribuem como antioxidantes naturais ( $\mathrm{Lu}$ e Foo, 2000; Areias, et al., 2000; Durling et al., 2007).

Tanto o orégano como a sálvia têm demonstrado um ótimo potencial antioxidante em alguns em alimentos susceptíveis a oxidação tais como maionese, salsichas, peru, hambúrgueres, frango e peixes (Botsoglou et al., 2002; Estévez e Cava, 2006; Fasseas et al., 2007).

\subsection{Mel}

O mel é um produto alimentício produzido pelas abelhas melíferas, a partir do néctar das flores ou das secreções procedentes de partes vivas das plantas ou de excreções de insetos sugadores de plantas que ficam sobre partes vivas de plantas, que as abelhas recolhem, transformam, combinam com substâncias específicas próprias, armazenam e deixam madurar nos favos da colméia (Brasil, 2000).

Os méis podem ser classificados em: monofloral, constituído do néctar de uma única espécie ou quando a maior predominância for de uma única espécie floral; ou polifloral, quando constituído do néctar de uma espécie floral e extrafloral que não provem do néctar, sendo produzido a partir de exsudato de plantas ou restos de frutas (Rossi et al., 1999).

Na composição do mel são encontradas, no mínimo, 181 substâncias (Sato e Miyata, 2000), entre as quais açúcares, com predominância de glucose e frutose, água, uma mistura complexá de outros carboidratos, enzimas, aminoácidos, ácidos orgânicos, minerais, substâncias aromáticas, pigmentos e grãos de pólen. Os carboidratos representam a maior porção de matéria seca do mel, sendo responsável por suas qualidades e propriedades físicas: viscosidade, propriedades térmicas, higroscópicas, granulométricas, valor energético e a atividade antibacteriana (Crane, 1975).

Em geral todos os méis são ácidos e o pH é influenciado pela origem botânica, como também pela concentração de diferentes ácidos e minerais, tais como cálcio, sódio, potássio, além de outros constituintes das cinzas (Frias e Hardisson, 1992). 
Os antioxidantes presentes no mel incluem enzimas (catalase, glucose oxidase e peroxidase) e substâncias não enzimáticas (ácidos orgânicos, produtos da Reação de Maillard, aminoácidos, proteínas, flavonóides, ácidos fenólicos (caféico, cumárico, ferrúlico, elágico e clorogênico), $\alpha$-tocoferol, flavonóis, catequinas, ácido ascórbico e carotenóides (Meda et al., 2005; Bertoncelj et al., 2007).

De acordo com Ferreres et al., (1994), Soler et al., (1995) e Bertoncelj et al., (2007) o perfil de fenólicos de mel é composto pelos seguintes flavonóides: miricetina, hesperetina, quercetina, luteolina, 8-metoxicanferol, canferol, apigenina, isorramnentina, pinocembrina, pinobanksina, crisina, galangina e tectocrisina.

Alguns estudos verificaram que o mel possui atividade antioxidante tanto no controle de reações de oxidação lipídica em produtos cárneos e do escurecimento enzimático de frutas e vegetais (Oszmianski e Lee, 1990; Antony et al., 2000; Mckibben e Engeseth, 2002) como no controle de processos oxidativos em sistemas biológicos, avaliado por métodos in vivo $e$ in vitro (Gheldolf e Engeseth, 2002; Gheldolf et al., 2002; Gheldolf et al., 2003; Al-Mamary et al., 2002; Schramm et al., 2003).

Outros trabalhos demonstraram haver correlação positiva entre o teor de fenólicos totais de mel e a sua atividade antioxidante (Gheldolf e Engeseth, 2002; AlMamary et al., 2002).

Nagai et al., (2006) que também utilizaram mel para avaliar a vida de prateleira de carnes, e os autores concluíram que o mel inibiu a oxidação, bem como o crescimento bacteriano nas carnes. 


\section{Objetivo geral}

O objetivo geral deste estudo foi avaliar o efeito protetor do mel e especiarias (sálvia e orégano) sobre a oxidação lipídica em diferentes cortes de carne de frango (peito e sobrecoxa)

\subsection{Objetivos específicos}

Avaliar a atividade antioxidante do mel e das especiarias como sálvia e orégano;

Verificar a eficácia'dos antioxidantes naturais incorporados aos experimentos e nos dois tipos de cortes avaliados;

Determinar o grau de oxidação dos sistemas microssomais e homogenatos;

Avaliar a estabilidade lipídica dos produtos (crus e após a cocção e refrigeração);

Realizar análise sensoriais dos produtos pós preparo e

Avaliar̃ o perfil microbiológico das preparações de frango.

\section{Experimentos.}

Este estudo foi estruturado em quatro experimentos apresentados da seguinte forma:

1 - Quantificação dos teores das substâncias antioxidantes do mel, orégano e sálvia;

2 - Avaliação da capacidade antioxidante dos compostos nos extratos microssomais das amostras;

3 - Avaliação da capacidade antioxidante no sistema modelo homogenato e

4 - Avaliar os efeitos das combinações de especiarias no mel na estabilidade oxidativa dos cortes de frangos assados e refrigerados. 


\section{Referências Bibliográficas}

* De acordo com a norma NBR 6023/2000, preconizada pela ASSOCIAÇÃO BRASILEIRA DE NORMAS TÉCNICAS (ABNT). As abreviaturas dos títulos dos periódicos seguem o CHEMICAL ABSTRACTS SERVICE SOURCE INDEX (CASSI), 2001.

[APINCO, 2003] (Campinas/SP) - II Seminário Latino-Americano de Ovos. Disponível on-line em 07 de maio de 2003.

Abdalla, D.S.P. Antioxidantes: conceitos básicos e perspectivas terapêuticas. ARS Curandi, São Paulo, nov., p. 141-164, 1993.

ABEF [Associação Brasileira dos Produtores e Exportadores de Frangos], Relatório anual, 2007/2008: on-line em 20/01/2009, http://www.abef.com.br/portal/_clientes/abef/cat/Relat\%F3rio\%20200708_9952.pdf

AL-Mamary.; M. AL-Meeria, A. AL-Habori, M. Antioxidant activities and total phenolics of different types of honey. Nutr. Res. v.2 , p. 1041-47, 2002

Antony, S.; Rieck, J.R.; Dawson, P.L. Effect of dry honey on oxidation in turkey breast meat. Poultry Science, v.79, p. 1849-50, 2000.

Arnaud, E.; Relkin, P.; Pina, M.; Collignan, A. Characterization of chicken fat dry fractionation at the pilot scale. Eur. J. Sci. Technol., v.106, n.9, p.591-598, 2004.

Areias, F.; Valentão, P.; Andrade, P.B.; Ferreres, F.; Seabra, R.M. Flavonoids and phenolics acids of sage: influence of some agricultural factors. J. Agric. Food. Chem., v.48, p. 6081-6081, 2000.

Aruoma, O. I. Nutrition and health aspects of free radicals and antioxidantes. Food Chem. Toxicol., v.32, n.7, p.671-83, 1994.

Asghar, A.; Torres, E.A.F.S.; Gray, J.I.; Pearson, A.M. Effect of salt on myoglobin derivatives in the sarcoplasmic extract from pre- and post-rigor beef in the , presence or absence of mitochondria and microsomes, Meat Science, v. 27, p. 197$209,1990$.

Barbut, S. Poultry products processing: an industry guide. Boca Raton: CRC Press, $2002 ; 548$.

Baron, D.P.; Andersen, H.J. Myoglobin-induced lipid oxidation. A review. J. Agric. Foòd chem., v. 50, p. 3887-3897, 2002. 
Bertoncelj, J.; Dobersek, U.; Mojca J.; Golob, T. Evaluation of the phenolic content, antioxidant activity and colour of Slovenian honey. Food Chemistry, v. 105, p. 822-28, 2007.

Botsoglou, N.A.; Christaki, E.; Fletouris,' D.J.; Florou-Paneri, P.; Spais, a.B. The effect of dietary oregano essential oil on lipid oxidation in raw and cooked chicken during refrigerated storage. Meat Science, v.62, p.259-265, 2002.

Brasil, 2000. Ministério da Agricultura. Instrução normativa n. 11, de 20 de outubro de 2000. Regulamento técnico de identidade e qualidade do mel.

Brasil, 2005. Agência Nacional de Vigilância Sanitária [ANVISA]. Resolução RDC276, de 22/09/05: dispõe sobre regulamento técnico para especiarias, temperos e molhos. Diário Ofícial da União, Brasília, 23/06/05.

Chang, S.; Ostric-Matijasevic, B.; Hsieh, O.; Huang, D.L. Natural antioxidants from rosemary and sage. Journal of food Science, v. 42, p. 1102, 1977.

Chipault, J.R.; Mizun, G.K.; Hawkins, J.M.; Lundberg, W.O. The antioxidant properties of natural spices. Food Res., v.17, p.46-55, 1952.

Chizzolini, R.; Novelli, E.; Zanardi, E. Oxidation in traditional Mediterranean meat products. Meat Science, v. 49, n. 1, p. 87-99, 1998.

Cichoski, A. J.; Terra, N. N. Características sensoriais em carne. Higiene Alimentar, v. 10 , n. 46, p. $32-43,1996$.

Crane, E. Bees and beekeeping: science, practice and world resources. Oxford: Heinemann Newnes, 1990, 614p.

Crane, E. Honey: a comprehensive survey. London: Heinemann, 1975. 608p.

Cross, H.R.; Durlanda, P.R.; Seideman, S.C. Sensory qualities of meat. In: Bechtel, P.J., Muscle as food. 3 ed. USA-ARS, US. Meat Animal Research Center, Clay Center: Nebrasca, 179-315, 1986.

Cuvelier, M E.; Berset, C.; Richard, H. Antioxidant constituents in sage (Salvia officinalis). Journal of Agriculture and Food Chemistry, v.42, p.665-69, 1994.

Decker, E.A.; Crum, A.D. Control of lipid oxidation in cooked ground pork by carnosine. Meat Science, V.34, p.345-253, 1993.

Donnelly, J.R.; Robinson, D.S. Free radical in foods. Free Radical Res., v.22, n.2., p.147-176, 1995.

Durling, N.E.; Catchpole, O.J.; Grey, J.B; Webby, R.F.; Mitchell, K.A.;Foo, L.Y; Perry, N.B. Extraction of phenolics and essential oil from dried sage (Salvia 
officinalis) using ethanol-water mixtures. Food Chemistry, v. 101, p.1417-1424, 2007.

Economou, K. D.; Oreopoulou, V.; Thomopoulos, C. D. Antioxidant activity of some plant extracts of the family Labiatae. Journal of the American Oil Chemists' Society, v.68, n. 2, p.109-113, 1991.

Estévez, M.; Cava, R. Effectiveness of rosemary essential oil as an inhibitor of lipid and protein oxidation:Contradictory effects in different types of frankfurters. Meat Science, v.72, p.348-355, 2006.

Evans, R.J. Optimizinf lipid stability with natural antioxidants. In: Natural Antioxidants. Ed. F. Shahidi, AOCS Press, Champaign, IL (USA), p. 224-244, 1997.

Fasseas, M.K.; Mountzouris, K.C.; Tarantilis, P.A.; Polissiou, M.; Zervas, G. Antioxidant activity in meat treated with oregano and sage essential oils. Food Chemistry, v. 106, p.1188-1194, 2007.

Ferreira, A.L.A.; Matsubara, L.S. Radicais livres: conceitos, doenças relacionadas; sistema de defesa e estresse oxidativo. Rev. Ass. Med. Brasil, v. 43, n. 1, p. 61-8, 1997.

Ferreres, F.; Blazquez, M.A.; Gil, M.I.; Tomas-Barberan, F.A. Separation of honey flavonoids by micellar electrokinetic capillary chromatography. Journal of Chromatography A, v. 669, p. 268-274, 1994.

Frias, I.; Hardisson, A. Estudio de los parâmetros analíticos de interes em la miel. II: Azúcares, cenizas y contenido mineral y color. Alimentaria, v.28, n.235, p.41-43, 1992.

Gheldolf, N.; Engeseth, N.J. Antioxidant capacity of honeys from various floral sources based on the determination of oxygen radical absorbance capacity and inhibition of in vitro lipoprotein oxidation in human serum samples. $J$ Agric Food Chem. v.50, p. 3050-3055, 2002.

Gheldolf, N.; Wang, X.; Engeseth, N.J. Buckwheat honey increases serum antioxidant capacity in humans. J Agric Food Chem. v. 51, p. 1500-1505, 2003.

Gheldolf, N.; Wang, X.; Engeseth, N.J. Identification and quantification of antioxidant components of honeys from various floral sources. J. Agric. Food Chem, v.50, p.5870-5877, 2002

Gordon, M.H. Factors affecting lipid oxidation. In: Understanding and measuring the shelf-life of food, R.Steel, Ed. CRC Press, Boca Rato, 2004. 
Hershko, C. Mechanism of iron toxicity and its possible role in red cell membrane damage. Semin Hematol, v. 26, p. 277-85, 1989.

Lai, S.; Gray, J.I.; Smith, D.M.; Booren, A.M.; Crackel, R.L.; Buckley, d.J. Effects of oleoresin rosemary, tertiary butylhydroquinone, and sodium tripolyphosphate on the development of oxidative rancidity in restructured chicken nuggets. $J$ Food Sci, v.56, n.3, p. 616-620, 1991.

Livingston, D.J.; Brown, W.D. The chemistry of myoglobin and its reactions. Food Technology, v. 35, p. 244-252, 1981.

Kanner, J. Oxidative processes in meat and meat products: Quality implications. Meat Sci., Barking, v.36, p.169-189, 1994.

Kikuzaki, H.; Nakatani, N. Antioxidant effects of some ginger constituents. J Food Sci., v. 58, p. $1407-1410,1993$.

Kirk, J.R. Biological availability of nutrients in processed foods. J. Chem. Educat., v. 61, n. 4, p. $364-7,1984$.

Kubow, S. Lipid oxidation products in food and atherogenesis. Nutr. Rev., New York, v. 51, n.2, p.33-40,1993.

Labuza, T.P. Kinetics of lipid oxidation in foods. CRC Crit. Rev. Food Technol., Cleveland, v.2, n.3, p.355-405, 1971.

Ladikos, D.; Lougovois, V. Lipid oxidation in muscle foods: a review. Food Chemestry., v.35, p.295-314, 1990.

Levy-Costa, R.B.; Sichieri, R.; Pontes, N.S.; Monteiro, C.A. Disponibilidade domicliar de alimentos no Brasil:distribuição e evolução (1974-2003). Rev. Saúde Pública, v. 39, n. 4, p. $530-540,2005$

Lu, Y.; Foo, L.Y. Antioxidante activities of polyphenols from sage (Salvia officinalis) Food Chemistry, v. 75, p. 197-202, 2001.

Machlin, J.L.; Bendich, A. Free radical tissue damage: protective role of antioxidant nutrients. FASEB Journal,Bethesda, v.1, n.6n p. 441-445, 1987.

Madsen, H. L.; Bertelsen, G. Spices as antioxidants. Trends in Food Science \& Technology, v.6, n. 8, p.271-277, 1995.

Mancini-Filho, J.; Van-Voiij, A.; Mancini, D.A.P., Cozzolino, F.F.; Torres, R.P. Antioxidant activity of cinnamon (Cinnamomun zeylanicum, Breyne) extracts. Bol. Chim. Farmac., v.137, p. 443-447, 1998. 
Matsingou, T.C.; Petrakis, N.; Kapsokefalou, M.; Saligoglou, A. Antioxidant activity of organic extracts from aqueous infusions of sage. $J$. Agric. Food Chem. v.51, p. 6696-6701, 2003.

McKibben, J.; Engeseth, N.J. Honey as a protective agent against lipid oxidation in ground turkey. J. Agric. Food Chem., v. 50, p. 592-595, 2002.

Meda, A.; lamien, C.E.; Romito, M.; Millogo, J.; Nacoulma, O.G. Determination of the total phenolic, flavonoid and proline contents in Burkinia Fasan honey, as well as their radical scavenging activity. Food Chemistry, v. 91, 9. 571-577, 2005.

Mello Filho, A.C.; Hoffman, M.E.; Meneghini, R. Cell killing and DNA damage by hydrogen peroxide are mediated by intracellular iron. Biochem $J$, v. 218, p. 273275, 1983.

Shan, B.; Yizhong, A. C.; Sun, M.; Corke, H. Antioxidant capacity of 26 spice extracts and characterization of their phenolic constituents. Journal of Agricultural and Food Chemistry, v. 53, n. 20, p. 7749-7759, 2005.

Moreira, A.V.B., Mancini-Filho, J. Influência dos compostos fenólicos de especiarias sobre a lipoperoxidação e o perfil lipídico de tecidos de ratos. Rev. Nutr., Campinas, v. 17, n. 4, p. 411-424, 2004.

Morey, K. S.; Hansen, S.P.; Brown, W. D. Reaction of hydrogen peroxide with myoglobins. J. Food Sci., v.38, p.1104-1107, 1973.

Morrissey, P.A.; Sheehy, P.J.A.; Galvin, K.; Kerry, J.P.; Buckley, D.J. Lipid stability in meat and meat products. Meat Science, v. 49, p.S 73-S86, 1998.

Nagai, T.; Inoue, R.; Kanamori, N.; Suzuki, N.; Nagashima, T. Characterization of honey from different floral sources. Its functional properties and effects of honey species on storage of meat. Food Chemistry, v. 97, p. 256-262, 2006.

Nakatani, N., Kikuzaki., H.A. A new antioxidative glucoside isolated from oregano (Origanum vulgare L.). Agric. Biol. Chem., v.51, n.10, p.2727-32, 1987.

Nawar, W.W. Lipids. In: Fennema OR (Ed) Food Chemistry. New York: Marcel Dekker, Inc. 1996; 49: 653-67.

Nawar, W.W. Lipids. In: FENNEMA, O.R., Food Chemistry 3 ed. New York: Marcel Dekker, p. 139-244, 1985.

Olivo, N. Mercado mundial de carnes. 50 ed. Criciúma: Ed. do autor, 154p., 2008.

Olivo, R. Alterações oxidativas em produtos cárneos. In Olivo, R. O Mundo do Frango: cadeia produtiva da carne de frango. Criciúma, SC. Editado por Rubison Olivo, 2006. cap. 44, p. 534-541. 
Olivo, R. Atualidades na qualidade da carne de aves. Revista Nacional da Carne, v.28, n. 331, p.38-50, 2004.

Olivo, R., Olivo, N. O mundo das carnes: ciência, tecnologia \& mercado. Ed. Gráfica Imprint, 3.ed- Criciúma, 214 p., 2006.

Oszmianski, J., Lee, C.Y. Inhibition of polyphenoloxidase activity and browning by honey. J. Agric. Food Chem., v. 38, p. 1892-95, 1990.

Pinho, O.; Ferreira, I.M.P.L.V.O.; Oliveira, M.B.P.P.; Ferreira, M.A. Quantification of synthetic phenolic antioxidants in liver pâtés. Food Chemistry, v. 68, p. 353-357, 2000 .

Pizzale, L.; Bortolomeazzi, R.; Vichi, S.; Überegger, E.; Conte, L.S. Antioxidant activity of sage (Salvia officinalis and $S$ fruticosa) and oregano (Origanum onites and $O$ indercedens) exracts related to their phenolic compound content. J.Sci Food Agric., v.82, p. 1645-51, 2002.

Pokorny, J. Are natural antioxidants better - and safer - than synthetic antioxidants? Eur. J. Lipid Sci. Technol. v. 109, p. 629-642, 2007.

Ramos, E.M. e Gomide, L.A.M. Avaliação da qualidade de carnes: fundamentos e Metodologias; Viçosa-MG-Brasil: Ed. UFV, 599p., 2007.

Rossi, N.F., Martinelli, L.A., Lacerda, T.H.M., Camargo, P.B., Victoria, R.L., Análise da adulteração de méis por açúcares comerciais utilizando-se a composição isotópica de carbono. Cienc. Tecnol. Aliment., Campinas, v. 19, n.2, p.1-16, 1999.

Sams, A.R. Poultry meat processing. Boca Raton CRC. Press, p. 334, 2001.

Sato, T.; Miyata, G. The Nutraceutical Benefit, Part III. Nutrition, v. 16, n.6, 2000.

Schramm, D.D., Karim, M., Schrader, H.R.; Holt, R.R., Cardetti, M, Keen, C. Honey with high levels of antioxidants can provide protection to healthy human subjects. J. Agric. Food Chem. v. 51, p. 1732-1735, 2003.

Shahidi, F., Janitha, P.K., Wanasundara, P.D. Phenolic antioxidants. Crit Rev. Food Sci. Nutr., Cleveland, v. 32, p. 67-103, 1992.

Silva, F.A.M.; Borges, M.F.M.; Ferreira, M.A. Métodos para avaliação do grau de oxidação lipídica e da capacidade antioxidante. Química Nova, São Paulo, v. 22, n. 1, p. 94-103, 1999.

Soler, C.; Gil, M.I; Garcia-Viguera, C.; Tomás-Barberán, F.A. Flavonoid patterns of Frech honeys with different floral origin. Apidologie, v. 26, p. 53-60, 1995. 
Sroka, Z.; Cisowki, W. Hydrogen peroxide scavenging, antioxidant and anti- radical activity of some phenolic acids. Food Chem. Toxicol., Amsterdam, c. 41, p. 753-8, 2003.

St. Angelo, A.J. Lipid oxidation on foods. Crit Rev Food Sci Nutr. v. 36, p. 175-224, 1996.

Suhaj, M. Spice antioxidants isolation and their antiradical activity: a review. J. Food Composition and Analysis, v. 19, p. 531-537, 2006.

Torres, E.; Pearson, A.M.; Gray, J.I.; Booren, A.M.; Shimokomaki, M. Effect of salt on oxidative changes in pre and post-rigor ground beef. Meat Science. v. 23, p. 151163,1988

Vekiari, S.A.; Oreopoulou, V.; Tzia,C.; Thomopoulos, C.D. Oregano flavanoids as lipid antioxidants. J. Am. Oil Chem. Soc., v.70, p.483-487, 1993. 
Capítulo II - Avaliação da atividade antioxidante in vitro do mel e das especiarias orégano (Origanum vulgare L.) e sálvia (Salvia officinalis L.) no decorrer da vida de prateleira.

\section{Introdução}

Os antioxidantes são capazes de inibir a oxidação de diversos substratos, de moléculas simples a polímeros e biossistemas complexos, por meio de dois mecanismos: o primeiro envolve a inibição da formação de radicais livres que possibilitam a etapa de iniciação; o segundo abrange a eliminação de radicais já formados na etapa de propagação, como alcoxila e peroxila, através da doação de átomos de hidrogênio a estas espécies, interropendo a reação em cadeia da oxidação (Namiki, 1990).

Os antioxidantes presentes em maior quantidade na dieta humana'são os compostos fenólicos, que podem ser quimicamente definidos como substâncias que possuem um anel aromático com uma ou mais hidroxilas. Também podem apresentar outros grupos substituintes em sua estrutura, como ésteres, metil ésteres, metil-ésteres e glicosídeos (Han et al., 2007). As propriedades antioxidantes dos compostos fenólicos agem, principalmente, devido a seu potencial de oxi-redução que os permitem atuar como agentes redutores, doando radical hidrogênio e neutralizando os radicais livres . (Rice-Evans et al., 1997).

As especiarias e ervas têm sido usadas durante muitos séculos para melhorar as características sensoriais e prorrogar a vida de prateleira dos alimentos (Shahidi et al., 1992), sendo as plantas originárias da família botânica das Lamiaceae uma das mais utilizadas. A família Lamiaceae (antiga Labiatae, Adanson - ou Labiadas) compreende cerca de 7000 espécies, subdivididas em 7 subfamílias, Muitas espécies são importantes para a extração de óleos essenciais (Mentha, Lavandula, Marrubium. Nepeta, Ocimum, Origanum, Rosmarinus, Salvia, Satureja, Thymus, etc.), para utilização cosmética, condimentar, aromática e/ou medicinal.

As propriedades antioxidantes das especiarias pertencentes à família Lamiaceae, como o orégano e sálvia estão particularmente relacionadas aos compostos fenólicos (Pokorný, 1991; Schwarz e Ternes, 1992; Pizzale, et al, 2002; Miliauskas et al., 2004). Os principais compostos fenólicos identificados nestas especiarias são: ácido rosmarínico, ácido carnósico, carnosol, metil carnosato, rosmanol, epirorosmanol e rosmadial (Schwarz é Ternes, 1992; Riccheimer et al., 1996). 
Cinco compostos fenólicos distintos foram isolados em extratos metanólicos do orégano, sendo que todos apresentaram atividade antioxidante. Sendo um deles o ácido rosmarínico (Nakatani e Kikuzaki, 1987). De acordo com Vekiari et al., (1993) o extrato etanólico do orégano apresentou alta atividade antioxidante, sendo os componentes principais isolados da fração os flavonóides (Vekiari et al., 1993).

Cintra e Mancini-Filho (2001), avaliando o efeito antioxidante de especiarias, constataram que extratos de orégano demonstraram alta efetividade in vivo. De acordo com autores os compostos flavonóides de folhas de orégano foramser os principais responsáveis pela atividade antioxidante.

A atividade antioxidante da sálvia inicialmente foi associada a fenólicos diterpênicos (Zhang et al., 1994; Cuvelier et al., 1994). Wang et al., (1998 e 1999) relataram que a sálvia possui dois fenólicos glicosídicos com moderada atividade antioxidante. Lu e Foo (2001) encontraram flavonóides com atividade antioxidante variável em extratos de sálvia.

O mel é um produto natural de abelhas obtido a partir do néctar das flores (mel floral), de secreções de partes vivas das plantas ou de excreções de insetos sugadores de partes vivas das plantas (mel de melato) (Barth, 1989). Pode ser classificado em monofloral, constituído do néctar de uma única espécie ou com predominância de uma única espécie floral; polifloral quando constituído do néctar de várias espécies florais e extrafloral quando não provém o néctar, sendo produzido a partir de exsudato de plantas ou restos de frutas (Rossi et al., 1999).

O mel é composto basicamente de carboidratos e considerado um alimento de alto valor energético para o organismo humano. Basicamente, é uma mistura complexa altamente concentrada de açúcares e sua composição química depende de diversos fatores, dentre eles a espécie botânica, a natureza do solo, a raça de abelhas, o estado físiológico da colônia, o estado de maturação do mel e as condições climáticas (Campos, 1987; Serrano et al., 1994).

Além dos açúcares em solução, o mel contém ácidos orgânicos, enzimas, vitaminas; acetilcolina, flavonóides, minerais e uma extensa variedade de compostos orgânicos que contribuem para sua cor, odor e sabor (Crane, 1987).

De acordo com Bertoncelj (2007) os compostos do mel responsáveis pela atividade antioxidante são os flavonóides (crisina, pinocembrina, pinobanksina, quercitina, kaempferol, luteolina, galangina, apigenina, hesperetina e mirecetina), ácidos fenólicos (caféico, cumárico, ferúlico, elágico e clorogênico), ácido ascórbico, catalase, 
peroxidase, carotenóides e produtos da reação de Maillard. As concentrações destes compostos variam de acordo com a flora, origem geográfica do mel, o processamento, a manipulação e tempo de estocagem (Gheldolf e Engeseth, 2002; Gheldolf et al., 2003).

Estudos observaram que o mel possui atividade antioxidante tanto no controle de reações de oxidação lipídica em produtos cárneos, como em relação ao escurecimento enzimático de frutas e vegetais (Oszmianski e Lee, 1990; Antony et al., 2000; Mckibben e Engeseth, 2002). Também age no controle de processos oxidativos em sistemas biológicos, sendo avaliado por métodos in vivo $e$ in vitro, (Gheldolf e Engeseth, 2002; Gheldolf et al., 2002; Gheldolf et al., 2003; Al-Mamary et al., 2002; Schramm et al., 2003)

\section{Objetivo}

O objetivo deste estudo foi avaliar a atividade antioxidante in vitro dos extratos orégano, sálvia e mel no decorrer da vida de prateleira.

\section{Materiais e Métodos}

\subsection{Materiais}

\subsubsection{Solventes e reagentes}

Foram utilizados os seguintes solventes e reagentes grau analítico:

Álcool etílico P.A., álcool metílico P.A., clorofórmio P.A., Tween 40, ácido gálico, ácido linoléico, $\beta$-caroteno, DPPH (1,1-difenil-2-picrilhidrazil), AAPH (2,2'azobis(2-amidinopropano) fluoresceína $\quad\left(3^{\prime}, 6^{\prime}\right.$-dihidroxi-espiro[isobenzofurano1[3H],9'[9H]-xanten-3-ona), e Trolox (ácido 6-hidroxi-2,5,7,8-tetrametilcroman-2carboxílico) da Sigma-Aldrich Co. - USA, $\mathrm{K}_{2} \mathrm{HPO}_{4}$ e $\mathrm{NaH}_{2} \mathrm{PO}_{4}$ da Merck KGaA Germany, Folin-Ciocalteu e carbonato de sódio utilizados neste trabalho tiveram as seguintes procedências: CAAL Produtos Químicos Ltda, Sigma Aldrich Brasil Ltda, Merck S.A e Synth- Labsynth produtos para laboratórios Ltda. 


\subsubsection{Amostras}

As especiarias desidratadas (orégano e sálvia) foram doadas pela empresa Fuchs do Brasil Ltda.

As amostras de mel (florada predominante laranjeira) foram obtidas diretamente da Associação Paulista de Apicultores (APACAME) - SP.

Para o estudo da variação da capacidade antioxidante dos produtos avaliados em relação à sua fabricação. Foram adquiridas várias unidades de cada produto, todas produzidas e adquiridas em fevereiro de 2007. As embalagens foram separadas pelo método da amostragem casual sistemática (Berquó et al., 2005) sendo analisadas nos tempos 0 (imediatamente após a aquisição), 6 e 12 meses, todas dentro do prazo de validade dos produtos.

Todas as amostras foram armazenadas em temperatura ambiente $\left(24{ }^{\circ} \mathrm{C}\right)$ conforme indicação dos fabricantes.

\subsubsection{Preparo dos extratos}

Solução aquosa do mel - A solução aquosa do mel foi preparada no momento do uso na proporção de $1: 1(\mathrm{v} / \mathrm{v})$ com água deionizada.

Extrato etanólico do orégano e sálvia (Figura 1) - A obtenção dos extratos etanólicos dos produtos foi realizada de acordo com Nuutila et al., (2003). Foram pesados 3,0 g de amostra e adicionados $20 \mathrm{~mL}$ de etanol. Em seguida, as amostras foram mantidas por uma hora em agitador magnético e ultrassonificada durante 20 minutos, sendo em seguida filtrada, utilizando-se papel de filtro com porosidade 3 micra. $O$ resíduo retido no filtro foi novamente extraído com $20 \mathrm{~mL}$ de etanol P.A., filtrado e lavado com 10 $\mathrm{mL}$ de etanol. Todos os extratos alcoólicos foram combinados e transferidos para um balão volumétrico de $50 \mathrm{~mL}$, sendo o volume completado com etanol. Os extratos foram colocados em frascos âmbar, sob atmosfera de nitrogênio e armazenados em freezer à $18^{\circ} \mathrm{C}$ até o momento das análises. 


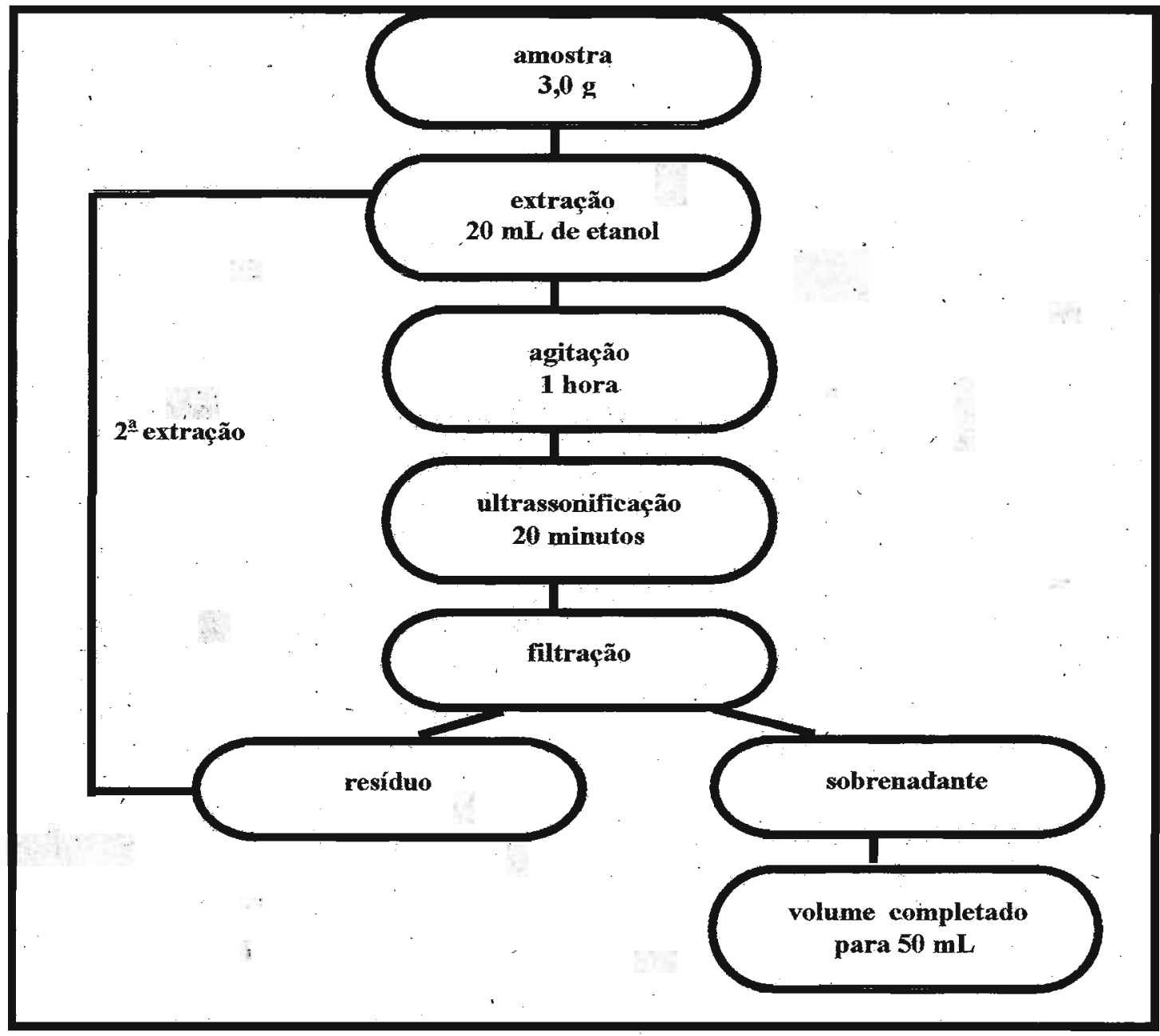

Figura 1 - Esquema da extração dos compostos das especiarias orégano e sálvia, adaptado de Nuutila et al., (2003). 


\subsection{Métodos}

3.2.1. Determinação do teor de sólidos totais dos extratos - $\mathrm{O}$ teor de sólidos totais foi obtido pelo método gravimétrico (AOAC, 1995), com a finalidade de determinar o rendimento dos extratos para padronização das concentrações das amostras para avaliação da atividade antioxidante. Os seguintes procedimentos foram adotados:

- $1 \mathrm{~mL}$ do extrato foi transferido para um vidro de relógio, previamente tarado, e este foi colocado em estufa a $105^{\circ} \mathrm{C}$, por 16 horas, seguido de resfriamento em dessecador e pesagem. A operação foi repetida até peso constante. $O$ teor de sólidos totais foi obtido $\mathrm{em} \mathrm{mg} / \mathrm{mL}$ de extrato.

3.2.2. Quantificação de fenólicos totais - Os compostos fenólicos totais da amostra foram determinados de acordo com Swain e Hillis (1959), com reagente FolinCiocalteu. Este método baseia-se na redução dos ácidos fosfomolíbdico e fosfotúngstico em solução alcalina. Foram adicionados a cada tubo de ensaio $0,25 \mathrm{~mL}$ do extrato, $2 \mathrm{~mL}$ de água destilada, $0,25 \mathrm{~mL}$ de solução de Folin-Ciocalteau 1:10 (v/v). Os tubos foram agitados e deixados em repouso por 3 minutos. Posteriormente, adicionou-se 0,25 mL de solução saturada de carbonato de sódio e, após agitação, deixados em repouso à $37^{\circ} \mathrm{C}$ durante 30 min para o desenvolvimento da cor. A cor azul é produzida devido à redução do reagente pelos compostos fenólicos e medida em espectrofotômetro a $750 \mathrm{~nm}$. $O$ teor dos compostos fenólicos totais foi calculado pela equação da curva de calibração, utilizando ácido gálico como padrão.

3.2.3. Sistema $\beta$-caroteno/ácido linoléico - A determinação da atividade antioxidante foi realizado pelo sistema $\beta$-caroteno/ácido linoléico de acordo com a metodologia descrita Miller (1971). Em $28 \mu \mathrm{L}$ da solução de $\beta$-caroteno (preparada na proporção de. $20 \mathrm{mg}$ de $\beta$-caroteno/mL de clorofórmio) foram adicionados $28 \mu \mathrm{L}$ de ácido linoléico e $200 \mathrm{mg}$ de Tween 40 (emulsificante). Em seguida, o clorofórmio foi evaporado sob atmosfera de nitrogênio e acrescentado de $140 \mathrm{~mL}$ de água aerada (água destilada aerada com oxigênio por 30 minutos). Em tubos de ensaio, $5 \mathrm{~mL}$ desta solução foram adicionados a $1 \mathrm{~mL}$ dos extratos das especiarias diluídos $(1 \mathrm{mg} / \mathrm{mL})$. Após homogeneização foi feita a leitura em espectrofotômetro à $470 \mathrm{~nm}$, sendo esta a leitura do tempo zero (tempo inicial). Os tubos foram então colocados em banho-maria $\left(50^{\circ} \mathrm{C}\right)$ 
B|BLIU|ELA

Faculłade de Ciências Farmacêuticas

Universidade de Sāo Paulo

com leituras realizadas a cada 15 minutos, até atingir 2 horas. $\mathrm{O}$ padrão (BHT) foi preparado da mesma forma que as amostras, assim como o controle, utilizando $1 \mathrm{~mL}$ de metanol substituindo os extratos das especiarias. A oxidação do $\beta$-caroteno indica a velocidade de transformação deste composto sob condições oxidantes (oxigênio e temperatura). Para o cálculo da porcentagem da inibição da oxidação lipídica (IOL), foram utilizadas as seguintes fórmulas:

$100 \%$ da oxidação = absorbância inicial do controle - absorbância final do controle

\% IOL $=100-$ (absorbância inicial da amostra - absorbância final da amostra) $\times 100$

absorbância inicial do controle - absorbância final do controle

3.2.4. Ensaio em meio lipídico $\left(\right.$ Rancimat $^{(\sqrt{3})}$ - $\mathrm{O}$ aparelho Rancimat ${ }^{\circledR}$ tem sido apresentado como um método para determinar a resistência de um óleo à oxidação, e pode ser usado como um método para determinar a atividade antioxidante de alimentos. As vantagens da técnica utilizando o Rancimat ${ }^{\circledR}$, consistem no fato de se basear em medidas contínuas, ou seja, não requer determinações períodicas; além disso, o aparelho não requer supervisão no decorrer do experimento (Hasenhutti e Wan 1992).

Para avaliar a capacidade protetora dos extratos em relação a oxidação lipídica, utilizou-se o aparelho Rancimat ${ }^{\circledR} 743$ da Metrohm. A banha suína foi utilizada como substrato par mensurar a oxidação (Queiroz et al., 2006).

Os volumes dos extratos foram previamente calculado com base no resíduo seco dos mesmos para que suas concentrações finais fossem de $1 \mathrm{mg} / \mathrm{mL}$. Os extratos foram adicionados nos tubos do Rancimat e evaporados sob atmosfera de nitrogênio.

Em seguida, adicionou-se $\pm 3,00 \mathrm{~g}$ de banha de foram adicionados em cada tubo, sendo as misturas homogeneizadas por 15 minutos em ultrasonificador.

Após esta estapa o aparelho foi programado nas seguintes condições: temperatura de $110^{\circ} \mathrm{C}, \Delta \mathrm{T}=1,5^{\circ} \mathrm{C}$, fluxo de ar de $20 \mathrm{~L} / \mathrm{h}$. 
Os tubos foram acoplados ao Rancimat, até que a curva de condutividade em relação ao tempo de indução (TI) fosse finalizada para se calcular o Índice de Atividade Antioxidante (IAA)

Um controle foi também preparado com a banha de suíno nas condições e o antioxidante sintético BHT $(1,0 \mathrm{mg} / \mathrm{mL})$ foi utilizado como padrão de referência.

Os resultados foram expressos como Índice de Atividade Antioxidante (IAA), calculados pela fórmula:

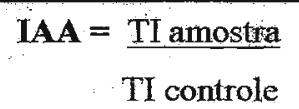

Onde: TI amostra = tempo de indução (h) da banha de suíno + extrato contendo a amostra. TI controle $=$ tempo de indução $(h)$ da banha de suíno sem o extrato.

3.2.5. Atividade antioxidante por ORAC - O ensaio da capacidade de absorbância do radical oxigênio (ORAC) avalia o efeito protetor da amostra em relação ao padrão TROLOX. Este método baseia-se no ataque de radicais livres, gerados pelo AAPH, que vão degradar a estrutura química da fluoresceína, levando à perda de sua conformação inicial com o consequente decréscimo da emissão de fluorescência (Cao, et. al 1993; Ou et al., 2001).

Para a realização do ensaio, foi preparada uma solução com $2700 \mu \mathrm{L}$ de tampão fosfato, $300 \mu \mathrm{L}$ de amostra convenientemente diluída, $15 \mu \mathrm{L}$ de $\mathrm{FL}(2,94 \mathrm{mg} / \mathrm{L})$ e 300 $\mu \mathrm{L}$ de AAPH (60 g/L), repetindo-se a medição feita para o branco. A temperatura do ensaio foi monitorada a $37^{\circ} \mathrm{C}$. $\mathrm{O}$ branco foi preparado com todos reagentes menos a amostra.

A medida da fluorescência (excitação $494 \mathrm{~nm}$, emissão $=515 \mathrm{~nm}$ ) foi calculada a área sob a curva de absorbância versus o tempo.

O resultado foi expresso comparando-se os resultados com o padrão Trolox. 
3.2.6. Análise Estatística - Os resultados das diferentes análises foram apresentados como média e desvio padrão. Para comparar as médias dos resultados das especiarias e do mel foi realizado o teste de Tukey. Todas'as análises foram realizadas em triplicata, com exceção do método utilizando o aparelho Rancimat, o qual utilizou-se amostras em duplicata. O nível de significância estabelecido para todos os testes estatísticos aplicados foi de 5\%, sendo utilizado o "software" Statistical Package for the Social Sciences (SPSS), versão 14.0 for Windows.

\section{Resultados e Discússão}

\subsection{Teor de fenólicos totais}

Na Tabela 1 são apresentados os teores médios dos fenólicos totais das amostras.

Os resultados indicaram que o orégano, a sálvia e o mel contêm compostos fenólicos, o que representa um importante fator na atividade antioxidante destas amostras.

Tabela 1 - Teores médios e desvio padrão (dp) de sólidos totais e de compostos fenólicos totais do orégano, sálvia e mel nos tempos 0,6 e 12 meses $(n=9)$.

\begin{tabular}{|c|c|c|c|c|c|c|}
\hline \multirow[t]{3}{*}{ Amostras } & \multicolumn{3}{|c|}{ Sólidos Totais $(\mathrm{mg} / \mathrm{mL})$} & \multicolumn{3}{|c|}{ Fenólicos totais $\left(\mathrm{mg} \mathrm{EAG} / \mathrm{mL}^{*}\right)$} \\
\hline & \multicolumn{6}{|c|}{ Meses } \\
\hline & 0 & 6 & 12 & 0 & 6 & 12 \\
\hline Orégano & 2,83 & 3,70 & 3,40 & $1154,09 \pm 234,73^{2}$ & $1556,48 \pm 220,67^{6}$ & $1611,28 \pm 25,67^{b}$ \\
\hline Sálvia & 3,37 & 4,70 & 4,60 & $1309,85 \pm 105,19^{\mathrm{a}}$ & $2032,42 \pm 276,35^{b}$ & $1608,40 \pm 20,23^{c}$ \\
\hline Mel & 485,05 & 515,00 & 603,00 & $1007,07 \pm 116,45^{\mathrm{a}}$ & $1830,36 \pm 239,74^{b}$ & $2129,86 \pm 129,29^{\circ}$ \\
\hline
\end{tabular}

* EAG = equivalentes de ácido gálico em relação ao teor de sólidos totais do extrato

Letras diferentes na mesma linha indicam diferença estatisticamente significante $(p<0,05)$.

Nota-se que variações no conteúdo de compostos fenólicos totais ao longo da vida de prateleira (Tabela 1) elevou-se pára todas as amostras. Os resultados de 
fenólicos totais do orégano indicaram um aumento de 1154,09 a 1611,28 mgEAG/100g e pela análise de variância, pode-se observar que existe diferença significativa entre os tempos avaliados $(\mathrm{p}=0,001)$.

De acordo com os resultados acima, observou-se que os maiores valores de fenólicos em relação ao teor de sólidos totais não corresponderam necessariamente aos maiores teores de fenólicos totais nos extratos, conforme Tabela 1. Este fato também foi constatado por Ishimoto (2006), que pesquisou a atividade antioxidante in vitro em diferentes vinhos e sucos de uva e também por Queiroz (2006) que estudou a atividade antioxidante em produtos de alho. É importante destacar que os extratos correspondem a diferentes amostras do mesmo lote, o que pode justificar as diferenças nos tempos estudados.

Capecka et al (2005) compararam o teor de fenólicos totais em algumas especiarias da família Lamiceae. Os autores analisaram o orégano (Origanum vulgare L.) e nos extratos o conteúdo de fenólicos totais foi de $2221 \mathrm{mgEAG} / 100 \mathrm{~g}$. Su et al., (2007) avaliaram o conteúdo de fenólicos em extratos de orégano (50\% acetona) e o valor médio encontrado foi de $548 \mathrm{mgEAG} / 100 \mathrm{~g}$ de especiaria.

A quantidade de compostos fenólicos nos extratos etanólicos de sálvia variou de 1309,8 a 2032,4 mgEAG/100g no decorrer do tempo (0 a 12 meses). Nesta especiaria a maior quantidade de fenólicos foi observada no tempo de 6 meses. Foram observadas diferenças estatisticamente significativa para os teores de fenólicos na vida de prateleira.

Miliauskas et al. (2004) avaliaram a quantidade de fenólicos em amostras de sálvia (Salvia officinalis) e observaram valores de $2260 \mathrm{mgEAG} / 100 \mathrm{~g}$, teores mais elevados aos determinados no presente estudo.

Os teores de fenólicos totais do mel de laranjeira observadas no presente estudo aumentaram durante a vida de prateleira (Tabela 1) os valores medidos foram 1007,1; 1830,4 e $2129,9 \mathrm{mg} / 100 \mathrm{~g} / \mathrm{EAG}$, tempos 0,6 e 12 meses, respectivamente. Ou, seja houve um acréscimo destes teores no decorrer do tempo.

Bertoncelj et al (2007) avaliaram o conteúdo de fenólicos totais de diversos tipos de mel, sendo: Acacia (448 mg/100g/EAG), Lima (837 mg/100g/EAG), Castanheira (1999 $\mathrm{mg} / 100 \mathrm{~g} / \mathrm{EAG})$, Multifloral (1573 $\mathrm{mg} / 100 \mathrm{~g} / \mathrm{EAG})$ e Silvestre (2339 $\mathrm{mg} / 100 \mathrm{~g} / \mathrm{EAG}$ ). Os autores concluíram que existem diferenças entre os diferentes tipos de mel. As grandes variações encontradas na composição do mel podem ser explicadas devido a fatores que interferem na sua qualidade, como condições climáticas, estágio de maturação, espécie de abelha, processamento e armazenamento, além do tipo de florada. 


\subsection{Sistema $\beta$-caroteno/ácido linoléico}

Os resultados obtidos para os extratos estão apresentados nas Figuras 2 e 3.

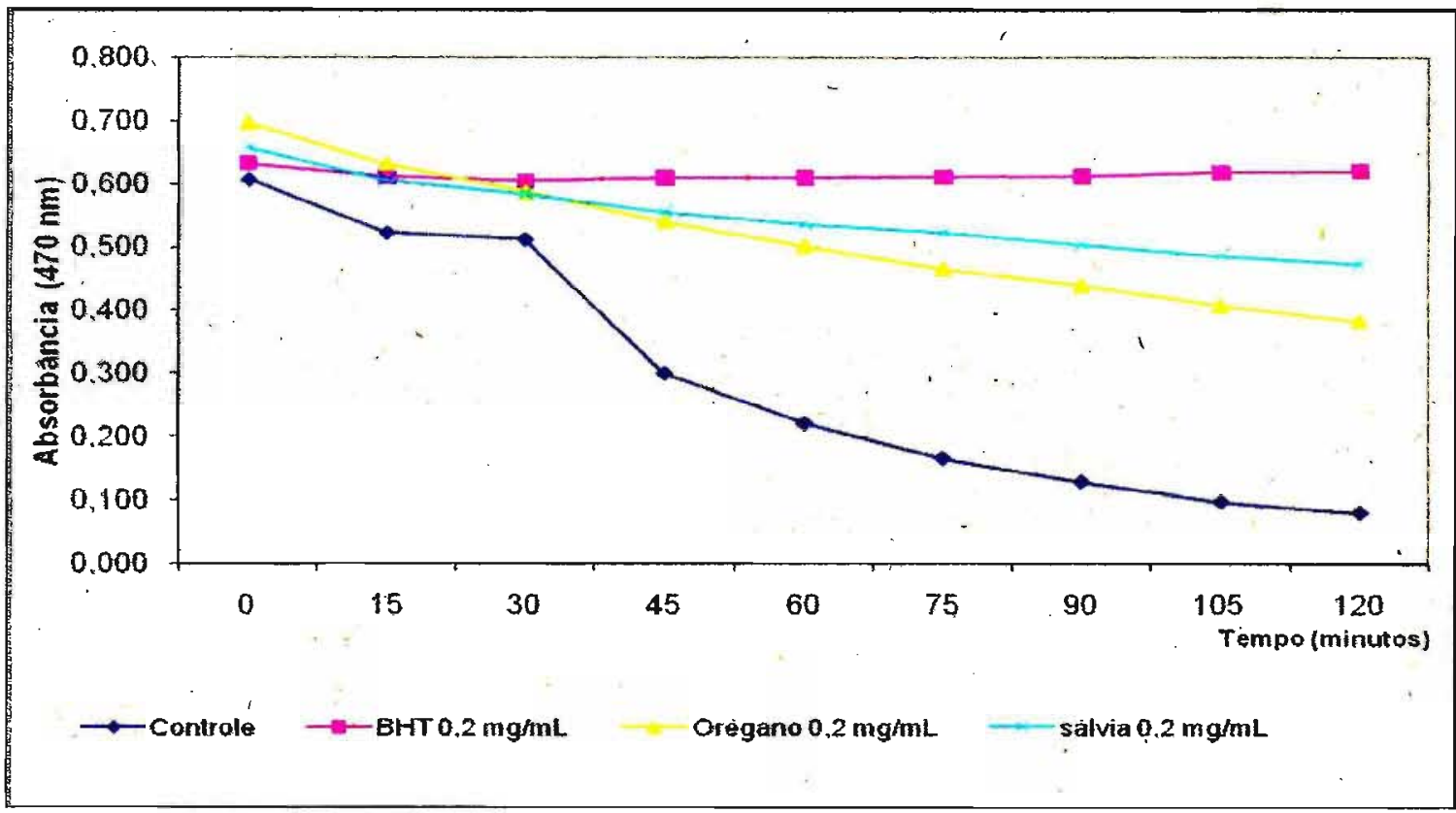

Figura 2 - Curva cinética da inibição da oxidação lipídica pelo sistema $\beta$ caroteno/ácido linoléico do extrato de orégano e sálvia.

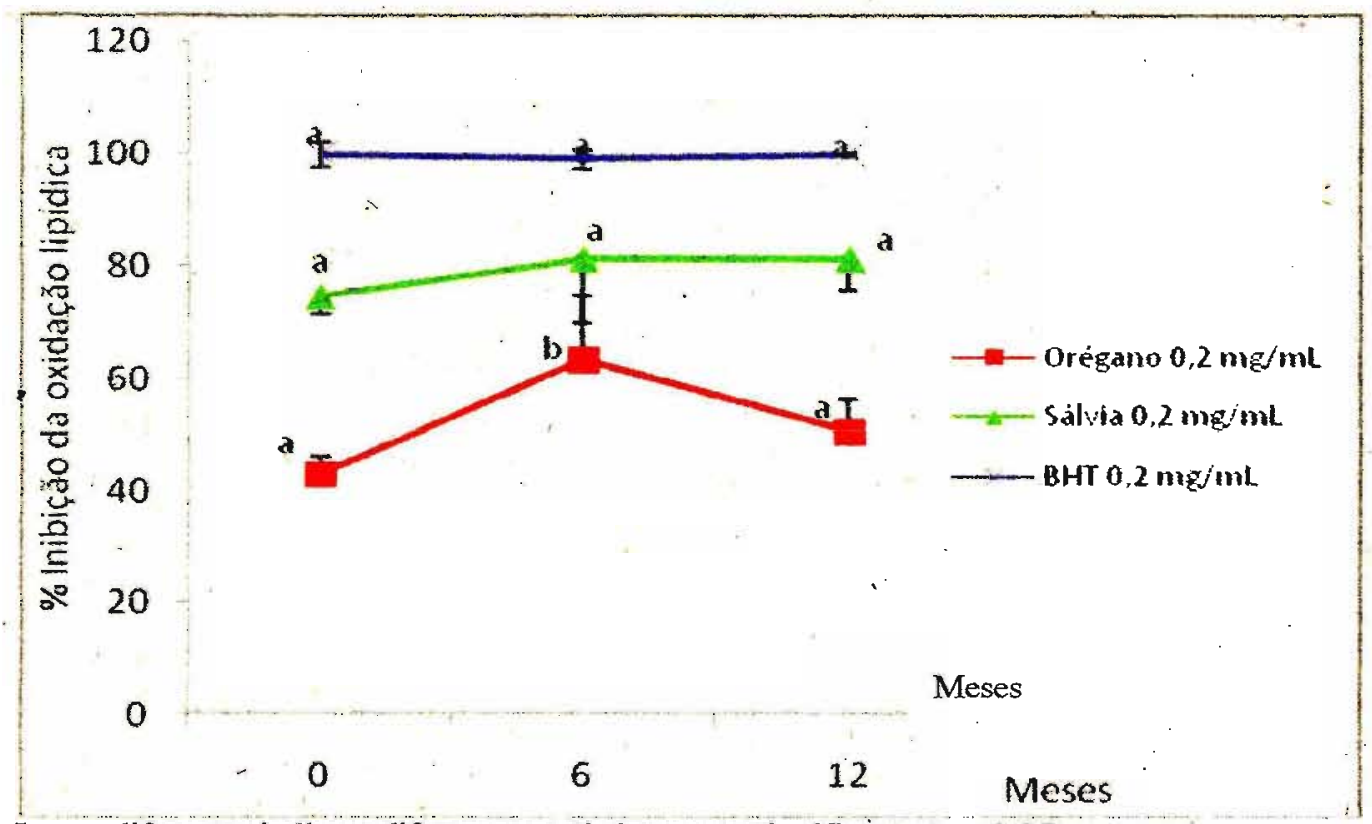

Letras diferentes indicam diferença estatisticamente significante $(\mathrm{p}<0,05)$

Figura 3 - Porcentagem da inibição da oxidação lipídica (\% IOL), pelo sistema $\beta$-caroteno/ácido linoléico do orégano e sálvia. 
A curva cinética que possibilita verificar o comportamento dos extratos de orégano e sálvia durante 120 minutos do teste está representada na Figura 2 . Os resultados foram comparados ao controle e ao BHT, sendo que este obteve a porcentagem de inibição da oxidação lipídica de 97,5 \%. Todos os extratos apresentaram valores inferiores ao padrão BHT em ambas as concentrações.

Pôde-se verificar que os resultados da inibição da oxidação lipídica da sálvia entre os tempos foram 74,6, 81,3 e 81,3\% e não diferiram estatisticamente. Em relação ao orégano foi observada diferença estatística no tempo 6 meses $(43,2,63,3$ e 50,7\%, respectivamente).

Tepe et al., (2006) determinaram a atividade antioxidante pelo sistema $\beta$ caroteno/ácido linoléico do extrato metanólico em várias espécies de sálvia e os resultados indicaram uma inibição média de 56,5\%. Kulisic et al. (2004) avaliaram a atividade antioxidante do óleo de orégano, pelo sistema $\beta$-caroteno/ácido linoléico foi menor quando comparado ao BHT e ao $\alpha$-tocoferol.

Neste ensaio do sistema $\beta$-caroteno/ácido linoléico não foi possível avaliar a inibição da oxidação lipídica nos extratos de mel, pois no final da reação o ensaio ficava turvo e os resultados foram inconclusivos.

\subsection{Avaliação da capacidade protetra da oxidação lipídica utilizando o aparelho} Rancimat $\AA^{8}$.

As especiarias e o mel foram testados no aparelho Rancimat ${ }^{\circ}$, sendo que o índice de atividade antioxidante (IAA) dos extratos e estão apresentados na Figura 4. Quanto maior o valor do IAA, melhor a proteção oxidativa, e consequentemente melhor a atividade antioxidante. 


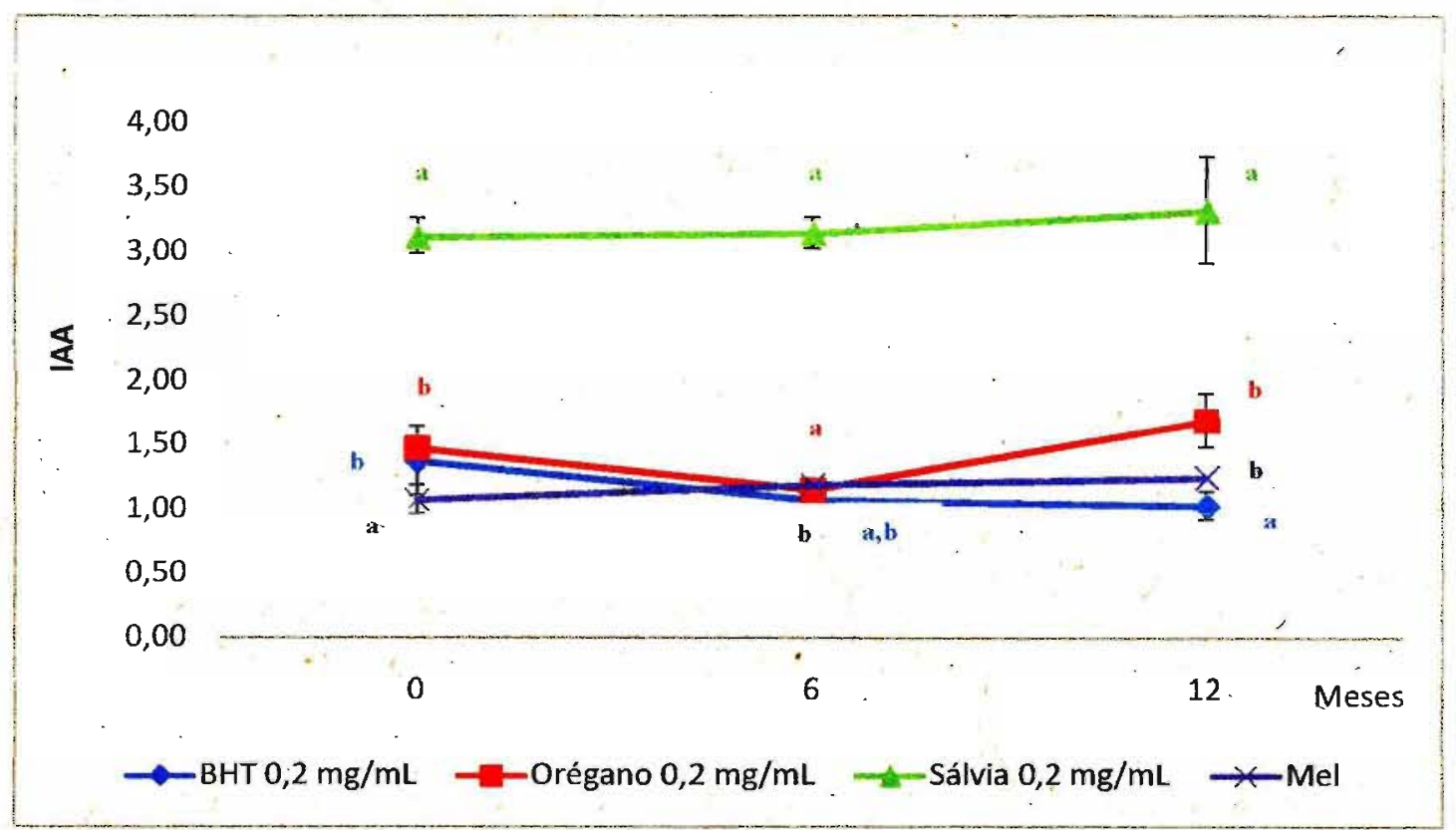

IAA $=$ tempo de indução (h) da amostra $/$ tempo de indução (h) do controle Letras diferentes indicam diferença estatisticamente significante $(p<0,05)$

Figura 4 - Índice de atividade antioxidante (IAA), utilizando o aparelho Rancimat, do extrato etanólico do orégano, sálvia e mel.

O IAA foi calculado considerando-se o tempo de indução da amostra dividido pelo tempo de indução do controle. Ou seja, valores de IAA acima de 1,0 indicam que a amostra apresentou atividade antioxidante. Entre os extratos analisados, a sálvia se destacou por apresentar um índice de atividade antioxidante $(3,35)$ superior aos demais, que foram: 1,69, 1,25 e 1,08, para o BHT, orégano e mel, respectivamente.

Avaliando diferentes tipos de extratos de oréganos (éter de petróleo, éter etílico, acetato de etila e butanol), Vekiari et al (1993) concluíram que a fração solúvel em éter etílico foi mais efetiva na proteção contra a oxidação e sua atividade foi equivalente ao BHT.

As especiarias e o mel foram submetidos ao ensaio da capacidade de absorbância do radical oxigênio (ORAC) e os resultados estão expressos na Figura 5 e Tabela 2: 


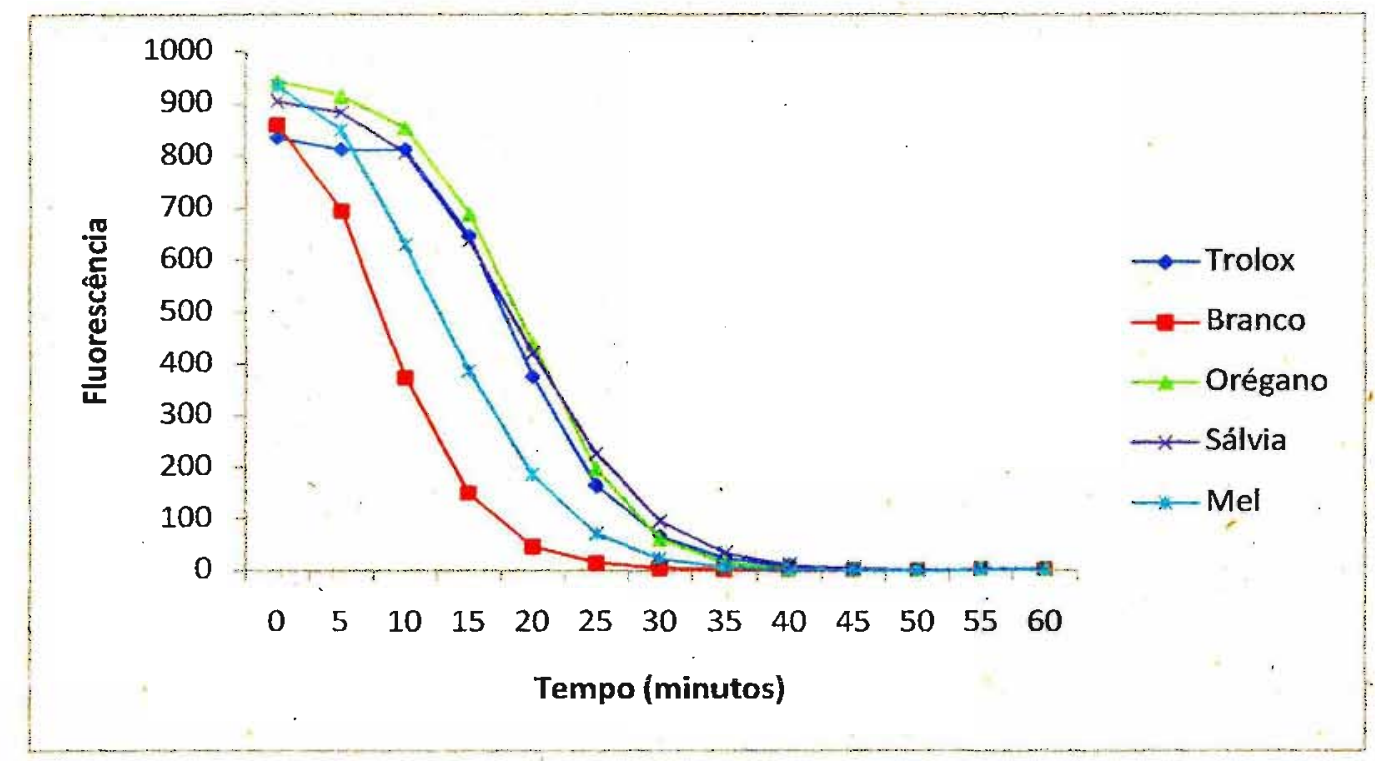

Figura 5 - Curvas de declínio da fluoresceína no método de ORAC na presença de extratos de orégano, sálvia, mel e padrão trolox $(20 \mu \mathrm{M})$.

Tabela 2 - Valores médios e desvio padrão ( $\mathrm{dp}$ ) do método ORAC no orégano, sálvia e mel nos tempos 0,6 e 12 meses $(n=9)$.

\begin{tabular}{|c|c|c|c|}
\hline \multirow[t]{3}{*}{ Amostras } & \multicolumn{3}{|c|}{ ORAC (ET $\mu \mathrm{mol} / \mathrm{g})^{*}$} \\
\hline & & Meses & \\
\hline & $\mathbf{0}$ & 6 & 12 \\
\hline Orégano & $544,57 \pm 20,47^{\mathrm{a}}$ & $430,70 \pm 61,17^{\mathrm{a}}$ & $1019,61 \pm 67,38^{5}$ \\
\hline Sálvia & $610,45 \pm 38,02^{a, b}$ & $467,44 \pm 119,20^{2}$ & $822,21 \pm 89,25^{b}$ \\
\hline Mel & $47,28 \pm 1,47^{b}$ & $22,40 \pm 7,01^{\mathrm{a}}$ & $26,08 \pm 1,67^{\mathrm{a}}$ \\
\hline
\end{tabular}

Conforme se observa na Tabela 2, o orégano apresentou valores de 544,6, 430,7 e 1019,6 ET $\mu \mathrm{mol} / \mathrm{g}$, nos meses 0, 6 e 12, respectivamente. E os extratos de sálvia apresentaram valores de ORAC de: 610,45 (0 meses), 467,44 (6 meses) e 822,21 (12 meses). 
As amostras de orégano e sálvia tiveram um comportamento semelhante ao TROLOX na proteção das curvas de declínio da fluoresceína (Figura 5).

$\mathrm{Wu}$ et al. (2004) avaliaram a atividade antioxidante pelo ensaio do ORAC em diferentes alimentos de origem vegetal e o valor para algumas especiarias: orégano (2640 ET $\mu \mathrm{mol} / \mathrm{g})$, cravo (1533 ET $\mu \mathrm{mol} / \mathrm{g})$ e salsa $(740,8 \mathrm{ET} \mu \mathrm{mol} / \mathrm{g})$.

$\mathrm{Su}$ et al., (2007) também avaliaram algumas especiarias, que apresentaram os seguintes valores ORAC: orégano (1233 ET $\mu \mathrm{mol} / \mathrm{g}$ de especiaria), pimenta (395 ET $\mu \mathrm{mol} / \mathrm{g}$ de especiaria), pimenta preta (363 ET $\mu \mathrm{mol} / \mathrm{g}$ de especiaria), noz moscada (398 ET $\mu \mathrm{mol} / \mathrm{g}$ de especiaria), noz moscada (1187 ET $\mu \mathrm{mol} / \mathrm{g}$ de especiaria) e canela (1256 ET $\mu \mathrm{mol} / \mathrm{g}$ de especiaria), canela (1069 ET $\mu \mathrm{mol} / \mathrm{g}$ de especiaria).

Comparando os resultados apresentados nos trabalhos acima com os resultados deste trabalho para o orégano e sálvia, os valores ORAC foram superiores quando comparados a outras especiarias, sugerindo que tanto o orégano e a sálvia possuem alto potencial antioxidante.

Os resultados deste estudo para a amostra de mel foram de: 47,$3 ; 22,4$ e 26,1 ET $\mu \mathrm{mol} / \mathrm{g}$, nos tempos 0,6 e 12 meses, respectivamente. As amostras de mel apresentaram valores intermediários na curva de declínio da fluoresceína, ou seja, entre o branco e o padrão TROLOX.

Beretta et al (2005) analisaram a atividade antioxidante de vários tipos de mel e determinaram que os valores de ORAC variaram de 1,40 a 21,7 ET $\mu \mathrm{mol} / \mathrm{g}$, ou seja, totalmente distintos entre os diversos tipos de mel analisados. Gheldof e Engeseth (2002) também estudaram os valores de ORAC para diferentes tipos de mel e distintas floradas e a variação foi de 1 a $16,95 \mathrm{ET} \mu \mathrm{mol} / \mathrm{g}$.

Comparando-se os resultados deste trabalhos com os obtidos por Beretta et al (2005) e Gheldolf e Engeseth (2002) pode-se considerar que o mel de laranjeira avaliado possui expressiva atividade antioxidante.

Não foram encontrados dados na literatura para, este teste onde outros autores discutissem ou reportassem sobre a vida de prateleira de quaisquer tipo de amostra. 


\section{Conclusão}

Os resultados obtidos neste estudo reafirmam a hipótese de que os compostos antioxidantes das especiarias poderiam substituir (parcial ou integralmente) os antioxidantes sintéticos, uma vez que foi demonstrada a sua capacidade de inibir a oxidação lipídica.

Sugere-se que novos estudos sejam realizados para acompanhamento da atividade antioxidante no decorrer da vida de prateleira de produtos de origem vegetal. 


\section{Referências Bibliográficas*}

* De acordo com a norma NBR 6023/2000, preconizada pela ASSOCIAÇÃO BRASLEIRA DE NORMAS TÉCNICAS (ABNT). As abreviaturas dos títulos dos periódicos seguem o CHEMICAL ABSTRACTS SERVICE SOURCE INDEX (CASSI), 2001.

[AOAC] - ASSOCIATION OF OFFICIAL ANALYTICAL CHEMISTS. Official Methods of Analysis. 16. ed. Arlington, 1995.

AL-Mamary; M. AL-Meeria, A. AL-Habori, M. Antioxidant activities and total phenolics of different types of honey. Nutr. Res. v.2 , p. 1041-47, 2002

Antony, S.; Rieck, J.R., Dawson, P.L. Effect of dry honey on oxidation in turkey breast meat. Poultry Science, v.79, p. 1849-50, 2000.

Barth, O.M. O Pólen Brasileiro. Rio de Janeiro: Ed. Luxor, p. 150, 1989.

Beretta, G.; Granata, P.; Ferrero, M.; Orioli, M.; Facino, R. M. Standardization of antioxidant properties of honey by a combination of spectrophotometric/fluorimetric assays and chemometrics. Analytica Chimica Acta, v 533, p. 185-191, 2005

Berquó, E.S, Souza, J.M.P, Gotlieb, S.L.D. Bioestatística. São Paulo: Editora Pedagógica e Universitária Ltda; 2005.

Bertoncelj, J.; Dobersek, U.; Mojca J.; Golob, T. Evaluation of the phenolic content, antioxidant activity and colour of Slovenian honey. Food Chemistry, v. 105, p. 822-28, 2007

Campos, M.G.R. Contribuição para o estudo de mel, pólen, geléia real e própolis. Bol. Fac. Farm. Coimbra., v.11, n.2, p.17-47, 1987.

Cao, G.; Alessio, H.M.; Cutler, R.G. Oxygen-radical absorbance capacity assay for antioxidants. Free Radical Biol. Med., 14, 303-11, 1993.

Capecka, E.; Mareczek, A.; Leja, M. Antioxidant activity of fresh and dry herbs of some Lamiaceae species. Food Chemistry, v.93, p.223-226, 2005.

Cintra, R.M.G.; Mancini-Filho, J. Efeito antioxidante de especiarias: avaliação e comparação de métodos in vitro e in vivo. Nutrire: Rev. Soc. Bras. Alim. Nur. $=J$. Brazilian Soc. Food Nutr., São Paulo, v. 22, p. 49-62, dez, 2001.

Crane, E. O livro do mel. 2 ed. São Paulo. Nobel, p. 226,1987.

Cuvelier, M. E.; Berset, C; Richard, H. Antioxidant constituents in sage (Salvia officinalis). Journal of Agriculture and Food Chemistry, v.42, p.665-69, 1994. 
Gheldolf, N.; Engeseth, N.J. Antioxidant capacity of honeys from various floral sources based on the determination of oxygen radical absorbance capacity and inhibition of in vitro lipoprotein oxidation in human serum samples. J. Agric. Food Chem. v. 50, p.3050-3055, 2002.

Gheldolf, N.; Wang, X.; Engeseth; N.J. Buckwheat honey increases serum antioxidant capacity in humans. J Agric Food Chem. v. 51, p. 1500-1505, 2003.

Gheldolf, N.; Wang, X.; Engeseth, N.J. Identification and quantification of antioxidant components of honeys from various floral sources. J. Agric. Food Chem, v.50, p. $5870-5877,2002$

Han, X.; Shen, T.; Lou, H. Dietary polyphenols and their biological significance. Int. $J$. Mol Sci, v. 8, p. 950-988, 2007.

Hasenhutti, G.L.; Wan, P.J. Temperature effects on the determination of oxidative stability with the Metrohm Rancimat. $J$ Am Oil Chem Soc, v; 69, n. 6, p. 525-527, 1992.

Ishimoto, E. Y.; Ferrari, C. K. B.; Bastos, D. H. M.; Torres, E. A.F.S. In vitro antioxidant activity of Brazilian wines and grape juices. Journal of wine research, v. 17, p. $107-115,2006$

Kulisic, T.; Radonic, A.; Katalinic, V.; Milos, M. Use of different methods for testing antioxidative activity of oregano essential oil. Food Chemistry, v. 85, p.633-640, 2004.

Lu, Y.; Foo, L.Y. Antioxidante activities of polyphenols from sage (Salvia officinalis) Food Chemistry, v. 75, p. 197-202, 2001.

McKibben, J.; Engeseth, N.J. Honey as a protective agent against lipid oxidation in ground turkey. J. Agric. Food Chem., v. 50, p. 592-595, 2002.

Miliauskas, G.; Venskutonis, P.R.; van Beek, T.A. Screening of radical scavenging activity of some medicinal and aromatic plant extracts. Food Chemistry, v. 85, p. 231-237., 2004.

Miller, H.E., A simplified method for the evaluation of antioxidants. J. Am. Oil Chem. Soc., Champaign, v. 48, p. 91, 1971.

Nakatani, N.; Kikuzaki, H.A. A new antioxidative glucoside isolated from oregano (Origanum vulgare L.). Agric. Biol. Chem., v.51, n.10, p.2727-32, 1987.

Namiki, M. Antioxidant/antimutagens in food. CRC Critical Review Food Science and Nutrition, v. 29, p: 273-300, 1990. 
Nuutila, A.M.; Puupponen-Pimia, R.; Aarni, M.; Oksman-Caldentey, K.M. Comparison of antioxidant activities of onion and garlic extracts by inhibition of lipid peroxidation and radical scavenging activity. Food Chemistry, v. 81, p. 485-93, 2003.

Oszmianski, J.; Lee, C.Y. Inhibition of polyphenoloxidase activity and browning by honey. J. Agric. Food Chem., v. 38, p. 1892-95, 1990.

Ou, B.; Hampsch-Woodill, M.; Prior, R.L. Development and validation of an improved oxygen radical absorbance capacity assay using fluorescein as the fluorescent probe. J Agric Food Chem, v. 49, p. 4619-4626, 2001.

Pizzale, L.; Bortolomeazzi, R.; Vichi, S.; Überegger, E.; Conte, L.S. Antioxidant activity of sage (Salvia officinalis and $S$ fruticosa) and oregano (Origanum onites and $O$ indercedens) exracts related to their phenolic compound content. J.Sci Food Agric., v.82, p. 1645-51, 2002.

Pokorny, J. Natural antioxidants for food use. Trend Food Sci Technol. v. 9, p. 223 $227,1991$.

Queiroz, Y.S.; Bastos, D. H. M.; Sampaio G.R.; Soares R.A.M.; Ishimoto, E. Y.; Torres, E.A.F.S. Influência dos aditivos alimentares na atividade antioxidante in vitro de produtos de alho, Alimentos e Nutrição (UNESP), v. 17, p. 287-293, 2006.

Riccheimer, S.L.; Bernart, M.W.; King, G.A.; Kent, M.C.; Bailey, D.T. Antioxidant activity of lipid-soluble phenolic diterpenes from rosemary. J. Am Oil Chem Soc., v. 73, p. $507-514,1996$.

Rice-Evans, C.A., Miller, N.J., Paganga, G. Antioxidant properties of phenolic compounds. Trends in Plant Science, v.2, p. 152-159, 1997.

Rossi, N.F.; Martinelli, L.A; Lacerda, T.H.M; Camargo, P.B.; Victoria, R.L.; Análise da adulteração de méis por açúcares comerciais utilizando-se a composição isotópica de carbono1. Cienc. Tecnol. Aliment., v. 19, n.2, p.1-16, 1999.

Schramm, D.D.; Karim, M.; Schrader, H.R.; Holt, R.R.; Cardetti, M.; Keen, C. Honey with high levels of antioxidants can provide protection to healthy human subjects. J. Agric. Food Chem. v. 51, p. 1732-1735, 2003.

Schwarz, K.; Ternes, W. Antioxidant constituints of Rosmarinus officinalis and Salvia officinalis. II. Isolation of carnosic acid and formation of other phenolic diterpenes. Z. Lebensm. Unters., v.195, p.99-103, 1992.

Serrano, R.B. La miel: edulcorante natural por excelencia. Alimentaria, v. 29, p. 29-35, 1994. 
Shahidi, F.; Janitha, P.K.; Wanasundara, P.D. Phenolic antioxidants. Crit Rev. Food Sci. Nutr, v. 32, p. 67-103, 1992.

'Su, L.; Yin, J-J.; Charles, D.; Zhou, K.; Moore, J.; Yu, L. Total phenolic contents, chelating capacities, and radical-scavenging properties of black peppercorn, nutmeg, rosehip, cinnamon and oregano leaf. Food Chemistry, v. 100, p. 990-97, 2007

Swain, T.; Hillis, W.W. The phenolic constituents of Prunes domestica I. The quantitative analysis of phenolic constituents, Journal of the Science of Food and Agriculture, v. 10, p. 63-68, 1959.

Tepe, B.; Sokmen, M.; Akpulat, H.A.; Sokmen, A. Screening of the antioxidant potential of six Salvia species from Turkey. Food Chemistry, v. 95, p.200-204, 2006

Vekiari, S.A.; Oreopoulou, V.; Tzia, C.; Thomopoulos, C.D. Oregano flavonoids as lipids antioxidants. J. Am. Oil Chem. Soc. Champaign, v.70, p.483-7, 1993.

Wang, M., Shao, Y., Li, J., Zhu, N.,Rangarajan, M., La Voie, E.J., Ho, C.T. Antioxidative Phenolic Glycosides from Sage (Salvia officinalis). J. Nat. Prod., v.62, n.3, p.454 -456, 1999.

Wang, M.ł Li, J.; Rangarajan, M.; Shao, Y.; La Voie, E.J.; Huang, T.C.; Ho, C.T. Antioxidative Phenolic Compounds from Sage (Salvia officinalis). J. Agric. Food Chem., v.46, n. 12, p. $4869-4873,1998$.

Wu, X.; Beecher, G.R.; Holden, J.M.; Haytowitz, D.B.; Gebhardt, S.E.; Prior, R.L. Lipophilic and hydrophilic antioxidant capacities of common foods in the United States. J. Agric. Food Chem, v.52, p. 4026-4037, 2004.

Zhang, K.Q.; Bao, Y.; Wu, P.; Rosen, R.T.; Hoi, C.T. Antioxidative components of Tanshen (Salvia mitiorrhiza Bung). J. Agric. Food Chem, v. 38, p. 1194-97, 1994. 
Capítulo III - Influência dos compostos bioativos da sálvia (Salvia officinalis)'e de orégano (Origanum vulgare L.) na proteção da oxidação lipídica em substrato microssomal de carne de frango.

\section{Introdução}

As reações oxidativas causam alterações em lipídios e proteínas, influenciando na qualidade dos alimentos. Os tecidos biológicos são contimuamente sujeitos ao estresse oxidativo por meio da ação das espécies reativas de oxigênio e radicais livres, produzidos por inúmeras vias bioquímicas (Decker, 1998).

Os lipídios presentes nos sistemas biológicos e alimentares são constituídos por uma mistura de tri-, di- e monoglicerídeos, ácidos graxos livres, glicolipídios, fosfolipídios; esteróis, etc. A maior parte destes constituintes é oxidável em diferentes graus (Hamilton, 1983). Uma das maiores dificuldades para avaliar o grau de oxidação reside na escolha do momento mais adequado para efetuar essa determinação. De um modo geral, procura-se avaliar, em condições padronizadas e selecionando um determinado parâmetro indicador, o "período de indução" da reação, ou seja, o tempo necessário para se atingir um ponto crítico de oxidação (Silva, 1999).

Os fenômenos de oxidação dos lipídios dependem de mecanismos reacionais diversos e extremamente complexos, os quais estão relacionados com o tipo de estrutura lipídica e o meio onde esta se encontra. 0 número e a natureza das insaturações presentes, o tipo de interface entre os lipídios e o oxigênio (fase lipídica contínua, dispersa ou em emulsão), a exposição à luz e ao calor, a presença de pró-oxidantes (íons metálicos de transição) ou de antioxidantes, são fatores determinantes para a estabilidade oxidativa dos lipídios (Frankel, 1993).

Devido ao constante risco de oxidação, os tecidos biológicos contêm distintos mecanismos para o controle das alterações oxidativas, das espécies reativas de oxigênio, dos radicais livres além dos produtos de oxidação lipídica. Tanto os compostos próoxidantes quanto os produtos de oxidação lipídica são solúveis em água e lipídios, por isso os sistemas endógenos são bifásicos. A identificação e caracterização dos sistemas 
biológicos que controlam a oxidação são importantes no desenvolvimento de sistemas antioxidantes, visando aumentar a estabilidade oxidativa dos alimentos. Para o sucesso no desenvolvimento de sistemas antioxidantes é imprescindível entender os fatores químicos e físicos que influenciam as interações entre lipídios, pro-oxidantes e antioxidantes (Decker, 1998).

Para a avaliação da atividade antioxidante in vitro de alimentos e de compostos fenólicos, outros substratos contendo lipídios como as hemácias (Tedesco, et al., 2001), hepatócitos primários (Morel, et al., 1998), membranas microssomais (De Beer et al, 2005; Daglia, et al, 2000; Mora, et al., 1990; Plumb, et al., 1997; van Acker et al., 1996) e micelas (Roginsky e Barsukova, 2001; Shi et AL., 1999) podem ser empregados.

Os microssomos são pequenas e heterôgeneas membranas vesiculares constituintes das membranas dos retículos endoplasmáticos e' citoplasmáticos, que contêm altas concentrações de ácidos graxos polìinsaturados e proteínas (Chan et al., 1997).

Em sistemas biológicos, os ácidos graxos poliinsaturados são propensos à oxidação, resultando na formação de produtos como alcanos, aldeídos, álcoois e hidroperóxidos, além de epóxidos, cetonas e ácidos. Esta propensão surge do fato de que os átomos de hidrogênio bis-alílicos do grupo metileno são mais suscetíveis à abstração pelos radicais oxidáveis que os hidrogênios metilênicos dos lipídios totalmente saturados (Dormandy, 1994). O malonaldeído é um dos principais produtos da peroxidação lipídica e tem sido amplamente utilizado como marcador de estresse oxidativo.

Os antioxidantes sintéticos mais utilizados na indústria de alimentos são BHA (butil hidroxianisol), BHT (butil hidroxitolueno), PG (propil galato) e TBHQ (terc-butil hidroquinona) (Wanasundara e Shahidi, 1998) e a estrutura fenólica destes compostos permite a doação de um próton a um radical livre, regenerando, assim, a molécula do acilglicerol e interrompendo o mecanismo de oxidação por radicais livres. Dessa maneira, os derivados fenólicos transformam-se em radicais livres. Entretanto, estes radicais podem se estabilizar sem promover ou propagar reações de oxidação (Namiki, 1990).

As especiarias e ervas têm sido usadas durante muitos séculos para melhorar as características sensoriais e prorrogar a vida de prateleira dos alimentos (Shahidi et al.,1992). Os compostos fenólicos presentes nas especiarias podem inibir os processos da oxidação em certos sistemas, devido a seu potencial de oxi-redução que os permite atuar 
como agentes redutores, doando radical hidrogênio e neutralizando os radicais livres (RiceEvans et al., 1997).

Atualmente, não existem informações disponíveis sobre a capacidade do orégano e sálvia na inibição oxidação lipídica em carne de frango quando utilizados em sistemas de membranas microssomais in vitro, justificando assim o objetivo do presente estudo.

\section{Objetivo}

O objetivo do presente estudo foi avaliar a capacidade antioxidante da sálvia (Salvia officinalis) e do orégano (Origanum vulgare L.) em inibir a peroxidação lipídica in vitro quando se utilizam sistemas de membranas microssomais de carne de frango.

\section{Materiais e métodos}

\subsection{Materiais}

\section{I.1. Solventes e reagentes}

Solventes e reagentes de grau analítico como: álcool etílico P.A., álcool metílico P.A., clorofórmio P.A., cloreto de potássio, $\mathrm{BHT}, \mathrm{FeSO}_{4}$, sulfato de cobre pentahidratado, albumina de soro bovino, ácido tricloroacético, 1,1,3,3 tetraetoxipropano, ácido 2tiobarbitúrico, EDTA, Tween 40, ácido gálico, ácido linoléico, $\beta$-caroteno, DPPH (1,1difenil-2-picrilhidrazil), fluoresceina (3',6'-dihidroxi-espiro[isobenzofurano-1 [3H],9' [9H]xanten-3-ona), AAPH (2,2'azobis(2-amidinopropano) e Trolox (ácido 6-hidroxi-2,5,7,8tetrametilcroman-2-carboxílico) da Sigma-Aldrich Co. - USA, K2HPO4 e $\mathrm{NaH}_{2} \mathrm{PO}_{4}$ da Merck KGaA - Germany, Folin- Ciocalteu e carbonato de sódio utilizados neste trabalho tiveram as seguintes procedências: CAAL Produtos Químicos Ltda, Sigma Aldrich Brasil Ltda, Merck S.A. produtos para laboratório Ltda, Synth- Labsynth produtos para laboratórios Ltda. 


\subsubsection{Amostras}

Os cortes de frangos (sobrecoxa e peito) foram obtidos de uma avícola de pequeno porte da cidade de Carapicuiba - SP. Após o abate, os cortes foram imediatamente acóndicionados em recipiente térmico contendo gelo e transportados sob refrigeração.

As especiarias orégano (Origanum vulgare L.) e sálvia (Salvia officinalis) desidratadas foram doadas pela Empresa Fuchs do Brasil. Todas as amostras foram armazenadas em temperatura ambiente $\left(24^{\circ} \mathrm{C}\right)$ conforme indicação dos fabricantes.

Para o estudo da variação da capacidade antioxidante dos produtos avaliados em relação à sua data de fabricação, foram adquiridas várias unidades de cada produto, todas produzidas e adquiridas em fevereiro de 2007. As embalagens foram separadas pelo método da amostragem casual sistemática (Berquó et al., 2005).

\subsubsection{Extratos}

A obtenção dos extratos etanólicos de oregâno e sálvia foram realizadas de acordo com Nuutila et al., (2003), conforme descrito no Capítulo II (item 3.1.3.).

\subsection{Métodos}

3.2.1. Determinação do teor de sólidos totais dos extratos - $O$ teor de sólidos totais foi determinado através do método gravimétrico (AOAC, 1995), detalhado no Capítulo II (item 3.2.1.).

3.2.2. Quantificação de fenólicos totais - Os compostos fenólicos totais da amostra foram determinados de acordo com Swain e Hillis (1959), conforme Capítulo II (item 3.2.2.).

3.2.3. Sistema $\boldsymbol{\beta}$-caroteno/ácido linoléico - A determinação da atividade antioxidante pelo sistema $\beta$-caroteno/ácido linoléico foi realizada de acordo com a metodologia descrita por Miller (1971), conforme Capítulo II (item 3.2.3.). 
3.2.4. Ensaio em meio lipídico (Rancimat ${ }^{\circledR}$ ) - Para avaliar a capacidade protetora utilizouse o aparelho Rancimat ${ }^{\circledR 4}$, marca Metrohm, conectado ao programa PC: 743 Rancimat 1.0 , onde foi medido o período de indução (Queiroz, 2006), descrito no Capítulo II (item $3.2 .4)$.

3.2.5. Atividade antioxidante por ORAC - Para avaliar a capacidade antioxidante da amostra; medindo sua capacidade de proteger a fluoresceína (FL) da oxidação pelo AAPH no meio reacional foi utilizado o método de ORAC descrito por Ou et al., (2001), descrito no Capítulo II (item 3.2.5.).

Tabela 1 - Quantidade dos ingredientes adicionados ao substrato microssomal do peito e da sobrecoxa.

\begin{tabular}{c|c|c|c|c}
\hline \multirow{2}{*}{$\begin{array}{c}\text { Substrato } \\
\text { Microssomal }\end{array}$} & \multicolumn{5}{c}{ Ingredientes } \\
\cline { 2 - 5 } & BHT (ppm) & Sal (\%) & Orégano (\%) & Sálvia (\%) \\
\hline Controle & - & 2 & - & - \\
\hline BHT & 100 & 2 & - & - \\
\hline Orégano+Sálvia & - & 2 & 0,2 & 0,2 \\
\hline \multicolumn{5}{|c|}{ Sobrecoxa } \\
\hline Controle & - & 2 & - & - \\
\hline BHT & 100 & 2 & - & - \\
\hline Orégano+Sálvia & - & -2 & 0,2 & 0,2 \\
\hline
\end{tabular}




\subsubsection{Obtenção do Substrato Microssomal}

Para a obtenção do substrato microssomal, pesou-se $5 \mathrm{~g}$ de carne de frango (peito ou sobrecoxa), previamente triturada em multiprocessador. Adicionou-se $50 \mathrm{~mL}$ de uma solução contendo $25 \%$ de cloreto de potássio $0,15 \mathrm{M}$ e $75 \%$ de tampão fosfato de sódio $0,1 \mathrm{M} \mathrm{pH} \mathrm{7,4.} \mathrm{O} \mathrm{concentrado} \mathrm{foi} \mathrm{homogeneizado} \mathrm{em} \mathrm{baixa} \mathrm{velocidade,} \mathrm{por} \mathrm{dois} \mathrm{minutos,} \mathrm{no}$ equipamento Ultraturrax IKA-T18 Basic. Em seguida, o concentrado foi centrifugado a $1.000 \times \mathrm{g}$ por 15 minutos a $4^{\circ} \mathrm{C}$ para que as células intactas e os núcleos densos sedimentassem no fundo do tubo. $O$ sobrenadante foi centrifugado novamente a $10.000 \mathrm{xg}$ por 20 minutos a $4^{\circ} \mathrm{C}$ para que as organelas subcelulares de densidade intermediária como mitocôndrias, cloroplastos, lisossomos e peroxissomos fossem precipitados.

O precipitado foi então descartado e o sobrenadante utilizado para obtenção da fração microssomal sendo ultracentrifugado a $105.000 \times g$ por $1 \mathrm{~h} \mathrm{a} 4^{\circ} \mathrm{C}$ visando o 'isolamento das frações microssomais de acordo com Fraga et al., (1988).

Por fim, o precipitado foi ressuspendido em $1 \mathrm{~mL}$ de tampão fosfato $(0,1 \mathrm{M} \mathrm{pH} \mathrm{7,4)}$ transferido para microtubos e mantido a $-70^{\circ} \mathrm{C}$ até o momento das análises (Fraga et al., 1988).

\subsubsection{Quantificação de proteínas totais}

A concentração de proteínas no substrato microssomal foi determinada de acordo com o método de Lowry (1951), no qual se utilizou albumina bovina sérica como padrão.

\subsubsection{Indução da oxidação lipídica no substrato microssomal}

A indução da oxidação no sistema microssomal foi realizada de acordo com Fraga et al., 1988. O sistema foi preparado para conter $0,5 \mathrm{mg}$ de proteina $/ \mathrm{mL}$. As análises foram realizadas em triplicatas e os extratos das especiarias e o sal (solução salina) foram preparados conforme os tratamentos descritos na Tabela 1 ,

Primeiramente, foram pipetadas, em tubos de ensaio, as soluções etanólicas de orégano, sálvia e/ou BHT e a seguir evaporadas sob nitrogênio. Adicionou-se ao sistema microssomal a solução salina e, em seguida, o tampão fosfato $(0,1 \mathrm{M} \mathrm{e} \mathrm{pH} 7,4)$ a fim de completar $1 \mathrm{~mL}$ de volume final. 
$\mathrm{Na}$ seqüência, adicionou-se $250 \mu \mathrm{M}$ de sulfato ferroso, seguidos de agitação e incubação dos tubos em banho-maria a $37^{\circ} \mathrm{C}$, durante os tempos 1, 2, 3 e 4 horas.

Após os tempos de indução foram adicionados aos tubos $1 \mathrm{~mL}$ da solução "stopper" composta de: $(10 \mathrm{~g}$ de TCA (Ácido Tricloroacético) + 0,0060 g de BHT (100ppm) e + $0,0056 \mathrm{~g} \mathrm{em} 100 \mathrm{~mL}$ de água destilada gelada) a fim de interromper a reação de oxidação. Na sequência foi realizada centrifugação por 25 minutos a $4.200 \mathrm{~g}$ (de BEER et. al., 2005).

Posteriormente, tomou-se $1 \mathrm{~mL}$ do sobrenadante e adicionou-se $1 \mathrm{~mL}$ da solução de TBA $(0,67 \%)$. Os tubos foram vedados e aquecidos em banho-maria a $95^{\circ} \mathrm{C}$ durante 15 minùtos. Após a reação os tubos foram resfriados em banho de gelo.

As leituras das absorbâncias foram realizadas em um comprimento de onda de 532 nm em espectrofotômetro Shimadzu modelo UV - 1650 PV. O padrão utilizado foi o $1,1,3,3$ tetraetoxi propano (TEP).

\subsubsection{Análise Estatística}

Os resultados das análises foram apresentados como média e desvio padrão. Para as comparações entre as médias foi realizado o teste de Tukey.

Todas as análises foram realizadas em triplicata e o nível de significância estabelecido para todos os testes estatísticos aplicados foi de $5 \%$, sendo utilizado o "software" Statistical Package for the Social Sciences (SPSS); versão 14.0 for Windows. 


\section{Resultados e discussão}

Os resultados médios de compostos fenólicos totais, a porcentagem de inibição da oxidação lipídica pelo sistema $\beta$-caroteno/ácido linoléico, o índice de atividade antioxidante pelo método do Rancimat ${ }^{\circledR}$ e ensaio da capacidade de absorbância do radical oxigênio das especiariais estão descritos na Tabela 2.

Tabela 2 - Valores médios e desvio padrão (dp) de compostos fenólicos totais, \% IOL, IAA e ORAC do orégano e sálvia $(n=3)$.

\begin{tabular}{|c|c|c|}
\hline Métodos & Orégano & Sálviạ \\
\hline $\begin{array}{l}\text { Fenólicos Totais } \\
(\mathrm{mg} E A G / \mathrm{mL})^{1}\end{array}$ & $1159,09 \pm 234,73$ & $1309,85 \pm 105,19$ \\
\hline $\begin{array}{l}\text { B-caroteno/ácido linoléico } \\
(\% \text { IOL })^{2}\end{array}$ & $43,17 \pm 3,03$ & $74,65 \pm 5,22$ \\
\hline $\begin{array}{l}\text { Rancimat }^{(2)} \\
(\mathrm{IAA})^{3}\end{array}$ & $1,48 \pm 0,01$ & $3,12 \pm 0,14$ \\
\hline $\begin{array}{l}\text { ORAC } \\
(\mathrm{ET} \mu \mathrm{mol} / \mathrm{g})^{4}\end{array}$ & $544,57 \pm 20,47$ & $610,45 \pm 38,02$ \\
\hline
\end{tabular}

Os resultados obtidos indicaram que o orégano e a sálvia contêm compostos fenólicos entre seus constituintes, um fator importante na avaliação da atividade antioxidante (Tabela 2).

A sálvia foi a especiaria que promoveu a maior porcentagem de inibição da oxidação lipidica (\% IOL), e consequentemente melhor atividade antioxidante em relação ao orégano (Tabela 2 ).

Valores de IAA acima de 1,0 indicam que a amostra apresentou atividade antioxidante. Nos extratos analisados, a sálvia se destacou por apresentar um índice de atividade antioxidante $(3,12)$ superior ao orégano $(1,48)$.

Em. relação ao ensaio ORAC observou-se que a sálvia foi superior no resultado de equivalentes de Trolox com 610,45 e o orégano apresenton um valor de 544,56 ET.

Os resultados obtidos com a padronização da determinação de TBARS para avaliação da influência de especiarias na proteção da oxidação lipídica em substrato microssomal de carne de frango, encontram-se na Tabela 3. 
Tabelà 3 - Valores médios de malonaldeído formado pela reação de oxidação lipídica no sistema microssomal em todos os tratamentos.

\begin{tabular}{|c|c|c|c|c|}
\hline TBARS* & Indução (h) & Controle & $\overline{B H T}$ & Oregáno+Sálvia \\
\hline \multirow{3}{*}{ Peito $^{1}$} & 1 & $7,61 \pm 0,52^{\mathrm{cis}, \mathrm{t}}$ & $2,51 \pm 0,21^{\mathrm{ajt}}$ & $3,80 \pm 0,31^{b ; t}$ \\
\hline & 2 & $8,05 \pm 0,41^{\text {cit }}$ & $2,18 \pm 0,37^{a ; 8}$ & $3,39 \pm 0,21^{b ; 5}$ \\
\hline & 3 & $7,18 \pm 0,44^{\mathrm{c} T, \mathrm{~s} s}$ & $1,39 \pm 0,23^{\mathrm{ax}}$ & $2,57 \pm 0,20^{6, x}$ \\
\hline & 4 & $6,95 \pm 0,09^{\mathrm{c}, T}$ & $1,54 \pm 0,18^{\mathrm{a} ; x}$ & $4,04 \pm 0,21^{b ; t}$ \\
\hline & & & & \\
\hline \multirow{4}{*}{ Sobrecoxa ${ }^{2}$} & 1 & $10,42 \pm 0,32^{b ; t}$ & $3,32 \pm 0,59^{\mathrm{ax} x}$ & $3,75 \pm 0,58^{a ; 5}$ \\
\hline & 2 & $11,54 \pm 0,51^{\mathrm{cuu}}$ & $5,13 \pm 0,35^{b, t}$ & $3,70 \pm 0,45^{2,8}$ \\
\hline & 3 & $8,02 \pm 0,36^{\mathrm{s}, T}$ & $3,96 \pm 0,31^{b ; s}$ & $1,71 \pm 0,17^{\mathrm{a}, \mathrm{x}}$ \\
\hline & 4 & $9,36 \pm 0,62^{c, 5}$ & $4,65 \pm 0,21^{6, t}$ & $3,45 \pm 0,26^{\mathrm{a} ; \mathrm{s}}$ \\
\hline
\end{tabular}

${ }^{*} \mu \mathrm{Mol}$ de $\mathrm{MDA} / \mathrm{mg}$ de proteina

1 e 2 - Diferentes letras na mesma linha $(a-c)$ são diferentes estatisticamente $(P<0.05)$. Diferentes letras na mesma coluna $(\mathrm{r}-\mathrm{t})$ säo diferentes estatisticamente $(\mathrm{P}<0.05)$.

As concentrações médias de TBARS ( $\mu$ Mol de MDA/mg de proteína) observadas nas amostras de peito foram (Tabela 3): controle $(7,45 \pm 0,57)$; BHT $(1,91 \pm 0,52)$ e orégano+sálvia $(3,45 \pm 0,61)$.

Quando analisamos os resultados das amostras de peito, em relação a proteção da oxidação lipídica, verificamos que o em todos os tempos de indução o tratamento com BHT foi mais eficiente na inibição da oxidação do que o tratamento orégano+sálvia (Figura 1): Devemos ressaltar que o tempo de três horas foi o ápice da inibição nos dois tratamentos.

Analisando as concentrações médias de TBARS ( $\mu$ Mol de MDA/mg de proteína) na came de sobrecoxa, observou-se os seguintes resultados: controle $(9,83 \pm 1,39)$; BHT $(4,27 \pm 0,79)$; oréganotsálvia $(3,15 \pm 0,93)$. Na Figura 1 podemos observar que o tratamento com BHT foi mais efetivo na imibição da oxidação na $1^{\underline{a}}$ hora de indução, nas demais horas o tratamento com orégano+sálvia mostrou-se mais eficaz. 


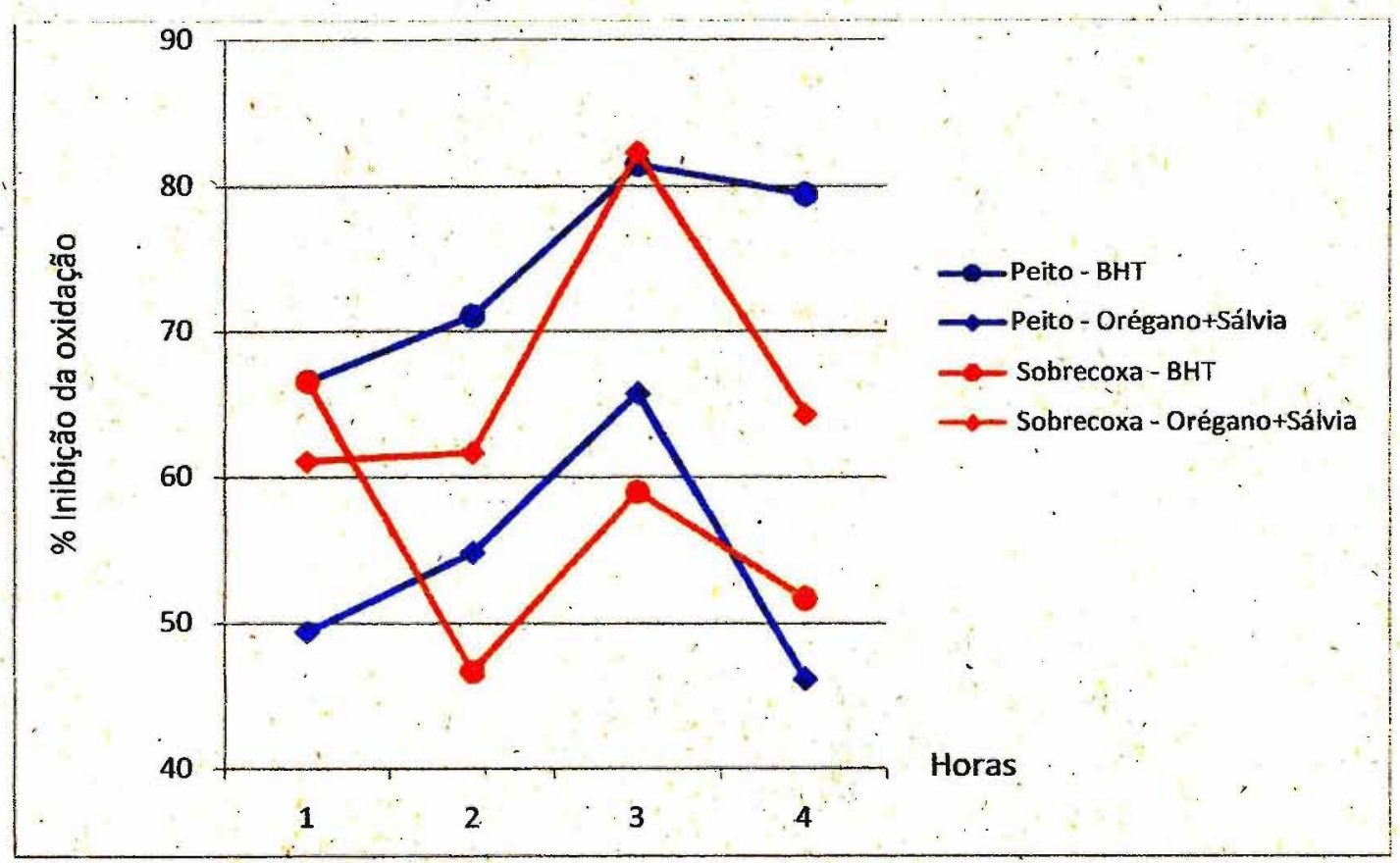

Figura 1 - Porcentagem dä inibição lipídica no sistema microssomal nos dois tipos de carne de frango em relação ao controle.

Os resultados encontrados nesse sistema modelo indicam que os extratos das especiarias sálviatorégano foram eficientes na inibição da oxidação dos lipidios prẹsentes nás amostras analisadas.

Ao avaliarmos os resultados da inibição da oxidação lipídiça durantẹ o periodo de indução, observamos que em relação ao controle, os tratamentos realizados apresentaram. influência positiva na proteção da oxidação lipídica em substrato microssomal de carne de peito de frango. Ambos os tratamentos (BHT e orégano+sálvia) atingiram o ápice de inibição no tempo de 3 horas $(82,42 \%$ e $82,25 \%$ ), respectivamente.

Porém quando analisamos a inibição da oxidação lipídica na fração mịcrossomal da carne de sobrecoxa, o tratamento BHT apresentou o seu ápice de inibição $(66,50 \%)$ no tempo de 1 hora de indução e o tratamento orégano+sálvia alcançou a maior porcentagem de inibição no tempo de 3 horas (82,25\%).

Cintra e Mancini-Filho (2001) avaliaram a capacidade antioxidante de extrato alcoólico e aquoso de oregáno em fração microssomal hepática e relataram que a inibição do extrato alcoólico no sistema foi de $93,05 \%$ e no extrato aquoso foi de $40,57 \%$. 
Quanto as diferenças dos resultados de TBARS para os dois tipos de cortes de carne de frango (peito e sobrecoxa) e consequentemente os resultados da inibição da oxidação lipídica, devemos associar oe mesmos a alguns fatores que podem determinar à quantidade de malonaldeído formados durante a peroxidação dos ácidos graxos polinsaturados como: grau de insaturação dos ácidos graxos. (Dahle et al., 1962; Pryor et al., 1976), a presença de metais (Janero e Burghardt, 1989), pH (Chen e Waimaleongora-Ek, 1981), temperatura e duração de aquecimento (Pikul et al., 1984).

O tipo de corte cárneo, se branco ou vermelho, também influencia na oxidação lipídica. Músculos vermelhos são mais suscetíveis à oxidação lipídica, quando comparados com músculos brancos (Ferrari, 2000). Ang e Lyon (1990) compararam coxa e peito de frango e observaram que os cortes de coxa apresentaram maior metabolismo oxidativo, maior grau de lipólise e que a fração dos triacilgliceróis sofreram hidrólise mais rapidamente do que os fosfolipidios, o que determina uma maior suscẹtibilidade oxidativa. Além disso, a concentração de ferro em músculos vermelhos é superior à encontrada em músculos brancos, o que pode afetar a oxidação lipídica (Monahan et al., 1993).

No presente estudo, verificou-se que a adição dos extratos de oregáno e sálvia foram capazes de inibir a oxidação dos lipídios, sugerindo que estas especiarias conferem proteção à membranan celular contra o ataque oxidativo de radicais livres. Este resultado reforça os dados apresentados anteriormente com respeito à atividade antioxidante destas especiarias. 


\section{Conclusão}

Os resultados obtidos neste estudo evidenciam que o substrato microssomal mostrou-se eficaz na avaliação da oxidação lipídica.

Os dados de todos os tratamentos reafirmam que os extratos das especiarias orégano e sálvia apresentaram potencial antioxidante eficiente na inibição da oxidação lipídica em substrato microssomal de carne de frango. Apesar deste potencial ter sido menor que o antioxidante sintético, o consumo dessas especiarias pode ser recomendado como parte de uma dieta saudável.

$O$ presente estudo fornece informações importantes sobre a influência das especiarias no controle da oxidação lipídica em um sistema microssomal e que precisam ser consideradas na avaliação dos seus possíveis efeitos na saúde. 
6. Referências bibliográficas *

* De acordo com a norma NBR 6023/2000, preconizada pela ASSOCIAÇÃO BRASILEIRA DE NORMAS TÉCNICAS (ABNT). As abreviaturas dos títulos dos periódicos seguem. o CHEMICAL ABSTRACTS SERVICE SOURCE INDEX (CASSI), 2001.

[AOAC] - ASSOCIATION OF OFFICIAL ANALYTICAL CHEMISTS. Official Methods of Analysis. 16. ed. Arlington, 1995.

Ang, C.Y.W.; Lyon, B.G. Evaluations of warmed-over-flavor during chill storage of cooked broiler breast, thigh and skin by chemical instrumental and sensory methods. $J$. Food Science, v. 55, p.644-8, 1990.

Chan, W.K.M.; Faustman, C.; Renerre, M. Model systems for studying pigment and lipid oxidation relevant to muscle-based foods, chapter 20, p. 319-331, 1997. in Shahid, F. Natural antioxidants chemistry, Health effects, and applications, Champaigns: AOCS Press.

Chen, T.C.; Waimaleongora-EK, C. Effect of pH on TBA values of ground raw poultry meat. J. Food Sci., v.46, p. 1946-7, 1981.1981

Cintra, R.M.G.; Mancini-Filho, J. Efeito antioxidante de especiarias: avaliação e comparação de métodos in vitro e in vivo. Nutrire: Rev. Soc. Bras. Alim. Nur.= J. Brazilian Soc. Food Nutr., São Paulo, v. 22, p. 49-62, dez, 2001.

Daglia, M.; Papetti, A.; Gregotti, C.; Berté, F.; Gazzani, G. In vitro antioxidant and ex vivo protective activities of Green and roasted coffee. Journal of Agricultural and Food Chemistry, v. 48, p. 1449-1454, 2000.

Dahle, L.K.; Hill, E.G.; Holman, R.T. The thiobarbituric acid reation and the autoxidation of polyunsaturated fatty acid methyl esters. Arch. Biochem. Biophys, v.98, p. 253-261, 1962

De Beer, D.; Joubert, E.; Gelderblom, W.C.A.; Manley, M. Antioxidant activity of South African red and white cultivar wines and selected phenolic compounds: In vitro inhibitation of microsomal lipid peroxidation. Food Chemistry, v.90, p. 569-577, 2005.

Decker, E.A. Strategies for manipulating the prooxidative/antioxidative balance of foods to maximize oxidative stability. Trends in Food Science \& Technology, v. 9, p. 241-248, 1998 
Dormandy, T.L. Antioxidant vitamins and nutrients. In: Gutteridge, J.M.C.; Halliwell, B. Antioxidants in nutrition, health, and disease. New York: Oxford University Press, 1994. p.63-81.

Ferrari, C.K.B. Fatores bioquímicos e físicos pró e antioxidantes, relacionados à oxidação lipídica em alimentos. Higiene Alimentar, São Paulo, v.14, n.78/79, p. 37-44, 2000.

Fraga, C.G.; Leibovitz, B.E.; Al-Tappel, L. Lipid peroxidation measured as thiobarbituric acid-reactive substances in tissue slices: characterization and comparison with homogenates and microsomes. Free Radical Biology \& Medicin., New York. v.4, p. $155-161,1988$.

Frankel, E.N. In search of better methods to evaluate natural antioxidants and oxidative stability in food lipids. Trends in Food Science \& Technology, v.4, p.220-225, 1993.

Hamilton, R. J.; Rossell, J. B.; Hudson, B. J. F.; Löliger, J.; In Rancidity in Foods; Allen J. C., Hamilton R. J., Ed.; Applied Science Publishers LTD.; London, 1983.

Janero, D. R.; Burghardt, B. Thiobarbituric Acid-reactive Malondialdehyde Formation During Superoxide-dependent, Iron-catalyzed Lipid Peroxidation: Influence of Peroxidation Conditions. Lipids, v.24, n. 2, p. 125-131, 1989.

Lowry, O.H.; Rosenberg, N.I.; Farr, A.L.; Randall, R.J. Protein measurement with the folin-phenol reagent. Journal of Biological Chemistry, v. 193, p. 265-275, 1951.

Marco, G.J.A. Rapid method fọr evaluation of antioxidants. J. Am. Oil Chem. Soc., n.45, p. 594-8, 1968.

Miller, H.E. A simplified method for the evaluation of antioxidants. J. Am. Oil Chem. Soc., v. 48, p. 91,1971 .

Monahan, F.J.; Crackel, R.L.; Gray, J.I.; Buckley, D.J.; Morrissey, P.A. Catalysis of lipid oxidation in muscle model systems by haem and inorganic iron. Meat Science, v.34, p. $95-106,1993$.

Mora, A.; Payá, M.; Ríos, J.L.; Alcaraz, M.J. Structure activity relationships of polymethoxyflavones and other flavonoids as inhibitors of non-enzymaic lipid peroxidation. Biochemical Pharmacology, v. 40, p. 793-797, 1990.

More1, I.; Abaléa, V.; Sergent, O.; Cillard, P.; Cillard, J. Involvement of phenoxyl radical intermediates in lipid antioxidant action of myricetin in iron-treated rat hepatocyte culture. Biochemical Pharmacology, v. 55, p. 1399-1404, 1998. 
Namiki, M., Antioxidant/antimutagens in food. CRC Critical Review Food Science and Nutrition, v. 29, pp. 273-300, 1990.

Nuutila, A.M.; Puupponen-Pimia, R.; Aarni, M.; Oksman-Caldentey, K.M. Comparison of antioxidant activities of onion and garlic extracts by inhibition of lipid peroxidation and radical scavenging activity. Food Chemistry, v. 81, p. 485-93, 2003.

Ou, B; Hampsch-Woodill, M.; Prior, R.L. Development and validation of an improved oxygen radical absorbance capacity assay using fluorescein as the fluorescent probe. $J$ Agric Food Chem., v. 49, p. 4619-4626, 2001.

Pikul, J.; Leszczynski, D.E; Kumerow, F.A. Relative role of 'phospholipids, triacylglycerols, and cholesterol esters on malonaldehyde formation in fat extracted. from chicken meat. $J$. Food Science, v.49, p.704-708, 1984.

Plumb, G.W.; Chambers, S.J.; Lambert, N.; Wanigatunga, S.; Williamson, G. Influence of fruit and vegetable extracts on lipid peroxidation in microsomes containing specific cytochrome P450s. Food Chemistry, v. 60, p. 161-164, 1997 :

Pryor, W.A.; Stanley, J.P.; Blair, E. Autoxidation of polyunsaturated fatty acids. II. A suggesed mechanism for the formation of TBA-reactive materials from prostaglandinlike endoperoxides. Lipids, v. 11, p. 370-379, 1976.

Queiroz, Y.S.; Bastos, D. H. M.; Sampaio G.R.; Soares R.A.M.; Ishimoto, E. Y.; Torres, E.A.F.S. Influência dos aditivos alimentares ná atividade antioxidante in vitro de produtos de alho. Alimentos e Nutrição (UNESP), v. 17, p. 287-293, 2006.

Rice-Evans, C.A.; Miller, N.J.; Paganga, G. Antioxidant properties of phenolic compounds. Trends in Plant Science, v.2, p. 152-159, 1997.

Roginsky,V.; Barsukova, T. Total chain-breaking antioxidant capability of some beverages as determined by the Clark electrode technique. Journal of Medical Food, v. 4, p. 219 $229,2001$.

Shahidi, F.; Janitha, P.K.; Wanasundara, P.D. Phenolic antioxidants. Crit Rev. Food Sci. Nutr., v. 32, p. 67-103, 1992.

Shi, H.; Noguchi, N.; Niki, E. Comparative study on dynamics of antioxidative action of $\alpha$ tocopheryl hydroquinone, ubiquinol, and $\alpha$-tocopherol against lipid peroxidation. Free Radical Biology and Medicine, v. 27, p. 334-346, 1999. 
Silva, F.A.M.; Borges, M.F.M.; Ferreira, M.A. Métodos para avaliação do grau de oxidação lipídica e da capacidade antioxidante. Química Nova, São Paulo, v. 22, n.1, p. 94-103, 1999.

Swain, T.; Hillis, W.W. The phenolic constituents of Prunes domestica I. The quantitative analysis of phenolic constituents. $J$. Sci. Food and Agric. v.10, p.63-68, 1959.

Tedesco, I.; Russo, G.L.; Nazarro, F.; Russo, M.; Palumbo, R. Antioxidant effect of red wine anthocyanins in normal and catalase-inactive human erythrocytes. $J$. Nutritional Biochemistry, v.12, p. 505-511,2001.

van Acker, S.A.B.E.; van den Berg, D.J.; Tromp, M.N.J.L.; Griffioen, D.H.; van Bennekom, W.P.; van der Vijgh, W.J.F.; Bast, A. Structural aspects of antioxidant activity of flavonoids, Free radical biology \& medicine, v. 20, n.3., p. 331-342, 1996.

Wanasundara, U. N.; Shahidi, F. Antioxidant and pro-oxidant activity of green tea extracts in marine oils. Food Chemistry, v.63, p.335-342, 1998. 
Capítulo IV - Efeito de especiarias e mel na proteção da oxidação lipídica em sistema modelo homogenato de carne de frango refrigerada

\section{Introdúção}

Os alimentos cámeos, devido a sua riqueza na composição de umidade, proteínas, gorduras e outros nutrientes, são produtos muito susceptíveis a alterações de ordem físico-química. Entre estas alterações, a oxidação lipídica e a alteração de cor são dificeis de serem controladas, principalmente devido a sua complexidade e variabilidade (Olivo, 2006), levando a muitos efeitos adversos sobre suas características de qualidade, tais como: sabor, aroma, cor, textura e valor nutritivo (Seideman, et al., 1984; Gray et al., 1996; Olivo e Olivo, 2006).

As modificações bioquímicas que acompanham a conversão do músculo em carne oferecem condições favoráveis para que ocorra a oxidação na fração mais insaturada de fosfolipídios nas membranas sub-celulares, onde o balanço entre os fatores pró-oxidativos e a capacidade antioxidativa não está controlado, favorecendo a oxidação lipídica (Morrissey et. al., 1998).

A carne de frango, devido ao seu conteúdo relativamente elevado de ácidos graxos insaturados, é particularmente suscetível à deterioração oxidativa, a qual pode ser acelerada pelos processamentos tecnológicos anteriores a estocagem, como o corte $\mathrm{e}$ o cozimento, os quais rompem as membranas celulares do músculo facilitando a interação dos ácidos graxos insaturados com substâncias pró-oxidantes (Tichivangana e Morrissey, 1985; O’Neill et al., 1998).

A cor da carne fresca está associada à proporção e distribuição relativa de três formas químicas da mioglobina: mioglobina reduzida ou deoximioglobina $\left(\mathrm{Mb}^{+}\right)$, de coloração vermelho-púrpura; oximioglobina $\left(\mathrm{O}_{2} \mathrm{Mb}\right)$, de coloração vermelho-brilhante; e a metamioglobina ( $\mathrm{MMb}$ ), de coloração marrom. Além destes pigmentos, outros derivados químicos são importantes na coloração de carnes e derivados cárneos, dentre eles a nitrosomioglobina (NOMb), de coloração vermelho rósea e a carboximioglobina (COMb), de coloração vermelho-brilhante (Livingston e Brown, 1981; Baron e Andersen, 2002; Ramos e Gomide, 2007).

No caso de carnes de aves e peixes, a ênfase dada à cor é diferente da observada em animais de carne vermelha. A falta de pigmentação nos músculos do peito de perus e frangos, por exemplo, é desejada pelo consumidor. Embora para os músculos de 
algumas espécies de peixes a falta de pigmentação também seja desejada, a coloração escura ou avermelhada é necessária em outras espécies de peixes, a exemplo do salmão (Ramos e Gomide, 2007).

A cor da carne também é influenciada pelo processamento a que esta é submetida, uma vez que diferentes condições podem modificar o estado químico dos pigmentos. Dos processamentos que interferem, direta ou indiretamente, na cor final da carne e derivados, podem-se citar: cozimento; refrigeração; congelamento; tipo de embalagem (vácuo, atmosfera modificada, etc.); presença e tipo de luz durante o armazenamento e adição de substâncias como sal e nitrito (Igene et al., 1979; Tichivangana e Morrissey, 1985; Rhee, 1988; Olivo, 2006; Ramos e Gomide, 2007; Bou et al., 2008).

Os agentes antioxidantes são utilizados para combater e/ou retardar as alterações oxidativas em produtos cárneos (Gray et al., 1996; Ahn et al., 2002, Lee et al., 2005). Estes compostos, mesmo manipulados e mantidos em condições adequadas de conservação, ficam expostos à deterioração de ordem intrínseca, promovida por ações de enzimas, do oxigênio existente no meio e luminosidade (Marques, 2006).

Os antioxidantes sintéticos mais utilizados na indústria de alimentos são os butilhidroxi-anisol (BHA), butil-hidroxi-tolueno (BHT), propil-galato (PG) e tercil-butilhidroquinona (TBHQ) (Ahmad, 1996), sendo os dois primeiros mais efetivos na supressão da oxidação em gorduras animais do que nas vegetais (Bailey, 1996).

Várias alterações biológicas podem ser provocadas pelo consumo de antioxidantes sintéticos (Namiki, 1990, Hettiarachchy et al., 1996, Pokorný, 2007). Desta forma, pesquisas têm-se dirigido no sentido de encontrar produtos naturais com atividade antioxidante, os quais permitirão substituir os sintéticos ou fazer associações entre eles, com o intuito de diminuir sua quantidade nos alimentos (Soares, 2002).

\section{Objetivo}

O objetivo deste estudo foi avaliar o efeito protetor do mel e das especiarias (Salvia officinalis) e orégano (Origanum vulgare L.) contra a oxidação dos lipídios e da cor em sistemas modelo de homogenatos de carnes de frango cruas e cozidas, mantidas sob refrigeração. 、 


\section{Material e métodos}

\subsection{Amostras}

Os cortes de frangos (sobrecoxa e peito) foram obtidos de uma avícola de pequeno porte da cidade de Carapicuiba - SP. Após o abate, os cortes foram acondicionados em recipiente térmico e gelo e transportados para o Laboratório de Bromatologia da USP para as análises.

As amostras de mel (florada predominante "laranjeira") foram obtidas diretamente da Associação Paulista de Apicultores (APACAME) e as especiarias desidratadas orégano (Origanum vulgare L.) e sálvia (Salvia officinalis) foram doadas pela Empresa Fuchs do Brasil. Todas as amostras foram armazenadas em temperatura ambiente $\left(24^{\circ} \mathrm{C}\right)$ conforme indicação dos fabricantes.

\subsection{Preparo do homogenato}

O experimento consistiu de 5 tratamentos (Tabela 1) e o homogenato foi elaborado em 3 repetições para cada tipo de carne.

No Laboratório de Bromatologia da FSP/USP, foram removidas a pele e a gordura aparente dos cortes de sobrecoxa e peito. Amostras de $100 \mathrm{~g}$ de carne picadas foram homogeneizadas em processador de alimentos, durante 10 segundos, com diferentes concentrações de mel e especiarias (sálvia e orégano), conforme Tabela 1.

Imediatamente após o processamento, os homogenatos foram acondicionados em sacos de polietileno (tipo zippy), com posterior cozimento em banho-maria, durante 30 minutos. Um termômetro digital calibrado da marca Traceable Long-Stem foi utilizado para medir a temperatura interna de $72^{\circ} \mathrm{C}$ dos homogenatos. Posteriormente, os homogenatos foram resfriados e armazenados em geladeira à $4^{\circ} \mathrm{C}$.

As amostras cruas e cozidas foram avaliadas nos seguintes parâmetros ( $\mathrm{pH}$, atividade de água, umidade, TBARS e derivados de mioglobina). Todas as análises foram realizadas em triplicatas nos tempos 0,48 e 96 horas para o acompanhamento das alterações da oxidação lipídica. 
Tabela 1 - Quantidade dos ingredientes (Tratamentos) adicionados no experimento.

\begin{tabular}{|c|c|c|c|c|c|}
\hline \multirow{2}{*}{ Tratamentos } & \multicolumn{5}{|c|}{ Ingredientes } \\
\hline & BHT (ppm) & SaI $(\%)$ & Orégano (\%) & Sálvia (\%) & $\operatorname{Mel}(\%)$ \\
\hline \multicolumn{6}{|c|}{ Peito e/ou Sobrecoxa } \\
\hline Controle & - & 2 & - & - & $-\cdot$ \\
\hline BHT & 100 & 2 & i & - & - \\
\hline Orégano+Sálvia & - & 2 & 0,2 & 0,2 & - \\
\hline Orégano+Sálvia+5\% Mel & - & 2 & 0,2 & 0,2 & 5 \\
\hline Orégano+Sálvia+10\%Mel & - & 2 & 0,2 & 0,2 & 10 \\
\hline
\end{tabular}

\subsection{Análises}

\subsection{1. pH}

$\mathrm{O} \mathrm{pH}$ foi determinado utilizando-se um potenciômetro portátil da marca Ingold, modelo pH 206. As amostras foram diluídas em água destilada na proporção 1:1 (m:v) e homogeneizadas com bastão de vidro, segundo técnica descrita por Terra e Braun (1985).

\subsubsection{Atividade de água (Aa)}

Foi determinada por meio do medidor automático da marca Aqualab, modelo CX-2. A atividade de água é expressa pela razão da pressão de vapor da água do alimento sobre pressão de vapor da água pura.

\subsubsection{Umidade}

Os teores de umidade foram realizadas por processo gravimétrico, o qual se baseia na determinação de perda de peso da amostra submetida a aquecimento em estufa a $105^{\circ} \mathrm{C}$, resultando no resíduo seca ou dessecado. A pesagem foi realizada somente após o resfriamento em dessecador, sendo a operação repetida até peso constante. (AOAC, 1995). 


\subsubsection{TBARS (Teste das substâncias reativas ao ácido tiobarbitúrico).}

O método utilizado para a quantificação das substâncias reativas ao ácido tiobarbitúrico foi o de extração descrito por Torres e Okani (1997).

A técnica consiste em pesar $10 \mathrm{~g}$ da amostra homogeneizada em frasco de Kjeldhal e adicionar $97,5 \mathrm{~mL}$ de água destilada, $2,5 \mathrm{ml}$ de HCL $4 \mathrm{~N}$, algumas gotas de anti-espumante. Pérolas de vidro foram adicionadas para evitar refluxo da amostra para o destilado.

Essa mistura foi destilada em destilador Kjeldhal, utilizando nível alto de aquecimento, por aproximadamente 20 minutos, ou até recolher $50 \mathrm{~mL}$ de destilado em erlenmeyer.

Posteriormente, foi retirada uma alíquota de $5 \mathrm{~mL}$ do destilado e transferida para um tubo de ensaio com tampa rosqueada, adicionando-se $5 \mathrm{~mL}$ de solução de ácido 2-tiobarbitúrico 0,02M. Neste momento, foi preparado o branco, contendo $5 \mathrm{~mL}$ de água destilada e $5 \mathrm{~mL}$ de solução TBA. Todos os tubos (branco e amostras) foram vedados, agitados e colocados em banho-maria a $100^{\circ} \mathrm{C}$, durante 35 minutos.

Por fim, as amostras foram retiradas do banho, resfriadas em água e transferidas para as cubetas.

O padrão utilizado foi o 1,1,3,3 tetraetoxipropano (TEP) e absorção das amostras e do padrão foi lida em um comprimento de onda de $530 \mathrm{~nm}$. As leituras das absorbâncias foram feitas em espectrofotômetro UV/VIS SḦIMADZU.

Os valores encontrados foram relatados como mg de substâncias que reagem com TBARS por $1000 \mathrm{~g}$ de amostra. 


\subsubsection{Derivados de mioglobina}

O método de extração utilizado foi de acordo com Asghar et al., (1990), onde pesóu-se $5 \mathrm{~g}$ de carne e adicionou-se $25 \mathrm{~mL}$ de água destilada gelada, seguido de homogeneização em aparelho Ultra Turrax, em velocidade média por aproximadamente 1 minuto.

Em seguida, as amostras foram filtradas em papel filtro Whatman $\mathrm{n}^{\circ} 1$." Os primeiros $3 \mathrm{~mL}$ foram descartados, sendo recolhidos $7 \mathrm{~mL}$ para a análise: Posteriormente, ajustou-se o pH da solução entre 5,9 a 6,1 , com o auxílio de solução tampão-fosfato. A leitura das amostras foi realizada em espectrofotômetro UV/VIS nos comprimentos de onda 485, 507, 573 e $597 \mathrm{~nm}$. Para a determinação dos derivados de mioglobina, foi utilizado o método de cálculo desenvolvido por Broumand et al., (1958), onde o uso de pontos isobésticos obtidos de coeficientes de extinção milimolar $\left(\varepsilon_{\mathrm{mM}}\right)$ são utilizados para estimar o percentual dos derivados químicos da mioglobina em extratos aquosos. Com base nos pontos isobésticos e no fato de que a razão dos valores de absorbâncias de dois comprimentos de ondas é igual à razão dós coeficientes de extinção destes mesmos comprimentos de ondas, então:

$\% \mathrm{MMb}$ (metamioglobina) $=507 / 573 \mathrm{~nm}$;

$\% \mathrm{Mb}($ mioglobina $)=485 / 597 \mathrm{~nm} \mathrm{e}$

$\% \mathrm{O}_{2} \mathrm{Mb}$ (oximioglobina) $=100-(\% \mathrm{MMB}-\% \mathrm{Mb})$

\subsection{Análise estatística}

Os resultados das diferentes análises foram apresentados como média e desvio padrão. Estas avaliações foram realizadas utilizando-se o programa Microsoft Excel, versão 2000 .

Foram realizadas a análise de variância (ANOVA) e as comparações múltiplas através do teste de Tukey nas variáveis com distribuição normal.

$\mathrm{O}$ nível de significância estabelecido, para todos os testes estatísticos aplicados, foi de $\alpha=5 \%$.

Todos os testes foram realizados com o "software" Statistical Package for the Secial Sciences (SPSS) versão 10.0 for Windows (SPSS 1999). 
Tabelas 3a e 3b - Valores médios e desvio padrão de atividade de água dos homogenatos de sobrecoxa crua e cozida.

\begin{tabular}{|c|c|c|c|c|c|}
\hline \multicolumn{6}{|c|}{ Tabela 3a - Atividade de água - Solzecena crua } \\
\hline \multirow{3}{*}{ Horas } & \multicolumn{4}{|c|}{ Tratamentos } & \multirow{3}{*}{$\begin{array}{c}\text { Orégano+Sálvia } \\
+10 \% \mathrm{Mel}\end{array}$} \\
\hline & Controle & BHT & Orégano+Sálvia & Orégano+Sálvia & \\
\hline & . & & & $+5 \%$ Mel & \\
\hline $\mathbf{0}$ & $0,960 \pm 0,00^{b ; r}$ & $0,951 \pm 0,00^{\mathrm{ab} ; 5}$ & $0,950 \pm 0,00^{\mathrm{a}, \mathrm{b} ; \mathrm{r}}$ & $0, \overline{948 \pm 0,00^{2, x}}$ & $0,944 \pm 0,01^{\mathrm{aF}}$ \\
\hline 48 & $0,962 \pm 0,01^{\mathrm{cor}}$ & $0,9 \dot{60} \pm 0,01^{\mathrm{b}, c_{5,5}}$ & $0,956 \pm 0,00^{b, c, s}$ & $0,949 \pm 0,00^{\mathrm{a}, \mathrm{b} x \mathrm{x}}$ & $0,944 \pm 0,00^{\text {axr }}$ \\
\hline 96 & $0,957 \pm 0,00^{\mathrm{ab} ; \mathrm{r}}$ & $0,960 \pm 0,00^{\mathrm{b}, \mathrm{r}}$ & $0,960 \pm 0,00^{\mathrm{b}: t}$ & $0,957 \pm 0,00^{2 \mathrm{~b} ; s}$ & $0,953 \pm 0,00^{\mathrm{a} ; \mathrm{s}}$ \\
\hline \multicolumn{6}{|c|}{ Letras de $(a, b)$ na mesma linha indicam diferenças estatisticamente significativas $p<0,05$} \\
\hline \\
\hline \multicolumn{6}{|c|}{ Tabela 3h-Atividade de água - Sobrecoxa cozida } \\
\hline \multirow{3}{*}{ Horas } & \multicolumn{4}{|c|}{ Tratamentos } & \multirow{3}{*}{$\begin{array}{c}\text { Orégano+Sálvia } \\
+10 \% \mathrm{Mel}\end{array}$} \\
\hline & Controle & BHT & Orégano+Sálvia & Orégano+Sálvia & \\
\hline & & & & $+5 \%$ Mel & \\
\hline 0 . & $0,945 \pm 0,00^{\bar{b}, \mathrm{c} ; x}$ & $0,950 \pm 0,00^{\mathrm{c}, \mathrm{r}}$ & $0,938 \pm 0,00^{\mathrm{a} b ;}$ & $0,940 \pm 0,00^{2, b ; x}$ & $0,936 \pm 0,01^{\mathrm{a} ; \mathrm{r}}$ \\
\hline 48 & $0,948 \pm 0,00^{\text {arr }}$ & $0,947 \pm 0,00^{\mathrm{ax}}$ & $0,945 \pm 0,01^{\mathrm{ajr}}$ & $0,953 \pm 0,01^{\mathrm{ax} x}$ & $0,942 \pm 0,00^{\mathrm{ar}}$ \\
\hline 96 & $0,955 \pm 0,00^{\mathrm{b} ; \mathrm{s}}$ & $0,960 \pm 0,00^{c, 8}$ & $0,955 \pm 0,00^{\mathrm{b} ; \mathrm{s}}$ & $0,948 \pm 0,00^{2, r}$ & $0,952 \pm 0,00^{\mathrm{a}, \mathrm{b} ; \mathrm{r}}$ \\
\hline \multicolumn{6}{|c|}{ Letras de $(a, b)$ na mesma linha indicam diferenças estatisticamente significativas $p<0,05$} \\
\hline & - & dicam diferenças & atisticamente significa & ivas $\mathbf{p}<0,05$ & \\
\hline
\end{tabular}

Para as medidas de atividade de água (Aa) do homogenato de peito cru (Tabela 2a), foram observadas (ANOVA) que existem diferenças significativas entre os tratamentos $(p=0,003)$ nos tempos analisados. Com relação ao tempo de refrigeração, apenas o tratamento (orégano+sálvia $+10 \% \mathrm{Mel}$ ) apresentou diferenças significativas de acordo com o teste de Tukey. Os valores de Aa para o homogenato de peito cozido (Tabela 2 b) mostraram-se estatisticamente diferentes em relação aos tratamentos e aos tempos de refrigeração avaliados, exceto para o controle.

De acordo com os resultados apresentados para os homogenatos de peito (cru ou cozido) o tratamento (orégano+sálvia $+10 \% \mathrm{Mel}$ ) reduziu os valores de atividade de água. Provavelmente, este resultado está relacionado à maior adição de mel neste tratamento. $\mathrm{O}$ mel deve ter propiciado uma perda de água livre devido à diferença de pressão osmótica na superfície da carne, levando a água do meio menos concentrado para o mais concentrado.

Em relação aos homogenatos de sobrecoxa cruas e cozidas (Tabelas 3 a e $3 b$ ) foram observados valores de Aa estatisticamente diferentes $(p=0,003$ e $p=0,049)$ para todos os tratamentos avaliados. Assim como ocorreu nas amostras do peito, os tratamentos com mel foram os que apresentaram menores valores de atividade de água, quando comparados aos demais. 


\section{2. $\mathrm{pH}$}

Nas Tabelas $4 a, 4 b, 5 a$ e $5 b$ estão apresentados os resultados das análises $p H$ do homogenatos de peito e sobrecoxa (crus e cozidos).

Tabelas $4 \mathrm{a}$ e $4 \mathrm{~b}$ - Valores médios e desvio padrão de $\mathrm{pH}$ do homogenato de peito cru e cozido.

\begin{tabular}{|c|c|c|c|c|c|}
\hline \multicolumn{6}{|c|}{ Tabela 4a-pH-Peito cru } \\
\hline \multirow[b]{2}{*}{ Horas } & \multicolumn{5}{|c|}{ Tratamentos } \\
\hline & Controle & BHT & Orégano+Sálvia & $\begin{array}{c}\text { Orégano+Sálvia } \\
+5 \% \mathrm{Mel}\end{array}$ & $\begin{array}{l}\text { Orégano+Sálvia } \\
+10 \% \mathrm{Mel}\end{array}$ \\
\hline 0 & $6, \overline{32} \pm \overline{0}, 01^{\bar{s} \bar{s}}$ & $6,21 \pm 0,01^{\mathrm{b} ; \mathrm{s}}$ & $6,15 \pm 0,01^{\mathrm{ar}}$ & $6,16 \pm 0,01$ & $6,15 \pm 0,01^{\text {ais }}$ \\
\hline 48 & $6,19 \pm 0,01^{c, 7}$ & $6,16 \pm 0,01^{c, r}$ & $6,12 \pm 0,01^{b ; r}$ & $6,07 \pm 0,01^{\mathrm{aj} ; \mathrm{T}}$ & $6,10 \pm 0,03^{\mathrm{a}, \mathrm{b} ; \mathrm{r}}$ \\
\hline 96 & $6,43 \pm 0,01^{b t t}$ & $6,39 \pm 0,02^{b-t}$ & $6,26 \pm 0,02^{a} ; \mathrm{s}$ & $6,27 \pm 0,01^{\mathrm{sit}}$ & $6,27 \pm 0,02^{\mathrm{a} ; \mathrm{t}}$ \\
\hline \multicolumn{6}{|c|}{ Letras de $(a, b, c)$ na mesma linha indicam diferenças estatistica mente significantes $(p<0,05)$} \\
\hline \multicolumn{6}{|c|}{ Tabela $4 \mathrm{~b}-\mathrm{pH}-$ Peito cozido } \\
\hline \multirow[b]{2}{*}{ Horas } & \multicolumn{5}{|c|}{ Tratamentos } \\
\hline & Controle & $\mathrm{BHT}$ & Orégano+Sáivia & $\begin{array}{c}\text { Orégano+Sáivia } \\
+5 \% \mathrm{Mel}\end{array}$ & $\begin{array}{c}\text { Orégano+ Sálvia } \\
10 \% \mathrm{Mel}\end{array}$ \\
\hline $\mathbf{0}$ & $6,32 \pm 0,01^{\text {c, }}$ & $6,21 \pm 0,01^{b, x}$ & $6,15 \pm 0,01^{8,5}$ & $6,16 \pm 0,01^{0, T}$ & $6,15 \pm 0,01^{2,5}$ \\
\hline 48 & $6,61 \pm 0,05^{\mathrm{ct}}$ & $6,53 \pm 0,05^{b, c, s}$ & $6,51 \pm 0,02^{b, c, s}$ & $6,43 \pm 0,06^{\mathrm{s}, \mathrm{b} ; \mathrm{s}}$ & $6,38 \pm 0,01^{a ; s}$ \\
\hline 96 & $6,49 \pm 0,05^{\text {b;s }}$ & $6,47 \pm 0,00^{\mathrm{bss}}$ & $6,47 \pm 0,04^{\mathrm{a}, \mathrm{b} ; \mathrm{s}}$ & $6,42 \pm 0,02^{\mathrm{s}, \mathrm{b} ; \mathrm{s}}$ & $6,39 \pm 0,02^{2 ; 5}$ \\
\hline \multicolumn{6}{|c|}{ Letras de $(a, b, c)$ na mesma linha indicam diferenças estatisticamente significativas $p<0,05$} \\
\hline
\end{tabular}

Tabelas $5 \mathrm{a}$ e $5 \mathrm{~b}$ - Valores médios e desvio padrão de $\mathrm{pH}$ do homogenato de sobrecoxa crua e cozida.

\begin{tabular}{|c|c|c|c|c|c|}
\hline \multicolumn{6}{|c|}{ Tabela $5 a-p H-$ Sobrecoxa crua } \\
\hline \multirow[b]{2}{*}{ Horas } & \multicolumn{5}{|c|}{ Tratamentos } \\
\hline & Controle & BHT & Orégano+Sálvia & $\begin{array}{l}\text { Orégano+ Sálvia } \\
+5 \% \mathrm{Mel}\end{array}$ & $\begin{array}{l}\text { Orégano+Sálvia } \\
10 \% \mathrm{Mel}\end{array}$ \\
\hline 0 & $6,52 \pm 0,08^{\mathrm{a} x}$ & $6,58 \pm 0,01^{\mathrm{sx}^{x}}$ & $6,60 \pm 0,0 \mathrm{~d}^{\mathrm{a} ; \mathrm{s}}$ & $6,60 \pm 0,01^{\mathrm{a}, t}$ & $6,54 \pm 0,01^{\mathrm{as}}$ \\
\hline 48 & $6,60 \pm 0,02^{\mathrm{bsr}}$ & $6,59 \pm 0,0 \mathrm{I}^{\mathrm{b} ; \mathrm{r}, \mathrm{s}}$ & $6,58 \pm 0,01^{\mathrm{bs} r}$ & $6,57 \pm 0,01^{b ; s}$ & $6,53 \pm 0,01^{\mathrm{as,5}}$ \\
\hline 96 & $6,64 \pm 0,02^{\epsilon, \pi}$ & $6,60 \pm 0,00^{\mathrm{ds} s}$ & $6,56 \pm 0,01^{\mathrm{c}, \mathrm{r}}$ & $6,21 \pm 0,01^{\mathrm{ar} x}$ & $6,25 \pm 0,01^{b+x}$ \\
\hline \multicolumn{6}{|c|}{$\begin{array}{l}\text { Letras de }(a, b, c) \text { na mesma linha indicam diferenças estatisticamente significativas } p<0,05 \\
\text { Letras de }(r, s, t) \text { na mesma coluna indicam diferenças estatisticamente significativas } p<0,05\end{array}$} \\
\hline \multicolumn{6}{|c|}{ Tabela 5b-pH - Sobrecoxa cozida } \\
\hline & \multicolumn{5}{|c|}{ Tratamentos } \\
\hline Horas & Controle & $\mathrm{BHT}$ & Orégano+Sálvia & $\begin{array}{l}\text { Orégano+Sálvia } \\
5 \% \text { Mel }\end{array}$ & $\begin{array}{l}\text { Orégano+Sálvia } \\
\quad+10 \% \text { Mel }\end{array}$ \\
\hline 0 & $6,94 \pm 0,03^{\mathrm{d} ; \mathrm{s}}$ & $6,89 \pm 0,01^{\mathrm{cs}}$ & $6,87 \pm 0,02^{\mathrm{css}}$ & $6,82 \pm 0,00^{b, t}$ & $6,77 \pm 0,01^{\mathrm{a}, \pi}$ \\
\hline 48 & $6,89 \pm 0,02^{\mathrm{b} ;, \mathrm{s}}$ & $6,87 \pm 0,02^{b ; 5, s}$ & $6,87 \pm 0,02^{b ; s}$ & $6,81 \pm 0,01^{\mathrm{a} ; \mathrm{s}}$ & $6,78 \pm 0,05^{\text {a;r }}$ \\
\hline .96 & $6,86 \pm 0,00^{c ; .5}$ & $6,85 \pm 0,01^{\sigma, r}$ & $6,81 \pm 0,01^{\mathrm{bsx}}$ & $\dot{6}, 79 \pm 0,01^{a x}$ & $6,78 \pm 0,01^{a ; x}$ \\
\hline \multicolumn{6}{|c|}{$\begin{array}{l}\text { Letras de }(a, b, c) \text { na mesma linha indicam diferenças estatisticamente significativas } p<0,05 \\
\text { Letras de }(r, s) \text { na mesma coluna indicam diferenças estatisticamente significativas } p<0,05\end{array}$} \\
\hline
\end{tabular}


Em relação aos valores de pH (Tabelas $4 \mathrm{a}$ e 4 b) para os homogenatos, de peito crus e cozidos, observou-se variação entre 6,07 a 6,43 (amostras cruas) e de 6,15 a 6,51 (amostras cozidas). Notou-se uma elevação nos valores de pH durante o período de refrigeração, em todos os tratamentos avaliados.

De acordo com Qiao et al., (2002) e Castellini, et al., (2002), os valores finais de . $\mathrm{pH}$ dos cortes de peito de frango variam entre 5,75 a 5,96, entretanto, valores superiores foram determinados no presente estudo.

Em relação aos cortes de sobrecoxa, foram encontrados valores de $\mathrm{pH}$ entre 6,21 a 6,60 nas amostras cruas e de 6,77 a 6,94 para as amostras cozidas. Assim como nas amostras de peito, observou-se redução significativa nos valores de $\mathrm{pH}$, que ocorreu gradativamente ao longo do tempo de refrigeração e em todos os tratamentos estudados.

A carne de sobrecoxa apresentou valores de $\mathrm{pH}$ acima dos observados na carne de peito. Isto se deve às características das fibras vermelhas, que por possuírem metabolismo oxidativo, favorecem um pH mais alto (Price e Schwiegert, 1994).

$\mathrm{O} \mathrm{pH}$ muscular pode ser afetado por fatores intrínsecos ao animal como tipo de músculo, espécie, raça, idade e sexo, e extrínsecos como condições climáticas, alimentação, tempo de jejum, tipo de insensibilização e refrigeração. Assim, os valores de estabilização do pH da carne impacta diretamente nos parâmetros sensoriais da carne de frango (Fletcher, 2002; Qiao et al., 2001).

Neste estudo os valores de $\mathrm{pH}$ dos homogenatos de peito e sobrecoxa (crus e cozidos) foram influenciados pelos tratamentos, onde observou-se um declínio após a adição dos antioxidantes naturais e sintético. Provavelmente, as alterações estão relacionadas aos compostos fenólicos presentes no BHT, mel e especiarias, que devido ao caráter ácido, pode ter reduzido o pH das amostras após a adição dos mesmos.

\subsection{Umidade}

Nas Tabelas 6a, 6b, 7a e $7 \mathrm{~b}$ estão apresentados os resultados das análises de umidade $(\mathrm{g} / 100 \mathrm{~g})$ dos homogenatos de peito e sobrecoxa (crus e cozidos). 
Tabelas $6 \mathrm{a}$ e $6 \mathrm{~b}$ - Valores médios e desvio padrão de umidade $(\mathrm{g} / 100 \mathrm{~g})$ do homogenato de peito cru e cozido.

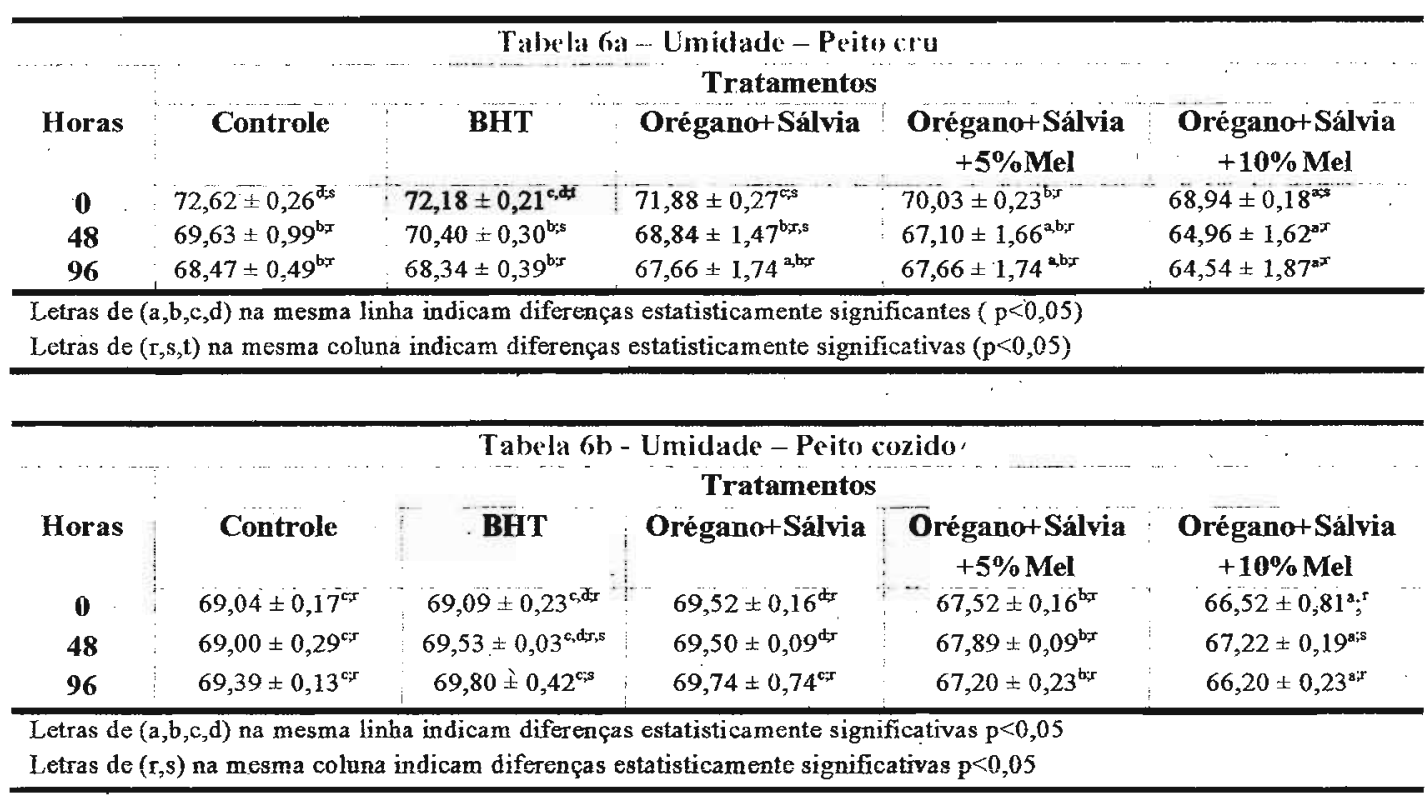

Tabelas $7 \mathrm{a}$ e $7 \mathrm{~b}$ - Valores médios e desvio padrão de umidade $(\mathrm{g} / 100 \mathrm{~g})$ do homogenato de sobrecoxa crua e cozida,

\begin{tabular}{|c|c|c|c|c|c|}
\hline & & Tabelat 7a-Um & nidade - Sobrecoxa & crua & \\
\hline & & & Tratamentos & & \\
\hline Horas & Controle & BHT & Orégano+Sálvia & $\begin{array}{c}\text { Orégano+Sálvia } \\
+5 \% \mathrm{Mel}\end{array}$ & $\begin{array}{c}\text { Orégano+Sálvia } \\
+\mathbf{1 0} \% \mathrm{Mel}\end{array}$ \\
\hline $\mathbf{0}$ & $62,04 \pm 0,43^{\mathrm{a} ; x}$ & $63,00 \pm 1,45^{\mathrm{a} ; \mathrm{r}}$ & $62,79 \pm 2,89^{\mathrm{a}, \mathrm{r}, \mathrm{s}}$ & $61,14 \pm 1,62^{18 x}$ & $60,82 \pm 1,69^{\mathrm{a} i}$ \\
\hline 48 & $66,96 \pm 0,05^{\mathrm{b}, \mathrm{t}}$ & $62,27 \pm 0,72^{\mathrm{a} ; r}$ & $66,94 \pm 0,44^{b ; s}$ & $62,68 \pm 1,30^{8 x}$ & $62,68 \pm 1,30^{\mathrm{a}, \mathrm{b} ; \mathrm{s}}$ \\
\hline 96 & $63,35 \pm 0,35^{2: s}$ & $62,75 \pm 0,92^{\mathrm{s}: x}$ & $62,38 \pm 0,41^{3 ; x}$ & $62,57 \pm 1,46^{25}$ & $61,12 \pm 1,31^{8, \pi, s}$ \\
\hline $\begin{array}{l}\text { Letras de (a) } \\
\text { Letras de (r }\end{array}$ & $\begin{array}{l}\text { a mesma linha inc } \\
\text { na mesma coluna }\end{array}$ & $\begin{array}{l}\text { am diferenças estatis } \\
\text { licam diferenças esta }\end{array}$ & $\begin{array}{l}\text { isticamente significativ } \\
\text { atisticamente significa }\end{array}$ & $\begin{array}{l}\text { as } p<0,05 \\
\text { ivas } p<0,05\end{array}$ & \\
\hline & & Tabela $7 \mathrm{~b}-\mathrm{Umi}$ & idade - Sobrecoxa & ozida & \\
\hline Horas & Controle & BHT & Orégano+Sálvia & $\begin{array}{c}\text { Orégano }+ \text { Sálvia } \\
+5 \% \mathrm{Mel}\end{array}$ & $\begin{array}{l}\text { Orégano+Sálvia } \\
+10 \% \mathrm{Mel}\end{array}$ \\
\hline $\mathbf{0}$ & $64,45 \pm 0,34^{\mathrm{b}, \mathrm{c}_{i} \mathrm{x}}$ & $66,32 \pm 0,18^{d r}$ & $64,97 \pm 0,18^{\mathrm{cr}}$ & $63,71 \pm 0,53^{b / T}$ & $61,38 \pm 0,28^{8 x}$ \\
\hline 48 & $64,39 \pm 0,11^{\mathrm{b}, \mathrm{c} \cdot x_{1}}$ & $65,82 \pm 0,54^{c x}$ & $65,80 \pm 0,30^{\mathrm{css}}$ & $63,05 \pm 0,75^{\mathrm{a}, \mathrm{b}, \mathrm{x}}$ & $61,77 \pm 0,21^{\mathrm{s} ; \mathrm{r}}$ \\
\hline 96 & $64,35 \pm 0,06^{b ; r}$ & $66,17 \pm 0,20^{\text {dr }}$ & $65,48 \pm 0,06^{\mathrm{cr}, 5}$ & $64,03 \pm 0,26^{\mathrm{b}, \mathrm{r}}$ & $62,04 \pm 0,32^{a ; r}$ \\
\hline Letras de ( & mesma linha & a diferenças esta & ticamente signifi & as $\mathbf{p}<0,05$ & \\
\hline
\end{tabular}


Os teores de umidade $(\mathrm{g} / 100 \mathrm{~g})$ nos homogenatos de peitos crus e cozidos estão apresentados nas tabelas $6 \mathrm{a}$ e $6 \mathrm{~b}$. Nos hómogenatos de peito cru observou-se uma perda acentuada de umidade em todos os tratamentos, e particularmente em todos os tempos de refrigeração. Nas amostras de peito cozido não foram observadas diferenças significativas entre os tratamentos controle e orégano+sálvia $+5 \% \mathrm{Mel}$. Diferenças foram observadas nos tratamentos BHT e oréganotsálvia $+10 \% \mathrm{Mel}$, onde se observou um aumento de umidade no tempo de 48 horas. Resultados semelhantes foram obtidos por Cotta e Campos (1981), eles observaram que a refrigeração não afetou os teores médios de umidade da carne de peito.

Nos homogenatos de sobrecoxa crua (Tabela $7 \mathrm{a}$ ) os valores de umidade variaram de 60,82 a $66,96 \mathrm{~g} / 100 \mathrm{~g}$. Já para o homogenato cozido a variação foi de 61,77 a $66,32 \mathrm{~g} / 100 \mathrm{~g}$ (Tabelas $7 \mathrm{~b}$ ). Foram observadas diferenças significativas durante os tempos de refrigeração (48 e 96 horas) apenas nas amostras cozidà tratadas com orégano+sálvia que áumentaram em relação ao controle.

\subsection{Derivados de mioglobina}

Nas tabelas $8 \mathrm{a}, 8 \mathrm{~b}, 9 \mathrm{a}$ e $9 \mathrm{~b}$ estão apresentados os valores médios do porcentual de metamioglobina (MMb), mioglobina $(\mathrm{Mb})$ e oximioglobina $\left(\mathrm{O}_{2} \mathrm{Mb}\right)$ encontrados nos homogenatos crus e cozidos de peito e sobrecoxa de frango . 
Tabelas $8 \mathrm{a}$ e $8 \mathrm{~b}$ - Valores médios e desvio padrão de porcentual de metamioglobina $(\mathrm{MMb})$, mioglobina $(\mathrm{Mb})$ e oximioglobina $\left(\mathrm{O}_{2} \mathrm{Mb}\right)$ do homogenato de peito.

\begin{tabular}{|c|c|c|c|c|}
\hline \multicolumn{5}{|c|}{ Tabcla 8a-Peito cru } \\
\hline \multicolumn{4}{|c|}{$\% \mathbf{M M b}$} & 96 horas \\
\hline Controlè & $1,36^{\mathrm{a}, \mathrm{s}}$ & $1,38^{\mathrm{a} ; \mathrm{r}}$ & & $1,38^{\mathrm{a}, \mathrm{r}}$ \\
\hline BHT & $1,37^{\text {ass }}$ & $1,42^{\mathrm{b} ; \mathrm{s}}$ & & $1,38^{\mathrm{a} r \mathrm{r}}$ \\
\hline Orégano+Sálvia & $1,29^{\mathrm{a} ; \mathrm{r}}$ & $1,42^{\mathrm{a} ; \mathrm{s}}$ & & $1,40^{\mathrm{a}, \mathrm{r}, \mathrm{s}}$ \\
\hline Orégano+Sálvia $+5 \%$ Mel & $1,35^{a ; s}$ & $137^{\mathrm{a}, \mathrm{r}}$ & & $1,41^{\mathrm{b} ; \mathrm{s}}$ \\
\hline Orégano+Sálvia $+10 \% \mathrm{Mel}$ & $1,37^{\mathrm{ass}}$ & $1,42^{\mathrm{c} ; \mathrm{s}}$ & & $1,38^{b ; r}$ \\
\hline \multicolumn{5}{|c|}{$\% \mathbf{M b}$} \\
\hline Controle & $1,95^{\mathrm{a} ; \mathrm{r}}$ & $1,95^{\mathrm{a} ; \mathrm{s}}$ & & $1,95^{\text {a's }}$ \\
\hline BHT & $2,00^{\text {ass }}$ & $2,02^{\mathrm{a} ; \mathrm{t}}$ & & $1,96^{\mathrm{a} ; \mathrm{s}}$ \\
\hline Orégano+Sálvia & $2,00^{\mathrm{css}}$ & $1,87^{b ; r}$ & & $1,96^{\mathrm{ass}}$ \\
\hline Orégano+Sálvia $+5 \%$ Mel & $1,97^{\mathrm{crr}}$ & $1,89^{b ; r}$ & & $1,85^{\mathrm{c}, \mathrm{r}}$ \\
\hline Orégano+Sálvia $+10 \%$ Mel & $2,01^{\mathrm{b} ; \mathrm{s}}$ & $2,03^{b ; t}$ & & $1,87^{\mathrm{a}, \mathrm{r}}$ \\
\hline \multicolumn{5}{|c|}{$\% \mathrm{O}_{2} \mathrm{Mb}$} \\
\hline Controle & $96,69^{a, x, s}$ & $96,67^{a_{j} x}$ & & $96,66^{\mathrm{a} ; \mathrm{r}}$ \\
\hline BHT & $96,63^{\mathrm{b} ; \mathrm{r}}$ & $96,56^{\text {a:r }}$ & & $96,67^{\mathrm{c}, \mathrm{r}}$ \\
\hline Orégano+Sálvia & $96,71^{\mathrm{a} ; \mathrm{s}}$ & $96,71^{\mathrm{arr}}$ & & $96,65^{\mathrm{a}, \mathrm{r}}$ \\
\hline Orégano+Sálvia+5\%Mel & $96,67^{\mathrm{a} b \mathrm{~b}}$ & $96,74^{\mathrm{a}, \mathrm{r}}$ & & $96,74^{\mathrm{a} ; \mathrm{s}}$ \\
\hline Orégano + Sálvia $+10 \%$ Mel & $96,62^{\mathrm{a} ; \mathrm{T}}$ & $96,55^{\mathrm{a} ; \mathrm{r}}$ & & $96,75^{\mathrm{a} ; \mathrm{s}}$ \\
\hline
\end{tabular}

Letras de $(a, b, c)$ na mesma linha indicam diferenças estatisticamente significativas $p<0,05$

Letras de $(r, s, t)$ na mesma coluna indicam diferenças estatisticamente significativas $p<0,05$

\begin{tabular}{|c|c|c|c|}
\hline \multicolumn{4}{|c|}{ Tabela 8b-Peito corido } \\
\hline Tratamentos & 0 hora & 48 horas & 96 horas \\
\hline \multicolumn{4}{|c|}{$\% \mathbf{M M b}$} \\
\hline Controle & $1,22^{\mathrm{a} ; 8}$ & $1,31^{\mathrm{b} ; \mathrm{t}}$ & $1,23^{\mathrm{a} ; \mathrm{r}}$ \\
\hline ВHT & $1,20^{\mathrm{a} ; \mathrm{r}, \mathrm{s}}$ & $1,28^{\mathrm{b} ; \mathrm{r}, \mathrm{s}}$ & $1,27^{\mathrm{b} ; \mathrm{s}}$ \\
\hline Orégano+Sálvia & $1,28^{\text {a }, t}$ & $1,27^{\mathrm{a} ; \mathrm{r}}$ & $1,29^{\mathrm{a} ; \mathrm{s}}$ \\
\hline Orégano+Sálvia+5\%Mel & $1,18^{\mathrm{a} ; \mathrm{r}}$ & $1,31^{\mathrm{b} ; \mathrm{t}}$ & $1,33^{\mathrm{b} ; \mathrm{t}}$ \\
\hline Orégano+Sálvia $+10 \% \mathrm{Mel}$ & $1,29^{\mathrm{b} ; \mathrm{t}}$ & $1,30^{\mathrm{b} ; \mathrm{s}, \mathrm{t}}$ & $1,24^{\mathrm{a} ; \mathrm{r}}$ \\
\hline \multicolumn{4}{|c|}{$\% \mathbf{M b}$} \\
\hline Controle $\quad=$ & $1,42^{\mathrm{a} ; \mathrm{t}}$ & $1,50^{\mathrm{c} ; \mathrm{r}}$ & $1,48^{\mathrm{b} ; \mathrm{s}}$ \\
\hline BHT & $1,37^{\mathrm{a} ; \mathrm{s}}$ & $1,49^{\mathrm{b} ; \mathrm{r}}$ & $1,65^{\mathrm{c}, 1 \mathrm{u}}$ \\
\hline Orégano+Sálvia & $1,54^{\mathrm{a}, 23}$ & $1,55^{\text {ass }}$ & $1,74^{\mathrm{b} ; \mathrm{v}}$ \\
\hline Orégano+Sảlvia+5\%Mel & $1,34^{\mathrm{a}, \mathrm{r}}$ & $1,57^{\mathrm{b} ; 3}$ & $1,61^{\mathrm{cst}}$ \\
\hline Orégano+Sálvia $+10 \% \mathrm{Mel}$ & $1,55^{\mathrm{b} ; \mathrm{u}}$ & $1,55^{\mathrm{b} ; \mathrm{s}}$ & $1,39^{\mathrm{a} ; \mathrm{r}}$ \\
\hline \multicolumn{4}{|c|}{$\% \mathrm{O}_{2} \mathrm{Mb}$} \\
\hline Controle & $97,36^{\mathrm{c} ; \mathrm{s}}$ & $97,19^{\mathrm{a} ; \mathrm{t}}$ & $97,30^{b ; t}$ \\
\hline BHT & $97,42^{\mathrm{css}}$ & $97,23^{\mathrm{b} ; \mathrm{u}}$ & $97,08^{\text {ass }}$ \\
\hline Orégano+Sálvia & $97,18^{\mathrm{b} ; 5}$ & $97,17^{\mathrm{b} ; \mathrm{s}, \mathrm{t}}$ & $96,97^{\mathrm{a}, \mathrm{r}}$ \\
\hline Orégano+Sálvia+5\%Mel & $97,48^{\mathrm{b} ; \mathrm{t}}$ & $97,11^{\mathrm{a} ; \mathrm{r}}$ & $97,06^{\text {ass }}$ \\
\hline Orégano+Sálvia $+10 \%$ Mel & $97,16^{\mathrm{ar}}$ & $97,15^{\text {ass }}$ & $97,38^{\mathrm{b} ; \mathrm{u}}$ \\
\hline
\end{tabular}


Tabelas 9a e 9b - Valores médios e desvio padrão de porcentual de metamioglobina $(\mathrm{MMb})$, mioglobina $(\mathrm{Mb})$ e oximioglobina $\left(\mathrm{O}_{2} \mathrm{Mb}\right)$ do homogenato de sobrecoxa.

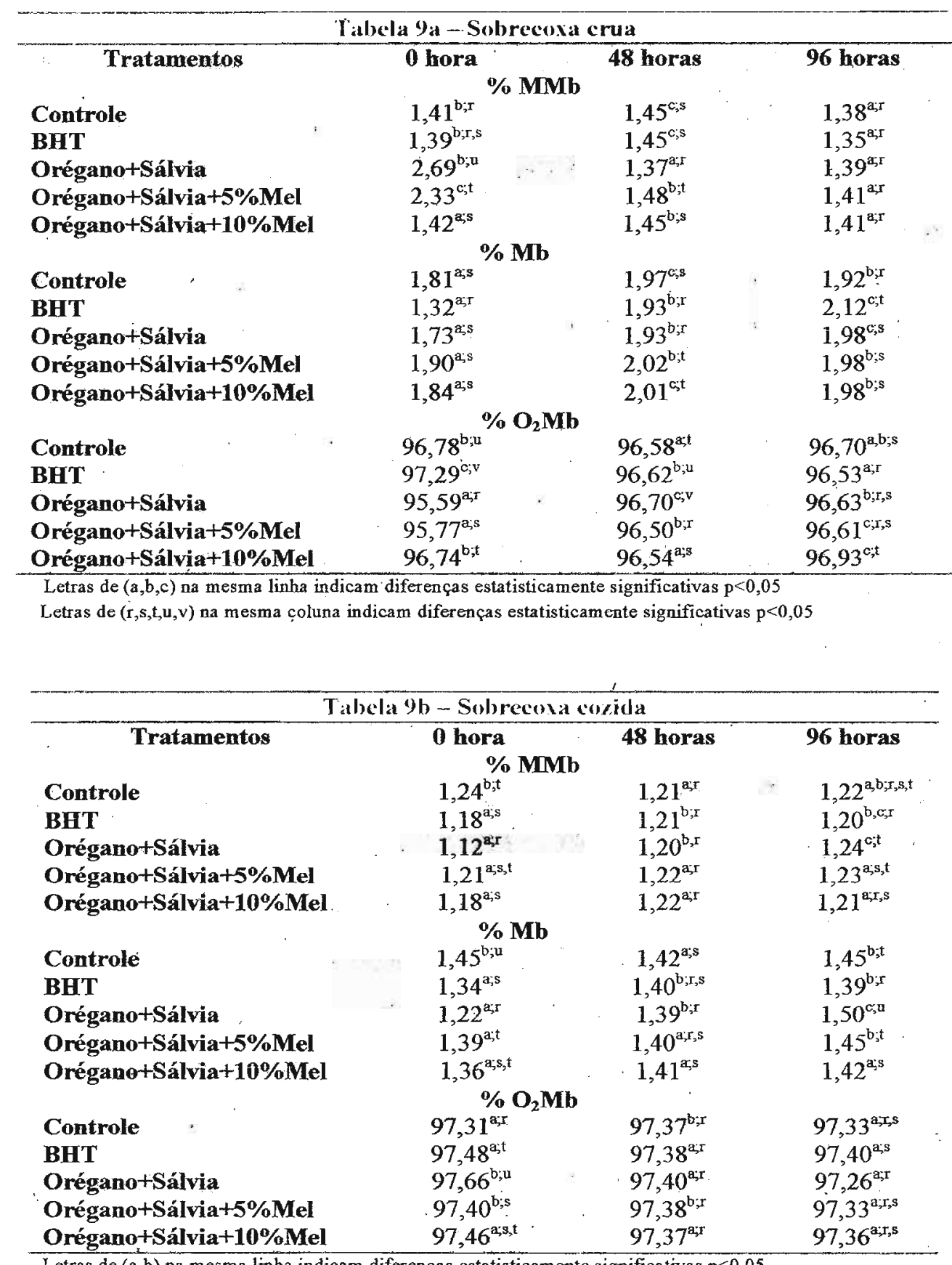

Letras de $(a, b)$ na mesma linha indicam diferenças estatisticamente significativas $\mathbf{p}<0,05$

Letras de $(r, \mathbf{s}, \mathbf{t}, \mathbf{u})$ na mesma coluna indicam diferenças estatisticamente significativas $\mathbf{p}<0,05$ 
Os resultados dos derivados de mioglobina apresentados nas tabelas (8a, 8b, 9a e 9b) sugerem que durante o experimento ocorreram variações dos parâmetros analisados entre os cortes de peito e sobrecoxa de frango.

Nos hömogenatos de peito cru, os teores de mioglobina no tempo 0 variaram entre $1,95 \%$ a $2,01 \%$. Ao final de 96 horas de refrigeração, a porcentagem de $\mathrm{Mb}$ variou entre 1,85 e 1,96, com redução nas concentrações das amostras tratados com especiarias e mel. Comportamento diferente foi apresentado pelos homogenatos de peito cozido, onde após 96 horas de refrigeração observou-se aumento das concentrações de mioglobina em todos os tratamentos avaliados, com exceção do homogenato contendo orégano + sálvia $+10 \%$ de mel.

Em relação aos valores de metamioglobina (\% $\mathrm{MMb})$ para os homogenatos de peito crus e cozidos observou-se pequenas variações ao longo do tempo de refrigeração.

Nas amostras de peito cru, as concentrações de oximioglobina $\left(\% \mathrm{O}_{2} \mathrm{Mb}\right)$ apresentaram-se similares após 96 horas de refrigeração nos tratamentos controle, BHT e orégano+sálvia, entretanto, estatisticamente diferentes das amostras contendo (orégano + sálvia $+5 \% \mathrm{Mel}$ ) e (orégano+sálvia $+10 \% \mathrm{Mel}$ ). Já nas amostras cozidas, os resultados foram similares nas amostras controle e BHT, mas estatisticamente diferentes nos demais tratamentos, após 96 horas de refrigeração.

Nas amostras de sobrecoxa cruas, após 96 horas de refrigeração, observou-se redução das concentrações de metamioglobina (\% $\mathrm{MMb}$ ) e elevação dos teores de mioglobina (\% $\mathrm{Mb}$ ) para todos os tratamentos avaliados. Nas amostras submetidas ao preparo térmico, ao contrário dos homogenatos crus, os teores de metamioglobina $(\%$ MMb) elevaram-se após 96 horas de refrigeração nos tratamentos BHT e orégano +sálvia, permanecendo estáveis nos demais. Entretanto, os teores de mioglobina (\% Mb) foram maiores aos obtidos no tempo 0, exceto nas amostras controle. Em relação às taxas de oximioglobina $\left(\% \mathrm{O}_{2} \mathrm{Mb}\right)$, as mesmas permaneceram constantes durante os tempos e tratamentos avaliados.

Segundo Olivo (2006) alguns fatores contribuem para o rompimento da integridade das membranas musculares como a desossa mecânica, moagem, reestruturação ou cozimento, alterando os compartimentos celulares, com a liberação do ferro cataliticamente ativo da mioglobina e de outras proteínas. A interação deste e de outros agentes pró-oxidantes com os ácidos graxos polinsaturados, resulta na geração de radicais livres e na propagação das reações oxidativas. A exposição a temperaturas 
elevadas, presença de oxigênio e a incidência demasiada de luz colaboram substancialmente para estas alterações, podendo ocorrer variações das taxas de metamioglobina $(\% \mathrm{MMb})$, mioglobina $(\% \mathrm{Mb})$ e oximioglobina $\left(\% \mathrm{O}_{2} \mathrm{Mb}\right)$ presentes na superficie das carnes (Kanner, 1994, Olivo, 2006, Ramos e Gomide, 2007).

Entretanto, os resultados obtidos no presente estudo apresentaram um comportamento irregular, não sendo possível concluir quais são exatamente as causas das variações para os pigmentos hemes avaliados. Provavelmente os resultados estão relacionados as baixas concentrações de mioglobina presentes nas carnes de peito e sobrecoxa de frango.

\subsection{TBARS}

Nas tabelas 10a, 10b, $11 \mathrm{a}$ e $11 \mathrm{~b}$ estão apresentados os valores de TBARS encontrados nos homogenatos de peito e sobrecoxa (crus e cozidos) durante o período de refrigeração.

Tabelas 10a e 10b - Valores médios e desvio padrão de TBARS (mg MDA / Kg) dos homogenatos de peito cru e cozido:

\begin{tabular}{|c|c|c|c|c|c|}
\hline \multicolumn{6}{|c|}{ Tahela loa TBARS Peito cru } \\
\hline Horas & Controle & BHT & Orégano+Sálvia & $\begin{array}{l}\text { Orégano+Sálvia } \\
+5 \% \text { Mel }\end{array}$ & $\begin{array}{l}\text { Orégano+Sálvia } \\
\quad+10 \% \text { Mel }\end{array}$ \\
\hline $\mathbf{0}$ & $0,014 \pm 0,01^{\mathrm{b} ; \mathrm{r}}$ & $0,010 \pm 0,01^{2 x}$ & $0,010 \pm 0,00^{\operatorname{axr}}$ & $0,010 \pm 0,01^{\mathrm{ax}}$ & $0,011 \pm 0,00^{2, b x}$ \\
\hline 48 & $0,011+0,01^{\mathrm{a}, \mathrm{b} ; \mathrm{r}}$ & $0,014 \pm 0,00^{b ; s}$ & $0,010 \pm 0,00^{\mathrm{ax}}$ & $0,011 \pm 0,00^{\mathrm{a}, \mathrm{b} ; \mathrm{r}}$ & $0,011 \pm 0,00^{\mathrm{ab} ; \mathrm{r}}$ \\
\hline 96 & $0,012 \pm 0,01^{\mathrm{s}, \mathrm{b} ; \mathrm{r}}$ & $0,014 \pm 0,00^{\mathrm{b} ; \mathrm{s}}$ & $0,009 \pm 0,00^{\mathrm{axr}}$ & $0,011 \pm 0,00^{2 ; r}$ & $0,011 \pm 0,00^{\mathrm{a} r \mathrm{r}}$ \\
\hline \multicolumn{6}{|c|}{$\begin{array}{l}\text { Letras de }(a, b) \text { na mesma linha indicam diferenças estatisticamente significantes }(p<0,05) \\
\text { Letras de }(r, s) \text { na mesma coluna indicam diferenças estatisticamente significativas }(p<0,05)\end{array}$} \\
\hline \multicolumn{6}{|c|}{$\begin{array}{c}\text { Tabela 10b-TBARS-Pcito cozido } \\
\text { Tratamentos }\end{array}$} \\
\hline Horas & Controle & ВНТ & Orégano+Sálvia & $\begin{array}{l}\text { Orégano+Sálvia } \\
+5 \% \text { Mel }\end{array}$ & $\begin{array}{l}\text { Orégano+ Sálvia } \\
\quad+10 \% \mathrm{Mel}\end{array}$ \\
\hline $\mathbf{0}$ & $0,389 \pm 0,04^{\text {cir }}$ & $0,189 \pm 0,00^{\text {bsr }}$ & $0,038 \pm \overline{0}, 00^{\mathrm{a}}$ & $0,022 \pm 0,00^{\mathrm{ar}}$ & $0,016 \pm 0,00^{\mathrm{grr}}$ \\
\hline 48 & $1,095 \pm 0,04^{5 ; s}$ & $0,282 \pm 0,00^{b ; s}$ & $0,063 \pm 0,00^{\mathrm{ars}}$ & $0,056 \pm 0,00^{\mathrm{g} / \mathrm{s}}$ & $0,026 \pm 0,00^{2: s}$ \\
\hline 96 & $1,338 \pm 0,02^{\mathrm{d}, \mathrm{t}}$ & $0,299 \pm 0,00^{c, t}$ & $0,088 \pm 0,00^{\mathrm{b}: t}$ & $0,077 \pm 0,00^{\mathrm{b} ; \mathrm{t}}$ & $0,039 \pm 0,00^{\text {a:t }}$ \\
\hline
\end{tabular}


Tabelas 11a e $11 \mathrm{~b}$ - Valores médios e desvio padrão de TBARS (mg MDA/ Kg) dos homogenatos de sobrecoxa crua e cozida.

\begin{tabular}{|c|c|c|c|c|c|}
\hline \multicolumn{6}{|c|}{ Tabela 9a - TBARS - Sobrecoxa crua } \\
\hline & \multicolumn{5}{|c|}{ Tratamentos } \\
\hline Horas & Controle & ВHT & Orégano+Sálvia & $\begin{array}{c}\text { Orégano+Sálvia } \\
+5 \% \mathrm{Mel}\end{array}$ & $\begin{array}{l}\text { Orégano+Sálvida } \\
+\mathbf{1 0} \% \text { Mel }\end{array}$ \\
\hline $\mathbf{0}$ & $0,019 \pm 0,00^{\mathrm{d} x}$ & $0,015 \pm 0,00^{\mathrm{abor}}$ & $0,013 \pm 0,00^{\mathrm{a} b, r}$ & $0,012 \pm 0,00^{\mathrm{a}, \mathrm{r}}$ & $0,016 \pm 0,00^{\mathrm{b}, \overline{\mathrm{c}} \mathrm{r}}$ \\
\hline 48 & $0,031 \pm 0,00^{c ; s}$ & $0,025 \pm 0,00^{6 ; 5}$ & $0,026 \pm 0,00^{\mathrm{b} ; \mathrm{s}}$ & $0,020 \pm 0,00^{\mathrm{ass}}$ & $0,020 \pm 0,00^{\mathrm{ass}}$ \\
\hline 96 & $0,033 \pm 0,00^{\mathrm{css}}$ & $0,025 \pm 0,00^{b ; s}$ & $0,016 \pm 0,00^{2: 4}$ & $0,017 \pm 0,00^{\mathrm{a}: \mathrm{s}}$ & $0,017 \pm 0,00^{\text {a;r }}$ \\
\hline \multicolumn{6}{|c|}{ Letras de $(a, b, c, d)$ na mesma linha indicam diferenças éstatisticamente significativas $p<0,05$} \\
\hline \multicolumn{6}{|c|}{ Tabela 9h - TBARS - Sobrecoxa cozida } \\
\hline & & & Tratamentos & 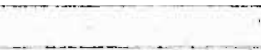 & \\
\hline Horas & Controle & BHT & Orégano+Sálvia & $\begin{array}{c}\text { Orégano+Sálvia } \\
+5 \% \mathrm{Mel}\end{array}$ & $\begin{array}{c}\text { Orégano+Sálvia } \\
+\mathbf{1 0} \% \mathrm{Mel}\end{array}$ \\
\hline $\mathbf{0}$ & $0,274 \pm 0,00^{6 ; 5}$ & $0,282 \pm 0,00^{\mathrm{c} r}$ & $0,021 \pm 0,00^{2,1}$ & $0,017 \pm 0,00^{\mathrm{agr}}$ & $0,023 \pm 0,00^{8}$ \\
\hline 48 & $1,314 \pm 0,00^{\mathrm{d}, s}$ & $0,288 \pm 0,00^{\mathrm{c}, \boldsymbol{r}}$ & $0,041 \pm 0,00^{\mathrm{b} ; \mathrm{t}}$ & $0,034 \pm 0,00^{\alpha s s}$ & $0,029 \pm 0,00^{\text {er }}$ \\
\hline 96 & $1,529 \pm 0,10^{\mathrm{cst}}$ & $0,363 \pm 0,00^{\mathrm{b} ; \mathrm{s}}$ & $0,035 \pm 0,00^{2 . s}$ & $0,030 \pm 0,00^{\mathrm{ms} s}$ & $0,030 \pm 0,00^{25 r}$ \\
\hline
\end{tabular}

Durante o tempo 0 , os homogenatos de peito cru das amostras controle apresentaram valores de TBARS mais elevados $(0,014 \mathrm{mg} \mathrm{MDA} / \mathrm{Kg})$ em relação aos demais. Os resultados dos tratamentos' contendo BHT, orégano+sálvia e orégano+sálvia $+5 \% \mathrm{Mel}$ mostraram-se semelhantes. Quando avaliamos cada tratamento individualmente, apenas o tratamento contendo BHT apresentou diferenças significativas no decorrer do tempo $(p=0,011)$, onde foram observados maiores valores $(0,014 \mathrm{mg} \mathrm{MDA} / \mathrm{Kg})$ nos tempos 48 e 96 horas.

Nos homogenatos de peito cozido observou-se um aumento nos valores de TBARS no decorrer do tempo, em todas as amostras analisadas. Assim como nos homogenatos crus, o grupo controle apresentou os teores mais elevados $(1,338 \mathrm{mg}$ MDA/Kg), seguido do tratamento BHT $(0,299 \mathrm{mg} \mathrm{MDA} / \mathrm{Kg})$. Já para os tratamentos com especiarias, os teores determinados foram: orégano+sálvia $(0,088 \mathrm{mg} \mathrm{MDA} / \mathrm{Kg})$, orégano + sálvia+ $5 \% \mathrm{Mel}(0,077 \mathrm{mg} \mathrm{MDA} / \mathrm{Kg})$ e orégano+sálvia $+10 \% \mathrm{Mel}(0,039 \mathrm{mg}$ MDA/Kg). De acordo com os resultados apresentados, pode-se afirmar que as especiarias mostraram-se mais eficazes em relação à proteção contra a oxidação lipídica, com teores de TBARS significativamente inferiores aos demais tratamentos. Comparando-se apenas o comportamento das amostras tratadas com as especiarias, 
destaca-se o tratamento contendo $10 \%$ de mel, onde os valores de TBARS mostraram-se $50 \%$ inferior ao tratamento contendo apenas orégano+sálvia.

Em relação aos homogenatos de sobrecoxa (cruas e cozidas) apresentados nas tabelas 9a e 9b, observamos que no tempo de 96 horas o grupo controle apresentou os maiores teores de TBARS $(0,033 \mathrm{mg} \mathrm{MDA} / \mathrm{Kg})$, seguido do tratamento com BHT $(0,025 \mathrm{mg} \mathrm{MDA} / \mathrm{Kg})$, enquanto os tratamentos orégano+sálvia, orégano+sálvia+5\%Mel e orégano+sálvia $+10 \% \mathrm{Mel}$ apresentaram valores estatisticamente semelhantes $(\mathrm{p}=$ 0,113) com 0,016, 0,017 e 0,017 mg MDA/Kg, respectivamente.

Nos homogenatos de sobrecoxa cozida, observou-se um aumento de TBARS em todas as amostras analisadas, semelhante ao ocorrido nas amostras de peito. No tempo de 96 horas a amostra controle de sobrecoxa apresentou o maior teor $(1,529 \mathrm{mg}$ $\mathrm{MDA} / \mathrm{Kg})$, seguido dos tratamentos com BHT (0,363 mg MDA/Kg). Diferente do observado nas amostras de peito, as amostras de sobrecoxa tratadas com especiarias orégano+sálvia, orégano+sálvia+5\% Mel e orégano+sálvia+10\%Mel apresentaram valores estatisticamente semelhantes $(p=0,979)$.

Assim, podemos concluir que as amostras de peito e sobrecoxa de frango tratadas com especiarias e mel foram mais efetivas no controle da oxidação lipídica. Isto pode ser explicado porque as especiarias utilizadas' neste estudo possuem atividade antioxidante, como descrito anteriormente no Capítulo II.

Resultados semelhantes foram descritos por Ho et al. (1995), que estudaram a vida-de-prateleira de embutidos frescos de carne suína contendo diferentes tipos de antioxidantes. A vida-de-prateleira foi monitorada pela análise sensorial, cor e TBARS durante 16 semanas, em estocagem sob congelamento. Em relação as propriedades antioxidantes, os autores observaram que o extrato contendo alecrim foi tão eficaz quanto BHT e Propil/galato/ácido cítrico.

A utilização de antioxidantes naturais para o controle da oxidação lipídica em produtos cárneos tem como vantagem a não limitação de seu uso pela legislação, além de outros fatores positivos como baixo custo, estabilidade, aceitação do consumidor e aumento da vida de prateleira dos produtos (Ahn et al., 1993, Lopez-Bote er al., 1998, Antony et al., 2000).

Nas figuras 1 e 2 estão demonstrados o percentual da inibição da oxidação lipídica nos homogenatos de peito e sobrecoxa. 


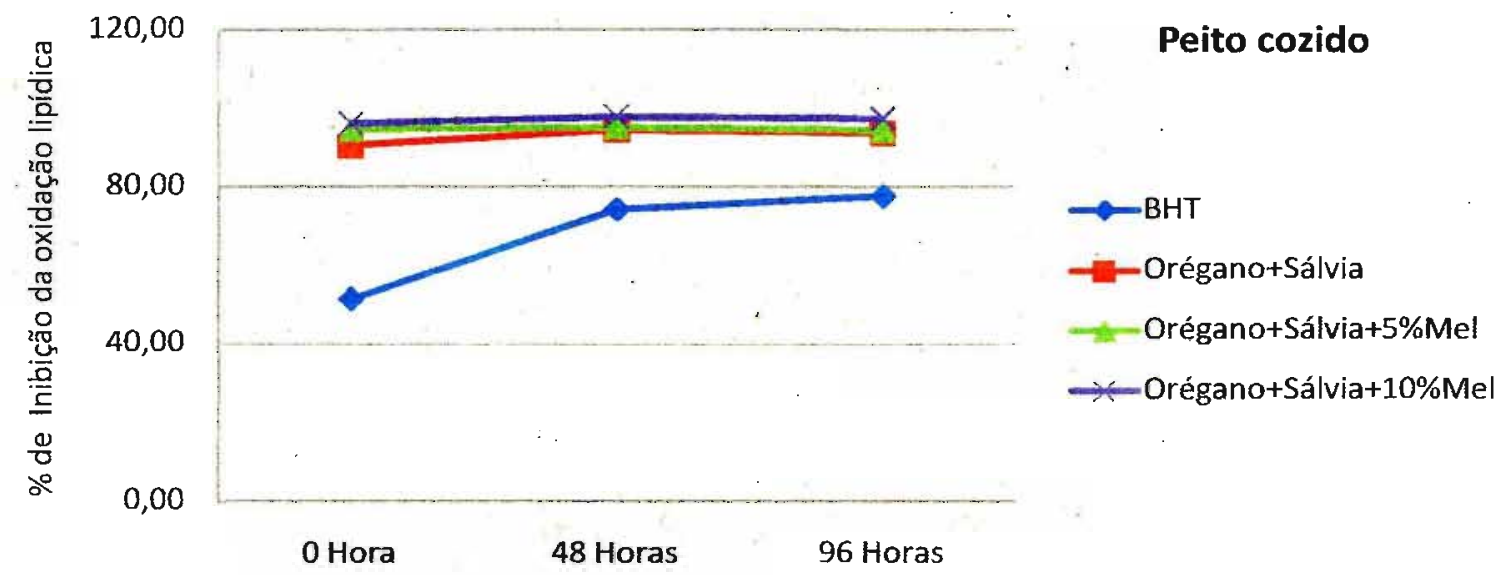

Figura 1 - Porcentagem de inibição da oxidação lipídica em relação ao controle nos homogenatos de peito cozido.

$\mathrm{Na}$ Figura 1, ao avaliarmos os resultados da inibição da oxidação lipídica durante o tempo de refrigeração, observamos que em relação ao controle, os tratamentos realizados apresentaram influência positiva. $O$ tratamento com BHT inibiu a oxidação em $51,4 \%$ no tempo 0 , após 48 horas em 74,3\% e atingiu o ápice de inibição no tempo de 96 horas, com 77,7\%. Dentre os tratamentos avaliados, o contendo orégano+sálvia $+10 \% \mathrm{Mel}$ foi o mais efetivo contra a oxidação em relação aos demaís. Pórém, devemos ressaltar que todos os tratamentos com especiarias chegaram a inibir a oxidação lipídica em mais de $90 \%$. 


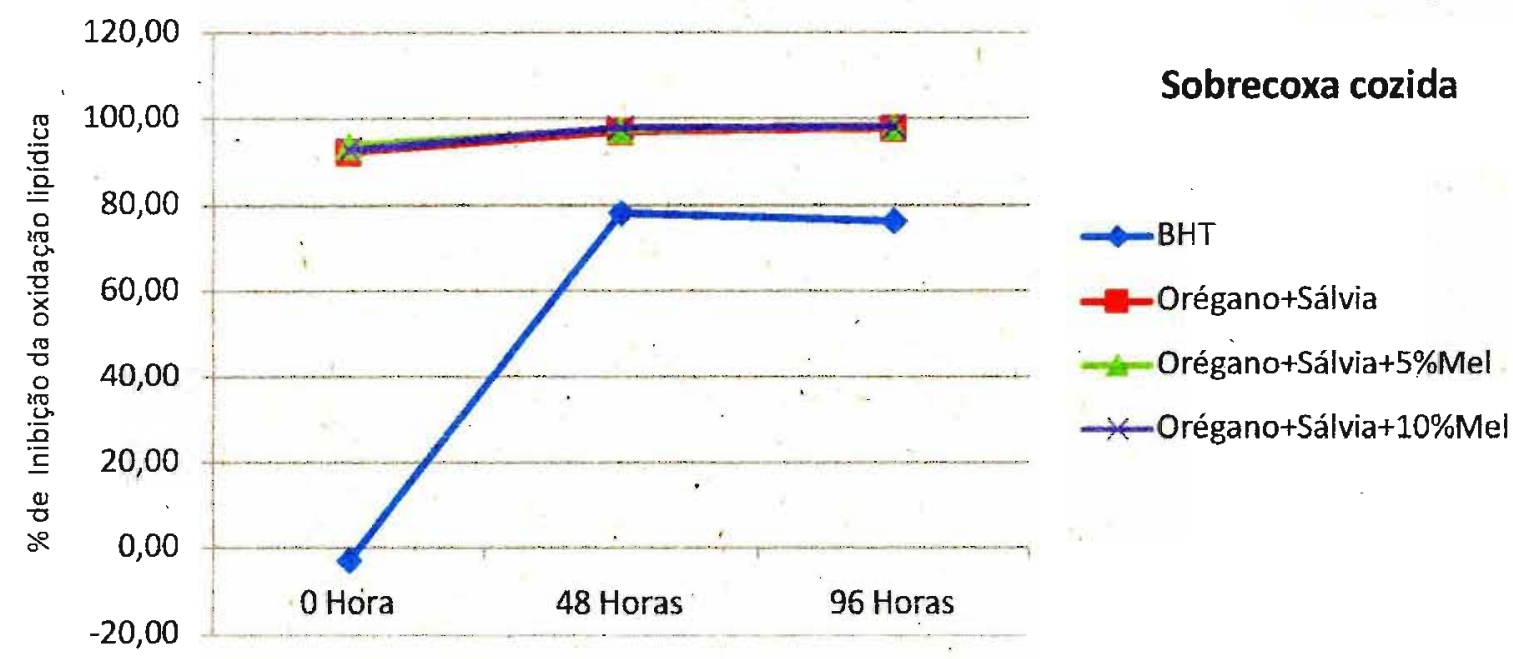

Figura 2 - Porcentagem de inibição da oxidação lipídica em relação ao controle no homogenato de sobrecoxa cozida.

Na figura 2 estão apresentados os resultados da inibição da oxidação lipídica nos homogenatos de sobrecoxa cozidas. Em relação ao BHT, os dados mostram que no tempo 0 a oxidação não foi inibida em relação ao controle. Entretando, nos outros tempos ocorreu um efeito protetor de 78,1 após 48 horas e 76,3\% após 96 horas. Nos tratamentos com especiarias, novamente o tratamento com orégano + sálvia $+10 \% \mathrm{Mel}$ foi o mais eficaz, com efeito protetor de $\mathbf{9 8 \%}$. Também observou-se uma proteção superior a $90 \%$ nos tratamentos contendo especiarias e $5 \%$ de mel.

Os resultados observados nos homogenatos indicam que a utilização de antioxidantes naturais mostrou-se mais eficaz do que o BHT. Resultados semelhantes foram descritos por Estévez et al., (2007). Os autores compararam a inibição da oxidação lipídica em patê de figado suíno, testando BHT e óleos essenciais de sálvia e de alecrim como ágentes antioxidantes. Os resultados médios de inibição no tempo de 90 dias de estocagem foram de 27,9\% no tratamento com BHT, 48,2 \% para a sálvia e $52,5 \%$ para o alecrim. Trabalhos realizados por Ahn et al., (2002); McCarthy et al., (2001); Yu et al., (2002) também relatam proteção oxidativa superior das especiarias em relação ao BHT. Tsimidou et al, (1995) constataram que $1 \%$ de orégano foi equivalente a 200 ppm de BHA no controle da oxidação lipídica de óleo de peixe. 


\section{Conclusão}

As especiarias e o mel apresentaram efeito antioxidante in vitro, quando avaliados em sistemas modelo de homogenatos de carne branca e escura de frango.

O sistema homogenato foi eficaz para estimar o acompanhamento da oxidação de lipídica ao longo da vida de prateleira dos produtos estudados.

\section{Referências bibliográficas*}

* De acordo com a nọma NBR 6023/2000, preconizada pela ASSOCIAÇÃO BRASILEIRA DE NORMAS TÉCNICAS (ABNT). As abreviaturas dos títulos dos periódicos seguem o CHEMICAL ABSTRACTS SERVICE SOURCE INDEX (CASSI), 2001.

[AOAC] - ASSOCIATION OF OFFICIAL ANALYTICAL CHEMISTS. Official Methods of Analysis. 16. ed. Arlington, 1995.

Ahmad, J.I. Free radicals and health: Is vitamin E the answer? Food Sci. Technol, v. 10, p. $147-152,1996$.

Ahn, D.U.; Wolfe, F.H.; Sim, J.S. Prevention of lipid oxidation in pre-cooked turkey meat patties with hot packaging and antioxidant combinations. Journal of Food Science, v. 58, p. 283-287, 1993.

Ahn, J.; Grün, I.U.; Fernando, L.N. Antioxidant properties of natural plant extracts containing polyphenolic compounds in cooked ground beef. Joumal of Food Science, v. 67, p. 1364-1369, 2002.

Antony, S.; Rieck, J.R.; Dawson, P.L. Effect of dry honey on oxidation in turkey breast. Poultry Science, v. 79, p. 1846-1850, 2000.

Asghar, A.; Torres, E. Gray, J.I.; Pearson, A.M. Effect of Salt on Myoglobin Derivatives in the Sarcoplasmic Extract from Pre- and Post-Rigor Beef in the Presence of Absence of Mitochondria and Microsomes. Meat Sci. 27:197, 1990.

Bailey, A.E. Bailey's Industrial Oil and Fat Products, 5 ed., John Wiley, New York, 1996, vol. 3. apud (Ramalho \& Jorge, 2006)

Baron, D.P.; Andersen, H.J. Myoglobin-induced lipid oxidation. A review. J. Agric. Food chem., v.50, p. 3887-3897, 2002. 
Bou, R.; Guardiola, F.; Codony, R.; Faustman, C.; Elias, R.J.; Decker, E. Effect of heating oxymyoglobin and metmyoglobin on the oxidation of muscle mirosomes. $J$. Agric. Food Chem, v. 56, p. 9612-9620, 2008.

Broumand, H.C., Ball, O., Stier, E.F. Factors Affecting the quality of prepackaged meat- Determining the proportions of meat. Food Technology, v. 12, p. 65-77, 1958

Castellini, C., Mugnai, C., Dal Bosco, A. Effect of organic production on broiler carcass and meat quality. Meat Science., 60: 219-225, 2002.

Cotta, J.T.B.; Campos, E.J. Refrigeração de carcaças de frangos. Efeitos sobre as qualidades gerais e suculência da carne. Arquivos Brasileiros de Medicina Veterinária e Zootecnia, v.33, n.3, p.471-475, 1981.

Estévez, M.; Ramírez, R.; Ventanas, S.; Cava, R. Sage and Rosemary essential oils versus BHT for the inhibition of lipid oxidative reactions in liver pâté. $L W T$, n. 40 , p. 58-65, 2007.

Fletcher D.L, 2002. Poultry meat quality. World's Poultry Science Journal 58: 131145.

Gray, J.I.; Gomaa, E.A.; Buckey, D.J. Oxidative quality and shelf life of meats. Meat Science, v. 43, p. S111-S123, 1996.

Hettiarachchy, N.S.; Glenn, K.C.; Granasambandam, R.; Johnson, M.G. Natural antioxidant extracts from fenugreek (Trigonella foenumgraecum) for ground beef patties.. Journal of Food Science, v. 61, p.5 16-519, 1996.

Ho, C.P.; Huffman, D.L..; Bradford, D.D.; Egbert, W.R.; Mikel, W.B., Jones, W.R. Storage stability of vacuum packaged frozen pork sausage containing soy protein concentrate, carrageenan or antioxidants. Journal of Food Science, v.60, n.2, p. 257-261, 1995.

Igene, J.O.; King, J.A.; Pearson, A.M.; Gray, J.I. Influence of heme pigments, nitrite, and non-heme iron on development of warmed-over flavor (WOF) in cooked meat. $J$. Agric. Food. Chem., v.27, p. 838-842, 1979.

Lee, S.; Decker, E.A.; Faustman, C.; Mancini, R.A. The effects of antioxidant combinations on color and lipid oxidation in n-3 oil fortified beef patties. Meat Science, v. 70, p. 683-689, 2005.

Livingston, D.J.; Brown, W.D. The chemistry of myoglobin and its reactions. Food Technology, v. 35, p. 244-252, 1981. 
López-Bote, C.J.; Gray, J.I.; Gomaa, A.; Flegal, C.J. Effect of dietary administration of oil extracts from rosemary and sage on lipid oxidation in broiler meat. British Poultry Science, v.39, p; 235-240, 1998.

Marques, M.F. Ingredientes e aditivos. In Olivo, R. $\mathbf{O}$ mundo do frango: cadeia produtiva da carne de frango. Criciúma, SC. Editado por Rubison Olivo, 2006. cap. 28 , p. 356-357.

McCarthy, T.L., Kerry, J.P., Kerry, J.F., Lynch, P.B., Buckley, D.J. Evaluation of the antioxidant potential of natural food/plant extracts as compared with synthetic antioxidants and vitamin E in raw and cooked pork patties. Meat Science, v. 57, p. $45-52,2001$.

Morrisey, P.A.; Sheehy, P.J.A.; Galvin, K.; Kerry, J.P.; Buckley, D.J. Lipid stability in meat and meat products. Meat Science, v.49, 73-86, n.4, 1998.

Namiki, A. Antioxidants/antimutagenic in food. Crit Rev Food Sci Nutr, v.29, p.273$300,1990$.

O'Neill, L. M., K. Galvin, P. A. Morrissey, and D. J. Buckley. Comparison of effects of dietary olive oil, tallow and vitamin $\mathrm{E}$ on the quality of broiler meat and meat products. Poult. Science.v, 39, p.365-371, 1998.

Olivo, R. Alterações oxidativas em produtos cámeos. In Olivo, R. O Mundo do Frango: cadeia produtiva da carne de frango. Criciúma, SC. Editado por Rubison Olivo, 2006. cap. 44, p. 534-541.

Olivo, R., Olivo, N. O mundo das carnes: ciência, tecnologia \& mercado. Ed. Gráfica Imprint, 3.ed- Criciúma, 214 p., 2006.

Price, J.f., Schwiegert, B.S. Ciencia de la carne y de los productos cárnicos. 2.ed. Zaragoza: Acribia, 1994, 581p.

Qiao, M., Flecher, D.L., Smith, D.P., Northcutt, J.K. The effect of broiler breast meat color on $\mathrm{pH}$, moisture, water-holding capacity and emulsification capacity. Poultry Science, v. 80, n.5, p.676-680, 2001.

Qiao, M., Flecher, D.L., Smith, D.P., Northcutt, J.K. The relationship between raw broiler breast meat color and composition. Poultry Science, v. 81, n.3, p.422-427, 2002.

Ramos, E.M. e Gomide, L.A.M. Avaliação da qualidade de carnes: fundamentos e Metodologias; Viçosa-MG-Brasil: Ed. UFV, 599p., 2007.

Rhee, K.S. Enzymic and nonenzymic catalysis of lipid oxidation in muscle foods. Food Technology, v. 500, p.127-132, 1988. 
Seideman, S.C.; Cross, H.R.; Smith, G.C.; Durland, P.R.; Factors associated with fresh meat color: A review. J. Food Qual., v. 6, p. 211-237, 1984.

Soares, S.E. Ácidos fenólicos como antioxidants. Revista de Nutrição da PUCCAMP, v. 15, n.1, p. 71-81, 2002.

Terra, N.M, Braun, M.A.R. Carne e seus derivados. Técnicas de controle de qualidade. São Paulo. Ed. Nobel, 1985. 121p.

Tichivangana, J. Z., Morrissey, P.A. Metmioglobin and inorganic metals as prooxidants in raw and cooked muscle systems. Meat Science, v. 15, p. 107-116, 1985.

Torres, E. A. F. S. \& Okani, E.T. Teste de TBA: Ranço em alimentos. Revista Nacional de Carne, 243: 68-76, 1997.

Tsimidou,M.; Papavergou, E.; Boskou, D. Evaluation of oregano antioxidant activity in mackerel oil. Food Res Intern. V. 28, p. 431-433, 1995.

Yu, L.; Scanlin, L.; Wilson, J., Schmidt, G. Rosemary extracts as inhibitors of lipid oxidation and color change in cooked turkey products during refrigerated storage. Journal of Food Science, v. 67, p. 582-585, 2002. 


\section{Capítulo V - Efeitos da combinação de espeçiarias e mel na estabilidade oxidativa em carne de frango assada e refrigerada.}

\section{Introdução}

Sabe-se que um dos maiores problemas na comercialização de carne de frangos tem sido a rancidez oxidativa, tendo início logo após a morte do animal e se intensificando durante a comercialização do produto, tornando o mesmo inaceitável do ponto de vista sensorial. A rancidez é uma das causas primárias da perda de qualidade em carnes e produtos cárneos cujos catalisadores são mioglobina, hemoglobina, citocromos, ferro não hemínico e outros metais de transição (Gray et al., 1996 e Nam et al., 1997).

A propensão da carne e de seus produtos serem submetidos à oxidação depende de vários fatores, incluindo a composição de ácidos graxos (grau de insaturação) e a presença de pró-oxidantes no músculo. Quanto maior o grau de insaturação dos ácidos graxos, maior a susceptibilidade à oxidação (Gray et al., 1996, Morrissey et al., 1998).

O termo "Aroma de Requentado" ou "Warmed-Over-Flavor" (WOF) foi introduzido por Tim e Watts (1958) para descrever o rápido desenvolvimento de flavor de ranço em carne cozida e posteriormente armazenada a frio. $\mathbf{O}$ cheiro de passado ou requentado surge rapidamente dentro do período de 48 horas, que o diferencia da lenta formação da rancidez, que é observada após o congelamento das carcaças ou outras matérias-primas derivadas das carnes. $\mathrm{O}$ WOF pode ser facilmente formado e constitui um problema de difícil solução para as indústrias.

Juntamente com a preferência do consumidor por produtos com apelo nutricional ou funcional, a indústria de alimentos tem optado pelo uso de antioxidantes naturais como especiarias e ervas e suas frações isoladas. Geralmente, estes antioxidantes são adicionados ao alimento com a função de prevenir a oxidação (Brenna e Pagliarini, 2001; Zheng e Wang, 2001; Racannicci et al., 2004), no entanto, podem funcionar como agentes redutores, como inibidores de radicais livres, desativadores de metais pró-oxidantes e como quelantes ou sequestrantes do oxigênio singlete (RiceEvans et al., 1995).

Uma das características dos antioxidantes é retardar o desenvolvimento de flavors desagradáveis, ocasionado pela oxidação de ácidos graxos insaturados, 
usualmente presentes como triacilgliceróis e/ou lipídios polares. Observa-se uma tendência geral, durante o processamento de alimentos, de substituir os antioxidantes sintéticos pelos inibidores da oxidação natural ou pelo uso preferencial de ingredientes que naturalmente possuem atividạde antioxidante (Mielche e Bertelsen, 1994, Tsaliki et al., 1999, López et al., 2007).

O orégano (Origanum vulgare L.) tem sido avaliado em alimentos e, em alguns estudos in vitro, tem apresentado atividade antioxidante. Em análise dos compostos fenólicos dos extratos aquoso e metanólico de orégano foram identificados os ácidos caféico, protocatequínico, cumarínico, rosmarínico e quercetina (Chun et al., 2004), sendo que todos apresentam atividade antioxidante.

A atividade antioxidante da sálvia (Salvia officinalis L.) inicialmente foi associada aos fenólicos diterpênicos (Zhang et al., 1994; Cuvelier et al., 1994). Posteriormente, Wang et al., (1998 e 1999) relataram que a sálvia possui dois compostos fenólicos glicosídicos com moderada atividade antioxidante. Lu e Foo (2001) encontraram flavonóides com atividade antioxidante variável em extratos de sálvia.

Bertoncelj (2007) relataram que os compostos do mel responsáveis pela atividade antioxidante são os flavonóides (crisina, pinocembrina, pinobanksina, quercitina, kaempferol, luteolina, galangina, apigenina, hesperetina, mirecetina, etc), ácidos fẹnólicos (caféico, cumárico, ferúlico, elágico, clorogênico, etc), ácido ascórbico, catalase, peroxidase, carotenóides e produtos da reação de Maillard.

O crescimento na produção de carne de aves é acompanhado por maior diversificação de produtos, com maior elaboração de itens de conveniência, praticidade e valor agregado, em detrimento da comercialização de carcaças inteiras e/ou cortes. Esta tendência ocorre em razão da mudança de hábitos dạ população, já que a praticidade, qualidade nutritiva e segurança alimentar, com preços acessíveis, são condições básicas para os negócios na área de alimentação. Sob este aspecto, a carne de frango tem vantagens, pois além de apresentar as referidas características, não sofre restrições religiosas ou culturais (Olivo, 2004; Arnaud et al., 2004).

Assim, a carne de frango representa uma importante fonte protéica de origem animal nos domicílios brasileiros (Levy-Costa et al., 2005). Devido à crescente preocupação do consumidor com a qualidade de vida e saúde, observa-se uma tendência 
do uso de substâncias antioxidantes encontradas na natureza em substituição às sintéticas (Hettiarachchy et al., 1996) e, desta forma, existe a necessidade de investimentos contínuos em estudos a respeito de ervas e especiarias como fontes de antioxidantes naturais em substituição aos convencionais, amplamente utilizados pela indústria de alimentos.

\section{Objetivo}

O objetivo deste trabalho foi avaliar o uso de mel e especiarias sálvia (Salvia officinalis) e orégano (Origanum vulgare L.) na proteção da oxidação lipídica em cortes de peito e sobrecoxa de frango assadas, por meio das análises dos produtos da oxidação lipídica, formados durante o armazenamento sob refrigeração, além da avaliação sensorial.

\section{Material e métodos}

\subsection{Amostras}

Os cortes de frango (sobrecoxa e peito) foram obtidos de um mesmo fornecedor, da Cooperativa de produção Agropecuária de Itatiba. Após o abate, os cortes foram acondicionados em recipiente térmico contendo gelo e imediatamente transportados sob refrigeração. Ao chegarem ao laboratório, foram armazenados em freezer $-18^{\circ} \mathrm{C}$ até o momento das análises.

As amostras de mel (florada predominante "laranjeira") foram obtidas diretamente da Associação Paulista de Apicultores (APACAME) e as especiarias desidratadas orégano (Origanum vulgare L.) e sálvia (Salvia officinalis) foram doadas pela Empresa Fuchs do Brasil. Todas as amostras foram armazenadas a temperatura ambiente $\left(24^{\circ} \mathrm{C}\right)$, conforme indicação dos fabricantes.

\subsection{Preparo das amostras}

$\mathrm{Na}$ planta piloto da Empresa (Global Food Sistemas Ingredientes e Tecnologia para Alimentos Ltda - São Paulo - SP) os cortes de sobrecoxa e peito foram descongelados, removidas a pele e a gordura aparente para o posterior tambleamento. 


\subsection{Processo de tambleamento}

O processo de marinação pode ser feito de forma estática ou dinâmica. A forma estática se realiza por imersão da carne em salmoura, em que os ingredientes devem penetrar por difusão, sem nenhuma aplicação de força e a maneira dinâmica é feita por massagem ou injeção (Judge et al, 1989). O tambleamento (massageamento) é o processo no qual a carne é colocada no interior de um tanque resfriado, de aço inoxidável, montado sobre uma base giratória, que serve para agitar o conteúdo enquanto faz o movimento de rotação, com velocidade ajustável (Pearson e Gillett, 1996).

Os cortes de frango (peito e sobrecoxa) foram identificados e pesados em balança semi-analítica com precisão de $\pm 0,01 \mathrm{~g}$ e após pesagem, foram adicionados ao tambler de aço inox, marca Vakona Qualitat e modelo 05483/8081 MG4-20, com controle de vácuo, tempo e rotação.

Juntamente com os cortes de frango, foram acrescentadas as salmouras compostas de água, sal e mel (cada tratamento foi tambleado individualmente, bem como cada tipo de corte). Para cada tratamento, foi adicionado $10 \%$ do peso das carnes em peso de salmoura e especiarias, conforme Tabela 1.

$\mathrm{O}$ equipamento de tambler foi colocado em refrigerador a $1{ }^{\circ} \mathrm{C}$, com a seguinte programação de: 30 minutos de tempo total, sendo os quais trabalhando 1 minuto e descansando 4 minutos.

Após o tambleamento, as amostras foram embaladas -em bandejas de poliestireno, recobertas com filme PVC e identificadas. A seguir, as amostras foram acondicionadas em recipiente térmico e gelo e transportadas para o Laboratório de Bromatologia do Departamento de Nutrição da FSP-USP.

No Laboratório de Bromatologia as amostras foram armazenadas em freezer à $18^{\circ} \mathrm{C}$ até o momento das análises. 


\subsection{Processamento térmico}

As amostras foram descongeladas sob refrigeração e embaladas em sacos para assar de filme de poliéster (Assa Pratsy(B)). Depois foram levadas ao Laboratório de Técnica Dietética da FSP-USP, onde foram assadas.

O preparo térmico dos cortes de peito e sobrecoxa foi realizado em forno convencional, sob temperatura de $200^{\circ} \mathrm{C}$ durante 1 hora. Um termômetro digital calibrado foi utilizado para medir a temperatura interna $\left(72^{\circ} \mathrm{C}\right)$ das amostras.

Após o cozimento as amostras foram desossadas. Posteriormente foram homogeneizados em processador de alimentos, durante 10 minutos e analisadas em triplicatas nos tempos 0 e após 48 e 96 horas de refrigeração.

Tabela 1 - Concentração dos ingredientes adicionados às amostras de peito e sobrecoxa de frango (Tratamentos).

\begin{tabular}{c|c|c|c|c|c|c}
\hline & \multicolumn{5}{c|}{ Ingredientes } \\
\cline { 2 - 6 } & BHT (ppm) & Sal (\%) & Orégano (\%) & Sálvia (\%) & Mel (\%) \\
\hline \multicolumn{5}{|c|}{ Peito e/ou Sobrecoxa } \\
\hline Controle & - & 2 & - & - & - \\
\hline BHT & 100 & 2 & - & - & - \\
\hline Orégano+Sálvia & - & 2 & 0,2 & 0,2 & - \\
\hline Orégano+Sálvia+5\%Mel & - & 2 & 0,2 & 0,2 & 5 \\
\hline Orégano+Sálvia+10\%Mel & - & 2 & 0,2 & 0,2 & 10 \\
\hline
\end{tabular}

\subsection{Planejamento experimental}

O experimento consistiu de 5 tratamentos (Tabela 1), sendo elaborados 3 lotes para cada tipo de carne. Assim, as amostras assadas selecionadas nesta pesquisa foram compostas por 180 porções: 90 de sobrecoxa e 90 de peito. A distribuição das porções segundo tratamento e tempo estão descritas na tabela 2. Todas as análises foram realizadas em triplicata. 
Tabela 2: Distribuição das porções, segundo tratamento e tipo de carne.

\begin{tabular}{ccc}
$\begin{array}{c}\text { Tratamento } \\
\text { Peito e/ou Sobrecoxa }\end{array}$ & Freqüência & Porcentagem \\
\hline Controle & 18 & $20 \%$ \\
BHT & 18 & $20 \%$ \\
Orégano+Sálvia & 18 & $20 \%$ \\
Orégano+Sálvia+5\%Mel & 18 & $20 \%$ \\
Orégano+Sálvia+10\%Mel & 18 & $20 \%$ \\
Total & 90 & $100 \%$ \\
\hline
\end{tabular}

\subsection{Métodos}

\subsubsection{Potencial Hidrogeniônico (pH)}

$\mathrm{O} \mathrm{pH}$ foi determinado utilizando-se um potenciômetro portátil da marca Ingold, modelo $\mathrm{pH}$ 206. As amostras foram diluídas na proporção de 1:1 e homogeneizadas com bastão de vidro, segundo a técnica descrita por Terra e Braun (1985).

\subsubsection{Atividade de Água (Aa)}

Foi medida por meio do medidor automático da marca Aqualab, modelo CX-2. A atividade de água é expressa pela razão da pressão da água do alimento sobre pressão de vapor da água pura.

\subsubsection{Composição}

- Umidade

A quantificação do teor de umidade foi realizada por processo gravimétrico, o qual se baseia na determinação de perda de peso da amostra submetida a aquecimento em estufa a $105^{\circ} \mathrm{C}$, resultando no resíduo seco ou dessecado. A pesagem foi realizada somente após o resfriamento em dessecador, sendo a operação repetida até peso constante (AOAC, 1995). 


\section{- Lipídios totais}

A extração dos lipídios totais foi realizada de acordo com Folch et al., 1957. Foram pesados $5 \mathrm{~g}$ da carne de frango previamente triturada em processador de alimentos. A carne foi colocada em um béquer e adicionado com $100 \mathrm{~mL}$ de uma mistura de clorofórmio-metanol na proporção 2:1. A seguir foi homogeneizada no ultraturrax durante 2 minutos.

A suspensão foi filtrada em papel de filtro Whatmann $\mathrm{n}^{\circ} 1$ para funil de separação de $250 \mathrm{~mL}$. Utilizou-se mais $10 \mathrm{~mL}$ de clorofórmio-metanol (2:1) para lavagem do béquer e do papel de filtro. O produto resultante da filtração foi colocado em funil de separação, com posterior adição de $40 \mathrm{~mL}$ de solução de $\mathrm{KCl}$ a $0,74 \%$. O funil foi então tampado, agitado vigorosamente e deixado em repouso cerca de 1 minuto para ocorrer à separação entre as fases (aquosa e orgânica).

Com o auxílio de uma pipeta de vidro, a fase aquosa (superior) foi retirada e foram adicionados $25 \mathrm{~mL}$ da solução de $\mathrm{KCl}$ a $0,74 \%$ ao funil. Após nova agitação e repouso, a fase orgânica (inferior) foi filtrada em papel de filtro Whatmann $\mathrm{n}^{\circ} 1$ contendo sulfato de sódio anidro e recolhida em erlenmeyer.

Por fim, essa fase orgânica foi transferida para um balão de $200 \mathrm{~mL}$ e o volume foi completado com a mistura clorofórmio-metanol (2:1).

A quantificação do teor de lipídios totais foi realizada por processo gravimétrico. Foram pipetados $5 \mathrm{~mL}$ do extrato lipídico em erlenmeyers previamente secos e tarados. Posteriormente, os erlenmeyers foram levados em estufa com circulação forçada de ar a $105^{\circ} \mathrm{C}$ por 12 horas. A pesagem foi realizada somente após o resfriamento em dessecador, sendo a operação repetida até peso constante (AOAC, 1995). 


\subsection{4 Ácidos Graxos}

Os ácidos graxos foram determinados por meio da saponificação das alíquotas dos extratos lipídicos de acordo com o método de Metcalfe et al., (1966).

Foi tomada uma alíquota de $100 \mathrm{mg}$ de lipídios. Em seguida, adicionou-se $4 \mathrm{~mL}$ de $\mathrm{NaOH}$ metanólico $(0,5 \mathrm{~N})$ amostra, com posterior homogeneização e aquecimento em banho-maria a $100^{\circ} \mathrm{C}$, durante 2 minutos. Após resfriamento imediato, adicionou-se $3 \mathrm{~mL}$ de trifluoreto de boro-metanol $\left(\mathrm{BF}_{3}\right)$, agitou-se levemente e novamente as amostras foram levadas ao banho-maria à $100^{\circ} \mathrm{C}$, durante 2 minutos.

Após resfriadas a temperatura ambiente, adicionou-se $3 \mathrm{~mL}$ de solução saturada de cloreto de sódio $(\mathrm{NaCl})$ e duas alíquotas de $3 \mathrm{~mL}$ de hexano (grau cromatográfico), com posterior agitação. Após separação das fases, os sobrenadantes foram recolhidos e evaporados em atmosfera de nitrogênio até um volume aproximado de $1 \mathrm{~mL}$ : Os extratos foram armazenados $\mathrm{a}-18^{\circ} \mathrm{C}$ até $\mathrm{o}$ momento das análises.

O perfil de ácidos graxos foi determinado em cromatógrafo a gás SHIMADZU, CG-2010, equipado com uma coluna capilar SP 2560 da SUPELCO (100 m x 0,25 $\mu \mathrm{me}$ filme $0,2 \mu \mathrm{m}$ ). O hidrogênio foi utilizado como gás de arraste com fluxo de $1,5 \mathrm{~mL} / \mathrm{min}$. As temperaturas do injetor e do detector foram de $250^{\circ} \mathrm{C}$ e $260^{\circ} \mathrm{C}$, respectivamente. A programação de temperatura da coluna foi de $140^{\circ} \mathrm{C}$ inicial com um acréscimo de $4^{\circ} \mathrm{C} / \mathrm{min}$, até atingir $240^{\circ} \mathrm{C}$, permanecendo nessa temperatura por 15 minutos. A razão de divisão "split" utilizada no injetor foi de 1:30.

O padrão utilizado foi uma mistura de 37 ésteres metil de ácidos graxos (FAME 37, código 47885, Sigma Chemical Co) (Figura 1). O volume de injeção foi de $1 \mu \mathrm{L}$, por injetor automático AOC 20i. Os ácidos graxos foram identificados por meio da comparação dos tempos de retenção do padrão com as amostras e quantificados por padronização externa. Os resultados foram expressos como \% do total de ácidos graxos presentes na amostra. 


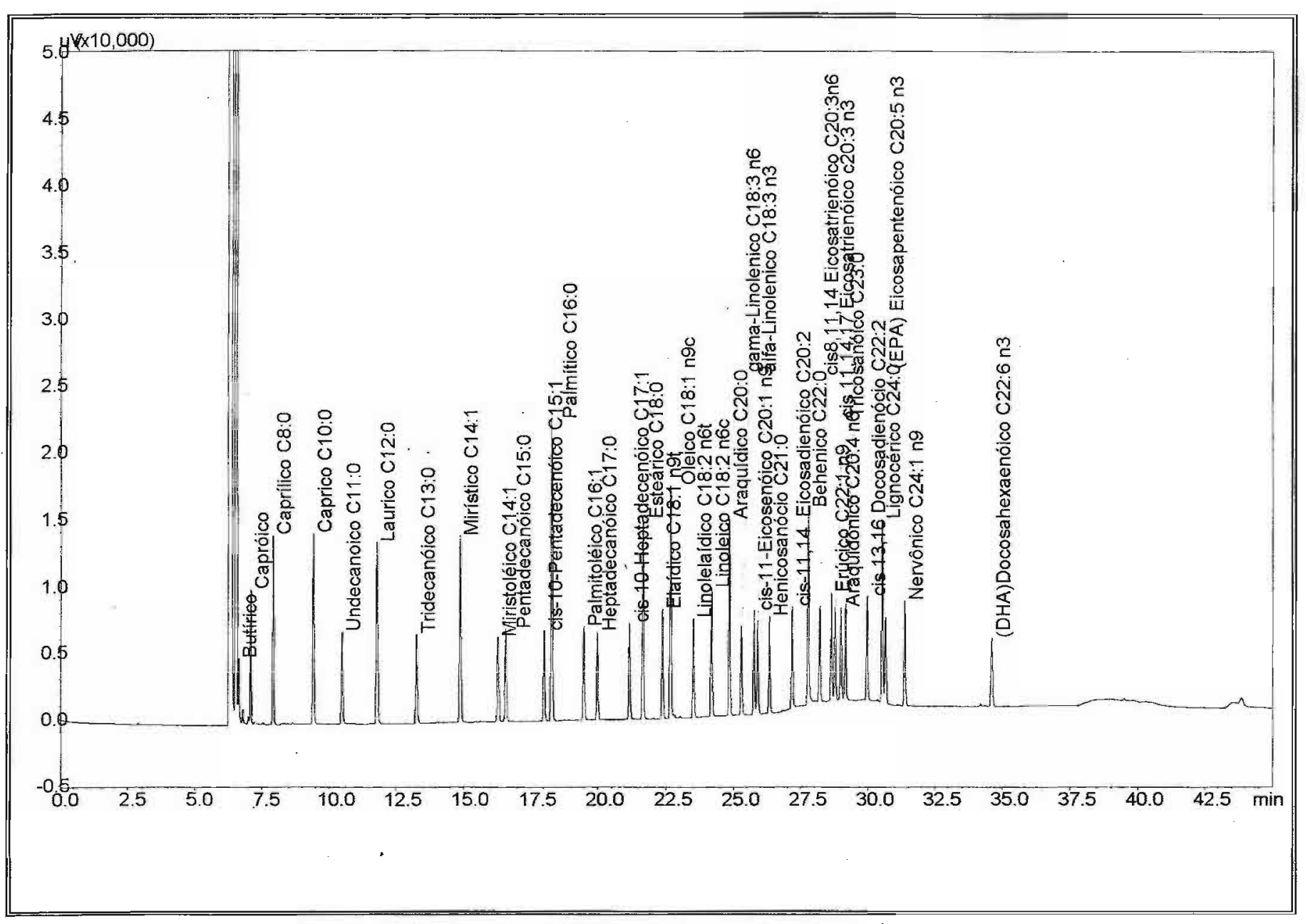

Figura 1 - Cromatograma dos 37 padrões de ácidos graxos 


\subsubsection{Colesterol e óxidos de colesterol}

Para a determinação do colesterol e seus óxidos utilizou-se o método descrito por Vicente e Torres (2007).

A partir de $50 \mathrm{ml}$ do extrato lipídico $( \pm 1,0 \mathrm{~g}$ de amostra) foram adicionados 20 $\mathrm{mL}$ da solução de clorofórmio-metanol (2:1), seguida da homogeneização em velocidade média por cerca de 1 minuto. $O$ homogeneizado foi transferido para um funil de separação e lavado duas vezes com $50 \mathrm{~mL}$ de água deionizada e agitado novamente por 1 minuto. A água da lavagem foi combinada e re-extraída por duas vezes com clorofórmio-metanol (2:1). A camada de clorofórmio foi removida e desidratada por filtração em sulfato de sódio anidro. Depois da filtração, o solvente foi seco em rotaevaporador e evaporado sob nitrogênio. $O$ resíduo foi dissolvido em $3 \mathrm{~mL}$ de fase móvel.

Os extratos obtidos foram injetados em HPLC da marca TSP (THERMO SEPARATION PRODUCTS) composto de: 1) Bomba (SpectraSystem e Spectra Series Gradient); 2) Degazeificador (SCM Vacuum Membrane); 3) Detector UV/VIS (SpectraSystem UV/VIS); 4) Injetor Automático (SpectraSystem e Spectra Series Autosamplers); Interface SN4000 (SpectraSystem).

As condições cromatográficas utilizadas foram de acordo com Vicente e Torres (2007): coluna de $\mathrm{CN}(25 \mathrm{~cm} \times 0.4 \mathrm{~cm})$. A fase móvel foi de $97: 3$ de hexanoisopropanol, com fluxo de $1 \mathrm{~mL} /$ minuto. Foram injetados $20 \mu \mathrm{L}$ da amostra. O colesterol e os óxidos $25-\mathrm{OH}, 7 \alpha-\mathrm{OH}, 7 \beta-\mathrm{OH}$ foram monitorados a $206 \mathrm{~nm}$, enquanto que o óxido 7 -cetocolesterol foi monitorado a $233 \mathrm{~nm}$. 


\subsubsection{Validação do método de quantificação de colesterol e óxidos de colesterol}

Para a validação do método foram determinados os seguintes parâmetros de linearidade, recuperação, limite de deteç̧ão, limite de quantificação e precisão (repetitividade) de acordo com a metodologia do Instituto Nacional de Metrologia, Normalização e Qualidade Industrial (Inmetro, 2007).

Os resultados dos parâmetros avaliados estão apresentados no Quadro 1.

Quadro 1 - Correlação linear e recuperação do colesterol e dos óxidos de colesterol.

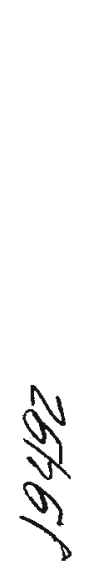

\begin{tabular}{|l|c|c|c|c|c|}
\hline \multicolumn{1}{|c|}{ Parâmetros } & Colesterol & $\mathbf{2 5 - O H}$ & $\mathbf{7 - C e t o}$ & $\mathbf{7 \alpha - O H}$ & $\mathbf{7 \beta - O H}$ \\
\hline Concentração $(\mu \mathrm{g} / \mathbf{2 0} \mu \mathrm{L})$ & 2,5 a 40,00 & 0,6 a 4,8 & 2,1 a 16,0 & 0,5 a 4 & 0,5 a 4 \\
\hline Coeficiente de Correlação & 0,9894 & 0,9989 & 0,9999 & 0,9994 & 0,9998 \\
\hline Limite de deteç̧ão (g) & 98,21 & 99,31 & 97,77 & 94,09 & 98,15 \\
\hline Limite de quantificação (g) & $1,59 \mathrm{E}-07$ & $2,18 \mathrm{E}-07$ & $7,09 \mathrm{E}-08$ & $\mathbf{8 , 6 9 \mathrm { E } - 0 8}$ & $1,07 \mathrm{E}-07$ \\
\hline Precisão (ug/20uL) CV (\%) & $0,29 \mathrm{E}-07$ & $7,25 \mathrm{E}-07$ & $2,36 \mathrm{E}-07$ & $2,90 \mathrm{E}-07$ & $3,56 \mathrm{E}-07$ \\
\hline
\end{tabular}

$\mathrm{CV}=$ Coeficiente de variação

O coeficiente de correlação da curva de regressão linear foi utilizado como parâmetro para verificar a linearidade.

Os limites de deteç̧ão e de quantificação estão relacionados à metodologia empregada, e também às condições do equipamento.

A precisão foi avaliada pela repetitividade, através do cálculo do desvio padrão relativo (coeficiente de variação, CV). Todos os coeficientes de variação obtidos encontram-se dentro do limite aceitável para as análises de micronutrientes (Leite, 1998).

O cromatograma com os padrões de colesterol e os óxidos de colesterol está apresentado na Figura 2. 


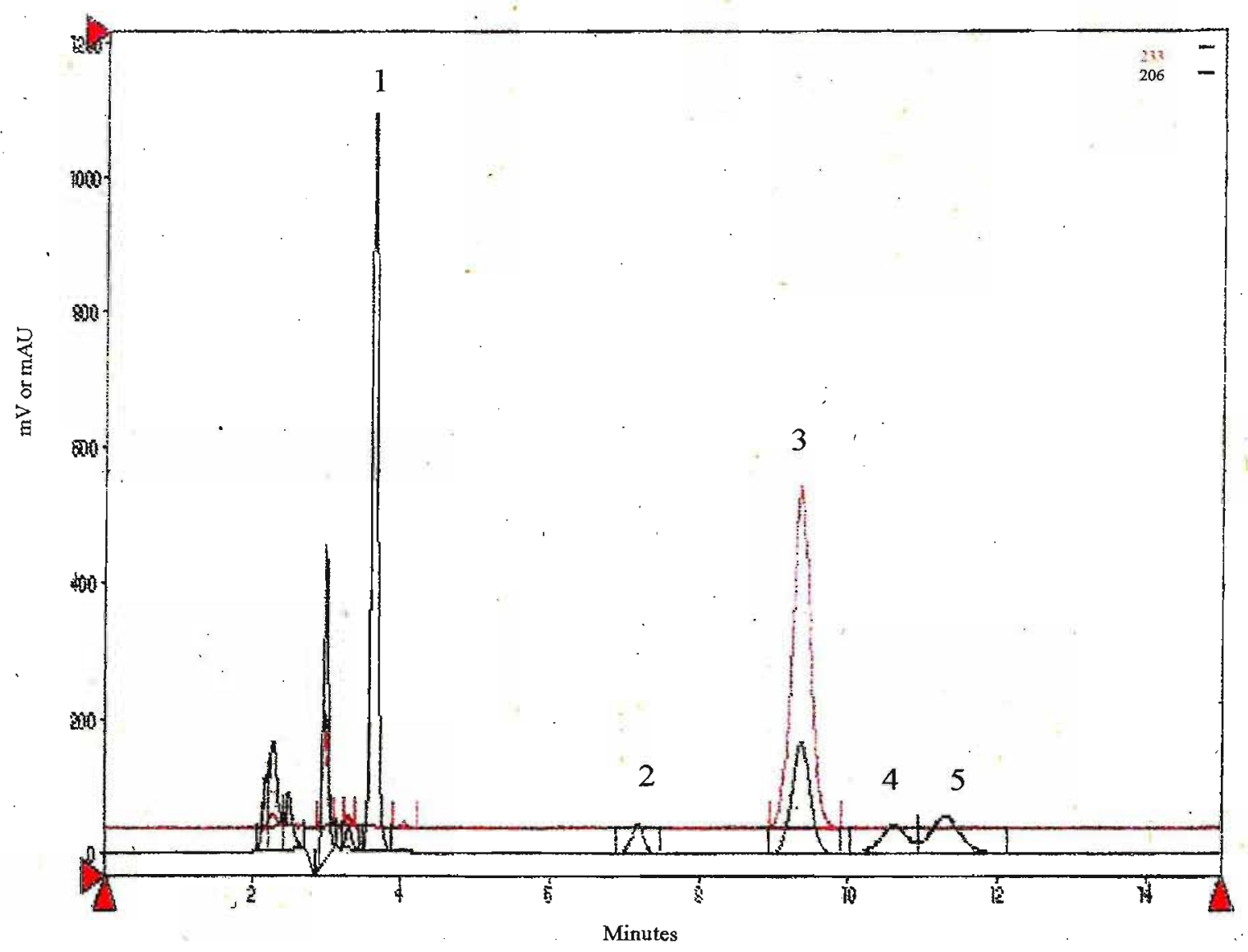

Figura 2 - Cromatograma dos padrões de colesterol e óxidos de colesterol. As

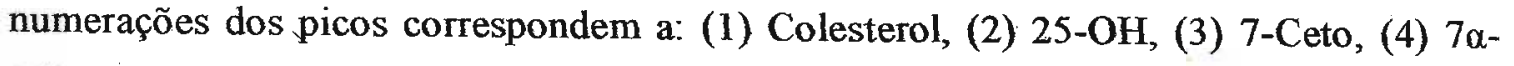
OH e (5) $7 \beta-O H$. 


\subsubsection{Hexanal}

A obtenção do extrato e a captura foram realizadas de acordo com a metodologia descrita por Brunton et al., (2000).

Pesou-se $5 \mathrm{~g}$ da carne e homogeneizou com $25 \mathrm{~mL}$ de água destilada. Uma alíquota de $5 \mathrm{~mL}$ foi transferida para um vial de $20 \mathrm{~mL}$ e este foi selado com tampa de polytetraflouroethylene (PTFE) e septo de silicone.

A captura do hexanal foi realizada por headspace estático em banho-maria a $40^{\circ} \mathrm{C}$ por 25 minutos, sendo 5 minutos para equilibrar a temperatura e 20 minutos o tempo de adsorção. Utilizou-se a fibra PDMS/DVB $65 \mu \mathrm{m}$ (Supelco).

A desorção do hexanal contido na fibra foi realizada no injetor de cromatógrafo gasoso de massas THERMO modelo FOCUS CG, equipado com detector de ionização de chama, por um período de 5 minutos com temperatura no injetor de $260^{\circ} \mathrm{C}$.

$\mathrm{O}$ analito foi separado utilizando uma coluna capilar $5 \%$ difenil $(30 \mathrm{~m} \times 0.32$ $\mu \mathrm{m}$ de diâmetro e $1 \mu \mathrm{m}$ de filme) da Thermo. O gás de arraste utilizado foi o hélio ( 2 $\mathrm{mL} / \mathrm{min}$ ) e a temperatura inicial da coluna foi de $60^{\circ} \mathrm{C}$, programada a $3{ }^{\circ} \mathrm{C} / \mathrm{min}$ até 160 ${ }^{\circ} \mathrm{C}$. O hexanal foi identificado e quantificado utilizando padrão Hexanal 98 \% (SigmaAldrich). 


\subsubsection{Validação do método de quantificação de hexanal}

Para a validação do método foram determinados os parâmetros de linearidade, recuperação, limite de deteç̧ão, limite de quantifícação e precisão (Inmetro, 2007).

Os resultados dos parâmetros avaliados estão aprésentados no Quadro 2.

Quadro 2 - Correlação linear e recuperação do hexanal.

\begin{tabular}{|l|c|}
\hline \multicolumn{1}{|c|}{ Parâmetros } & Hexanal \\
\hline Concentração (ppm) & 3,907 a 375 \\
\hline Coeficiente de Correlação & 0,9901 \\
\hline Recuperação $(\%)$ & 97,3 \\
\hline Limite de detecção $(\boldsymbol{\mu g} / \mathbf{g})$ & 0,268 \\
\hline Limite de quantificaçăo $(\boldsymbol{\mu g} / \mathbf{g})$ & 0,8945 \\
\hline Precisão $(\mathbf{u g} / \mathbf{g}) \mathbf{C V}(\%)$ & 2,20 \\
\hline
\end{tabular}

$\mathrm{CV}=$ Coeficiente de variação

O cromatograma do padrão de hexanal está representado na Figura 3a.

O espectro em modo de varteadura de 40 a $150 \mathrm{~m} / \mathrm{z}$ do tempo de retenção do padrão está demonstrado na Figura $3 b$.

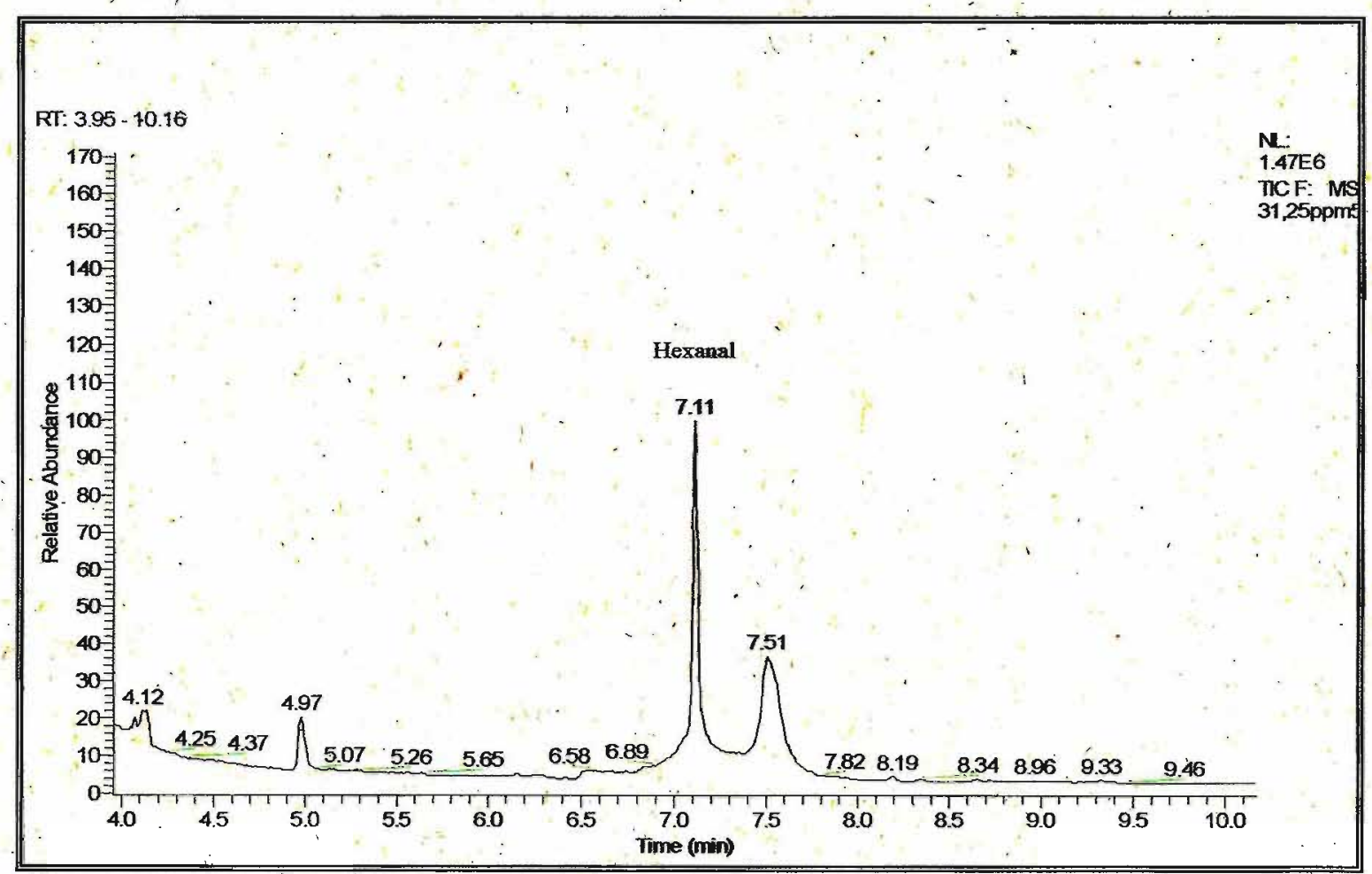

Figura 3a-Cromatograma do padrão de hexanal. 


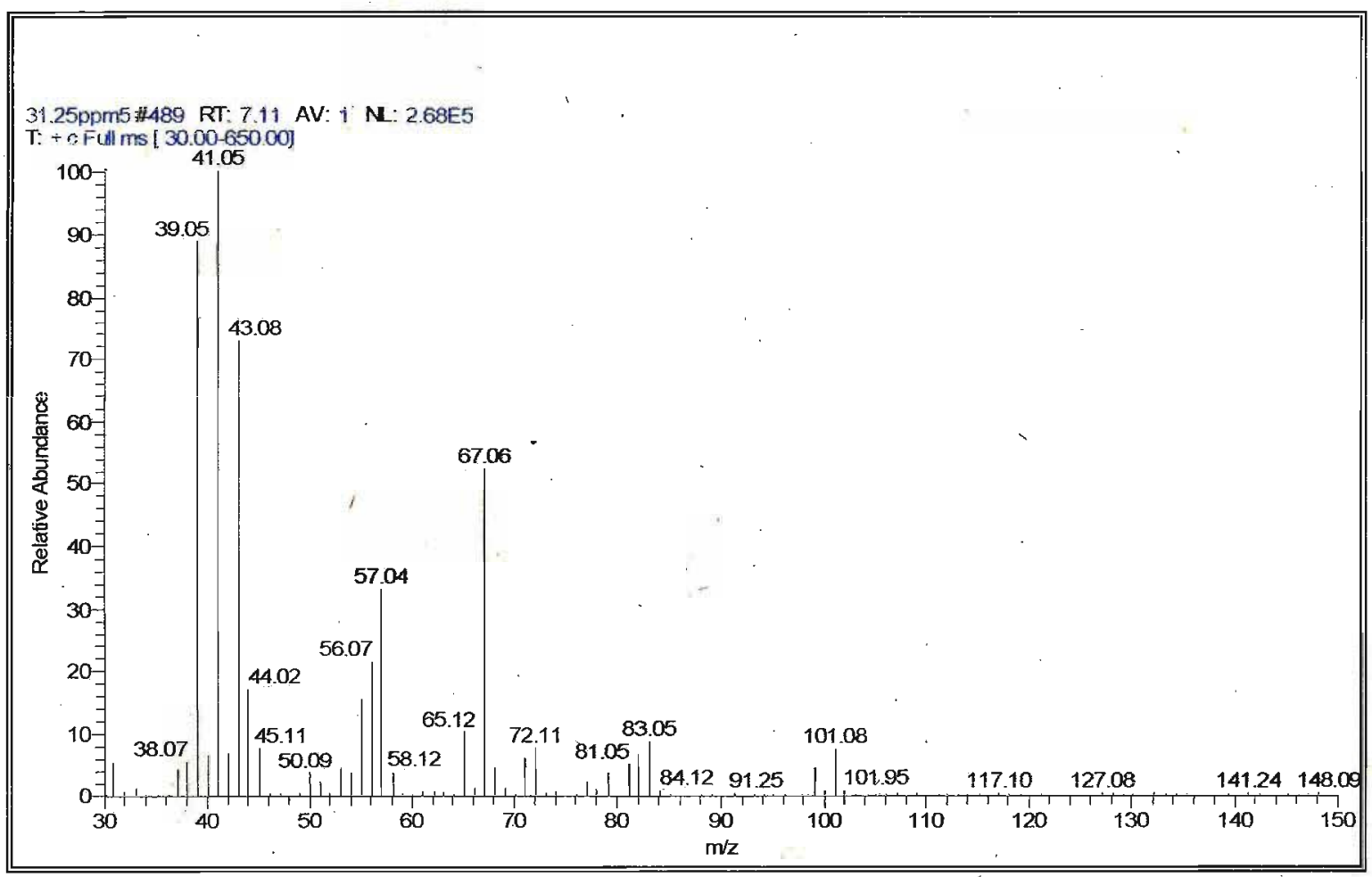

Figura $3 \mathrm{~b}$ - Espectro em modo de varreadura de 40 a $150 \mathrm{~m} / \mathrm{z}$ do temṕo de retenção do padrão 


\subsubsection{Dienos Conjugados}

A análise dos dienos conjugados foi realizada de acordo com o Método Oficial da AOCS (2003). Uma alíquota do extrato lipídico ( $\pm 70 \mathrm{mg}$ de lipídios) foi evaporada sob nitrogênio e ressuspendida com $75 \mathrm{~mL}$ de isooctano. A amostra foi agitada a fim de dissolvê-la por completo.

Posteriormente, a amostra foi mantida a temperatura ambiente por 15 minutos, a fim de atingir uma temperatura estável. As medidas da absorbância foram efetuadas no comprimento de onda de $233 \mathrm{~nm}$, utilizando-se espectofotômetro ultravioleta visível SHIMADZU (UV/VIS). Para a leitura foi utilizada uma cubeta de quartzo de $1 \mathrm{~cm}$ e isoctano como branco. A medida dos dienos conjugados foi determinada pela fórmula abaixo, sendo que a concentração da amostra expressa como a quantidade de óleo, dissolvida por $100 \mathrm{~mL}$ de isoctano:

Dienos conjugados: $\%=0.84\left[\begin{array}{l}\underline{\mathrm{As}}-\mathrm{K}_{0} \\ \mathrm{bc}-\end{array}\right]$

Onde: $\mathrm{K}_{0}=$ Absortividade para ácidos (0.03)

As = Absorbância observada na amostra

$\mathrm{b}=1$ (largura da cubeta em $\mathrm{cm}$ )

c $=$ Concentração da amostra, g/L de lipídios

\subsubsection{Avaliação da Oxidação Lipídica pelo teste do ácido 2-Tiobarbitúrico} (TBARS)

O método utilizado para a quantificação das substâncias reativas ao ácido tiobarbitúrico foi o de extração descrito por Torres e Okani (1997).

O padrão utilizado foi o $1,1,3,3$ tetraetoxi propano. As leituras das absorbâncias foram feitas em espectrofotômetro UV/VIS SHIMADZU. Os valores encontrados foram relatados como mg de substâncias que reagem com TBARS por $1000 \mathrm{~g}$ de amostra. 


\subsubsection{Análises Microbiológicas ,}

As análises microbiológicas foram realizadas de acordo com a metodologia analítica descrita no "Compedium of Methods for the Microbiological Examination of Foods" e "Standard Methods for the Examination of Dairy Products" (APHA) segundo os padrões microbiológicos para alimentos definidos pela resolução RDC N.12 de 02/01/2001 (Brasil, 2001).

As amostras de frango assadas foram transportadas em sacos plásticos específicos para alimentos e mantidos sob refrigeração, desde o momento da recepção no laboratório até o momento das análises. Foram determinados:

- Coliformes totais e fecais: realizado pela técnica de tubos múltiplos para a determinação do Número Mais Provável (NMP) de coliformes - segundo recomendações do FDA (Garthright, 2001);

- Contagem total de microorganismos aeróbios mesófilos foi realizada pela contagem padrão em placas (CPP);

- Staphylococcus aureus: foi feita por contagem direta e estimativa do número de $\mathrm{UFC}^{4.1} / \mathrm{g}$ de alimento;

- Bacillus cereus: realizada por meio da contagem direta em placa, estimativa do número de UFC/g de alimento e avaliação dá presença ou ausência de Salmonella spp.

\subsubsection{Análise Sensorial}

A análise sensorial foi realizada no Laboratório de Técnica Dietética da Faculdade de Saúde Pública (FSP-USP).

- Este trabalho foi avaliado pelo Comitê de Ética em Pesquisa da Faculdade de Saúde Pública da Universidade de São Paulo - COEP e aprovado de acordo com os requisitos da Resolução CNS/196/96 (Anexo 1).

As amostras foram preparadas como descrito anteriormente no item 3.4.

O teste contou com a participação de 50 provadores entre alunos, professores e funcionários; pertencentes à comunidade da FSP. 
Primeiramente, os consumidores receberam as amostras de frango, sendo estas codificadas com números de três digitos aleatórios. Foi servida água para purificação do paladar antes e entre a avaliação das amostras.

Os provadores receberam as amostras em cabines individuais, sob luz branca, e, por fim, expressaram suas opiniões sobre a aceitação e preferência do produto.

O fluxograma do procedimento da análise sensorial pode ser visualizado na figura 4 .

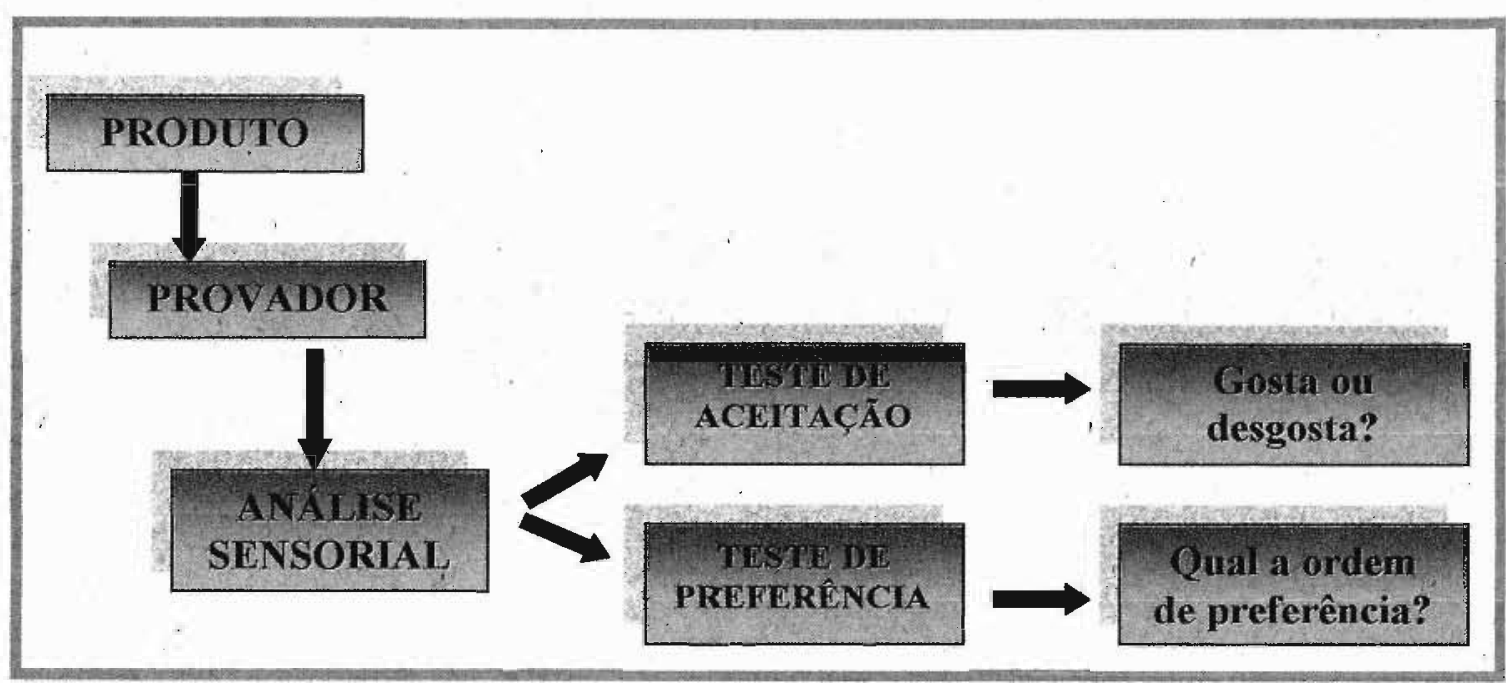

Figura 4 - Fluxograma do processo de análise sensorial

Foi utilizado um método para análise sensorial com teste afetivo de aceitabilidade, no programa FIZZ (Sensory Analysis and Consumer Test Management software version 2.00, Biosystems). Utilizou-se uma escala hedônica estruturada de nove pontos ancorada nos extremos de " 1 = desgostei muitíssimo a 9 = gostei muitíssimo" (Meilgaard, 1999). O modelo de ficha empregado na análise sensorial pode ser visualizado na figura 5 .

As preparações testadas foram as que possuíam especiarias e mel, ou seja, as amostras de peito e sobrecoxa de frango que foram submetidas aos tratamentos conforme tabela 1 . 
O delineamento estatístico empregado na avaliação dos resultados foi o de blocos completos (Teste de Friedman).

Os dados foram submetidos à análise de variância (ANOVA) e, posteriormente, seguidos pelo teste de comparação de médiạs de Tukey, a 5\% de significância.

Nome: Data: 1 I

Você está recebendo três diferentes amostras de peito de frango assado. Por favor, prove as amostras da esquerda para direita e avalie o quanto você gostou utilizando a escala abaixo.

9- Gostei muitíssimo

8- Gostei muito

7- Gostei regularmente

6- Gostei ligeiramente

5 - Nem gostei ñem desgostei

4- Desgostei ligeiramente

3- Desgostei regularmente

2- Desgostei muito

1- Desgostei muitíssimo

\begin{tabular}{|c|l|l|l|}
\hline AMOSTRA & & & \\
\hline SABOR & & & \\
\hline
\end{tabular}

Comentários:

Figura 5 - Modelo de ficha empregado na análise sensorial de peito e sobrecơxa de frango assado. 


\subsection{Análise Estatistica}

A análise estatística de todas as informações coletadas nesta pesquisa foi inicialmente feita de forma descritiva.

Para as variáveis de natureza quantitativa (numérica) foram calculadas algumas medidas-resumo, como médias e desvios-padrão, além da confecção de gráficos do tipo boxplot (Bussab e Morettin, 2006).

A análise inferencial foi empregada com o intuito de confirmar ou refutar evidências encontradas nas análises descritivas. A Análise de Covariância (ANCOVA) empregadas na comparação das medidas das variáveis: oxidaçạ̃o, segundo tratamento e tempo, utilizando à variável lipídios como covariada.

Foram realizadas:

- Comparações pelo método de Bonferroni quando detectado efeito de interação entre tratamento e tempo (Neter et al, 1996);

- Comparações pelo método LSD, quando não detectado efeito de interação entre tratamento e tempo (Neter et al, 1996).

Em todas as conclusões obtidas nas análises inferenciais foi utilizado o nível de significância $\alpha$ igual a $5 \%$.

Os dados foram digitados em planilhas do Excel 2007 for Windows. As análises estatísticas foram realizadas com o software Statistical Package for Social Sciences (SPSS) versão 11.0 for Windows e Statistica versão 5.0. 


\section{Resultados e Discussão}

Os efeitos protetores da adição do mel e das especiarias (sálvia e orégano) sobre a oxidação lipídica nos cortes de peito e sobrecoxa assados foram avaliados durante o período o tempo zero, e após 48 e 96 horas de refrigeração.

\subsection{Umidade e lipídios}

Nas tabelas 3 e 4 estão apresentados os resultados de umidade (g/100g) e lipídios (g/ $100 \mathrm{~g}$ base seca) das amostras de peito e sobrecoxa assados.

Tabela 3 - Valores médios e desvio padrão de umidade $(\mathrm{g} / 100 \mathrm{~g})$ e lipídios (g/ $100 \mathrm{~g}$ base seca) em peito ašsado, segundo tratamento e termpo.

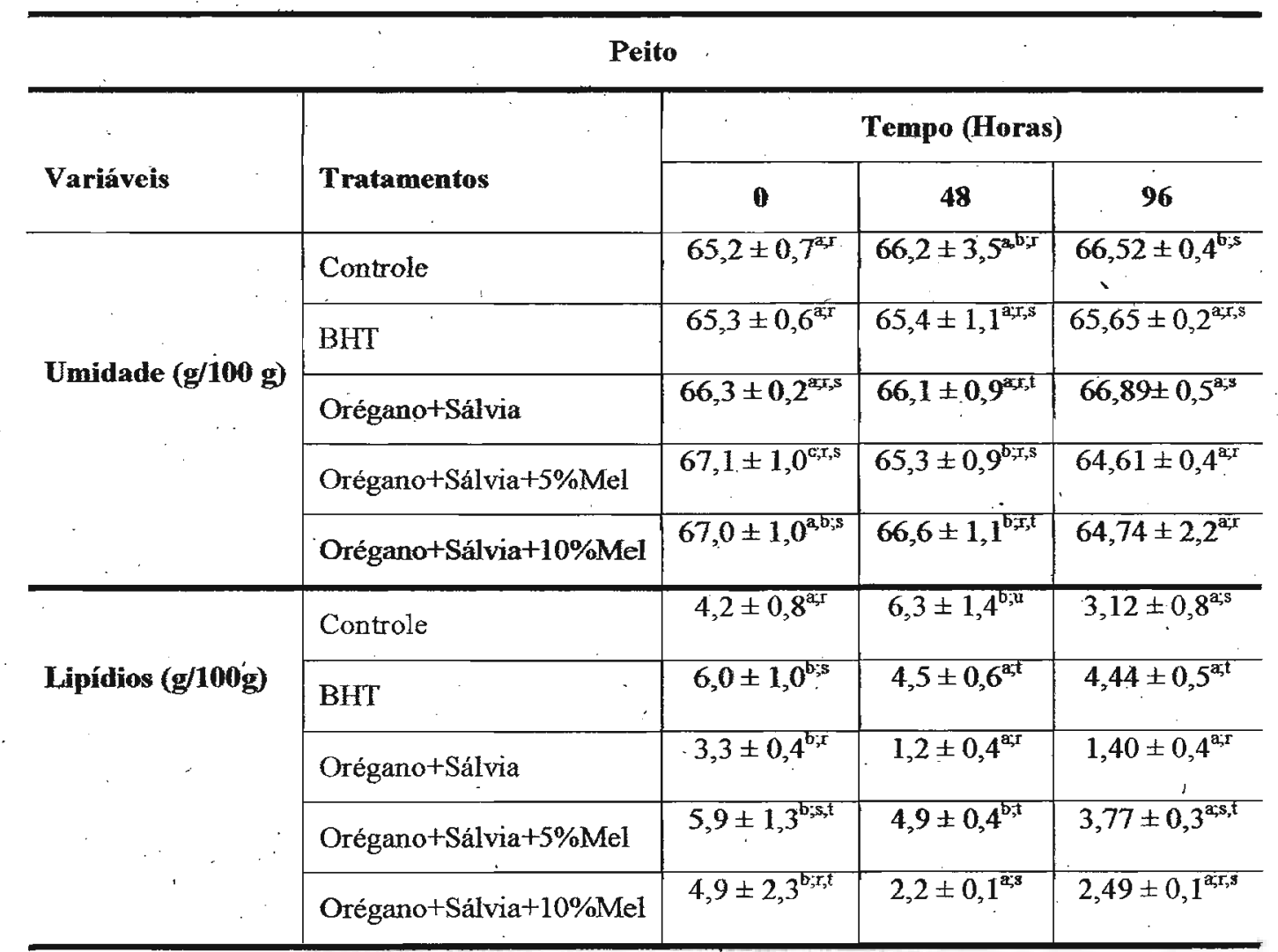

Letras de $(a, b)$ na mesma linha indicam diferenças estatisticamente significativas p<0,05

Letras de $\left(\mathrm{r}_{2} \mathrm{~s}, \mathrm{t}, \mathrm{u}\right)$ na mesma coluna indicam diferenças estatisticamente significativas $p<0,05$ 
Tabela 4 - Valores médios e desvio padrão de umidade $(\mathrm{g} / 100 \mathrm{~g})$ e lipídios $(\mathrm{g} / 100 \mathrm{~g}$ base seca) em sobrecoxa assada, segundo tratamento e tempo.

\begin{tabular}{|c|c|c|c|c|}
\hline \multicolumn{5}{|c|}{ Sobrecoxa } \\
\hline \multirow[b]{2}{*}{ Variáveis } & \multirow[b]{2}{*}{ Tratamentos } & \multicolumn{3}{|c|}{ Tempo (Horas) } \\
\hline & & $\mathbf{0}$ & 48 & 96 \\
\hline \multirow{5}{*}{ Umidade (\%) } & Controle & $61,5 \pm 0,8^{2, t}$ & $62,0 \pm 1,3^{a, s, t}$ & $62,4 \pm 0,2^{\mathrm{a}, \mathrm{t}}$ \\
\hline & BHT & $60,5 \pm 0,4^{2, t}$ & $63,3 \pm 0,5^{6, t}$ & $64,8 \pm 1,6^{6 ; s}$ \\
\hline & Orégano+Sálvia & $58,3 \pm 1,7^{\mathrm{ajs}}$ & $59,3 \pm 0,3^{\mathrm{a}, \mathrm{t}}$ & $62,0 \pm 0,1^{b ; t}$ \\
\hline & Orégano+Sálvia $+5 \% \mathrm{Mel}$ & $58,5 \pm 1,4^{\alpha, x}$ & $59,9 \pm 1,1^{2,8}$ & $63,5 \pm 1,4^{b ; u}$ \\
\hline & Orégano+Sálvia $+10 \% \mathrm{Mel}$ & $61,2 \pm 0,3^{c, u}$ & $52,4 \pm 0,2^{\mathrm{ax} x}$ & $57,5 \pm 1,2^{6 ; T}$ \\
\hline \multirow{5}{*}{ Lipídios (g/100g) } & Controle & $-14,8 \pm 1,6^{\mathrm{c}, \mathrm{s}}$ & $10,0 \pm 0,6^{6 ; \mathrm{s}}$ & $8,45 \pm 1,2^{a, b ; r}$ \\
\hline & $\mathrm{BHT}$ & $20,8 \pm 1,1^{\mathrm{c} ; \mathrm{t}}$ & $10,6 \pm 1,4^{\mathrm{as}}$ & $13,9 \pm 2,2^{b ; s, t}$ \\
\hline & Orégano+Sálvia & $9,2 \pm 0,6^{6 ; r}$ & $6,1 \pm 0,9^{\mathrm{a}, \mathrm{r}}$ & $7,0 \pm 0,7^{a_{2} b_{p} r}$ \\
\hline & Orégano + Sálvia $+5 \% \mathrm{Mel}$ & $20,0 \pm 2,8^{c, t}$ & $14,9 \pm 2,0^{\text {ab; } ;}$ & $12,6 \pm 0,6^{\mathrm{ass}}$ \\
\hline & Orégano+Sálvia $+10 \% \mathrm{Mel}$ & $24,4 \pm 4,9^{\mathrm{c}, \mathrm{a}}$ & $12,0 \pm 1,3^{\mathrm{ars}}$ & $15,6 \pm 3,8^{\mathrm{b} ; \mathrm{t}}$ \\
\hline
\end{tabular}

Avaliando os resultados das tabelas 3 e 4 para a variável umidade, foram encontrados valores entre $64,6 \pm 0,4$ e $67,1 \pm 1,0 \%$ nas amostras de peito assado, enquanto que nas amostras de sobrecoxa os teores de umidade variaram de $52,4 \pm 0,2$ a $64,8 \pm 1,6 \%$.

No tempo inicial, os resultados de umidade das amostras de peito de frango no tratamento controle apresentaram os menores valores $(65,2 \%)$ e o tratamento contendo orégano+sálvia $+5 \% \mathrm{Mel}$ o maior valor $(67,1 \%)$. Em 48 horas, a porcentagem de umidade variou entre 65,3 e $66,6 \%$, sendo que teores mais elevados foram observados no tratamento orégano+sálvia+10\%mel. Após 96 horas de refrigeração, o tratamento orégano+sálvia apresentou os maiores teores de umidade em relação aos demais. 
Resultados semelhantes de umidade para carne de peito de frango sem pele grelhada $(63,8 \%)$ foram obtidos na Tabela Brasileira de Composição de Alimentos TACO (2006).

Em estudo realizado por Vieira et al. (2007), sobre os efeitos dos métodos de cocção na composição centesimal e colesterol do peito de frangos de diferentes linhagens, constatou que a carne de peito de frango assada em forno convencional apresentava em média $63,18 \%$ de umidade, $34,07 \%$ de proteína, $1,55 \%$ de lipídios e $1,18 \%$ de cinzas.

Os resultados inferenciais revelaram que há efeito de interação entre tratamento e tempo nas amostras de peito e sobrecoxa assadas $(p<0,001)$. As tabelas 3 e 4 trazem, respectivamente, as comparações múltiplas entre os tratamentos dentro de cada tempo, e entre os tempos dentro de cada tratamento, demonstradas pelas letras sobrescritas.

Analisando os dados de lipídios (Tabelas 3 e 4) verificou-se uma variação entre $1,4 \pm 0,4$ a $6,3 \pm 1,4(\mathrm{~g} / 100 \mathrm{~g}$ - base seca) para a carne de peito assada. Nas amostras de sobrecoxa assadas os teores de lipídios encontrados variaram de $6,1 \pm 0,9$ a $24,4 \pm 4,9$ $(\mathrm{g} / 100 \mathrm{~g}$ - base seca)

Os resultados inferenciais para a variável lipídios revelaram que há efeito de interação entre tratamento e tempo para os dois tipos de carnes $(p<0,001)$.

Os teores de lipídios apresentados na Tabela Brasileira de Composição de Alimentos - TACO (2006) são semelhantes aos encontrados neste estudo, onde a carne de peito grelhada sem pele apresenta um teor médio de $6,91 \mathrm{~g} / 100 \mathrm{~g}$ na base seca e a sobrecoxa sem pele assada $(27,03 \mathrm{~g} / 100 \mathrm{~g}$ na base seca).

A grande variação dos teores de lipídios encontrada nos dois cortes de frango (peito e sobrecoxa) avalíados no presente estudo, provavelmente se deve a grande diferença de tamanho e peso entre os cortes. Por esta razão optou-se pela análise estatística covariada, onde foi possível normalizar esta variável. Além disso, o conteúdo de lipídios no músculo é influenciado pela composição da dieta, pelo ambiente, pela linhagem do animal, entre outros (Cobos et al., 1994; Valsta et al., 2005).

As carnes brancas de aves como o peito possuem baixo teor de gordura devido à reduzida necessidade de estocar energia nestes músculos. Já os depósitos de gordura sub-cutânea, na cavidade abdominal e nas sobrecoxas são bastante acentuados, caracterizando regiões onde a reserva de energia é importante para o isolamento térmico 
e também para permitir atividades físicas de longa duração (Langslow e Lewis, 1974). Devido a este fato os lipídios totais são mais acentuados na carne de sobrecoxa em relação a carne de peito.

\subsection{Atividade de água e pH}

Nas tabelas 5 e 6 estão apresentados os resultados de atividade de água e $\mathrm{pH}$ das amostras de peito e sobrecoxa assados.

Tabela 5 - Valores médios e desvio padrão de atividade de água e pH em peito assado, segundo tratamento e tempo.

\begin{tabular}{|c|c|c|c|c|}
\hline & Peito & & & \\
\hline \multirow[b]{2}{*}{ Variáveis } & \multirow{2}{*}{ Tratamentos } & \multicolumn{3}{|c|}{ Tempo (Horas) } \\
\hline & & 0 & 48 & 96 \\
\hline \multirow{5}{*}{ Atividade de água } & Controle & $0,97 \pm 0,0^{2 ; r}$ & $0,98 \pm 0,0^{2, T}$ & $0,98 \pm 0,0^{\text {a; } ; \tau}$ \\
\hline & $\mathrm{BHT}$ & $0,96 \pm 0,0^{\alpha, 3}$ & $0,98 \pm 0,0^{6 ; x}$ & $0,97 \pm 0,0^{\mathrm{c,s}}$ \\
\hline & Orégano+Sálvia & $0,97 \pm 0,0^{\mathrm{aj} T}$ & $0,98 \pm 0,0^{b ; \Gamma}$ & $0,98 \pm 0,0^{b, r}$ \\
\hline & Orégano+Sálvia $+5 \% \mathrm{Mel}$ & $0,97 \pm 0,0^{8,7}$ & $0,96 \pm 0,0^{a, s}$ & $0,97 \pm 0,0^{\mathrm{a} ; 3}$ \\
\hline & Orégano+Sálvia+10\%Mel & $0,97 \pm 0,0^{6 ; r}$ & $0,96 \pm 0,0^{b ; s^{\prime}}$ & $0,94 \pm 0,0^{\text {att }}$ \\
\hline \multirow{5}{*}{ pH } & Controle & $5,7 \pm 0,0^{\mathrm{a} ; \mathrm{r}}$ & $5,9 \pm 0,0^{b ; x}$ & $6,0 \pm 0,0^{\mathrm{c}, \pi}$ \\
\hline & BHT & $6,0 \pm 0,1^{\mathrm{a} ; \mathrm{s}}$ & $6,3 \pm 0,1^{\mathrm{b} ; \mathrm{s}}$ & $6,4 \pm 0,2^{\mathrm{b} ; \mathrm{s}}$ \\
\hline & Orégano+Sálvia & $6,4 \pm 0,2^{\text {ats }}$ & $6,4 \pm 0,0^{a b ; s}$ & $6,3 \pm 0,0^{b ; t}$ \\
\hline & Orégano+Sálvia $+5 \% \mathrm{Mel}$ & $6,4 \pm 0,1^{\mathrm{a} ; \mathrm{t}}$ & $6,3 \pm 0,0^{\text {ass }}$ & $6,4 \pm 0,1^{\text {a;s }}$ \\
\hline & Orégano+Sálvia $+10 \% \mathrm{Mel}$ & $6,4 \pm 0,1^{2 t^{t}}$ & $6,3 \cdot \pm 0,0^{\mathrm{a} ; \mathrm{s}}$ & $6,3 \pm 0,0^{a, t}$ \\
\hline
\end{tabular}

Letras de $(a, b, c)$ na mesma linha indicam diferenças estatisticamente significativas $p<0,05$

Letras de $(r, s, t)$ na mesma coluna indicam diferenças estatisticamente significativas $p<0,05$ 
Tabela 6 - Valores médios e desvio padrão de atividade de água e pH em sobrecoxa assada, segundo tratamento e tempo.

\begin{tabular}{|c|c|c|c|c|}
\hline \multicolumn{5}{|c|}{ Sobrecoxa } \\
\hline \multirow[b]{2}{*}{ Variáveis } & \multirow[b]{2}{*}{ Tratamentos } & \multicolumn{3}{|c|}{ Tempo (Horas) } \\
\hline & & 0 & 48 & 96 \\
\hline \multirow{5}{*}{ Atividade de água } & Controle & $\overline{0,98} \pm 0,0^{\mathrm{a}, \mathrm{b} ; \mathrm{s}}$ & $0,98 \pm 0,0^{b ; \mathrm{s}}$ & $\overline{0,97 \pm 0,0^{\alpha ; s}}$ \\
\hline & $\mathrm{BHT}$ & $0,96 \pm 0,0^{\mathrm{a}, \mathrm{r}}$ & $0,98 \pm 0,0^{6 ; s}$ & $0,98 \pm 0,0^{b ; s}$ \\
\hline & Orégano+Sálvia & $0,98 \pm 0,0^{\mathrm{ab} ; \mathrm{s}}$ & $0,98 \pm 0,0^{6 ; s}$ & $0,97 \pm 0,0^{\mathrm{a} ; \mathrm{s}}$ \\
\hline & Orégano+Sálvia $+5 \% \mathrm{Mel}$ & $0,96 \pm 0,0^{2,9}$ & $0,96 \pm 0,0^{\mathrm{a}, \bar{r}}$ & $0,97 \pm 0,0^{b ; s}$ \\
\hline & Orégano+Sálvia $+10 \% \mathrm{Mel}$ & $0,96 \pm 0,0^{b ; \Gamma}$ & $0,97 \pm 0,0^{\mathrm{G}, \mathrm{r}}$ & $0,94 \pm 0,0^{\mathrm{a} ; \mathrm{r}}$ \\
\hline \multirow{5}{*}{$\mathbf{p H}$} & Controle & $6,4 \pm 0,1^{a, b ; r}$ & $6,3 \pm 0,1^{\text {a,r }}$ & $6,4 \pm 0,0^{\mathrm{a}, \mathrm{b} ; \mathrm{r}}$ \\
\hline & BHT & $6,4 \pm 0,2^{\mathrm{ass}}$ & $6,8 \pm 0,0^{b ; t}$ & $6,8 \pm 0,1^{b ; t}$ \\
\hline & Orégano+Sálvia & $6,9 \pm 0,1^{b, t}$ & $6,8 \pm 0,0^{2 ; t}$ & $6,7 \pm 0,0^{\text {ass }}$ \\
\hline & Orégano+Sálvia $+5 \% \mathrm{Mel}$ & $6,8 \pm 0,0^{2, t}$ & $6,8 \pm 0,0^{\alpha, t}$ & $6,9 \pm 0,1^{a, t}$ \\
\hline & Orégano+Sálvia $+10 \% \mathrm{Mel}$ & $6,9 \pm 0,0^{6, t}$ & $6,6 \pm 0,0^{a, s}$ & $6,6 \pm 0,0^{2, s}$ \\
\hline
\end{tabular}

Para as medidas de atividade de água (Aa) determinadas nos dois cortes de frangos assados, pode-se constatar que os resultados inferenciais revelaram que há efeito de interação entre tratamento e tempo $(p<0,001)$. As diferenças entre os tratamentos e tempos estão apresentadas nas tabelas 6 e 7.

As medidas de atividade de água na carne de peito assada variaram de 0,94 a 0,98 . No decorrer do tempo, o tratamento orégano + sálvia $+10 \%$ mel foi o que perdeu água livre em sua composição, enquanto que os outros tratamentos permaneceram praticamente estáveis. Este mesmo comportamento também foi observado para a sobrecoxa assada.

As carnes frescas possuem uma atividade de água média de 0,99 , sendo que a susceptibilidade à oxidação pode ser função da mesma, já que faixas entre 0,8 a 0,6 favorecem o. aumento das reações de oxidação lipídica (Van Laack, et al., 2000).

Os valores de atividade de água encontrados neste trabalho foram semelhantes aos determinados por Muguruma et al.,(1987) que observaram valores de 0,96 para o 
peito de frango, e por Brannan (2009), que encontrou valores de atividade de água de 0,97 a 0,99 em peito e sobrecoxa de frango cozidos tratados com extratos de sementes de uva.

Em relação aos valores de $\mathrm{pH}$ das carnes de frango (Tabelas 5 e 6 ) verificou-se que ocorreu uma variação de 5,7 até 6,4 (peito assado), sendo que o tratamento controle apresentou o valor mais baixo de $\mathrm{pH}$. Os tratamentos que continham as especiarias e o mel apresentaram os valores mais elevados de pH. Já para a sobrecoxa assada aos resultados foram entre 6,3 a 6,9 .

Para a variável $\mathrm{pH}$ os resultados inferenciais também revelaram que há efeito de interação entre tratamento e tempo para os cortes de peito e sobrecoxa $(p<0,001)$.

Brannan (2009) avaliou o comportamento do $\mathrm{pH}$ de amostras de peito de frango cozido e não encontrou diferenças estatisticamente significativas entre as amostras controle e as amostras tratadas com extrato de semente de uva ao longo de um período de 12 dias de refrigeração. Este mesmo autor, também avaliou o $\mathrm{pH}$ de sobrecoxa de frango cozidas e observou que os resultados de $\mathrm{pH}$ declinaram ao longo do tempo de refrigeração. Entretanto, nas àmostras tratadas com o extrato de uva, os valores aumentaram durante os 12 dias de refrigeração.

Após ter ocorrido o abate, a carne continua em processo bioquímico. Assim, o pH da carne de frango diminui devido à produção de ácido lático, onde a carne de peito deve apresentar pH final entre 5,7 e 5,9 (Venturirni et al., 2007). Souza et al. (2006) constataram que o $\mathrm{pH}$ da carne de peito de frango variou entre 5,92 no post mortem e 5,7 em 30 dias após o abate. Outro estudo realizado por Castellini et al., (2002) demonstraram que o $\mathrm{pH}$ final da carne de peito de frango variou entre 5,75 e 5,96.

Os valores de $\mathrm{pH}$ dos cortes de sobrecoxa foram superiores aos dos cortes de peito, devido a maior quantidade e às características das fibras vermelhas, que por possuírem metabolismo oxidativo, favorecem um $\mathrm{pH}$ mais alto (Price e Schwiegert, 1994). 


\subsection{TBARS}

Na tabela 7 estão apresentados os resultados de TBARS nos dois cortes de frango (peito e sobrecoxa) assados.

Tabela 7 - Valores médios (base seca) e desvio padrão de TBARS nos cortes de frango (peito e sobrecoxa) assados, segundo tratamento e tempo.

\begin{tabular}{|c|c|c|c|c|}
\hline \multicolumn{5}{|c|}{ Peito } \\
\hline \multirow[b]{2}{*}{ Variáveis } & \multirow[b]{2}{*}{ Tratamentos } & \multicolumn{3}{|c|}{ Tempo (Horas) } \\
\hline & & 0 & 48 & 96 \\
\hline \multirow{5}{*}{$\begin{array}{c}\text { TBARS } \\
\text { (mg MDA/Kg) }\end{array}$} & Controle & $1,83 \pm 0,1^{\mathrm{b}, t}$ & $1,49 \pm 0,3^{\alpha, \sqrt{3}}$ & $2,07 \pm 0,1^{\mathrm{c}, u}$ \\
\hline & $\mathrm{BHT}$ & $0,21 \pm 0,0^{\mathrm{ag}, \mathrm{s}}$ & $0,62 \pm 0, \mathrm{I}^{\mathrm{b}, \mathrm{t}}$ & $1,34 \pm \overline{0,0^{c, t}}$ \\
\hline & Orégano+Sálvia & $0,10 \pm 0,0^{\alpha, r}$ & $0,36 \pm 0,0^{6 ; 9}$ & $0,38 \pm 0,0^{b ; s}$ \\
\hline & Orégano+Sálvia $+5 \% \mathrm{Mel}$ & $0,04 \pm 0,0^{\mathrm{a}, \mathrm{r}}$ & $0,19 \pm 0,0^{\mathrm{b} ; \mathrm{F}}$ & $0,24 \pm 0,0^{b ; x}$ \\
\hline & Orégano+Sálvia $+10 \% \mathrm{Mel}$ & $0,06 \pm 0,0^{2 \pi x}$ & $0,24 \pm 0,0^{b ; r}$ & $0,38 \pm 0,0^{\mathrm{css}}$ \\
\hline \multicolumn{5}{|c|}{ Sobrecoxa } \\
\hline \multirow[b]{2}{*}{ Variáveis } & \multirow[b]{2}{*}{ Tratamentos } & \multicolumn{3}{|c|}{ Tempo (Horas) } \\
\hline & & $\mathbf{0}$ & 48 & 96 \\
\hline \multirow{5}{*}{$\begin{array}{c}\text { TBARS } \\
\text { (mg MDA/Kg) }\end{array}$} & Controle & $0,46 \pm 0,1^{\text {a, } 3 \mathrm{u}}$ & $0,94 \pm 0,1^{b ; u}$ & $1,19 \pm 0,0^{\mathrm{c} ; \mathrm{s}}$ \\
\hline & BHT & $0,15 \pm 0,0^{\text {का }}$ & $0,58 \pm 0,0^{b, t}$ & $1,54 \pm 0,1^{\mathrm{c}, \mathrm{t}}$ \\
\hline & Orégano+Sálvia & $0,08 \pm 0,0^{a ; r, s}$ & $0,36 \pm 0,0^{6 ; \mathrm{s}}$ & $0,51 \pm 0,0^{\mathrm{c} ; 1}$ \\
\hline & Orégano + Sálvia $+5 \% \mathrm{Mel}$ & $0,05 \pm 0,0^{\alpha, x}$ & $0,35 \pm 0,0^{b ; 3}$ & $0,53 \pm 0,0^{\mathrm{c}, r}$ \\
\hline & Orégano+Sálvia $+10 \% \mathrm{Mel}$ & $0,06 \pm 0,0^{\mathrm{ar}, \mathrm{r} s}$ & $0,22 \pm 0,0^{6 ; \mathrm{r}}$ & $0,51 \pm 0,0^{\mathrm{c}, \mathrm{r}}$ \\
\hline
\end{tabular}

Letras de $(\mathrm{a}, \mathrm{b}, \mathrm{c})$ na mesma linha indicam diferenças estatisticamente significativas $\mathrm{p}<0,05$

Letras de $(r, s, t, u)$ na mesma coluna indicam diferenças estatisticamente significativas $p<0,05$

Os valores médios de TBARS na carne de peito assada variaram entre 0,04 a 2,07 mg MDA/Kg de amostra (base seca) durante o tempo de refrigeração (Tabela 7). 
Durante o tempo de refrigeração observou-se um aumento de TBARS em todos os tratamentos avaliados. $O$ tratamento que apresentou os menores valores de TBARS foi o (orégano+sálvia $+5 \%$ de mel), seguido do (orégano+sálvia $+10 \%$ de mel). Em ordem decrescente o comportamento dos tratamentos para TBARS foram: Controle $\rightarrow$ BHT $\rightarrow($ Orégano + Sálvia $) \rightarrow($ Orégano + Sálvia $+10 \%$ mel $) \rightarrow($ Orégano + Sálvia + $5 \% \mathrm{mel}$ ).

$\mathrm{Na}$ amostra controle, observou-se que após 48 horas de refrigeração os valores de TBARS foram menores do que no tempo 0. Entretanto, após 96 horas ocorreu uma elevação, com $2,07 \mathrm{mg} \mathrm{MDA} / \mathrm{Kg}$. Obervou-se que o tratamento contendo BHT apresentou uma elevação de TBARS durante a vida de prateleira, demonstrando a baixa eficácia do mesmo em relação aos demais tratamentos. Ao final das 96 horas, as amostras com adição de especiarias e mel apresentaram valores de TBARS mais baixos que o controle e ao BHT, sugerindo que a sálvia, o orégano e o mel tenham exercidó efeito antioxidante durante o experimento.

A análise estatística confirmou que ocorreu efeito de interação entre tratamento e tempo $(\mathrm{p}<0,001)$ para a análise de TBARS nestas amostras de peito de frango assadas.

Os resultados TBARS na carne de sobrecoxa assada variaram entre 0,05 a 1,19 mg MDA/Kg de amostra (base seca) (Tabela 7). Em ordem crescente os tratamentos mais efetivos na proteção contra a oxidação lipídica no tempo 0 foram: $($ Orégano + Sálvia $+5 \%$ mel $) \rightarrow($ Orégano + Sálvia $+10 \%$ mel $) \rightarrow($ Orégano+Sálvia $) \rightarrow$ BHT $\rightarrow$ Controle.

Quando analisamos os resultados da sobrecoxa no tempo 96 horas, observamos que os tratamentos contendo Orégano+Sálvia, Orégano+Sálvia $+5 \%$ mel e Orégano+Sálvia $+10 \%$ mel mostraram-se estatisticamente semelhantes $(\mathrm{p}<0,05)$.

Como descrito na literatura, a oxidação lípidica é uma das principáas reações deteriorativas que ocorrem durante o processamento, distribuição, armazenamento e preparo final dos alimentos (Jahan et al., 2004).

Neste estudo, os tratamentos que possuíam mel em sua preparação apresentaram valores de TBARS menores nos tempos 0 e 48 horas em relação aos tratamentos que possuíam apenas as especiarias (Orégano+Sálvia), nos dois cortes avaliados. Após 96 horas de refrigeração, observou-se que o tratamento Orégano + Sálvia $+5 \% \mathrm{Mel}$ foi o mais eficaz na proteção oxidativa dos cortes de peito, com menores teores de TBARS. Os 
outros dois tratamentos Orégano+Sálvia e Orégano+Sálvia+10\%Mel mostraram-se estatisticamente semelhantes. Já para a sobrecoxa assada, os tratamentos com especiarias e mel não apresentaram diferenças estatísticas após 96 horas de refrigeração.

Resultados semelhantes foram encontrados por McKibben e Engeseth (2002) que avaliaram a inibição da oxidação lipídica em carne de peru utilizando mel, $\alpha$ tocoferol e BHT e concluíram que o tratamento que continha mel foi o mais efetivo na redução da oxidação lipídica da carne cozida. Nagai et al., (2006) observaram que o mel inibiu a oxidação, bem como o crescimento bacteriano durante a vida de prateleira de carnes cruas de bovinos, suínos, frangos e peixes.

Existe uma relação bem estabelecida entre os valoreś médios de TBARS e as avaliações sensoriais em carnes (Bou et al., 2001). Galvin et al. (2002) afirmaram que "off-flavours" podem ser detectados em carnes oxidadas a partir de valores de TBARS entre 0,5 e $2,0 \mathrm{mg} / \mathrm{Kg}$ de amostra.

Os resultados de TBARS apresentados neste estudo confirmaram a atividade antioxidante das especiarias e do mel, pois em todos os tempos de refrigeração, os extratos de orégano, sálvia e o mel mostraram-se eficazes na proteção contra a oxidação lipídica em todas as amostras avaliadas. Além disso, os resultados de TBARS demonstraram que os antioxidantes retardaram a oxidação dos lipídios imediatamente após a cocção. Resultados semélhantes foram verificados em outros estudos (Ahn et al., 2002, Fernández-López et al., 2003, Juntachote et al., 2007) que avaliaram o comportamento dos antioxidantes após o cocção de carnes.

Nas figuras 6. e 7 estão demonstrados o percentual da inibição da oxidação lipídica nos cortes de peito e sobrecoxa assados. 


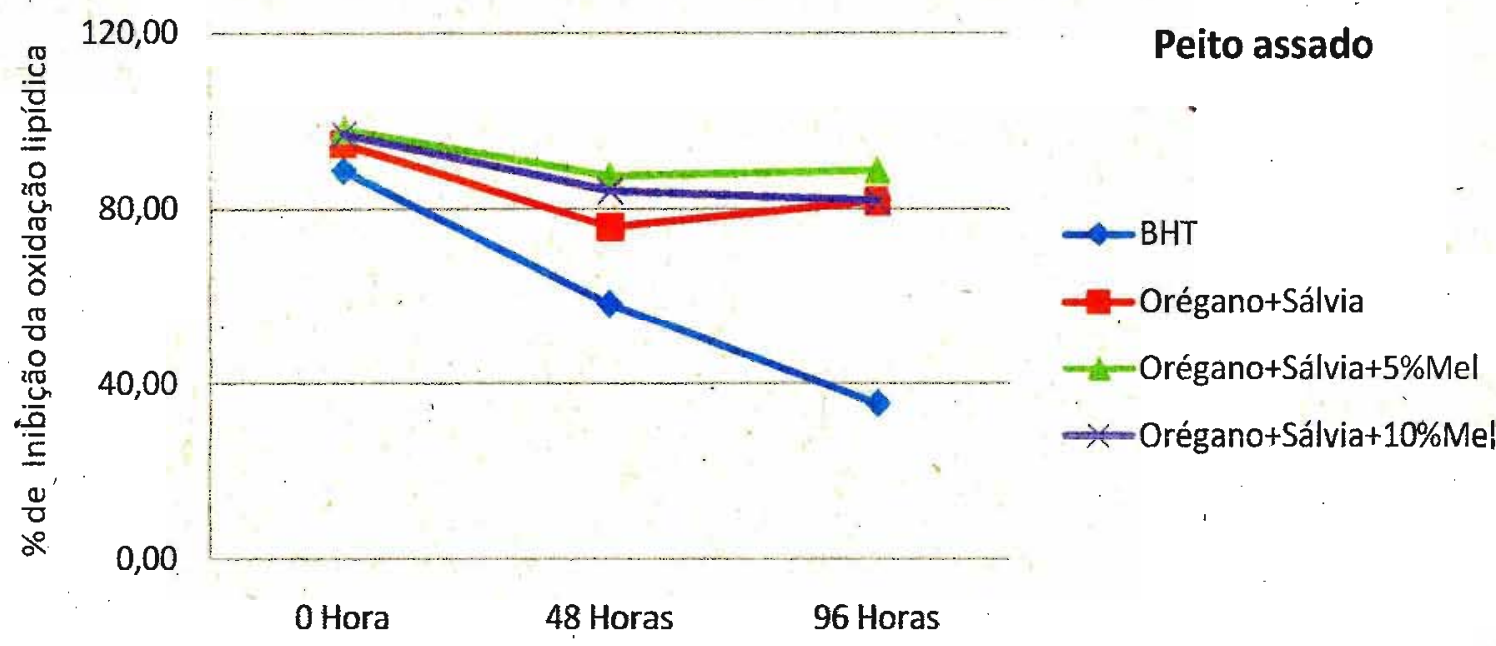

Figura 6 - Porcentagem de inibição da oxidação lipídica em relação ao controle nos tratamentos de peito assado.

Na Figura 6, ao avaliarmos os resultados da inibição da oxidação lipídica durante o tempo de refrigeração na carne de peito assado, observamos que em relação ao controle, os tratamentos realizados apresentaram influência positiva. $O$ tratamento com Orégano+Sálvia inibiu a oxidação em 97,8 \% no tempo 0. Após 48 horas, o tratamento Orégano + Sálvia $+5 \% \mathrm{Mel}$ foi o mais eficaz com $87,3 \%$ de proteção oxidativa. Este mesmo tratamento atingiu o ápice de inibição no tempo de 96 horas com $\mathbf{8 8 , 4 \%}$. Dentre os tratamentos avaliados, o contendo Orégano+Sálvia+5\% Mel foi o mais efetivo contra a oxidação em relação aos demais. Em relação ao tratamento com BHT, o mesmo foi perdendo eficiência no decorrer do tempo de refrigeração $(88,5 \% \rightarrow 53,9 \% \rightarrow 35,3$ $\%$ ), nos tempos 0, 48 e 96 horas, respectivamente. Assim, devemos ressaltar que todos os tratamentos com especiarias chegaram a inibir a oxidação lipídica em mais de $80 \%$. 


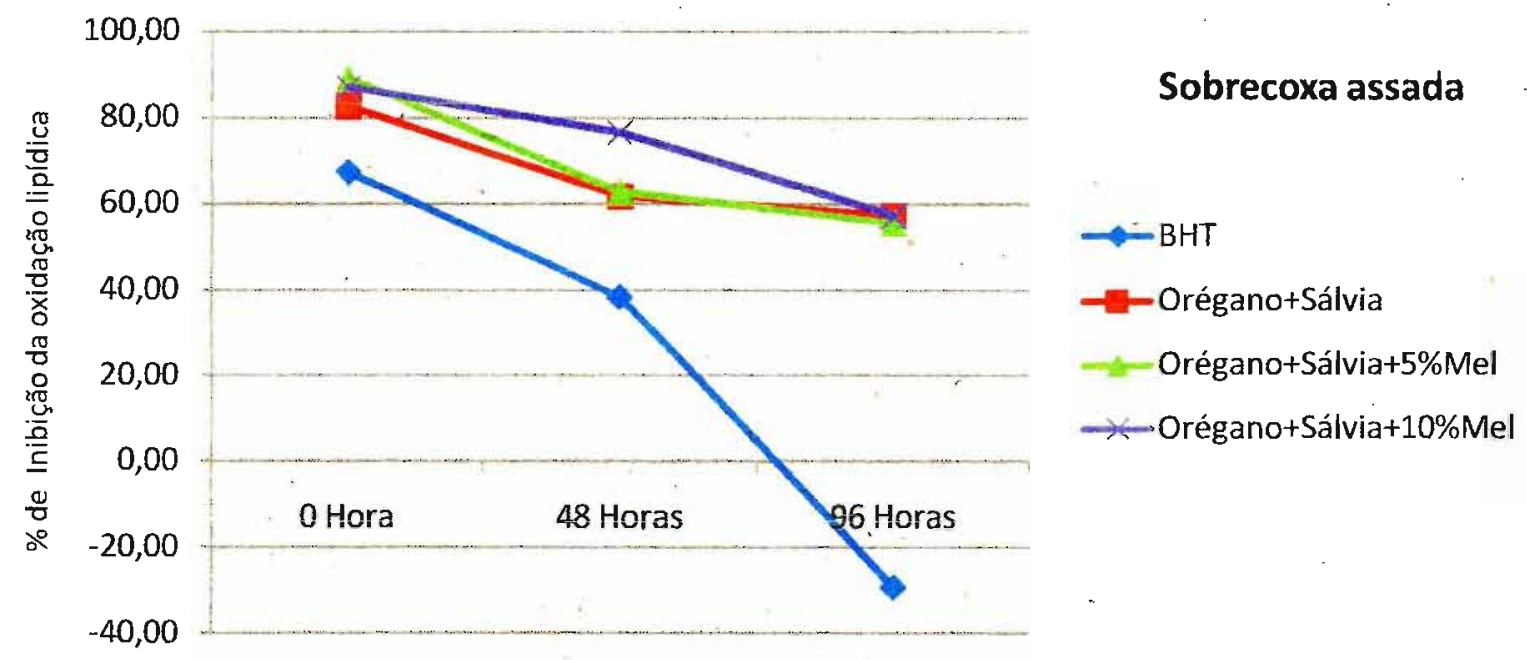

Figura 7 - Porcentagem de inibição da oxidação lipídica em relação ao controle nos tratamentos de sobrecoxa assada.

Na figura 7 estão apresentados os resultados da inibição da oxidação lipídica na carne de sobrecoxa cozida. Em relação ao BHT, os dados mostram que a inibição foi inferior aos tratamentos com especiarias e que ao longo do tempo este tratamento perde eficiência. No tempo 96 horas, o mesmo não protegeu contra a oxidação em relação ao controle. Nos tratamentos com especiarias, o Orégano+Sálvia+5\%Mel foi o mais eficaz, com efeito protetor de $89,1 \%$ no tempo 0 . No tempo 48 horas o tratamento Orégano+Sálvia+10\% Mel mostrou-se mais eficaz com 76,6 \%. Após 96 horas de refrigeração, os tratamentos Orégano + Sálvia e Orégano+Sálvia $+10 \% \mathrm{Mel}$ mostraram-se semelhantes, com $57,1 \%$ de inibição da oxidação lipídica.

Os resultados obtidos neste estudo reforçam que a utilização de antioxidantes naturais mostrou-se mais eficaz do que o BHT em carnes de frango assado, durante o tempo de refrigeração. Resultados semelhantes foram descritos por (Estévez et al., 2007; Ahn et al., 2002; McCarthy et al., 2001; Yu et al., 2002; Tsimidou et_al., 1995).

\subsection{Dienos conjugados e hexanal}

Na tabela 8 estão apresentados os resultados de dienos conjugados e hexanal das amostras de peito e sobrecoxa assados. 
Tabela 8 - Valores médios (base seca) e desvio padrão de dienos conjugados e hexanal em peito e sobrecoxa assados, segundo tratamento e tempo.

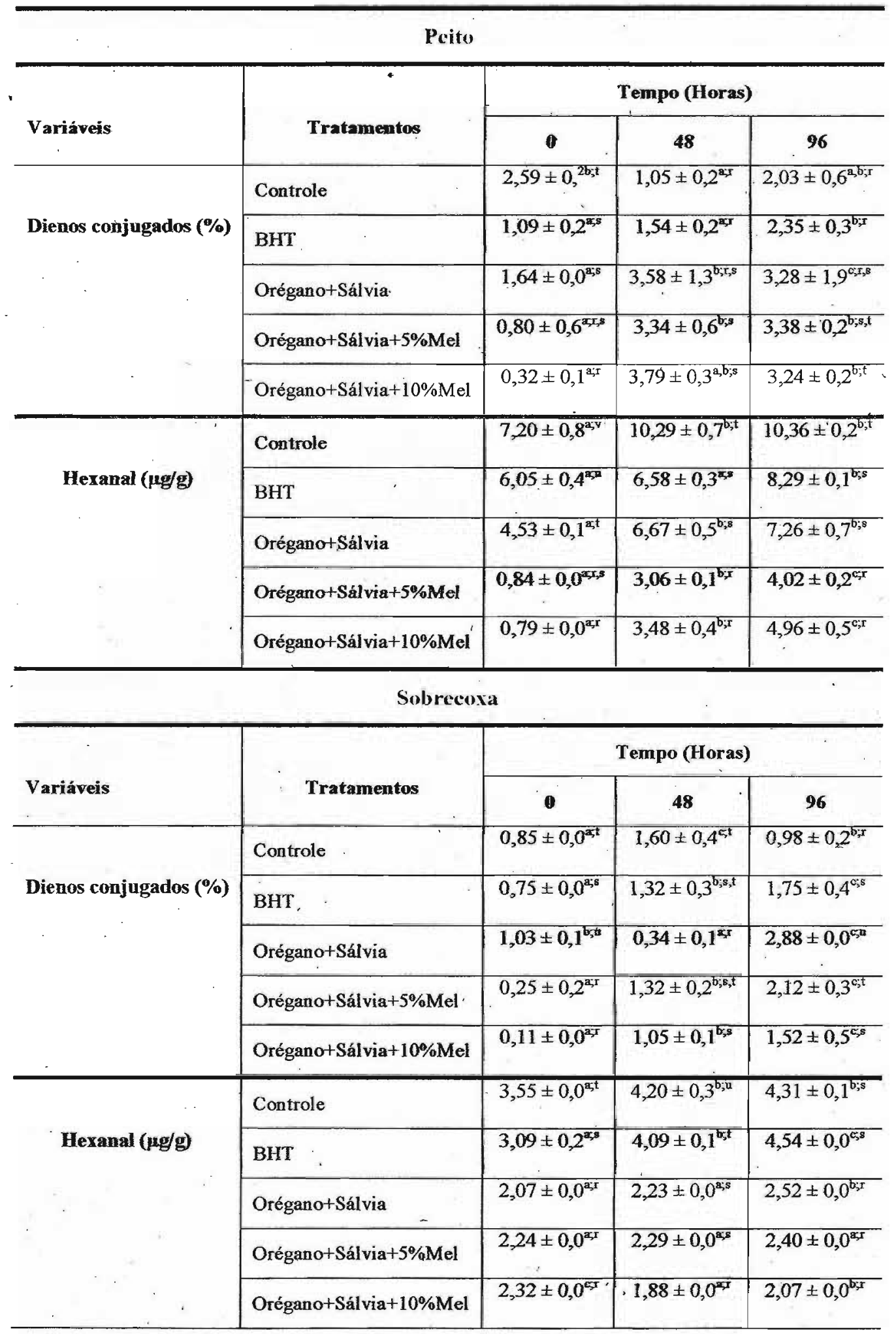

Letras de $(a, b, c)$ na mesma linha indicam diferenças estatisticamente significativas $p<0,05$

Letras de $(r, \mathrm{~s}, \mathrm{t}, \mathrm{n})$ na mesma coluna indicam diferenças estatisticamente significativas $p<0,05$ 
Quando avaliamos os resultados da análise de dienos conjugados, todas as amostras analisadas apresentaram um acréscimo nos valores durante os tempos de refrigeração (Tabela 8 ).

Este aumento nos valores dos dienos conjugados está relacionado com reações da oxidação dos lipídios, que oçorrem na presença do oxigênio.

No peito assado, maiores valores de dienos foram determinados no tempo 0 para o tratamento controle, seguido dos tratamentos: Orégano+Sálvia $\rightarrow$ BHT $\rightarrow$ Orégano+Sálvia $+5 \%$ Mel e Orégano+Sálvia+10\%. Em relação aos tempos 48 e 96 horas, os tratamentos controle e BHT mostraram-se estatisticamente semelhantes, com valores inferiores e os valores de dienos inferiores em relação aos demais tratamentos.

Na tabela 8 estão apresentados os valores de hexanal ( $\mu \mathrm{g} / \mathrm{g}$ de amostra - base seca) para todos os tratamentos estudados.

Os valores médios de hexanal na carne de peito assada variaram entre 0,79 a $10,36 \mu \mathrm{g} / \mathrm{g}$ de amostra - base seca (Tabela 8). Durante o tempo de refrigeração, observou-se um acréscimo nos teores de hexanal. O tratamento que apresentou os menores valores de hexanal após 96 horas de refrigeração foi o (orégano+sálvia $+5 \%$ de mel), seguido do (orégano+sálvia $+10 \%$ de mel). Em ordem decrescente, o comportamento dos tratamentos para os teores de hexanal foram: Controle $\rightarrow$ BHT $\rightarrow($ Orégano + Sálvia $) \rightarrow($ Orégano + Sálvia $+5 \%$ mel $) \rightarrow($ Orégano + Sálvia $+10 \%$ mel $)$.

Para a carne de sobrecoxa assada, as amostras tiveram um comportamento similar ao observado na carne de peito assado. Os valores variaram de 1,88 a $4,54 \mu \mathrm{g} / \mathrm{g}$ de amostra - base seca (Tabela 8). $O$ tratamento que apresentou os menores valores de hexanal após 96 horas foi o (orégano+sálvia+5\% de mel), seguido do (orégano+sálvia+10\% de mel)

O hexanal é considerado um indicador importante da oxidação lipídica por ser o produto mais abundante desta reação. Este aldeido contribui com o odor final indesejável e pode ser encontrado em concentrações crescentes durante a estocagem dos produtos alimentícios (St. Angelo et al., 1987). 


\subsection{Correlações lineares entre as variáveis}

Pela análise dos resultados obtidos por diferentes métodos para a verificação da proteção da oxidação lipídica na came de frango, foram estimados os coeficientes de correlação linear de Pearson.

No quadro 3 apresentamos as estimativas dos coeficientes de correlação linear de Pearson encontradas neste estudo.

Quadro 3 - Correlações lineares entre as variáveis estudadas

\begin{tabular}{|c|c|c|}
\hline Variáveis & $\begin{array}{c}\text { Estimativa do Coeficiente de } \\
\text { Correlação }\end{array}$ & $\begin{array}{c}\text { Nível } \\
\text { descritivo (p) }\end{array}$ \\
\hline Aa X TBARS & Peito & 0,003 \\
\hline pH X TBARS & 0,354 & $<0,001$ \\
\hline Hexanal X TBARS & $-0,625$ & $<0,001$ \\
\hline Dienos X TBARS & 0,820 & 0,249 \\
\hline Aa X Hexanal & $-0,140$ & 0,409 \\
\hline pH X Hexanal & 0,176 & 0,021 \\
\hline Dienos X Hexanal & $-0,467$ & 0,635 \\
\hline Aa X TBARS & 0,102 & $<0,001$ \\
\hline pH X TBARS & Sobrecoxa & 0,007 \\
\hline Hexanal X TBARS & 0,391 & $<0,001$ \\
\hline Dienos X TBARS & $-0,282$ & $<0,001$ \\
\hline Aa X Hexanal & 0,795 & 0,018 \\
\hline pH X Hexanal & 0,429 & 0,004 \\
\hline Dienos X Hexanal & 0,431 & 0,086 \\
\hline Aa) Ata & $-0,509$ & \\
\hline
\end{tabular}

- (Aa) = Atividade de água. 
Analisando as correlações lineares das variáveis da carne de peito assada, verificamos que entre a atividade de água e TBARS ocorreu uma correlação lineár pouco significativa $(0,354)$ (Quadro3). Quando se verificou a correlação entre pH e TBARS encontrou-se uma correlação linear negativa $(-0,625)$, ou seja, quanto maior o valor de TBARS menor o $\mathrm{pH}$ da carne. Também ocorreu uma correlação linear negativa $(-0,467)$ entre $\mathrm{pH}$ e hexanal onde, quanto maior a quantidade de hexamal na carne de peito menor o valor de pH. Verificando-se a correlação de hexanal e TBARS encontrouse uma correlaçáo linear positiva na carne de peito de $(0,820)$ (Figura 8).

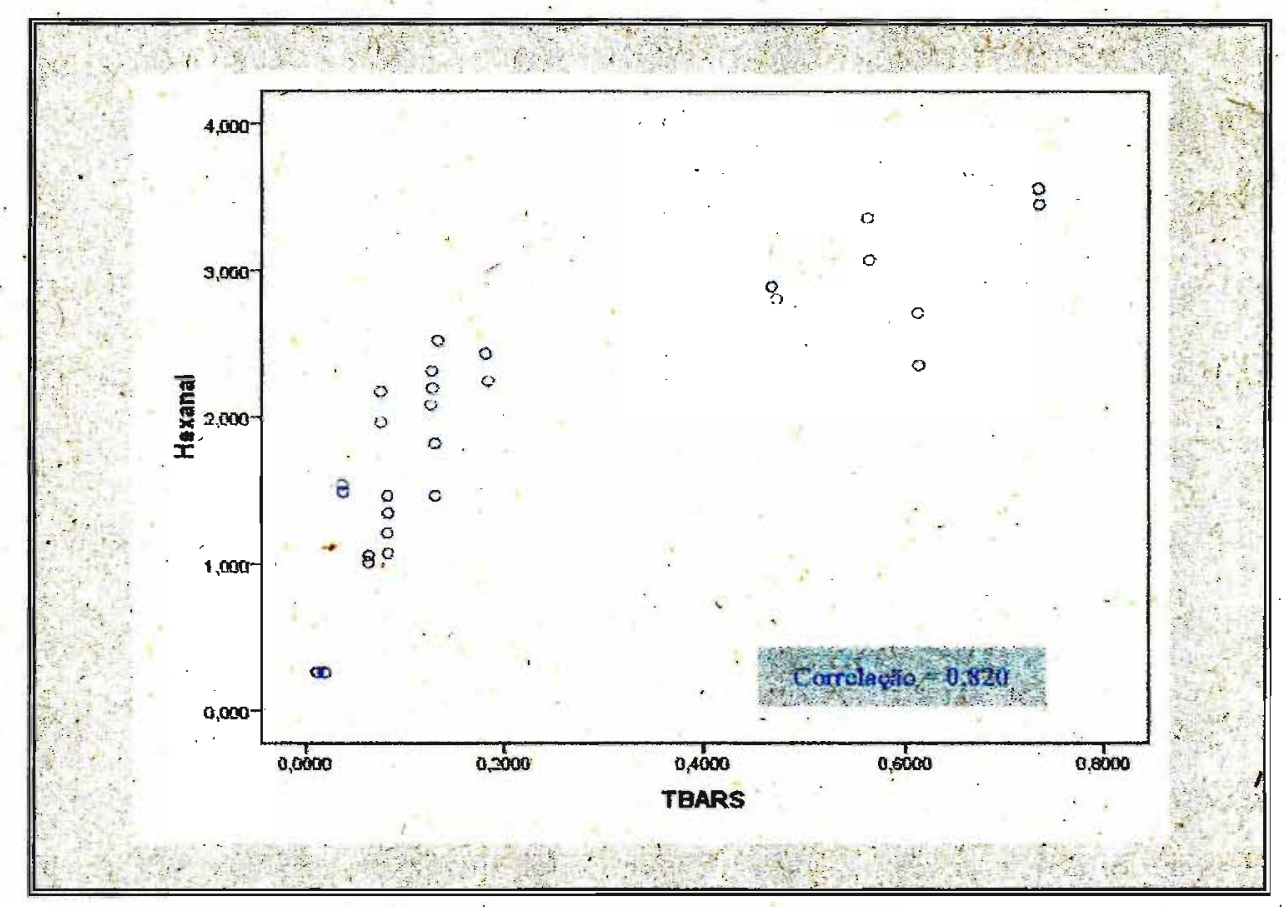

Figura 8 - Gráfico de dispersão das variáveis hexanal e TBARS na carne de peito assada

Quando avaliamos as correlações lịneares das variáveis encontradas na carne de sobrecoxa assada, concluímos que entre a atividade de água e TBARS encontrou-se uma correlação linear pouco significativa $(0,391)$ (Quadro3). Entre o pH e TBARS a correlação linear encontrada foi negativa $(-0,282)$, ou seja, quanto maior o valor de TBARS mentor o pH da carne. Também ocorreu uma correlação linear negativa $(-0,509)$ entre $\mathrm{pH}$ e hexanal onde, quanto maior a quantidade de hexanal na carne de sobrecoxa menor o valor de $\mathrm{pH}$. Ao verificar a correlação de hexanal e TBARS encontrou-se uma correlação linear positiva na carne de sobrecoxa de $(0,795)$ (Figura '9). 


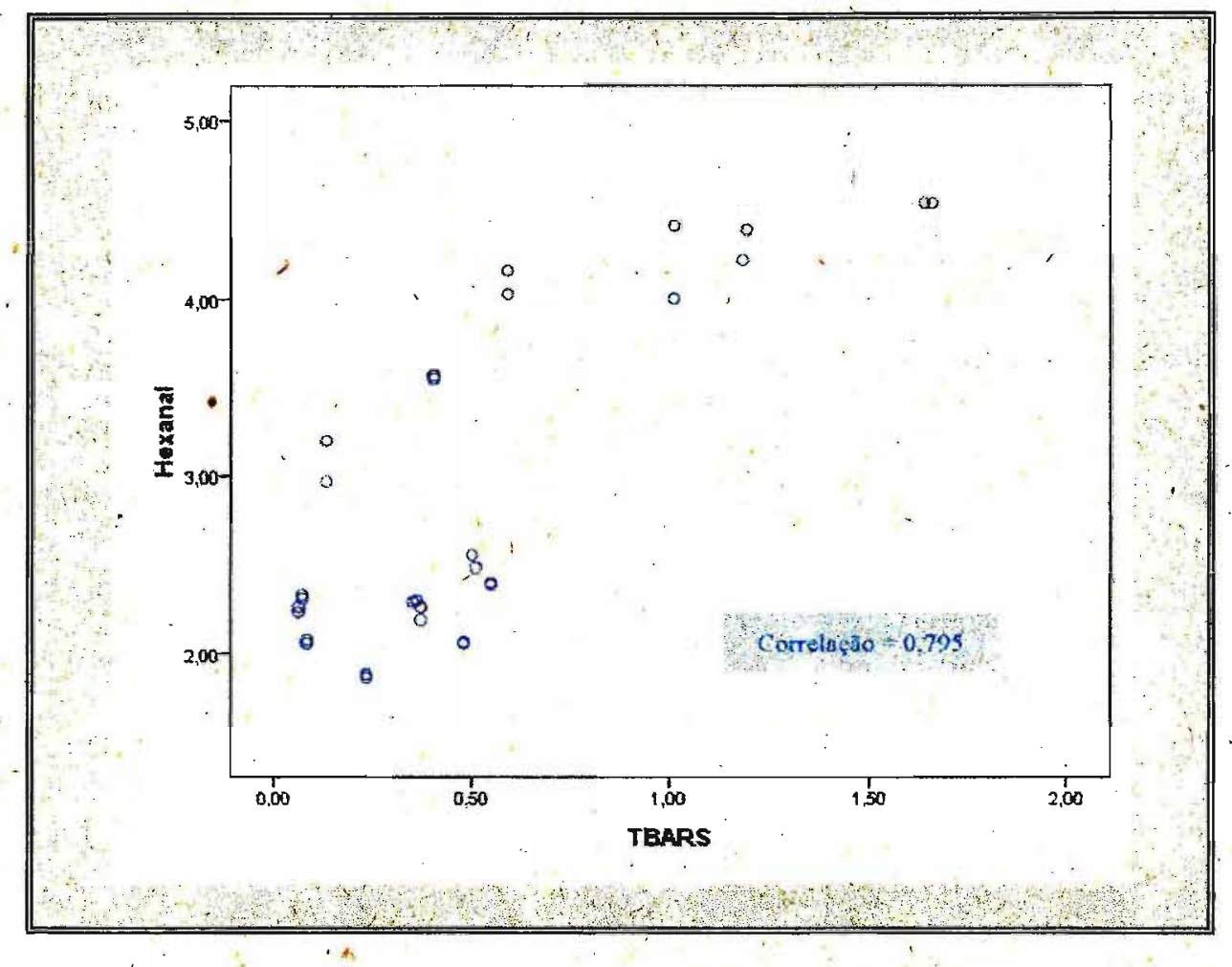

Figura 9 - Gráfico de dispersão das variạveis hexanal e TBARS na carne de sobrecoxa assada

Chen e Waimaleongora (1981) estudaram carne de aves domésticas, submetidas' a tratamentos com diferentes ácidos. Os autores observaram o mesmo comportamento observado no presente estudo, onde ocorreu a redução do pH e aumento da oxidação lipídica. Isso deve-se ao fato de que a queda do $\mathrm{pH}$ propicia a desnaturação de proteínas, com liberação de conteúdo celular e consequentemente do ferro heme, que age como pro-oxidante, propiciando a elevação dos teores de TBARS.

Resultados semelhantes também foram relados por Jensen et al., (1998), que avaliaram a quantidade de hexanal e TBARS em carne bovina cozida observaram um coeficiente de correlação de 0,83 . Outros autores encontraram correlações significatica de 0,95 entre TBARS, e hexanal durante o armazenamento de carnes (Ahn et al., 2000, Ahn et al., 2002).

Conforme anteriormente relatado em outros estudos (Dupuy et al., 1987, Jensen et al., 1998), podemos sugerir que os valores de TBARS e o conteúdo de hexanal podem ser utilizados como indicadores confiáveis na formação do aroma-requentado (WOF) em carnes cozidas/assadas. 


\subsection{Colesterol e óxidos de colesterol}

Nas Figuras 10 e 11 estão apresentados os teores médios de colesterol $(\mathrm{mg} / 100 \mathrm{~g}$ na base seca) dos dois tipos de carnes.
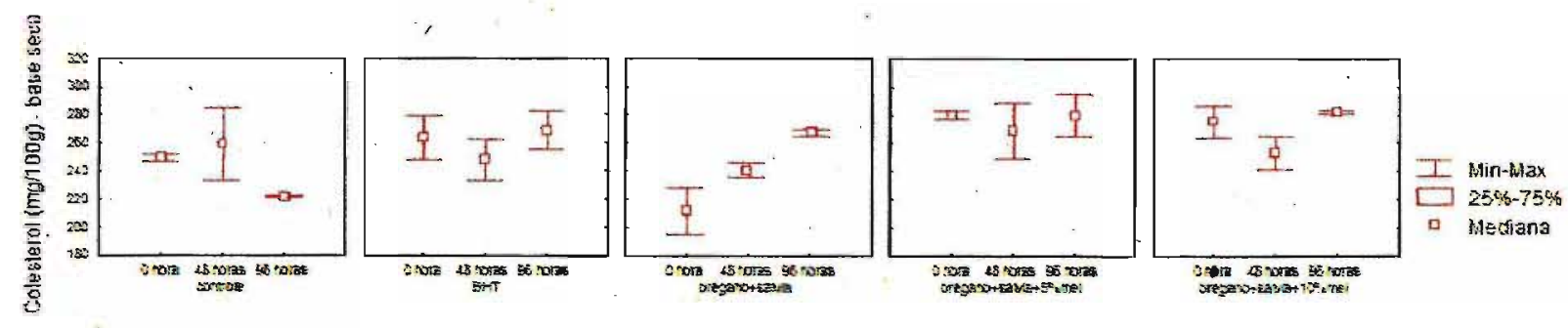

Figura 10 - Concentração do colesterol (mg/ $100 \mathrm{~g})$ do peito assado, segundo tratamento e tempo.
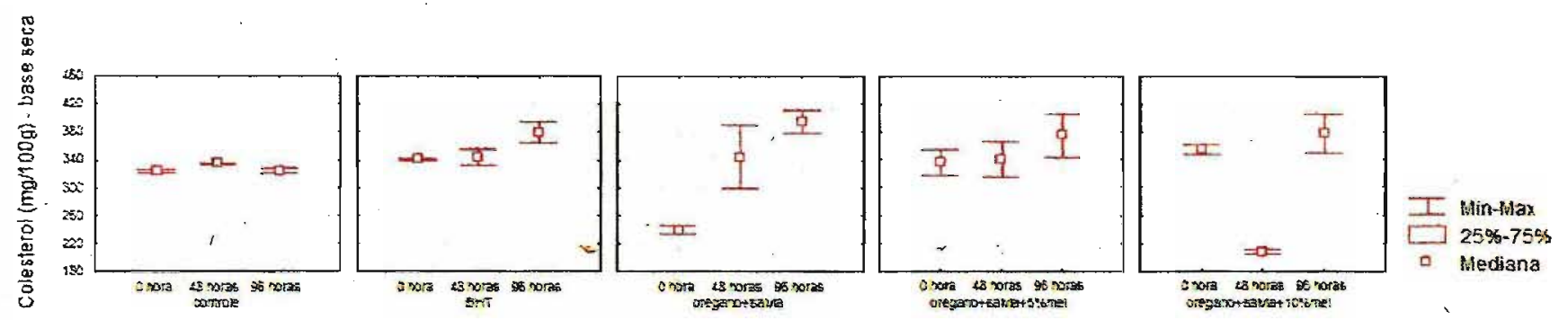

Figura 11 - Concentração do colesterol (mg/ $100 \mathrm{~g}$ ) da sobrecoxa assada, segundo tratamento e tempo.

As concentrações médias de colesterol (mg/100 $\mathrm{g}$ - base seca) observadas $\mathrm{n}$ as amostras de peito de frango foram entre $221,5 \pm 0,5$ e $281,9 \pm 1,5$ (Figura 10).

Os resultados inferenciais revelaram que as porções de peito assado apresentaram os mesmos valores médios de colesterol, segundo tratamento $(p=0,052)$ e tempo $(p=0,190)$.

Resultados semelhantes para colesterol foram encontrados na Tabela Brasileira de Composição de Alimentos - TACO (2006), que determinou valores de 245,86 $\mathrm{mg} / 100 \mathrm{~g}$ na base seca em amostras de peito sem pele grelhadas. 
Para as amostras de sobrecoxa assadas os teores de colesterol variaram de $208,11 \pm 4,9$ a $395,17 \pm 22,5 \mathrm{mg} / 100 \mathrm{~g}$ - base seca (Figura 11 ).

Na Tabela Brasileira de Composição de Alimentos - TACO (2006) os dados de colesterol para sobrecoxa sem pele assada $(326,58 \mathrm{mg} / 100 \mathrm{~g}$ na base seca) mostraram-se semelhantes aos encontrados neste estudo.

Em relação às amostras de sobrecoxa, observamos que os tratamentos não apresentam em média os mesmos valores $(\mathrm{p}=0,001)$ (Figura 8). É importante ressaltar também, que ao longo do tempo, os valores médios desta variável não foram estatisticamente iguais $(\mathrm{p}<0,001)$.

Estas diferenças no conteúdo de colesterol nos tecidos animais podem ser influenciadas pela linhagem, idade, composição da dieta, especialmente pela produção de ácidos graxos polinsaturados, (Komprda, et al., 2003). 
Nas tabelas 9 e 10 estão apresentados os resultados das análises de óxidos de colesterol.

Tabela 9 - Óxidos de colesterol ( $\mu \mathrm{g} / \mathrm{g}$ - base seca) (25-OH, 7-Ceto, $7 \alpha-\mathrm{OH}$

e $7(3-\mathrm{OH})$ do peito assado, segundo tratamento e tempo.

\begin{tabular}{|c|c|c|c|c|}
\hline \multirow[b]{3}{*}{ Variáveis } & \multicolumn{4}{|l|}{ Peito } \\
\hline & \multirow[b]{2}{*}{ Tratamentos } & \multicolumn{3}{|c|}{ Tempo (Horas) } \\
\hline & & $\mathbf{0}$ & 48 & 96 \\
\hline \multirow{5}{*}{ 7-Ceto $(\mu \mathrm{g} / \mathrm{g})$} & Controle & - & - & - \\
\hline & BHT & - & tr & - \\
\hline & Orégano+Sálvia & - & - & - \\
\hline & Orégano+Sálvia+5\%Mel & tr & tr & tr \\
\hline & Orégano+Sálvia $+10 \% \mathrm{Mel}$ & - & tr & $\operatorname{tr}$ \\
\hline \multirow{5}{*}{$25-\mathrm{OH}(\mu \mathrm{g} / \mathrm{g})$} & Controle & - & - & - \\
\hline & BHT & - & tr & - \\
\hline & Orégano+Sálvia & - & - & - \\
\hline & - Orégano+Sálvia $+5 \% \mathrm{Mel}$ & - & - & - \\
\hline & Orégano + Sálvia $+10 \% \mathrm{Mel}$ & tr & - & tr \\
\hline \multirow{5}{*}{$7 a-O H(\mu g / g)$} & Controle & - & - & - \\
\hline & BHT & - & tr & - \\
\hline & Orégano+Sálvia & - & - & - \\
\hline & Orégano+Sálvia $+5 \% \mathrm{Mel}$ & - & - & - \\
\hline & Orégano+Sálvia+10\%Mel & - & - & tr \\
\hline \multirow{5}{*}{$7 \beta-O H(\mu g / g)$} & Controle & - & - & - \\
\hline & BHT & - & - & - \\
\hline & Orégano+Sálvia & $\operatorname{tr}$ & - & tr \\
\hline & Orégano+Sálvia+5\%Mel & tr & $\mathbf{t r}$ & tr \\
\hline & Orégano+Sálvia+10\%Mel & tr & tr & tr \\
\hline \multirow{5}{*}{$\begin{array}{l}\text { Total de óxidos } \\
\text { de colesterol }(\mu \mathrm{g} / \mathrm{g})\end{array}$} & Controle & - & - & - \\
\hline & BHT & - & tr & - \\
\hline & Orégano+Sálvia & tr & - & tr \\
\hline & Orégano+Sálvia+5\%Mel & tr & $\mathbf{t r}$ & tr \\
\hline & Orégano+Sálvia+10\%Mel & $\operatorname{tr}$ & tr & tr \\
\hline
\end{tabular}

(tr) Valores abaixo do limite de quantificação 
Tabela 10 - Óxidos de colesterol ( $\mu \mathrm{g} / \mathrm{g}$ - base seca) (25-OH, 7-Ceto, 7 $\alpha-\mathrm{OH}$ e $7 \beta-\mathrm{OH})$ de sobrecoxa assada, segundo tratamento e tempo.

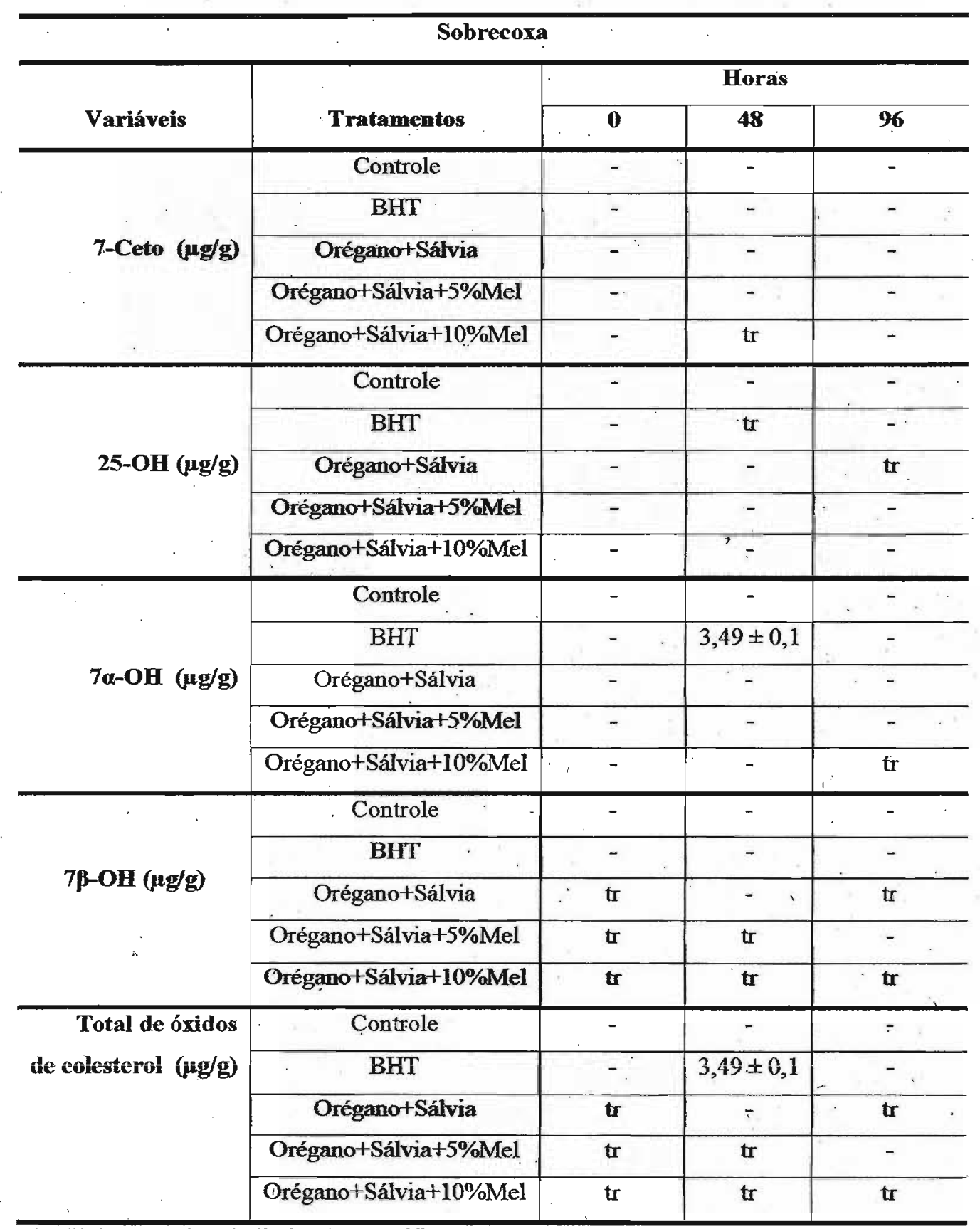

(tr) Valores abaixo do limite de quantificação 
Neste estudo, durante o processamento e ao longo do tempo de refrigeração foram encontrados apenas traços dos óxidos (25-OH, 7-Ceto, $7 \alpha-\mathrm{OH}$ e $7 \beta-\mathrm{OH})$, com exceção para a sobre coxa assada no tratamento BHT, no tempo de 48 horas, onde observou-se a presença de $7 \alpha-\mathrm{OH}(3,49 \mu \mathrm{g} / \mathrm{g}$ - base seca) (Tabelas 9 e 10).

Estes traços podem ter sido gerados por fatores que afetam a oxidação do colesterol, que podem estar relacionados a certas características do alimento: conteúdo de água, pH, quantidade, tipo de ácido graxo presente, presença de antioxidantes ou próoxidantes; a interações com outros constituintes do sistema alimentar e as condições de tratamento: tipo de processamento, tempo e condições de estocagem, entre outros (Addis, 1986; Hubbard et al., 1989; Dionisi et al., 1998; Paniangvait et al., 1995).

$\mathrm{O}$ processamento pode levar à oxidação dos lipídios presentes na carne e em seus produtos processados. O tratamento térmico tem efeitos negativos na estrutura celular, pois provoca a desnaturação das proteínas, principalmente da globina, deixando o íon ferro $^{+2}$ mais susceptíveis à oxidação com liberação de oxigênio molecular da oximioglobina presente nos músculos, propiciando condições para a produção de peróxidos de hidrogênio. Fragmentação, fracionamento e mistura da carne desfaz em estrutura muscular da mesma, aumentando a superficie de exposição ao oxigênio e a outros catalisadores da oxidação, $o$ que pode dar origem a radicais livres e, conseqüentemente, desencadear reações de oxidação do colesterol (Novelli et al., 1998).

\section{7. Ácidos graxos}

Nas tabelas 11 e 12 estão apresentadas a composição média dos ácidos graxos das amostras de peito assado analisadas. 
Tabela 11 - Composição média de ácidos graxos (\%) do peito de frango assado submetido aos cinco tratamentos, no tempos 0,48 e 96 horas de refrigeração.

\begin{tabular}{lcccccc}
\hline \multicolumn{7}{c}{ Pcito Tempon } \\
\hline Ácidos Graxos & Controle & BHT & Orégano+Sálvia & Orégano+Sálvia+5\%Mel & Orégano+Sálvia+10\%Mel \\
C14:0 & - & 0,52 & - & - & - \\
C15:0 & - & - & 1,26 & - & - \\
C16:0 & 24,15 & 24,91 & 21,04 & 22,65 & 25,01 \\
C16:1 & 7,69 & 8,67 & 5,89 & $\ddots$ & 7,17 & 7,96 \\
C18:0 & 5,25 & 4,36 & 5,67 & 5,63 & 5,30 \\
C18:1n9c & 33,03 & 32,84 & 35,25 & 39,44 & 34,84 \\
C18:2n6c & 23,61 & 23,81 & 25,51 & 22,41 & 22,73 \\
C18:3n3-a & 0,58 & 1,28 & 0,69 & - & 0,56 \\
C20:4n6 & 4,02 & 3,62 & 4,14 & 2,70 & 3,60 \\
C20:5n3 & 0,71 & - & - & - & - \\
C24:109 & - & - & 0,55 & - & - \\
C22:6n3 & 0,97 & - & - & - & - \\
\hline
\end{tabular}

Paitu-Tempo 48 horas

\begin{tabular}{lccccc}
\hline Ácidos Graxos & Controle & BHT & Orégano+Salvia & Orégano+Sálvia+5\%Mè & Orégano+Sálvia+10\%Mel \\
C16:0 & 21,34 & 25,63 & 23,34 & 22,42 & 26,26 \\
C16:1 & 4,84 & 6,30 & 7,05 & 7,77 & 7,26 \\
C18:0 & 6,50 & 6,73 & 5,93 & 5,29 & 5,14 \\
C18:1n9c & 39,29 & 37,25 & 37,45 & 37,41 & 36,64 \\
C18:2n6c & 22,07 & 24,09 & 21,14 & 23,57 & 24,70 \\
C22:1n9 & - & -- & 1,20 & - & - \\
C20:3n3 & 3,34 & - & 2,93 & 3,54 & - \\
$\mathbf{C 2 0 : 4 n 6}$ & - & - & - & - & - \\
$\mathbf{C 2 0 : 5 n 3}$ & 2,27 & - & - & - & - \\
$\mathbf{C 2 2 : 6 n 3}$ & 0,36 & - & - & - & - \\
\hline
\end{tabular}

Peitn ... Trmpo 96 how

\begin{tabular}{lccccc}
\hline Acidos Graxos & Controle & BHT & Orégano+Sálvia & Orégano+Sálvia+5\%Mel & Orégano+Sálvia+10\%Mel \\
C15:0 & - & - & 1,37 & - & - \\
C16:0 & 21,66 & 23,13 & 21,32 & 22,62 & 22,95 \\
C16:1 & 7,81 & 6,81 & 7,59 & 8,20 & 6,60 \\
C18:0 & 6,95 & 6,52 & 5,49 & 6,17 & 6,68 \\
C18:109c & 36,38 & 39,34 & 32,52 & 37,76 & 34,74 \\
C18:2n6c & 23,19 & 24,20 & 24,53 & 25,24 & 24,38 \\
C20:3n6 & - & - & - & - & 4,66 \\
C20:3n3 & 3,34 & - & - & - & - \\
C20:4n6 & - & - & 5,05 & - & - \\
C24:1n9 & - & - & 2,13 & & -
\end{tabular}


Tabela 12 - Composição média de ácidos graxos (\%) do peito de frango assado, segundo tratamento e tempo.

\begin{tabular}{|c|c|c|c|c|}
\hline \multirow[b]{3}{*}{ Variáveis } & \multicolumn{2}{|l|}{ Peito } & & \\
\hline & \multirow[b]{2}{*}{ Tratamentos } & \multicolumn{3}{|c|}{ Horas } \\
\hline & & $\mathbf{0}$ & 48 & 96 \\
\hline \multirow{5}{*}{$\begin{array}{l}\text { Ácidos graxos } \\
\text { saturados (\%) }\end{array}$} & Controle & $29,4^{6 ; r, 5}$ & $27,8^{\mathrm{a}, \mathrm{T}}$ & $28,6^{2, b ; r}$ \\
\hline & $\mathrm{BHT}$ & $29,8^{\mathrm{a}, \mathrm{r}, \mathrm{s}}$ & $32,4^{6 ; 3}$ & $29,7^{\mathrm{a} ; \mathrm{s}}$ \\
\hline & Orégano+Sálvia & $28,0^{x, r}$ & $30,2^{\mathrm{b} ; \mathrm{r}}$ & $28,2^{\text {a,r }}$ \\
\hline & Orégano+Sálvia+5\%Mel & $28,3^{\mathrm{a}, \mathrm{r}}$ & $27,7^{\mathrm{a}, \mathrm{I}}$ & $28,8^{2 \pi, 5}$ \\
\hline & Orégano+Sálvia $+10 \% \mathrm{Mel}$ & $30,3^{2 b ; r ; s}$ & $31,4^{\mathrm{b}, \mathrm{t}}$ & $29,6^{\mathrm{a} ; \mathrm{r}, \mathrm{s}}$ \\
\hline \multirow{5}{*}{$\begin{array}{r}\text { Ácidos graxos } \\
\text { insaturados (\%) }\end{array}$} & Controle & $70,6^{\operatorname{arx}}$ & $72,2^{b, t}$ & $71,4^{\mathrm{a}, \mathrm{b} ; \mathrm{s}}$ \\
\hline & $\mathrm{BHT}$ & $70,2^{b ; \pi}$ & $67,6^{2 / 9}$ & $70,4^{\mathrm{b} ; \mathrm{r}}$ \\
\hline & Orégano+Sálvia & $72,0^{b ; s}$ & $69,8^{8, t}$ & $71,8^{\mathrm{b} ; \mathrm{s}}$ \\
\hline & Orégano+Sálvia $+5 \% \mathrm{Mel}$ & $71,7^{\mathrm{a}, \mathrm{r}, \mathrm{s}}$ & $72,3^{\mathrm{at}}$ & $71,2^{1, s}$ \\
\hline & Orégano+Sálvia $+10 \% \mathrm{Mel}$ & $69,7^{b ; \pi}$ & $68,6^{a, b ; r}$ & $70,4^{6 ; r, s}$ \\
\hline \multirow{5}{*}{$\begin{array}{r}\text { Ácidos graxos } \\
\text { monoinsaturados } \\
(\%)\end{array}$} & Controle & $40,7^{\mathrm{a}, \mathrm{r}}$ & $44,1^{6, r}$ & $44,2^{\text {b,r }}$ \\
\hline & $\mathrm{BHT}$ & $41,5^{\text {ass }}$ & $43,6^{\mathrm{b} ; \mathrm{r}}$ & $46,2^{\mathrm{c} ; \mathrm{s}}$ \\
\hline & Orégano+Sálvia & $41,7^{2 ; s}$ & $45,7^{\mathrm{c} ; \mathrm{s}}$ & $42,2^{b ; r}$ \\
\hline & Orégano+Sálvia+5\%Mel & $46,6^{b, t}$ & $45,2^{\mathrm{ajs}}$ & $46,0^{6 ; s}$ \\
\hline & Orégano+Sálvia+10\%Mel & $42,8^{2,3}$ & $43,9^{b ; x}$ & $41,3^{\mathrm{a}, \mathrm{T}}$ \\
\hline \multirow{5}{*}{$\begin{array}{r}\text { Ácidos graxos } \\
\text { polinsaturados (\%) }\end{array}$} & Controle & $29,3^{\mathrm{a,5}}$ & $28,0^{\mathrm{a}, \mathrm{t}}$ & $27,2^{\text {2,s }}$ \\
\hline & BHT & $28,7^{b ; x}$ & $24,1^{\mathrm{a} ; \mathrm{I}}$ & $24,2^{\mathrm{a} ; \mathrm{r}}$ \\
\hline & Orégano+Sálvia & $30,3^{b ; r, s}$ & $24,1^{\mathrm{ar} \mathrm{r}}$ & $29,6^{b ; s, t}$ \\
\hline & Orégano+Sálvia $+5 \% \mathrm{Mel}$ & $25,1^{\alpha, r}$ & $27,1^{2 ; s}$ & $25,2^{\mathrm{a} ; \mathrm{r}}$ \\
\hline & Orégano+Sálvia+10\%Mel & $26,9^{a, b, r}$ & $24,7^{\mathrm{a}, \mathrm{r}}$ & $29,0^{b ; s, t}$ \\
\hline
\end{tabular}

Letras de $(a, b, c)$ na mesma linha indicam diferenças estatisticamente significativas $p<0,05$

Letras de $(r, s, t)$ na mesma coluna indicam diferenças estatisticamente significativas $p<0,05$ 
Em relação aos cortes de peito, os ácidos graxos saturados encontrados em maior. abundância foram os ácidos graxos palmítico (16:0) e o esteárico (18:0). $O$ ácido graxo monoinsaturado em maior concentração foi o ácido oléico (18:1 n-9), entretanto, outros ácidos graxos monoinsaturados foram encontrados em menor proporção, como o ácido palmitoléico (16:1) e o nervônico (24:1 n-9). Já os ácidos graxos polinsaturados determinados em maior predominância nas amostras de peito foram: linoléico (18:2 n6); araquidônico (20:4 n6) e linolênico (18:3 n3), respectivamente (Tabela 11).

Para analisar os efeitos do processamento térmico e da refrigeração sobre o perfil de ácidos graxos das amostras de peito assado, foram agrupados o total de ácidos graxos saturados, monoinsaturados e polinsaturados, segundo tratamento e tempo (Tabela 12).

De acordo com a análise estatística, os teores de ácidos graxos saturados, insaturados e polinsaturados das amostras de peito sofreram efeito de interação entre tratamento e tempo $(p<0,001)$. A tabela 12 também mostra as comparações múltiplas entre os tratamentos dentro de cada tempo, e entre os tempos dentro de cada tratamento.

Em amostras de peito, pequenas reduções dos ácidos graxos saturados foram observadas nos tratamentos controle e orégano + sálvià $+5 \%$ mel, no decorrer do tempo de refrigeração. Comportamento semelhante foi determinado por Conchillo et al (2004), onde os autores observaram que os ácidos graxos saturados são estáveis frente a. autoxidaçã̃o, porém pequenas reduções nos teores de ácidos graxos saturados podem ocorrer devido à cocção e ao armazènamento.

Quando avaliamos o perfil de ácidos graxos polinsaturados no decorrer do tempo das amostras de peito assados durante o período de refrigeração pode ser observado na Tabela 12 , onde nos tratamentos controle, BHT e orégano+sálvia o porcentual destes ácidos graxos foi reduzido nos tempos 48 e 96 horas. Entretanto, no tratamento orégano+sálvia $+5 \%$ mel a quantidade não mudou significativamente, mas no tratamento orégano + sálvia $+10 \%$ mel a concentração de ácidos graxos polinsaturados aumentou no período de refrigeração.

Estes resultados estão de acordo com o perfil de ácidos graxos para a carne de peito de frango determinado por Bragagnolo e Rodriguez-Amaya (1992), que obtiveram $33 \%$ de ácidos saturados, $46 \%$ monoinsaturados e $21 \%$ de poliinsaturados. 
Nas tabelas 13 e 14 estão apresentadas a composição média dos ácidos graxos e o perfil das amostras de sobrecoxa assadas.

Tabela 13 - Composição média de ácidos graxos (\%) da sobrecoxa de frango assada submetido aos cinco tratamentos, no tempos 0,48 e 96 horas de refrigeração.

\begin{tabular}{|c|c|c|c|c|c|}
\hline \multirow[b]{2}{*}{ Ácidos Graxos } & \multirow[b]{2}{*}{ Controle } & \multicolumn{3}{|c|}{ Sobrecoxa-Tempon } & . \\
\hline & & BHT & Orégano+Sálvia & Orégano+Sálvia $+5 \% \mathrm{Mel}$ & Orégano+Sálvia $+10 \%$ Mel \\
\hline C16:0 & 24,15 & 24,91 & 21,04 & 22,65 & 25,01 \\
\hline C16:1 & 7,69 & 8,67 & .. $\quad 5,89$ & \multirow[t]{2}{*}{7,17} & 7,96 \\
\hline C18:0 & 5,25 & 4,36 & 5,67 & & 5,30 \\
\hline C18:1n9c & 33,03 & 32,84 & 35,25 & & $34,84^{\prime}$ \\
\hline C18:2n6c & 23,61 & 23,81 & 25,51 & 22,41 & \multirow[t]{2}{*}{22,73} \\
\hline C18:3n3-a & 0,58 & 1,28 & 0,69 & $\gamma(2)+$ & \\
\hline C20:4n6 & 4,02 & 3,62 & 4,14 & 2,70 & 3,60 \\
\hline \multicolumn{6}{|c|}{ Sobrecoxa - Tempo +8 horas } \\
\hline Ácidos Graxos & Controle & BHT & Orégano+Sálvia & Orégano + Sálvia $+5 \% \mathrm{Me}$ & Orégano+Sálvia $+10 \% \mathrm{Mel}$ \\
\hline C16:0 & 23,67 & 23,16 & 20,35 & 22,93 & 21,91 \\
\hline C16:1 & 5,77 & 5,55 & 6,32 & 5,97 & 6,03 \\
\hline C18:0 & 6,35 & 5,95 & 5,36 & 6,74 & 5,77 \\
\hline C18:1n9c & 45,25 & 42,09 & 40,98 & 42,34 & 43,22 \\
\hline C18:2n6c & 17,91 & 20,80 & 24,24 & 19,71 & 21,04 \\
\hline C18:3n3-a & 0,04 & - & $-\cdots$ & - & - \\
\hline C20:1n 9 & - & - & 1,38 & 1,10 & 1,23 \\
\hline C22:1n9 & - & 1,04 & - & - & $\therefore$ \\
\hline$C 20: 3 n 3$ & 1,01 & 1,43 & 1,37 & 1,21 & 0,81 \\
\hline & & & Sobrecoxa - & empe 96 horas & \\
\hline Ácidos Graxos & Controle & BHT & Orégano+Sálvia & Orégano+Sálvia $+5 \% \mathrm{Me}$ & Orégano+Sálvia+10\% Mel \\
\hline C16:0 & 21,48 & 22,10 & 22,20 & 21,54 & 21,83 \\
\hline C16:1 & 6,33 & 7,73 & 5,97 & 6,00 & 6,31 \\
\hline C18:0 & 5,99 & 4,89 & 5,76 & 5,64 & 4,86 \\
\hline C18:1n9c & 42,35 & 42,86 & 41,61 & 43,11 & 42,05 \\
\hline C18:2n6c & 21,31 & 20,19 & 22,11 & 21,21 & 22,69 \\
\hline C20:2 & 1,08 & $-\quad$ & - &.$^{-}$ & - \\
\hline C20:1n9 & - & 1,12 & 1,26 & 1,13 & 1,26 \\
\hline C20:3n3 & 1,47 & - & 1,10 & 1,38 & 1,01 \\
\hline
\end{tabular}


Tabela 14 - Composição média de ácidos graxos (\%) da sobrecoxa de frango assada, segundo tratamento e tempo.

\begin{tabular}{|c|c|c|c|c|}
\hline & Sobrecoxa & . & & \\
\hline \multirow[b]{2}{*}{ Variáveis } & \multirow[b]{2}{*}{ Tratamentos } & \multicolumn{3}{|c|}{ Horas } \\
\hline & & 0 & 48 & 96 \\
\hline \multirow{5}{*}{$\begin{array}{l}\text { Ácidos graxos } \\
\text { saturados (\%) }\end{array}$} & Controle & $26,3^{\text {arr }}$ & $30,0^{6, t}$ & $27,5^{\text {a,r }}$ \\
\hline & $\overline{\mathrm{BHT}}$ & $27,3^{\mathrm{ab} ; \mathrm{r}}$ & $29,1^{\mathrm{b} ; \mathrm{s}, \mathrm{t}}$ & $27,0^{\mathrm{a}, \mathrm{r}}$ \\
\hline & Orégano+Sálvia & $27,9^{a b ; 5}$ & $25,7^{\mathrm{a}, \mathrm{r}}$ & $28,0^{\mathrm{b}, \mathrm{I}}$ \\
\hline & Orégano+Sálvia+5\%Mel & $27,0^{\mathrm{a}, \mathrm{I}}$ & $29,7^{6, s, t}$ & $27,2^{\mathrm{a}, \mathrm{r}}$ \\
\hline & Orégano+Sálvia $+10 \% \mathrm{Mel}$ & $27,8^{a \cdot r}$ & $27,7^{\text {arr }}$ & $26,7^{\mathrm{a} ; \mathrm{r}}$ \\
\hline \multirow{5}{*}{ insaturados (\%) } & Controle & $73,8^{6,1}$ & $70,0^{2, x}$ & $72,5^{b ; r}$ \\
\hline & BHT & $72,8^{2,6 ; 5}$ & $70,9^{2, r, 8}$ & $73,0^{6 ; r}$ \\
\hline & Orégano+Sálvia & $72,1^{\mathrm{a}, \mathrm{b} ; \mathrm{r}}$ & $74,3^{\mathrm{b} ; \mathrm{t}}$ & $72,0^{\mathrm{ajr}}$ \\
\hline & Orégano+Sálvia $+5 \% \mathrm{Mel}$ & $73,0^{6,5}$ & $70,3^{\operatorname{arrs} 3}$ & $72,8^{6, r}$ \\
\hline & Orégano+Sálvia+10\%Mel & $72,2^{x, r}$ & $72,3^{x, 2}$ & $73,3^{\alpha, r}$ \\
\hline \multirow{5}{*}{$\begin{array}{r}\text { Ácidos graxos } \\
\text { monoinsaturados (\%) }\end{array}$} & Controle & $48,6^{\text {air }}$ & $51,0^{6, t}$ & $48,7^{\mathrm{a}, \mathrm{r}}$ \\
\hline & BHT & $50,8^{a, b ; r, s}$ & $48,7^{\mathrm{a}, \mathrm{r}, \mathrm{s}}$ & $51,7^{\mathrm{b;r,5}}$ \\
\hline & Orégano+Sálvia & $51,2^{a ; s, t}$ & $48,7^{\text {a,s }}$ & $48,8^{\text {काI }}$ \\
\hline & Orégano+Sálvia+5\%Mel & $49,6^{\overline{\mathrm{a} ; \mathrm{r}}}$ & $49,4^{\mathrm{ass}, t}$ & $50,2^{\mathrm{a} \cdot \mathrm{T}}$ \\
\hline & Orégano+Sálvia+10\%Mel & $50_{2} 0^{a, r, s, t}$ & $50,5^{\alpha ; \mathrm{s}, \mathrm{t}}$ & $49,6^{\mathrm{a} ; \mathrm{r}}$ \\
\hline \multirow{5}{*}{$\begin{array}{r}\text { Ácidos graxos } \\
\text { polinsaturados (\%) }\end{array}$} & Controle & $25,2^{\mathrm{j}, \mathrm{s}}$ & $19,0^{\mathrm{ar} r}$ & $23,9^{b ; r}$ \\
\hline & BHT & $22,0^{2,2}$ & $22,2^{\mathrm{a} ; \mathrm{s}}$ & $21,3^{\text {ajr }}$ \\
\hline & Orégano+Sálvia & $20,9^{a ; r}$ & $25,6^{\mathrm{b} ; \mathrm{s}}$ & $23,2^{\mathrm{ajr} r}$ \\
\hline & Orégano+Sálvia $+5 \% \mathrm{Mel}$ & $23,4^{\mathrm{cr,s}}$ & $20,9^{\mathrm{arr}, \mathrm{s}}$ & $22,6^{6 ; x}$ \\
\hline & Orégano+Sálvia+10\%Mel & $22,2^{\alpha ; r, 5}$ & $21,8^{\mathrm{a} ; \mathrm{s}}$ & $23,7^{\text {arr }}$ \\
\hline
\end{tabular}

Assim como observado nas amostras de peito, os ácidos graxos saturados encontrados em maior prevalência foram os ácidos palmítico (16:0) e o esteárico (18:0). O ácido graxo monoinsaturado em maior concentração foi o ácido oléico (18:1 n-9) e o principal polinsaturado foi o linoléico (18:2 n6).

Nas amostras de sobrecoxa foram observados efeitos de interação entre tratamento e tempo $(p<0,001)$ para todas as classes de ácidos graxos (saturados, insaturados, monoinsaturados e polinsaturados). Na tabela 14 também observamos as comparações múltiplas entre os tratamentos dentro de cada tempo, e entre os tempos dentro de cada tratamento. 
O perfil dos ácidos graxos da sobrecoxa assada foi agrupado em ácidos graxos saturados, insaturados, monoinsaturados e polinsaturados, segundo tratamento e tempo (Tabela 14).

$\mathrm{Na}$ composição dos ácidos graxos saturados observou-se, após 48 de refrigeração, diferenças significativas em relação ao tempo 0 , onde nos tratamentos controle, BHT e orégano+sálvia $+5 \%$ mel ocorreu um aumento significativo na porcentagem desta classe de ácido graxo. Mas, quando avaliamos o tempo 96 horas os teores dos saturados apresentaram as concentrações do tempo 0 .

O perfil de ácidos graxos polinsaturados no decorrer do tempo das amostras de sobrecoxa assadas durante o período de refrigeração pode ser observado na Tabela 14 , onde nos tratamentos controle, BHT e orégano+sálvia o porcentual destes ácidos graxos foi reduzido nos tempos 48 e 96 horas. Entretanto, nos tratamentos orégano + sálvia $+5 \%$ mel e orégano + sálvia $+10 \%$ mel a concentração de ácidos graxos polinsaturados aumentou no período de refrigeração.

Os resultados médios encontrados neste estudo para os ácidos graxos saturados e insaturados são semelhantes aos descritos por Rhee et al., (1996) que determinaram teores de $30,6 \%$ de ácidos graxos saturados e 70,4\% de insaturados em amostras de sobrecoxa. 


\subsection{Análise Microbiológica}

Os cortes (peito e de sobrecoxa) de frango assados apresentaram aspecto, odor e cor característicos. As quantidades médias dos indicadores higiênicos e sanitários podem ser observadas nas tabelas 15 e 16.

Tabela 15 - Média da quantidade de microorganismos encontrados nas amostras de peito de frango assado.

\begin{tabular}{|c|c|c|c|c|c|c|}
\hline \multirow[t]{2}{*}{ Parâmetros } & \multicolumn{5}{|c|}{ Indicadores Higiênicos } & \multirow{2}{*}{$\begin{array}{c}\text { Tolerância } \\
\text { (g) }\end{array}$} \\
\hline & Controle & BHT & Orégano+Sálvia & Orégano+Sálvia $+5 \% \mathrm{Mel}$ & Orégano+Sálvia $+10 \% \mathrm{Mel}$ & \\
\hline Contagem & $<10^{3}$ & $<10^{3}$ & $<10^{3}$ & $<10^{3}$ & $<10^{3}$ & ---X--- \\
\hline Bolores e & $<10^{3}$ & $<10^{3}$ & $2.10^{3}$ & $<10^{3}$ & $<10^{3}$ & $-X--$ \\
\hline Coliformes & $<3$ & $<3$ & $<3$ & $<3$ & $<3$ & $-\mathrm{X}--$ \\
\hline \multicolumn{7}{|c|}{ Indicadores Sanitários } \\
\hline Coliformes & $<3$ & $\therefore<3$ & $<3$ & $<3$ & $<3$ & 2.10 \\
\hline Staphylococcus & $<100$ & $<100$ & $<100$ & $<100$ & $<100$ & $10^{3}$ \\
\hline Bacillus cereus & $<100$ & $<100$ & $<100$ & $<100$ & $<100$ & $10^{3}$ \\
\hline Clostridium $S R$ & $<100$ & $<100$ & $<100$ & $<100$ & $<100$ & $10^{3}$ \\
\hline Salmonella sp & $A^{*}$ & A & A & A & A & Ausente \\
\hline
\end{tabular}


Tabela 16 - Média da quantidade de microorganismos encontrados nas amostras de sobrecoxa assada de frango.

\begin{tabular}{|c|c|c|c|c|c|c|}
\hline \multirow{2}{*}{ Parâmetros } & \multicolumn{5}{|c|}{ Indicadores Higiênicos } & \multirow{2}{*}{$\begin{array}{l}\text { Tolerância } \\
\text { (g) }\end{array}$} \\
\hline & Controle & BHT & Orégano+Sálvia & Orégano + Sálvia $+5 \%$ Mel & Orégano + Sálvia $+10 \% \mathrm{Mel}$ & \\
\hline Contagem & $5.10^{3}$ & $<10^{3}$ & $2.10^{3}$ & $<10^{3}$ & $<10^{3}$ & $\cdots X$ \\
\hline Bolores e & $<10^{3}$ & $<10^{3}$ & $<10^{3}$ & $<10^{3}$ & $10^{3}$ & $--\mathrm{X}--$ \\
\hline \multirow[t]{2}{*}{ Coliformes } & $<3$ & $<3$ & $<3$ & $<3$ & $<3$ & $---X---$ \\
\hline & \multicolumn{5}{|c|}{ Indicadores Sanitários } & . \\
\hline Coliformes & $<3$ & $<3$ & $<3$ & $<3$ & $<3$ & 2.10 \\
\hline Staphylococcus & $<100$ & $<100$ & $<100$ & $<100$ & $<100$ & $10^{3}$ \\
\hline Bacillus cereus & $<100$ & $<100$ & $<100$ & $<100$ & $<100$ & $10^{3}$ \\
\hline Clostridium $S R$ & $<100$ & $<100$ & $<100$ & $<100$ & $<100$ & $10^{3}$ \\
\hline Salmonella sp & $A^{*}$ & A & A & A & A & Ausente \\
\hline
\end{tabular}

Os valores dos indicadores higiênicos das carnes de peito e sobrecoxa assadas apresentados na Tabelas 15 e 16 estão em conformidade com os indicados para este tipo de carne, conforme a regulamento técnico sobre padrões microbiológicos para alimento (Brasil, 2001).

Com relą̧ão às quantidades dos microorganismos Staphylococcus, Bacillus cereus e Clostridium $S R$, as análises das amostras de peito e sobrecoxa de frango demonstraram valores abaixo de $100 \mathrm{~g}$, ou seja, bem abaixo de $1000 \mathrm{~g}$, quantidade máxima tolerada pela ANVISA (Brasil, 2001). A análise de Salmonella sp detectou a ausência desta bactéria nas amostras.

Portanto, pode-se considerar que os produtos analisados encontram-se de acordo com os padrões legais vigentes, e assim, apropriados para o consumo. 


\subsection{Análise Sensorial}

Primeiramente é importante salientar que a nota 5 ("nem gostei, nem desgostei"), ponto central da escala hedônica, foi considerada como nota de corte para o teste de aceitabilidade.

A avaliação dos resultados obtidos nas amostras de peito de frango demonstraram que a maior parcela dos provadores atribuiu notas acima das notas de corte estabelecidas (Figura 12). Dos 50 provadores que participaram desta pesquisa, apenas 8 pessoas eram do sexo masculino.

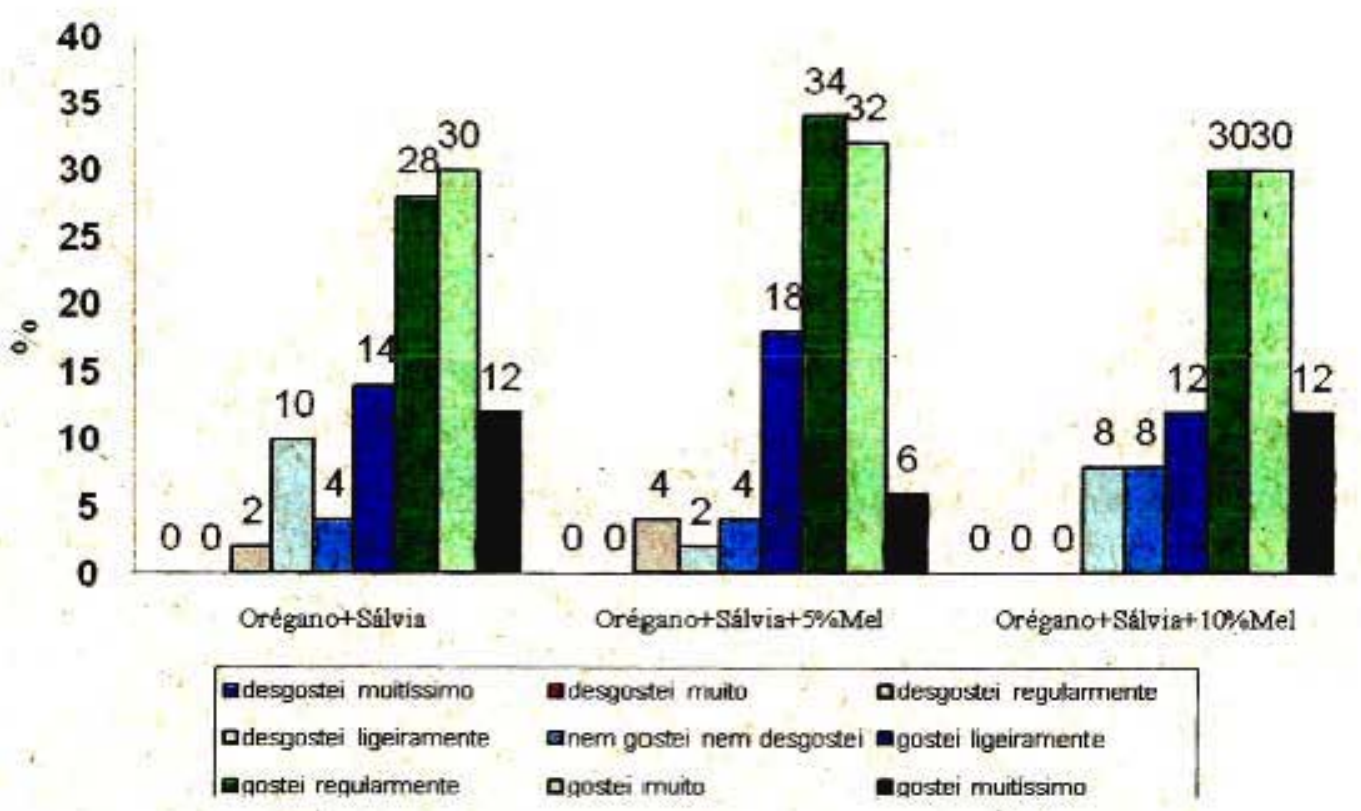

Figura 12 - Gráfico da distribuição percentual dos valores hedônicos atribuídos à aceitabilidade geral de peito de frango submetido a três tratamentos distintos. 
Nas amostras submetidas ao tratamento orégano+sálvia+5\%Mel, $90 \%$ dos provadores atribuíram nota acima de 5 , sendo esta a maior porcentagem entre os três tratamentos. Desse percentual, $18 \%$ dos participantes atribuíram nota 6 ("gostei ligeiramente"); 34\%, nota 7 ("gostei regularmente"); 32\%, nota 8 ("gostei muito") e $6 \%$, nota 9 ("gostei muitíssimo"). Com relação à rejeição da amostra, apenas $12 \%$ dos participantes as rejeitaram.

Já nas amostras de peito submetidas aos tratamentos orégano+sálvia e orégano+sálvia $+10 \% \mathrm{Mel}$, observou-se que o mesmo percentual de provadores atribuíram nota acima da estabelecida como nota de corte. Quanto a não-aceitação, houve $12 \%$ para o tratamento orégano+sálvia e $8 \%$ para o tratamento orégano+sálvia $+10 \% \mathrm{Mel}$.

Quando se aplicou o teste estatístico de Tukey, pode-se perceber que não foram observadas diferenças estatísticas entre o tratamento orégano + sálvia $+5 \% \mathrm{Mel} e$ orégano+sálvia $+10 \% \mathrm{Mel}(\mathrm{p}<0,05)$.

Quando avaliamos as fichas dos participantes que apontaram índices de não aprovação aos produtos, observamos que os comentários inseridos nas avaliações foram: a falta de sal no preparo das amostras, o sabor fraco de ervas e não perceberem a diferença entre as três amostras degustadas. Além disso, apenas um provador relatou o fato da carne estar seca e com muito tempero em sua superficie. 
De acordo com os dados obtidos para a sobrecoxa de frango, conforme Figura 13, observamos que a maioria dos provadores atribuiu notas acima do ponto central da escala hedônica para todas as amostras analisadas. Dos 50 provadores que participaram desta pesquisa, apenas 2 pessoas eram do sexo masculino.

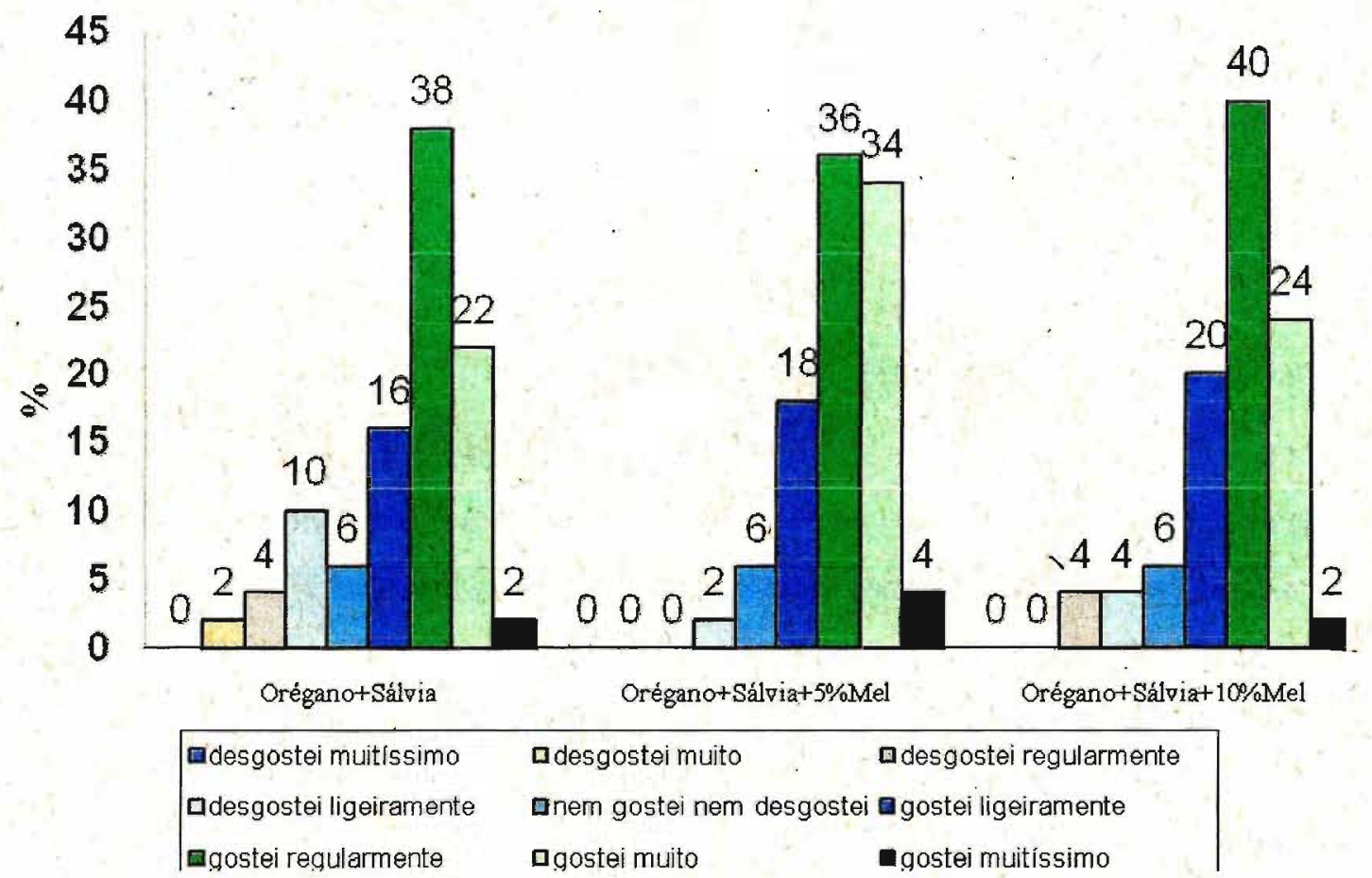

Figura 13 - Gráfico da distribuição percentual dos valores hedônicos atribuídos à aceitabilidade geral da sobrecoxa de frango submetido a três tratamentos distintos.

Uma avaliação global dos resultados mostrou que $92 \%$ dos provadores atribuíram nota acima de 5 para as amostras de sobrecoxa submetidas ao tratamento orégano+sálvia $+5 \% \mathrm{Mel}$, demonstrando sua maior aceitação entre os participantes. Desse percentual, $18 \%$ dos provadores atribuíram nota 6 ("gostei ligeiramente"); 36\%, nota 7 ("gostei regularmente"); 34\%, nota 8 ("gostei muito") e 4\%, nota 9 ("gostei muitíssimo"). No que diz respeito à rejeição, apenas $2 \%$ das pessoas atribuíram notas abaixo das notas de corte. 
Em relação às amostras submetidas ao tratamento orégano+sálvia $+10 \% \mathrm{Mel}$, $86 \%$ dos provadores atribuíram notas aceitáveis, sendo que destes, $20 \%$ atribuíram nota 6 ("gostei ligeiramente"); 40\%, nota 7 ("gostei regularmente"); 24\%, nota 8 ("gostei muito") e $2 \%$, nota 9 ("gostei muitíssimo"). Nesta amostra, somente $8 \%$ demonstraram não-aceitação do produto.

Por fim, $78 \%$ dos provadores atribuíram notas acima da nota de corte às amostras de sobrecoxa submetidas ao tratamento orégano+sálvia. Deste percentual, $16 \%$ dos participantes atribuíram nota 6 ("gostei ligeiramente"); 38\%, nota 7 ("gostei regularmente"); $22 \%$, nota 8 ("gostei muito") e $2 \%$, nota 9 ("gostei muitíssimo"). Nas amostras que levàvam somente as especiarias como tempero, a porcentagem de nãoaceitação foi de $16 \%$.

Por meio do teste de Tukey, podé-se perceber que os tratamentos orégano+sálvia e orégano+sálvia+5\% $\mathrm{Mel}^{\star}$ não diferiram do tratamento orégano+sálvia+10\%Mel $(\mathrm{p}>0,05)$, porém, os tratamentos orégano+sálvia e orégano+sálvia $+5 \% \mathrm{Mel}$ diferiram entre si $(p<0,05)$.

De acordo com os comentários observados nas fichas de avaliação, a maioria dos provadores alegou que as amostras de sobrecoxa também foram preparadas com pouco sal; dois deles relataram que a carne estava um pouco gordurosa, e um deles comentou sobre o sabor semelhante entre as amostras.

De modo geral, todas as amostras oferecidas na análise sensorial receberam notas acima da nota de corte, no eñtanto, a maior parcela dos provadores atribuiu notas altas às amostras submetidas aos tratamentos com especiarias e mel.

Os atributos sensoriais, tais como cor, odor, textura e o sabor são fatores que determinam à aceitabilidade ou não de um produto, sendo que o sabor é a propriedade mais importante (Chaib, 1983). Para que um produto seja considerado como aceito, em termos de suas propriedades sensoriais é necessário que se obtenha um índice de aceitabilidade de no mínimo $70 \%$ (Teixeira, 1987). 


\section{Conclusão}

Os resultados obtidos neste estudo reafirmam a hipótese de que os compostos bioativos da sálvia, orégano e do mel foram capazes de inibir a oxidação lipídica, em todas as amostras analisadas

Os antioxidantes naturais garantiram a qualidade oxidativa e sensorial da carne de frango, proporcionando uma diminuição na velocidade do processo oxidativo.

Além disso, o tempo de refrigeração exerceu importante influência nas taxas de oxidação.

De modo geral, todas as amostras oferecidas na análise sensorial, receberam notas acima da nota de corte, no entanto, a maior parcela dos provadores atribuiu notas altas às amostras submetidas aos tratamentos que continham mel e especiarias.

Assim, o orégano, a sálvia e principalmente o mel podem ser ingredientes aplicáveis em produtos cárneos, pois além de prevenirem a formação do aroma de requentado nos cortes de frangos foram aceitos sensorialmente neste estudo. 


\section{Referências Bibliográficas*}

* De acordo com a norma NBR 6023/2000, preconizada pela ASSOCIAÇÃo BRASILEIRA DE NORMAS TÉCNICAS (ABNT). As abreviaturas dos títulos dos periódicos seguem o CHEMTCAL ABSTRACTS SERVICE SOURCE INDEX (CASSI), 2001.

Addis, P,B. Occurrence of lipid oxidation products in foods. Food Chem. Toxic., Oxford, v.24, n.10/11, p.1021-30, 1986.

Ahn, D.U,. Jo.; C.; Du, M.; Olson, D.G.; Nam, K.C. Quality characteristics of pork patties irradiated and stores in different packaging and storage conditions. Meat Science, v.56, p. 203-209, 2000.

Ahn, J.; Grun, I.U.; Fernando, L.N. Antioxidant properties of natural plant extracts containing polyphenolic ompounds in cooked ground beef. Journal of Food Science, v. 67, p. 1364-1369, 2002.

AOAC [1995] Association of official analytical chemists. Official methods of Analysis of the AOAC. (16th ed.). Arlington, 1995.

AOCS [2003] Spectrophotometric determination of conjugated dienoic acid. AOCS Official Method Ti la-64

Arnaud, E.; Relkin, P.; Pina, M.; Collignan, A. Characterization of chicken fat dry fractionation at the pilot scale. Eur. J.Sci. Technol., v.106, n.9, p.591-598, 2004.

Bertoncelj, J.; Dobersek, U.; Mojca J.; Golob, T. Evaluation of the phenolic content, antioxidant activity and colour of Slovenian honey. Food Chemistry, v. 105, p. 822-28, 2007.

Bou, R.; Guardiola, F.; Grau, A.; Grimpa, S.; Manich, A.; Barroeta, A.; Codony, R.. Influence of dietary fat source, $\alpha$-tocopherol, and ascorbic acid supplementation on sensory quality of dark chicken meat. Poult. Sci. v. 80, p.1-8, 2001.

Bragagnolo, N.; Rodriguez-Amaya, D.B. Teores de colesterol em carne de frango. Revista de Farmácia e Bioquímica da Universidade de São Paulo, São Paulo, v.28, n.2., p. 122-131, 1992.

Brannan, R.G. Effect of grape seed extract on descriptive sensory analysis of ground chicken during refrigerated storage. Meat Science, v.81, p. 589-595, 2009.

Brasil (2001) - ANVISA - Agência Nacional De Vigilâncìa Sanitária. Resolução RDC N. 12 de 02 de janeiro de 2001. Aprova o Regulamento Técnico sobre padrões 
microbiológicos para alimentos. Site da agência nacional de vigilância sanitária. Disponível em: http://www.anvisa.gov.br. Acesso em: 12/07/2006.

Brenna, O.V.; Pagliarini, E. Multivariate analyses of antioxidant power and polyphenolic composition in red wines. J. Agric. Food Chemistry. Chicago: v.49, p. 4841-4844, 2001.

Brunton, N.P.; Cronin, D.A.; Monahan, F.J.; Durcan, R. A comparison of solid-phase microextraction (SPME) fibre for measurement of hexanal and pentanal in cooked turkey. Food Chemistry, v. 68 p. 339-345, 2000.

Bussab, W.O.; Morettin, P.A. Estatística Básica. 5. ed. São Paulo: Saraiva, 2006

Castellini, C.; Mugnai, C; Dal Bosco, A. Effect of organic production on broiler carcass and meat quality. Meat Science, v.60, p.219-225, 2002.

Chaib, M.A. Métodos para avaliação sensorial dos alimentos. 4 ed. Campinas: Unicamp, p. 62, 1983.

Chen, T.C.; Waimaleongora, C. Effect of $\mathrm{pH}$ on TBA values ground raw poutry meat. Journal Food Science, v.46, p. 1946-7, 1981.

Chun, S.S.; Vattem, D.A.; Lin, Y.T.; Shetty, K. Phenolic antioxidants from clonal oregano (Origanum vulgare) with antimicrobial activity against Helicobacter pylori. Process Biochemistry. v.16, p.2-7, 2004.

Cobos, A.; De La Hoz, L.; Campero, M.I.; Ordóñez, J.A. Revisión: Influencia de la dieta animal en los ácidos grasos de los lípidos de la carne. Revista Española de Ciencia y Tecnologia de Alimentos, v. 34, n. 1, p.35-51, 1994.

Conchillo, A.; Ansorena, D.; Astiasarán, I. The effet of cooking and storage on the fatty acid profile of chicken breast. European Journal of Lipid Science and Technology, v. 106, p.301-306, 2004

Cuvelier, M. E.; Berset, C.; Richard, H. Antioxidant constituents in sage (Salvia officinalis). Journal of Agricultural and Food Chemistry, v. 42, n. 3, p. 665-669, 1994.

Dionisi, F.; Golay, P. A.; Aeschlimann, J. M.; Fay, L. B. Determination of cholesterol oxidation products in milk powders: Methods comparison and validation. J. Agric Food Chem. v.46, p.2227-2233, 1998

Dupuy, H.P.; Bailey, M.E.; St Angelo, A.J.; Legendre, M.G., Vercelotti, J.R. (1987). In: Juntachote, T.; Berghofer, E; Siebenhandl, S.; Bauer, F. Antioxidative effect of added Holy basil and its ethanolic extracts on susceptibility of cooked ground pork to lipid oxidation. Food Chemistry, v. 100, p. 129-135, 2007. 
Estévez, M.; Ramírez, R.; Ventanas, S.; Cava, R. Sage and Rosemary essential oils versus BHT for the inhibition of lipid oxidative reactions in liver pâté. $L W T$, n. 40 , p. 58-65, 2007.

Fernández-López, J.; Sevilla, L.; Sayas-Barberá, M.E.; Navarro, C:; Marín, F.; PérezAlvarez, J.A. Evaluation of the antioxidant potential of hyssop (Hyssopus officinalis L.) and rosemary (Rosmarinus officinalis L.) extract in cooked pork meat. Journal of Food Science, v. 68, p-660-664.

Folch, J.; Lees, M.; Stanley, G.H.S. A simple method for the isolation and purification of total lipids from animal tissues. J. Biol Chem., v. 226, n. 497-509, 1957.

Galvin, K.; Lynch, A.M.; Kerry, J.P.; Morrissey, P.A.; Buckley, D.J. Effect of dietary vitamin $\mathrm{E}$ supplementation on cholesterol oxidation in vacuum packaged cooked beef steaks, Meat Science, v. 55, p.7-11, 2002.

Garthright, W.E. Most probable number from serial dilutions [appendix 2]. In: Food \& Drug Administration. Center for Food Safety \& Applied Nutrition. Bacteriological Analytical manual online. 8th ws. January 2001.

Gray, J.I.; Gomaa, E.A.; Buckey, D.J. Oxidative quality and shelf life of meats. Meat Science, v. 43, p. S111-S123, 1996.

Hettiarachchy, N.S.; Glenn, K.C.; Granasambandam, R; Johnson, M.G. Natural antioxidant extracts from fenugreek (Trigonella foenumgraecum) for ground beef patties. Journal of Food Science, v. 61, p.5 16-519, 1996.

Hubbard, R. W.; Ono, Y.; Sanchez, A. Atherogenic effect oxidized products of cholesterol. Prog. Food Nutr. Sci., v. 13, p. 17-44, 1989.

INMETRO- (Instituto Nacional de Metrologia, Normalização e Qualidade Industrial). DOQ- CGCRE- 008. Orientações sobre validação de métodos de ensaio químicos. Revisão 2 - Junho de 2007. Rio de Janeiro: INMETRO, 2007.

Jahan, K.; Paterson, A.; Spickett, C.M. Fatty acid composition, antioxidants and lipid oxidation in chicken breasts from different production regimes. International Journal of Food Science and Technology., Oxford, v. 39, p. 443-453, 2004.

Judge, M. D.; Aberle, E.D.; Forrest, J.C.; Hedrick, H.B.; Merkel, R.A. Principles of Meat Science. 2nd edition. Iowa, USA: Kendall/Hunt Publishing Company, 1989.

Jensen, C.; Lauridsen, C.; Bertelsen, G. Dietary vitamin E: quality and storage stability of pork and poultry. Trends in Food Science and Technology, v.9, p.62-72, 1998. 
Juntachote, T.; Berghofer, E.; Siebenhandl, S.; Bauer, F. Antioxidative effect of added Holy basil and its ethanolic extracts on susceptibility of cooked ground pork to lipid oxidation. Food Chemistry, v. 100, p. 129-135, 2007.

Komprda, T.; Zelenka, E.; Faimonová, P.; Bakai, P.; Pechová, P. Cholesterol content in meat of some poultry and fish species as influenced by live weight and total lipid content. J. Agric Food Chem. v. 17, n. 51, 2003.

Kulas, E.; Ackman, R. Different tocopherols and the relationship between two methods for determination of primary oxidation products in fish oil. Journal of Agricultural and Food Chemistry, v.49, p. 1724-1729, 2001.

Langslow, D.R.; Lewis, R.J. Alterations with age in compositions and lipolytic activity of adipose tissue from male and female chickens. British Poultry Science, v. 15; n.3, p. 267-273, 1974.

Leite, F. Validação em análise química. Ed. Atomo, Campinas-SP, 3ed., 1998, 224p.

Levy-Costa, R.B.; Sichieri, R.; Pontes, N.S.; Monteiro, C.A. Disponibilidade domicliar de alimentos no Brasil:distribuição e evolução (1974-2003). Rev. Saúde Pública; v. 39, n. 4, p. $530-540,2005$.

López, V.; Akerreta, S.; Casanova, E.; Gárcia-Mina, J.M.; Cavero, R.Y.; Calvo, M.I. In vitro antioxidant and anti-rhizopus activities of Lamiaceae herbal extracts. Plant Foods Hum Nutr., v.62, p. 151-155, 2007.

Lu, Y.; Foo, L.Y. Antioxidants activities of polyphenols from sage (Salvia officinalis) Food Chemistry, v. 75, p. 197-202, 2001.

McCarthy, T.L., Kerry, J.P., Kerry, J.F., Lynch, P.B., Buckley, D.J. Evaluation of the antioxidant potential of natural food/plant extracts as compared with synthetic antioxidants and vitamin $\mathrm{E}$ in raw and cooked pork patties. Meat Science, v. 57, p. 45-52, 2001.

McKibben, J.; Engeseth, N.J. Honey as a protective agent against lipid oxidation in ground turkey. J. Agric. Food Chem., v. 50, p. 592-595, 2002.

Meilgaard, M. Civille, G.V.; Carr, B.T. Sensory evaluation techniques. 3rd ed. Boca Raton: CRC, 1999. 390p.

Metcalfe, L.D.; Schmitz, A.A.; Pelka, J.R. Rapid preparation of fatty acid esters from lipids for gas chromatographic analysis. Analytical Chemistry, v. 12, p. 514, 1966.

Mielche, M.M.; Bertelsen, G. Approaches to the prevention of warmed over-flavor. Trends in Food Science and Technology, v.5, p.322-327, 1994. 
Morrissey, P.A.; Sheehy, P.J.A.; Galvin, K.; Kerry, J.P.; Buckley, D.J. Lipid stability in meat and meat products. Meat Science, v.49, 73-86, n.4, 1998.

Muguruma, M.; Katayama, K; Nakamura, M. Low-temperature osmotic dehydration improves the quality of intermediate moisture meats. Meat Science, v. 21, p 99-109, 1987.

Nagai, T.; Inoue, R.; Kanamori, N.; Suzuki, N:; Nagashima, T. Characterization of honey from different floral sources. Its functional properties and effects of honey species on storage of meat. Food Chemistry, v. 97, p. 256-262, 2006.

Nam, K.T.; Lee, H.A.; Min, B.S.; Kang, C.W. Influence of dietary supplementation with linseed and vitamin $\mathrm{E}$ on fatty acids, $\alpha$-tocopherol and lipid peroxidation in muscles of broiler chicks. Animal Feed Science and Technology, v.66, 149-158, 1997.

Neter, J.; Kutner, M. H.; Nachtsheim, C. J.; Wasserman, W. Applied linear statistical models. 4 ed. Boston: Irwin, 1996.

Novelli, E.; Zanardi, E.; Ghiretti, G, P.; Campanini, G.; Dazzi, G.; Madarena, G.; Chizzolini, R. Lipid and cholesterol oxidation in frozen stored pork, salame milano and mortadella. Meat Science, v.48, p.29-40, 1998.

Olivo, R. Atualidades na qualidade da carne de aves. Revista Nacional da Carne, v.28, n. 331, p.38-50, 2004.

Paniangvait, P.; King, A.J.; Jones, A.D.; German, B.G.A critical review cholesterol oxides in foods of animal origin. J. Food Sci., Chicago, v: 60, n. 6, 1995.

Pearson, A.M.; Gillett, T.A. In Processed Meats. Chapman and Hall, New York, New York. $3^{a}$ ed. Cap. 11, p. 291-310, 1996.

Price, J.f., Schwiegert, B.S. Ciencia de la carne y de los productos cárnicos. 2.ed. Zaragoza: Acribia, 1994, 581p.

Racanicci, A. M. C.; Danielsen, B.; Menten, J. F. M.; Regitano-D'Arce, M. A. B.; Skibsted, L. K. Antioxidant effect of dittany (Origanum dictamnus) in pre-cooked chicken meat balls during chill storage in comparison to rosemary (Rosemarinus officinalis), European Food Research and Technology, 218, p. 521-524, 2004.

Rhee K. S.; Anderson L. M.; Sams A. R. Lipid oxidation potential of beef, chicken and pork. J. Food Sci. v.61, p.8-12, 1996.

Rice-Evans, C.; Miller, N. J.; Bolwell, G. P.; Bramley; P. M.; Pridham, J. B. The relative antioxidant activities of plant derived polyphenolic flavonoids. Free Rad. Res., v. 22, p. 375-383, 1995. 
Souza, P.A.; Souza H.B.A.; Pelicano E.R.L.; Gardini C.H.C.; Oba A.; Lima T.M.A. Efeito da suplementação de vitamina $E$ no desempenho e na qualidade da carne de frangos de corte. Rev. Portuguesa de Ciências Veterinárias, n. 101, p. 87-94, 2006.

St. Angelo, A.J.; Vercellotti, J.R.; Legendre, M.G.; Vinnett, C.H.; Kuan, J.W.; James, C.; Dupuy, H.P. Chemical and instrumental analysis of warmed-over flavor in beef. J. Food Science, v. 52, p.1147-9, 1987.

TACO - Tabela Brasileira De Composição De Alimentos Da UNICAMP. Versão 2. Núcleo de Estudos e Pesquisas em Alimentação (NEPA) da UNICAMP, Campinas, $113 \mathrm{p}, 2006$.

Teixeira, E.; Meinert, E. M.; Barbetta, P. A Métodos sensoriais. In: Análise sensorial de alimentos. Florianópolis, Editora da UFSC, 1987. p. 66-119

Terra, N.M.; Braun, M.A. R Carne e seus derivados. Técnicas de controle de qualidade. São Paulo. Ed. Nobel, 1985. 121p.

Tims, M.J.; Watts, B.M. Protection of cooked meats with phosphates. Food Technol. v. 12 , p. $240-243,1958$

Torres, E. A. F. S.; Okani, E.T. Teste de TBA: Ranço em alimentos. Revista Nacional de Carne, v.243, p.68-76, 1997.

Tsaliki, E.; Lagouri, V.; Doxastakis, G. Evaluation of the antioxidant activity of lupin seed flour and derivatives (Lupinus albus ssp. Graecus). Food Chemistry, v. 65, p. 71-75, 1999.

Tsimidou,M.; Papavergou, E.; Boskou, D. Evaluation of oregano antioxidant activity in mackerel oil. Food Res Intern. V. 28, p. 431-433, 1995.

Valsta, L.M.; Tapanainen, H.; Mannisto, S. Meat fats in nutrition, Meat Science, v.70, p. $525-530,2005$.

Van Laack, R. L.; C. H. Liu, M. O. Smith; and H. D. Loveday. Characteristics of pale, soft, exudative breast meat. Poult. Sci. v.79, p. 1057-1061, 2000.

Venturini, K.S.; Sarcinelli, M.F.; Silva, L.C. Características da carne de frango. Boletim Técnico - PIE-UFES:01307 - Editado: 18.08.2007. Universidade Federal do Espírito Santo - UFES, 2007.

Vicente, S.J.; Torres, E.A.F.S. Formation of four cholesterol oxidation products and loss of free lipids, cholesterol and eater in beef hamburgers as a function of thermal processing. Food Control, v. 18, n. 1; p. 63-68, 2007.

Vieira, J.O.; Bressan, M.C.; Faria, P.B.; Ferreira, M.W.; Ferrão, S.P.B.; Souza, X.R. Efeito dos métodos de cocção na composição centesimal e colesterol do peito de 
frangos de diferentes linhagens. Ciênc. Agrotec., Lavras, v. 31, n. 1, p. 164-170, 2007.

Wang, M.; Li, J.; Rangarajan, M.; Shao, Y.; La Voie, E.J.; Huang, T.C.; Ho, C.T. Antioxidative phenolic compounds from sage (Salvia officinalis). J. Agric. Food Chem., v.46, n. 12, p. $4869-4873,1998$.

Wang, M.; Shao, Y.; Li, J.; Zhu, N.; Rangarajan, M.; La Voie, E.J.; Ho, C.T. Antioxidative phenolic glycosides from sage (Salvia officinalis L.). J. Nat. Prod., v.62, n.3, p.454 $-456,1999$.

Yu, L.; Scanlin, L.; Wilson, J., Schmidt, G. Rosemary extracts' as inhibitors of lipid oxidation and color change in cooked turkey products during refrigerated storage. Journal of Food Science, v. 67, p. 582-585, 2002.

Zhang, K. Q.; Bao, Y.; Wu, P.; Rosen, R.T.; Hoi, C.T. Antioxidative components of Tanshen (Salvia mitiorrhiza Bung). Journal of Agricultural and Food Chemistry. v. 38, p. 1194-97, 1994.

Zheng, W.; Wang, S. Y. Antioxidant activity and phenolic compounds in selected herbs. Journal Agriculture Food Chemistry, Chicago, v. 49, p. 5165-5170, 2001. 


\section{Anexo 1 - Aceite do Comitê de Ética em Pesquisa - COEP/FSP}

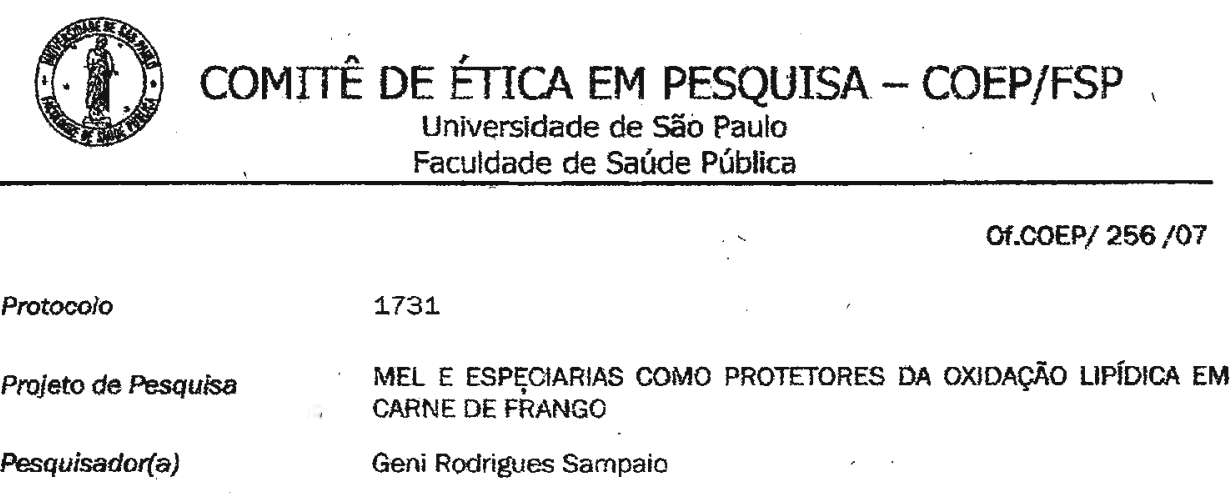

14 de dezernbro de 2007

Prezado(a) Orientador(a).

o Comitê de Ética em pesquisa da Faculdade de Saúde Píblica da Universidade de São Paulo - COEP analisou, em sua 10.\%/07. Sessāo Ordinária, realizada em $07 / 12 / 2007$, de acordo com as requisitos da Resolução CNS/196/96 e suas complementares, o protocolo de pesquisa acima intitulado e o considerou APROVADO COM RECOMENDAÇÃO, devendo $\mathrm{Q}$ (a) pesquisador (a) corrigir no Termo de Consentimento Livre e Esclarecido, onde se lê "carne bovina", leia-se "came de frango":

Cabe lembrar que conforme Resolução CNS/196/96 sāo deveres do (a) pesquisador (a): 1. Comunicar, de imediato, qualquer akteraçāo no projeto e aguardar manifestação deste CEP (Comitê de Ética em Pesquisa), para dar continuidade à pesquisa;

2. Manter sob sua guarda e em local seguro, pelo prazo de 5 (cinco) anos; os dados da pesquisa, contendo fichas individuais e todos as demais documentos recomendados peio CEP, no caso eventual auditoria;

3. Comunicar. formaimente a este Comitê, quando do encerramento deste projeto:

4. Elaborar e apresentar relatórios parciais e finais;

5. Justificar, perante o CEP, interrupção do projeto ou a nāo publicação dọ resultados.

Atenciosamente

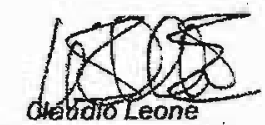

Profossor Associado

Coordenador do Comite de Ética em Pesquisa - FSP/COEP

$1 \mathrm{Im}^{\mathrm{a}} \mathrm{Sr}$

Prof. ${ }^{3} \mathrm{Dr}{ }^{\circ}$ ELIZABETH APARECIDA FERRAZ DA SILVA TORRES

DEPARTAMENTO DE NUTRIÇĀO 


\section{CONCLUSÃO FINAL}

Dentre das condições experimentais, conclui-se que a adição dos antioxidantes naturais (orégano, sálvia e mel) exerceu uma influência positiva sobre a qualidade oxidativa da carne de frango.

Os extratos das especiarias orégano e sálvia apresentaram potencial antioxidante eficiente na inibição da oxidação lipídica em substrato microssomal de carne de frango.

O sistema homogenato foi eficaz para estimar o acompanhamento da oxidação de lipídica ao longo da vida de prateleira dos produtos estudados.

Os antioxidantes naturais garantiram a qualidade oxidativa e sensorial da carne de frango, proporcionando uma diminuição na velocidade do processo oxidativo. Assim, os compostos antioxidantes das especiarias podem substituir (parcial ou integralmente) os antioxidantes sintéticos, uma vez que foi demonstrada a sua capacidade de inibir a oxidação lipídica. 
APÊNDICE I - Artigo enviado para publicação APÊNDICE II - Curriculum Lattes.

APÊNDICE III - Ficha de aluno 
Elsevier Editorial System(tm) for Food Chemistry

Manuscript Draft

Manuscript Number:

Title: Antioxidant activity of oregano and sage: in vitro inhibition of lipid peroxidation in microsomal fraction from chicken muscle

Article Type: Research Article

Keywords: Key words: Microsomal substrate, Chicken meat, Antioxidant, Herbs, Lipid oxidation.

Corresponding Author: Prof Elizabeth AFS Torres, PhD

Corresponding Author's Institution: University of Säo Paulo SP

First Author: Geni R Sampaio, PhD student

Order of Authors: Geni R Sampaio, PhD student; Carolina A Martins, MSc Student; Caroline A Zavatte, Undergraduate Student; Simone Mendonça, PhD; Deborah H Bastos, PhD; Elizabeth A Torres, PhD

Abstract: Synthetic antioxidants previously used to prevent or delay lipid oxidation in meat products are now being replaced by natural antioxidants because of health concerns. The potential of oregano and sage for inhibiting lipid oxidation in the microsomal substrate of chicken muscle was evaluated. Three combinations of these herbs were tested in the proportions in which they would be used for meat seasoning, against BHT as the control. In vitro oxidation was induced using Fe2+ and was measured according to the production of thiobarbituric acid-reactive substances. All the treatments with the substances studied presented positive influences regarding protection against lipid oxidation in the microsomal substrate, in comparison with the control. The herb mixture presented great potential as an antioxidant source and might result in greater shelf-life of chicken meat and prevent the negative health implications of oxidised meats or of synthetic additives. 


\section{GMil}

Geni Sampaio <genirsampaio@gmail.com>

\section{Enc: A manuscript number has been assigned: FOODCHEM-D-09-00230}

1 mensagem

Elizabeth Torres <eatorres@usp.br>

20 de janeiro de 2009 08:30

Para: genirs@terra.com.br

Cc: dmbastos@usp.br, simone.mendonca@embrapa.br, caguiar@gmail.com, family@usp.br

Continuando na torcida!!!!!

Elizabeth

Prof. Elizabeth A F S Torres, PhD

University of Sao Paulo USP

School of Public Health

Departament of Nutrion

Av. Dr. Arnaldo 715 HNT

01246-904 Sao Paulo SP BRAZIL

551130617587

551130617130

\footnotetext{
-... Mensagem encaminhada de esubmissionsupport@olsevier.com --.--

Data: 20 Jan 2009 08:43:09 +0000

De: Food Chemistry <esubmissionsupport@eisevier. com>

Endereço para Resposta (Reply-To):"Food Chemistry <esubmissionsupport@elsevier.com>

Assunto: A manuscript number has been assigned: FOODCHEM-D-09-00230

Para: eatorres@usp.br
}

Ms. Ref. No: FOODCHEM-D-09-00230

Title: Antioxidant activity of oregano and sage: in vitro inhibition of lipid peroxidation in microsomal fraction from chicken muscle

Food Chemistry

Dear Prof Elizabeth AFS Torres,

Your submission entitled "Antioxidant activity of oregano and sage: in vitro inhibition of lipid peroxidation in microsomal fraction from chicken muscle" has been assigned the following manuscript number: FOODCHEM-D$09-00230$.

You may check on the progress of your paper by logging on to the Elsevier Editorial System as an author. The URL is http:lees elsevier.com/foodcheml.

Thank you for submitting your work to this journal

Kind regards

Liz Wang

Central Administrator

Food Chemistry

....- Final da mensagem encaminhada 


\section{Antioxidant activity of oregano and sage: in vitro inhibition of}

2

4

5 Geni R. Sampaio ${ }^{a, b}$, Carolina A. Martins ${ }^{a}$, Caroline A. Zavatte ${ }^{a}$, Simone 6 7

\section{muscle}

\section{lipid peroxidation in microsomal fraction from chicken} Mendonça $^{c}$, Deborah H. M. Bastos ${ }^{a}$, Elizabeth A. F. S. Torres ${ }^{a, *}$

\section{7}

a Department of Nutrition, School of Public Health, University of São Paulo (USP), Brazil

${ }^{b}$ PRONUT-FCF/FEA/FSP, School of Public Heaith, University of São Paulo (USP), Brazil

${ }^{c}$ Embrapa Agroenergia, Parque Estação Biológica (PqEB), Brasília-DF, Brazil

Av. Dr. Arnaldo, 715 - São Paulo - SP - BRAZIL - ZIP Code 01246-904-Master of Public

$$
\text { Health-USP. }
$$

5 Corresponding author: Tel.: +55 1130617857 ; fax: +55 1130617130 .

$6 \quad *$ E-mail address: eatorres@usp.br (Elizabeth A. F. S. Torres)

7 Running title: Antioxidant activity of oregano and sage in microsomal fraction

\section{8}

9 


\section{Abstract}

2 Synthetic antioxidants previously used to prevent or delay lipid oxidation in meat

3 products are now being replaced by natural antioxidants because of health concerns

4 The potential of oregano and sage for inhibiting lipid oxidation in the microsomal

5 substrate of chicken muscle was evaluated. Three combinations of these herbs were

6 tested in the proportions in which they would be used for meat seasoning, against BHT

7 as the control. In vitro oxidation was induced using $\mathrm{Fe}^{2+}$ and was measured according to

8 the production of thiobarbituric acid-reactive substances. All the treatments with the

9 substances studied presented positive influences regarding protection against lipid

10 oxidation in the microsomal substrate, in comparison with the control. The herb mixture

11 presented great potential as an antioxidant source and might result in greater

12 acceptability of chicken meat and prevent the negative health implications of oxidised

13 meats or of synthetic additives.

14

15 Key words: Microsomal substrate, Chicken meat, Antioxidant, Herbs, Lipid oxidation. 


\section{Introduction}

Oxidative reactions cause damage to lipids and proteins, thus influencing food quality. Biological tissues are continuously subjected to oxidative stress from reactive oxygen species and free radicals that are produced by many biochemical pathways. Because of the constant risk of oxidation, the biological tissues from which foods are derived contain several distinctively different mechanisms for controlling oxidation catalysts, reactive oxygen species, free radicals and lipid oxidation products. Since prooxidants and lipid oxidation products are both water and lipid-soluble, these endogenous antioxidant systems are biphasic. Identification and characterisation of the biological systems that control oxidation will help in developing antioxidant hurdle technology systems for increasing the oxidative stability of foods. In order to successfully develop such antioxidant systems, it is crucial to understand the chemical and physical factors that influence the interactions between lipids, pro-oxidants and antioxidants (Decker, 1998).

Other lipid-containing substrates, such as erythrocytes (Tedesco, Russo, Nazarro, Russo \& Palumbo, 2001), primary hepatocytes (Morel, Abaléa, Sergent, Cillard \& Cillard, 1998), microsomal membrane preparations (Ṕlumb, Chambers, Lambert, Wanigatunga \& Williamson, 1997) and micelles (Shi, Noguchi and Niki, 1999), can also be used to evaluate the in vitro antioxidant activity of foods and phenolic compounds. These test systems either contain intact cell membranes or simulate a membrane environment. Lipid peroxidation in membranes is associated with ageing (Halliwell and Gutteridge, 1989), and methods using membrane substrates could therefore provide information complementary to that obtained using the in vitro LDL peroxidation method. 
1 Microsomes are small heterogeneous membranous vesicles of endoplasmic

2 reticulum and cytoplasmic membrane that contain high concentrations of

3 polyunsaturated fatty acids and proteins. Microsomal membranes are authentic

4 biological membranes capable of biochemical function. Microsomes can be derived

5 from muscle tissue and thus provide a phospholipid fatty acid profile that is

6 representative of the profile found in muscle tissue-based foods (Chan, Faustman \&

$7 \quad$ Renerre, 1992).

8 The components of biological tissues are an ideal mixture of substrates for

9 oxidation. Polyunsaturated fatty acids (PUFAs), transition metals and oxygen are

10 present in abundance but are prevented from reaction by cellular organisation and

11 structure. PUFAs are present in membranes but are always found with vitamin E.

12 Transition metals, particularly iron, bind to both transport and storage proteins;

13 abundant binding sites on such proteins prevent overloading of the protein molecule

14 with metal ions (Dormandy, 1994).

15 Antioxidants are capable of preventing or delaying oxidative processes by 16 inhibiting the initiation or propagation of an oxidative chain reaction. They are

17 important for preventing many oxidative stress-related diseases (Gerber, Boutron-Ruaul,

18 Hercberg, Riboli, Scalbert \& Siess, 2002) and are used to maintain the nutritional

19 quality and increase the shelf life of food. However, there are suspicions that the most

20 frequently used synthetic antioxidants in the food industry, such as 2,3-tert-butyl-4-

21 methoxyphenol (BHA) and 2,6-di-tert-butyl-4-methylphenol (BHT), cause undesirable

22 effects on health (Namiki, 1990). This situation has created a need to investigate

23 naturally occurring antioxidant substances that may be used in foods in place of

24 synthetic antioxidants. It has been shown that various plant materials containing 
1 phenolic compounds are effective antioxidants in model systems (Juntachote,

2 . Berghofer, Siebenhandl \& Bauer, 2007).

3 Phenolic antioxidants are products from secondary metabolism in plants and are

4 good sources of natural antioxidants in human diets (Chun, Vattem, Li \& Shetty, 2005).

5 Aromatic plants such herbs and spices are especially rich in phenolic content and have

6 been widely used to extend the shelf life of foods (Botsoglou, Christaki, Fletouris,

7. Florou-Paneri \& Spais, 2002).

8 The objective of the present study was to determine the ability of oregano and

9 sage to inhibit lipid peroxidation when using an in vitro microsomal membrane system

10 consisting of chicken muscle.

12 2. Materials and methods

13 2.1. Reagents and solvents

14 Folin-Ciocalteu and Tween 40 were obtained from Merck (Darmstadt,

15 Germany). Gallic acid, $\beta$-carotene, linoleic acid, 1, 1-diphenyl-2-picrylhydrazyl (DPPH),

16 butylated hydroxytoluene (BHT), ethylenediamine tetracetic acid (EDTA), ferrous

17 sulphate, 2-thiobarbituric, 1,1,3,3-tetraethoxypropane (TEP), Trolox (6-hydroxy-

18 2,5,7,8-tetramethylchroman-2-carboxylic acid), fluorescein (FL), 2,20-azobis-(2-

19 amidinopropane) dihydrochloride (AAPH) were obtained from Sigma-Aldrich

20 (Steinheim, Germany). Chloroform was obtained from Synth (Diadema, Brazil); ethanol

21 and sodium carbonate $\left(\mathrm{Na}_{2} \mathrm{CO}_{3}\right)$ were purchased from CAAL (São Paulo, Brazil) and

22 trichloroacetic (TCA) anhydride, $\mathrm{K}_{2} \mathrm{HPO}_{4}$ and $\mathrm{NaH}_{2} \mathrm{PO}_{4}$ were obtained from Merck

23 (Darmstadt, Germany). All other chemicals used were of analytical grade. 
1

列

\subsection{Samples}

Samples of dehydrated oregano (Origanum vulgare) and sage (Salvia officinalis) were donated by Fuchs, Brazil. The leaves were dried at $25^{\circ} \mathrm{C}$ in darkness and analysed after grinding in a household blender.

To obtain chicken microsomes, fresh hand-deboned chicken thigh and breast meat without skin was obtained from the Agricultural and Livestock Production Cooperative of Itatiba, SP, Brazil.

\subsection{Extraction of the polyphenol fraction}

About $3.0 \mathrm{~g}$ of each herb was extracted with ethanol $(10 \mathrm{~mL})$ under magnetic stirring for $1 \mathrm{~h}$ and then 20 min under ultrasonic vibration. The extract was centrifuged at 3,000 rpm for $20 \mathrm{~min}$, and the supernatant was filtered. The extraction procedure was repeated once and the supernatants were pooled together. In order to standardise the concentrations at $1 \mathrm{mg} / \mathrm{mL}$, the weight of the dry matter of the extracts was determined gravimetrically.

\subsection{Determination of total phenol content}

The total phenol content was measured in duplicate samples from each extract in accordance with the method of Swain and Hillis (1959), using the Folin-Ciocalteu reagent and gallic acid as standards. The results were expressed as gallic acid equivalents (GAE). 
1 2.5. Determination of antioxidant activity

2 2.5.1. $\beta$-carotene/linoleic acid assay

3 The inhibition of linoleic acid peroxidation (volatile organic compounds and

4 conjugated diene hydroperoxides) was determined in accordance with Miller (1971).

$5 \quad$ A stock solution of $\beta$-carotene/linoleic acid mixture was prepared as follows: $20 \mathrm{mg}$

6 of $\beta$-carotene was dissolved in $1 \mathrm{~mL}$ of chloroform. About $28 \mu \mathrm{l}$ of $20 \mathrm{mg} / \mathrm{mL} \beta$ -

7 carotene methanol solution was mixed with $28 \mu \mathrm{l}$ of linoleic acid and $200 \mathrm{mg}$ of Tween

8 40. The chloroform present was completely evaporated and $140 \mathrm{~mL}$ of distilled water

9 saturated with oxygen ( $30 \mathrm{~min}, 100 \mathrm{~mL} / \mathrm{min}$ ) was added. After vigorous shaking, $5 \mathrm{~mL}$

10 of the reaction mixture were dispensed to test tubes and $1 \mathrm{~mL}$ portions of the diluted

11 extracts $(1 \mathrm{mg} / \mathrm{mL})$ were added. After shaking the mixtures, the absorbance was

12 measured at $470 \mathrm{~nm}$. The tubes were placed in a water bath at $50^{\circ} \mathrm{C}$ and then

13 measurements were made every $15 \mathrm{~min}$ for $2 \mathrm{~h}$.

15 2.5.2. Preservation against induced oxidative rancidity (Rancimat ${ }^{(}$method)

16 This test was carried out using partially hydrogenated vegetable fat as the

17 matrix, supplemented with extracts as described by Antolovich, Prenzler, Patsalides,

18 McDonald \& Robards (2002). The exact volume of each extract needed to achieve a

19 final concentration of $0.03 \%(\mathrm{w} / \mathrm{w})$ soluble solids in partially hydrogenated vegetable

20 fat oil were dispensed into the Rancimat $^{\circledR}$ reaction vessels and dried under nitrogen.

21 Then, $3.0 \mathrm{~g}$ of vegetable fat oil were introduced into the vessels. Distilled water was

22 added and the measuring cells were connected in the equipment, thereby ensuring

23 freedom from air bubbles. Vegetable fat oil alone was added to a reaction vessel as a

24 control. The apparatus used was a Rancimat Metrohm ${ }^{\circledR}$ (Herisau, Switzerland)

25 operating at $110^{\circ} \mathrm{C}$ and airflow rate of $20 \mathrm{~mL} / \mathrm{h}$. The test was performed six times for 
1 each extract. The induction period (IP) (h) was recorded automatically. The protection

2 factor (PF) was calculated according to the following formula: $\left(\mathrm{PF}=\mathrm{IP}_{\text {extrat }} / \mathrm{IP}_{\text {control }}\right)$.

3 The protection factor could be used as a criterion for the effectiveness of 4 antioxidants.

5

\subsubsection{Oxygen Radical Absorbance Capacity (ORAC)}

The ORAC assay was based on the procedure described by Ou, HampschWoodill \& Prior (2001). Free radical AAPH reacted with the fluorescent probe fluorescein (FL) that lost its fluorescence. The antioxidant capacity of the sample protected the FL, thereby keeping the fluorescence longer. The result was obtained by comparing the antioxidant capacity of the sample against Trolox (standard antioxidant). All reagents and samples were diluted in phosphate buffer (pH 7.0). The reaction mixture consisted of $2700 \mu \mathrm{L}$ of phosphate buffer, $15 \mu \mathrm{L}$ of $\mathrm{FL}$ at $2.94 \mathrm{mg} / \mathrm{L}, 300 \mu \mathrm{L}$ of diluted sample and $300 \mu \mathrm{L}$ of AAPH at $60 \mathrm{~g} / \mathrm{l}$. After adding the reagents, the mixture was homogenised and the initial and the remaining fluorescence were recorded every 5 min until reaching $60 \min ($ excitation $=494 \mathrm{~nm}$, emission $=515 \mathrm{~nm}$ ). The whole test was performed at $37^{\circ} \mathrm{C}$ and the ORAC value was calculated as the ratio of the area under the curve (AUC) obtained for the sample, divided by the AUC of Trolox. Phosphate buffer was used as a blank sample.

\subsection{Preparation of microsomal substrate}

The chicken breast and thigh meats were minced twice in a food processor prior to preparing the substrates. The substrates consisted of about $5 \mathrm{~g}$ of this minced meat. To this, $50 \mathrm{~mL}$ of a solution containing $25 \% 0.15 \mathrm{M}$ potassium chloride and $75 \% 0.1 \mathrm{M}$ sodium phosphate buffer ( $\mathrm{pH}$ 7.4) was added. This concentrate was mixed at low speed 
1 for 2 min, using the Ultra-Turrax Basic IKA-T18 equipment. The concentrate was then

2 centrifuged at $1,000 \mathrm{~g}$ for $15 \mathrm{~min}$ at $4{ }^{\circ} \mathrm{C}$ for the intact cells. The supernatant was

3 centrifuged again at $10,000 \mathrm{~g}$ for $20 \mathrm{~min}$ at $4{ }^{\circ} \mathrm{C}$ to precipitate the subcellular organelles

4 of intermediate density, such as mitochondria, chloroplasts, lysosomes and

5 peroxisomes. The precipitate was then discarded and the supernatant was used to obtain

6 the microsomal fraction, by means of ultracentrifugation at $105,000 \mathrm{~g}$ for $1 \mathrm{~h}$ at $4{ }^{\circ} \mathrm{C}$.

7 Finally, the precipitate was resuspended in $1 \mathrm{~mL}$ of phosphate buffer $(0.1 \mathrm{M} ; \mathrm{pH} 7.4)$

8 and transferred to microtubes. This was then kept at $-70^{\circ} \mathrm{C}$ until the time of analysis

9 (Fraga, Leibovitz \& Al-Tappel, 1988).

10 The protein content in the microsomes was determined in accordance with the 11 method described by Lowry, Rosenberg, Farr \& Randall (1951).

\subsection{Lipid peroxidation assay}

14 The induction of microsomal oxidation in the system was performed in accordance with Fraga, Leibovitz \& Al-Tappel, 1988. The system was prepared to

16 contain $0.5 \mathrm{mg}$ protein $/ \mathrm{mL}$. The tests were performed in triplicate and the extracts of

17 herbs and salt (solution) were prepared in accordance with the treatments described in

18 Table 1. Firstly, ethanol solutions.from oregano, sage and/or BHT were pipetted into

19 test tubes and then evaporated under nitrogen. The salt, and then the phosphate buffer

20 (0.1 M; pH 7.4), were added to the microsomal system to make it up to a final volume 21 of $1 \mathrm{~mL}$. Next, $250 \mu \mathrm{M}$ of ferrous sulphate were added, followed by shaking. The tubes were then incubated in a water bath at $37^{\circ} \mathrm{C}$ for periods of $1,2,3$ and 4 hours. After the induction period, $1 \mathrm{~mL}$ of solution "stopper" (10 g of TCA (trichloroacetic acid), 0.0060 $\mathrm{g}$ of BHT (100 ppm) and $0.0056 \mathrm{~g}$ of EDTA in $100 \mathrm{~mL}$ of distilled water ice) was added 
1 for $25 \mathrm{~min}$ at 4,200 $\mathrm{g}$ (De Beer, Joubert, Gelderblom, Manley, 2005). Then, $1 \mathrm{~mL}$ of

2 TBA solution $(0.67 \%)$ was added to $1 \mathrm{~mL}$ of the supernatant. The tubes were sealed and

3 heated in a water bath at $95{ }^{\circ} \mathrm{C}$ for $15 \mathrm{~min}$. After the reaction, the tubes were cooled in

4 ice. The absorbance at $532 \mathrm{~nm}$ was measured in a UV spectrophotometer (Shimadzu

$51650 \mathrm{PV}$ ). The standard used was 1,1,3,3 tetraethoxypropane (TEP).

$7 \quad 2.8$. Data analysis

8 The data were expressed as means \pm standard deviations. ANOVA $(p<0.05)$ and

9 Tukey's post-hoc test were used to investigate whether there were any significant

10 differences $(\mathrm{p}<0.05)$ among the products. The SPSS software (version 10.0) was used.

\section{3. Results and Discussion}

\section{3.1. Total phenol content}

14 Table 2 shows the extraction yields, total phenol content, antioxidant activity

15 against the $\beta$-carotene-linoleic acid emulsion system, preservation against induced 16 oxidative rancidity (Rancimat ${ }^{\circledR}$ method) and Oxygen Radical Absorbance Capacity

17 (ORAC) of the ethanol extracts from oregano and sage.

18 The total phenol content in the ethanol extracts was analysed using the Folin-

19 Ciocalteu method. The highest amounts were found in the extracts of oregano and sage.

20 For the commercial oregano and sage samples, the total phenol content was 1154.09 and $21 \quad 1309.85$, respectively.

\subsection{Antioxidant activity}

Sage caused greater percentage inhibition of lipid oxidation (\% IOL), and

25 consequently better antioxidant activity, compared with oregano (Table 2). The higher 
1 antioxidant protection activity of sage (74.65\% IOL) than of oregano (43.17\% IOL) in

2 the $\beta$-carotene assay may suggest the possibility of higher levels of lipophilic phenolic

3 antioxidants.

5 indicate that the sample presented antioxidant activity. In the extracts analysed, sage

6 was distinguished by presenting a protection factor of 3.12 , i.e. greater than oregano

7 (protection factor of $1: 48$ ).

In the ORAC test, we observed that sage gave a higher result in terms of Trolox

9 equivalents (TE) than seen for oregano (610.45 versus 544.56). Wu, Beecher, Holden, 10 Haytowitz, Gebhardt \& Prior (2004) analysed antioxidant activity using the ORAC test 11 on 100 different kinds of foods, including fruits, vegetables, nuts, dried fruits, herbs, 12 spices, cereals, infant foods and other foods. The values found for some herbs and 13 spices were: oregano, $1831 \mathrm{TE} \mu \mathrm{mol} / \mathrm{g}$; cloves, $1533 \mathrm{TE} \mu \mathrm{mol} / \mathrm{g}$; and parsley, $741 \mathrm{TE}$ $14 \mu \mathrm{mol} / \mathrm{g}$.

15 Su, Yin, Charles, Zhou, Moore \& Yu (2007) evaluated various herbal extracts 16 that showed high ORAC levels, ranging from 363 to $1256 \mathrm{TE} \mu \mathrm{mol} / \mathrm{g}$. $50 \%$ acetone 17 extract of cinnamon showed the greatest ORAC value of $1256 \mathrm{TE} \mu \mathrm{mol} / \mathrm{g}$, followed by 18 oregano leaf $(1232 \mu \mathrm{mol} / \mathrm{g})$, rosehip $(838 \mu \mathrm{mol} / \mathrm{g})$, nutmeg $(398 \mu \mathrm{mol} / \mathrm{g})$ and black 19 peppercorn $(39.5 \mu \mathrm{mol} / \mathrm{g})$. These data suggest that the extraction solvent may have an 20 influence on the ORAC estimate for a given botanical sample. Comparing these data 21 with those obtained for oregano and sage, it can be seen that the ethanol extracts present 22 greater ORAC values for other herbs and spices evaluated by those authors, thus 23 suggesting that both oregano and sage have high antioxidant potential.

24 Herbs like oregano and sage, both belonging to the mint family (labiatae), have 25 been shown to be the most potent natural antioxidants among the common herbs 
1 (Madsen and Bertelsen, 1995). Many members of the genus Salvia have been shown to

2 have antioxidant activity. Tepe, Eminagaoglu, Akpulat \& Aydin, (2007) confirmed that

3 this genus had great potential for the food and cosmetic industries, especially in

4 antioxidant systems.

\subsection{Lipid peroxidation}

The results obtained from standardized thiobarbituric acid reactive substances

8 (TBARS) determinations for evaluating the influence of herbs and spices in protecting

9 against lipid oxidation in a microsomal substrate of chicken meat are shown in Table 3.

10 The mean TBARS concentrations ( $\mu \mathrm{Mol}$ of MDA/mg of protein) observed in the breast

11 meat samples were: control, 7.45; BHT, 1.91; and oregano + sage, 3.45 .

12 Analysis of the results from breast meat according to the percentage inhibition

13 of lipid oxidation in relation to the control showed that, for all induction periods, the

14 treatment with BHT was more efficient for inhibiting oxidation than was the oregano +

15 sage treatment (Figure 1). It needs to be emphasized that three hours was the apex of

16 the inhibition for both treatments.

17 From analysis of the mean TBARS concentrations ( $\mu$ Mol of $\dot{M D A} / \mathrm{mg}$ of

18 protein) in the thigh meat, the following results were observed: control, $9.84 ; \mathrm{BHT}$,

194.27 ; and oregano + sage, 3.15. Figure 1 shows that the treatment with BHT was more

20 effective for inhibiting oxidation over the first hour of induction, while for subsequent

21 periods, the treatment with oregano + sage was more effective.

22 The results from this model system indicate that the herbal extracts from 23 oregano + sage were efficient for inhibiting the oxidation of lipids in the samples 24 analysed. 
Evaluation of the results from inhibition of lipid oxidation over the induction period showed that, in relation to the control, the treatments carried out had a positive influence regarding protection against lipid oxidation in the microsomal substrate of chicken breast meat. Both of the treatments (BHT and oregano + sage) attained their peak inhibition after three hours (82.42\% and $82.25 \%$, respectively). However, analysis of the inhibition of lipid oxidation in the microsomal fraction of thigh meat showed that the BHT treatment attained its peak inhibition $(66.50 \%)$ after one hour of induction, while the oregano + sage treatment attained its peak inhibition after three hours $(82.25 \%)$.

Cintra and Mancini-Filho (2001) evaluated the antioxidant capacity of alcohol and aqueous extracts of oregano in the microsomal fraction of liver tissue and reported that the inhibition caused by the alcohol extract in the system was $93.05 \%$ and it was $40.57 \%$ in the aqueous extract.

Regarding the differences in the TBARS results in the two types of meat (breast and thigh) and consequently in the results for inhibition of lipid oxidation, these results need to be correlated with several factors that might determine the quantity of malonaldehyde formed during the peroxidation of polyunsaturated fatty acids, such as the degree of unsaturation of the fatty acids (Pryor, Stanley \& Blair, 1976), presence of metals (Janero and Burghardt, 1989); pH (Chen and Waimaleongora-Ek, 1981), temperature and duration of heating (Pikul, Leszczynski \& Kummerow, 1984).

Ang and Lyon (1990) compared chicken thigh and breast meat and observed that thigh cuts presented greater oxidative metabolism and a greater degree of lipolysis, and that the triacylglycerol fraction underwent hydrolysis more rapidly than did the phospholipids, which caused greater oxidative susceptibility. Furthermore, the 
1 iron concentration in red muscles is greater than that of white muscles, which could

2 affect lipid oxidation.

3 In the present study, it was found that the addition of oregano and sage extracts

4 was capable of inhibiting lipid oxidation, thus suggesting that these herbs confer

5 protection to the cell membrane against oxidative attack by free radicals. This result

6 strengthens the data presented previously regarding the antioxidant activity of these

7 herbs.

8

9 Acknowledgements

10 We like to address our thanks to the State of São Paulo Research Foundation

11 (FAPESP) and Coordination Office for Academic Staff Improvement (CAPES) for their

12 support and for granting scholarships to the authors, as well as to the Postgraduate in

13 Applied Human Nutrition Program (PRONUT) of the University of São Paulo. 


\section{References}

2 Ang, C.Y.W, \& Lyon, B.G. (1990). Evaluations of warmed-over-flavour during chill storage of cooked broiler breast, thigh and skin by chemical instrumental and sensory methods. J. Food Science, 55, 644-648.

Antolovich, M., Prenzler, P. D., Patsalides, E., McDonald, S., \& Robards, K. (2002). Methods for testing antioxidant activity. The Analyst, 127, 186-198.

Botsoglou, N.A., Christaki, E., Fletouris, D.J., Florou-Paneri, P., \& Spais, A.B. (2002). The effect of dietary oregano essential oil on lipid oxidation in raw and cooked chicken during refrigerated storage. Meat Science, 62, 259-265.

Chan, W.K.M., Faustman, C., \& Renerre, M. (1997). Model systems for studying pigment and lipid oxidation relevant to muscle-based foods. In Shahid, F. Natural antioxidants chemistry, Health effects, and applications, chapter 20, p. 319-331, Champaigns: AOCS Press.

Chen, T.C., \& Waimaleongora-EK, C (1981). Effect of pH on TBA values of ground raw poultry meat. J. Food Sci., 46, 1946-1947.

Chun, S-S., Vattem, D.A., Lin, Y-T., \& Shetty, K. (2005). Phenolic antioxidants from clonal oregano (Origanum vulgare) with antimicrobial activity against Helicobacter pylori. Process Biochemistry, 40, 809-816.

Cintra, R.M.G., \& Mancini-Filho, J. (2001). Efeito antioxidante de especiarias: avaliação e comparação de métodos in vitro e in vivo. J. Brazilian Soc. Food Nutr., $22,49-62$.

Dahle, L.K., Hill, E.G., \& Holman, R.T. (1962). The thiobarbituric acid reaction and the autoxidation of polyunsaturated fatty acid methyl esters. Arch. Biochem, Biophys, $98,253-261$. 
1 De Beer, D., Joubert, E., Gelderblom, W.C.A., \& Manley, M. (2005). Antioxidant activity of South African red and white cultivar wines and selected phenolic compounds: In vitro inhibitiom of microsomal lipid peroxidation. Food Chemistry, $90,569-577$

Decker, E.A. (1998). Strategies for manipulating the prooxidative/antioxidative balance of foods to maximize oxidative stability. Trends in Food Science \& Technology, 9, $241-248$

Dormandy, T.L. antioxidant vitamins and nutrients. In: Gutteridge, J.M.C., Halliwell, B. (1994). Antioxidants in nutrition, health, and disease. New York: Oxford University Press, pp.63-81.

Fraga, C.G., Leibovitz, B.E., \& Al-Tappel, L. (1988). Lipid peroxidation measured as thiobarbituric acid-reactive substances in tissue slices: characterization and comparison with homogenates and microsomes. Free Radical Biology \& Medicin., $4,155-161$.

Gerber, M, Boutron-Ruault, M.L., Hercberg, S., Riboli, E., Scalbert, A., \& Siess, M.H. (2002). Food and cancer: state of the art about the protective effect of fruits and vegetables. B. Cancer, 89, 293-312.

Halliwell, B. \& Gutteridge, J.M.C. (1989) Lipid peroxidation: A radical chain reaction. In: Free Radicals in Biology and Medicine, edited by B. Halliwell \& J.M. C. Gutteridge, Oxford University Press, New York, pp. 188-276.

Janero, D. R, \& Burghardt, B. (1989). Thiobarbituric acid-reactive malondialdehyde formation during superoxide-dependent, iron-catalyzed lipid peroxidation: influence of peroxidation conditions. Lipids, 24(2), 125-131. 
1 Juntachote, T., Berghofer, E., Siebenhandl., \& Bauer, F. (2007). Antioxidative effect of added dried Holy basil and its ethanolic extracts on susceptibility of cooked ground pork to lipid oxidation. Food Chemistry, 100, 129-135.

Lowry, O.H., Rosenberg, N.I., Farr, A.L., \& Randall, R.J. (1951). Protein measurement with the folin-phenol reagent. Journal of Biological Chemistry, 193, 265-275.

6 Madsen, H.L. \& Bertelsen, G. (1995). Spices as antioxidants. Trends in Food Science 7 、 and Technology, 6(8), 271-277.

8 Miller, H. E. (1971). A simplified method for the evaluation of antioxidants. Journal of the American, Oil Chemists' Society, 48, 91.

10 Morel, I., Abaléa, V., Sergent, O., Cillard, P., \& Cillard, J. (1998). Involvement of 11 phenoxyl radical intermediates in lipid antioxidant action of myricetin in iron12 treated rat hepatocyte culture. Biochemical Pharmacology, 55, 1399-1404.

13 Namiki, M. (1990). Antioxidant/antimutagens in food. CRC Critical Review Food 14 Science and Nutrition, 29, 273-300.

15 Ou, B., Hampsch-Woodill, M., \& Prior, R.L. (2001). Development and validation of an 16 improved oxygen radical absorbance capacity assay using fluorescein as the 17. fluorescent probe. J Agric Food Chem, 49, 4619-4626.

18 Pikul, J., Leszczynski, D.E, \& Kumerow, F.A. (1984). Relative role of phospholipids, 19 triacylglycerols, and cholesterol esters on malonaldehyde formation in fat extracted 20. from chicken meat. J. Food Science, 49, 704-708.

21 Plumb, G.W., Chambers, S.J., Lambert, N., Wanigatunga, S., \& Williamson, G. (1997).

22 Influence of fruit and vegetable extracts on lipid peroxidation in microsomes containing specific cytochrome P450s. Food Chemistry, 60, 161-164. 
. 1 Pryor, W.A., Stanley, J.P., \& Blair, E. (1976). Autoxidation of polyunsaturated fatty acids. II. A suggested mechanism for the formation of TBA-reactive materials from prostaglandin-like endoperoxides. Lipids, 11, 370-379.

Shi, H., Noguchi, N., \& Niki, E. (1999). Comparative study on dynamics of antioxidative action of $\alpha$-tocopheryl hydroquinone, ubiquinol, and $\alpha$-tocopherol against lipid peroxidation. Free Radical Biology and Medicine, 27, 334-346.

Su, L., Yin, J-J., Charles, D., Zhou, K., Moore, J., \& Yu, L. (2007). Total phenolic contents, chelating capacities, and radical-scavenging properties of black peppercorn, nutmeg, rosehip, cinnamon and oregano leaf. Food Chemistry, 100, 990-997.

Swain, T. \& Hillis, W.W. (1959). The phenolic constituents of Prunes domestica I. The quantitative analysis of phenolic constituents, Journal of the Science of Food and Agriculture, 10, 63-68.

Tedesco, I., Russo, G.L., Nazarro, F., Russo, M.; \& Palumbo, R. (2001). Antioxidant effect of red wine anthocyanins in normal and catalase-inactive human erythrocytes. Journal of Nutritional Biochemistry, 12, 505-511.

Tepe, B., Eminagaoglu, O., Akpulat, H.A., \& Aydin, E. (2007). Antioxidant potentials and rosmarinic acid levels of the methanolic extracts of Salvia verticillata (L.) subsp. verticillata and S. verticillata (L.) subsp. Amasiaca (Freyn \& Bornm.) Bornm. Food Chemistry, 100, 985-989.

Wu, X., Beecher, G.R., Holden, J.M., Haytowitz, D.B., Gebhardt, S.E., \& Prior, R.L. (2004). Lipophilic and hydrophilic antioxidant capacities of common foods in the United States. J. Agric. Food Chem, 52, 4026-4037. 


\section{Figure captions}

2

3. Figure 1

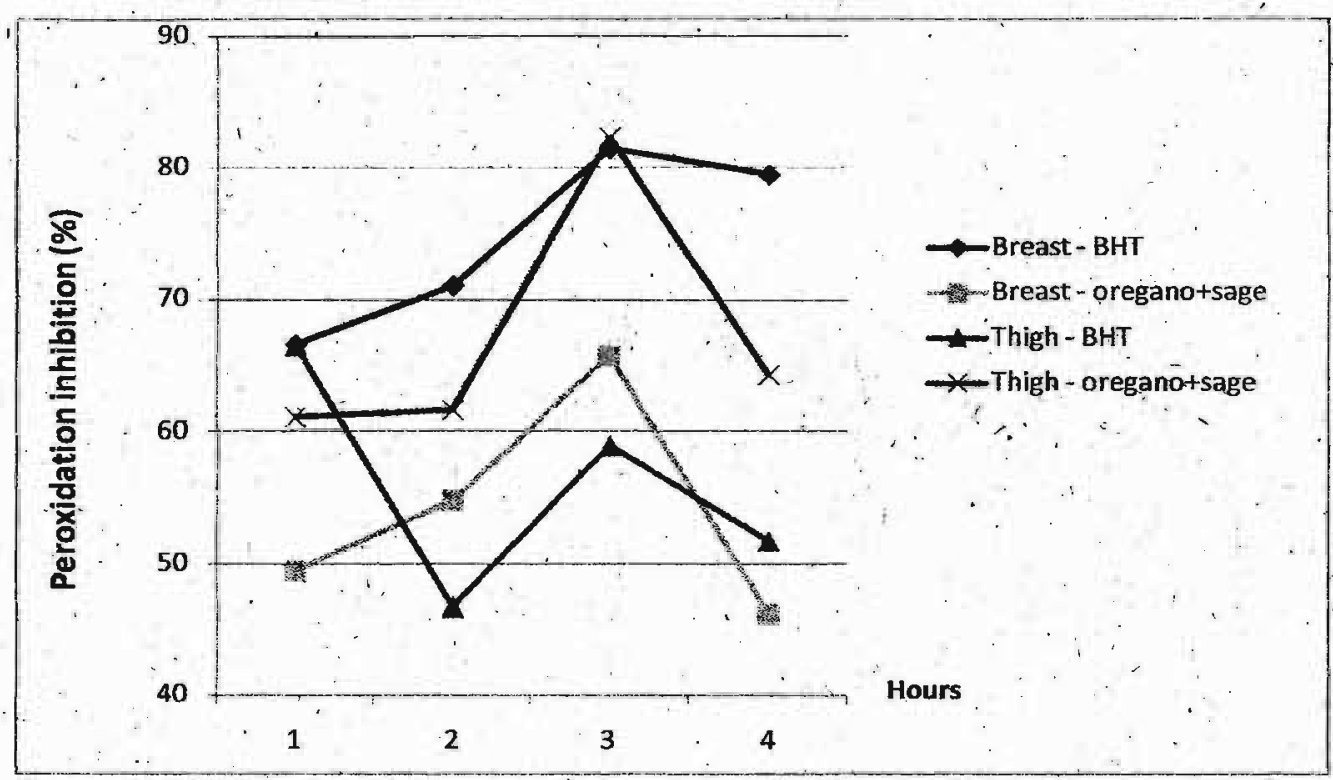

4

5

6. Fig. 1 - Inhibition of lipid peroxidation of BHT and oregano + sage extracts in the 7 microsomal fraction from chicken muscle tissue. 
$1 \quad$ Table 1

2 Ingredients added to the microsomal fraction from chicken muscle tissue

\begin{tabular}{l|c|c|c|c}
\hline \multirow{2}{*}{ Treatments } & \multicolumn{4}{|c}{ Ingredients } \\
\cline { 2 - 5 } & BHT (ppm) & Salt (\%) & Oregano (\%) & Sage (\%) \\
\hline
\end{tabular}

Microsomal fraction from chicken breast

\begin{tabular}{c|c|c|c|c}
\hline Control & - & 2 & - & - \\
\hline BHT & 100 & 2 & - & - \\
\hline Oregano + sage & - & 2 & 0.2 & 0.2 \\
\hline
\end{tabular}

Microsomal fraction from chicken thigh

\begin{tabular}{c|c|c|c|c}
\hline Control & - & 2 & - & - \\
\hline BHT & 100 & 2 & - & - \\
\hline Oregano + sage & - & 2 & 0.2 & 0.2 \\
\hline
\end{tabular}

3

4

5

6

7

8

9

10

11

12

13

14

15

16

17 
1 Table 2

2 Total phenol content, $\beta$-carotene-linoleic acid, protection factor (Rancimat ${ }^{\circledR}$

3 method) and ORAC of ethanol extracts from oregano and sage.

\begin{tabular}{|c|c|c|}
\hline Methods & oregano & Sage \\
\hline $\begin{array}{l}\text { Total phenol content } \\
\text { (mg GAE/mL) }\end{array}$ & $1154.09 \pm 234.73^{a}$ & $1309.85 \pm 105.19$ \\
\hline $\begin{array}{l}\text { B-carotene/linoleic acid } \\
(\% \mathrm{IOL})^{2}\end{array}$ & $43.17 \pm 3.03$ & $74.65 \pm 5.22$ \\
\hline $\begin{array}{l}\text { Rancimat } \\
(\mathrm{PF})^{3}\end{array}$ & $1.48 \pm 0.01$ & $3.12 \pm 0.14$ \\
\hline $\begin{array}{l}\text { ORAC } \\
(\mathrm{TE} \mu \mathrm{mol} / \mathrm{g})^{4}\end{array}$ & $\quad 544.57 \pm 20.47$ & $610.45 \pm 38.02$ \\
\hline $\begin{array}{l}\text { - GAE }=\text { Gallic acid equive } \\
(\text { Protection factor }) ;{ }^{4}-\text { Trolo } \\
\text { - Values are means } \pm \text { stand }\end{array}$ & $\begin{array}{l}\% \text { IOL }=\% \text { inhibition of lipi } \\
\text { alent; } \\
\text { rations from three analyses. }\end{array}$ & dation; ${ }^{3}-\mathrm{PF}$ \\
\hline
\end{tabular}

9

10

11

12

13

14

15

16

17

18

19 
1 Table 3

2 TBARS* values from the lipid oxidation reaction in the microsomal system, for

3 the different treatments.

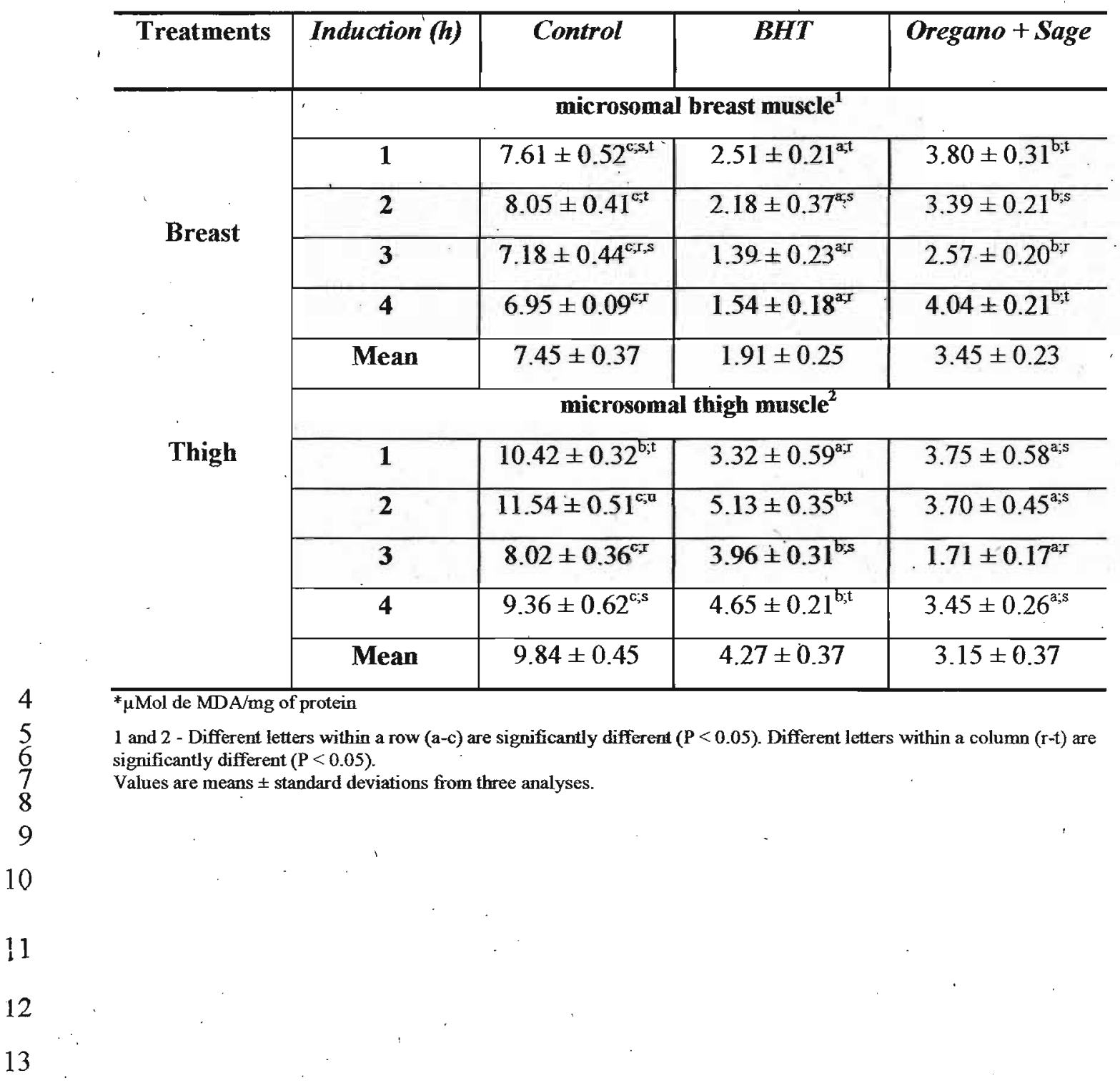

